\title{
Towards sustainable tuna fishing: Understanding the role of private incentive mechanisms
}

CAPABILITIES

INCENTIVE

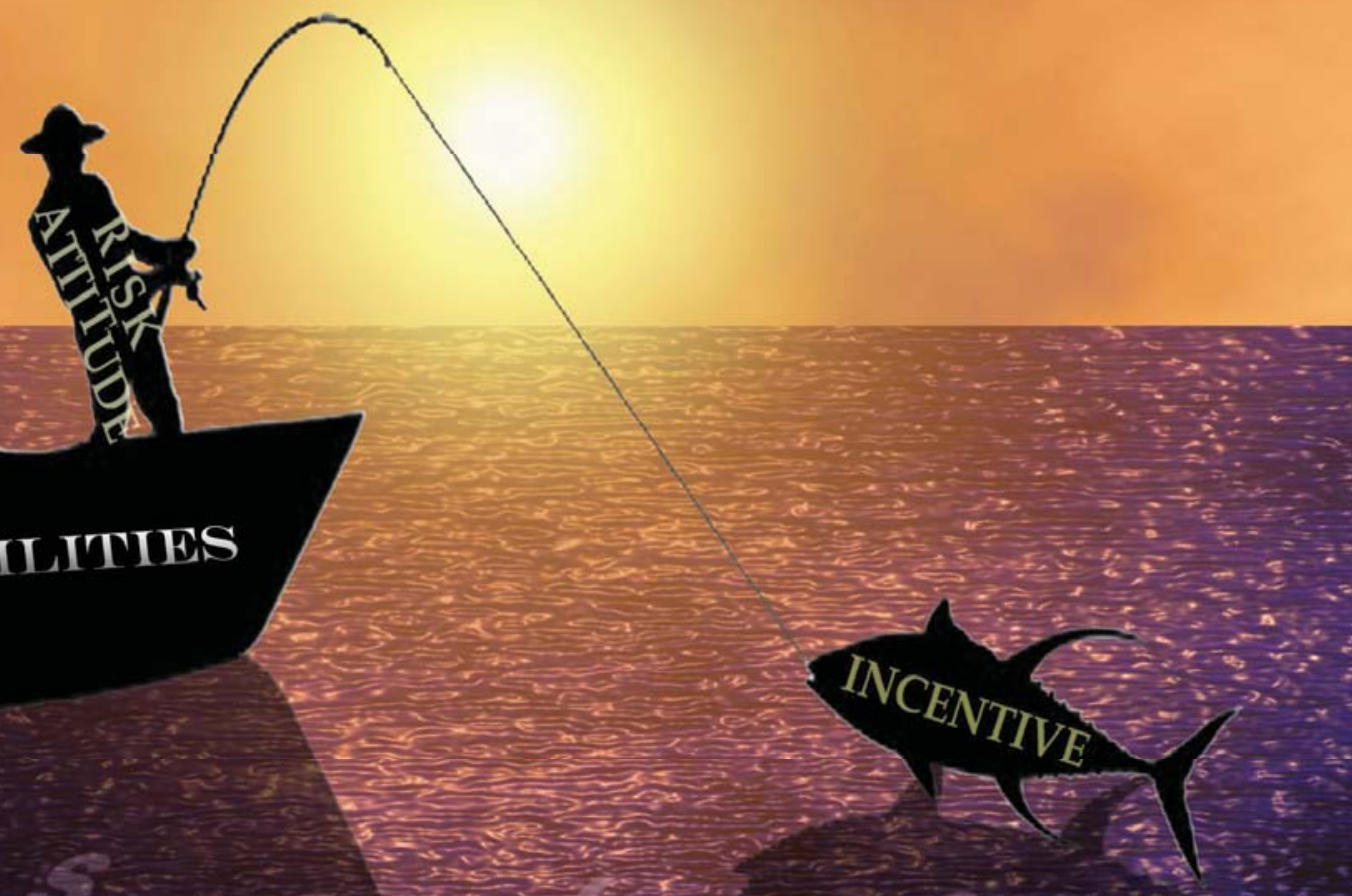

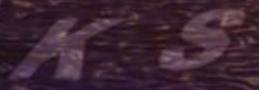

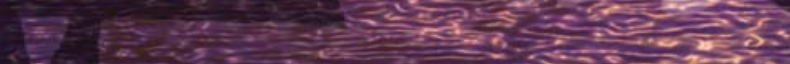

Frazen Tolentino-Zond ervan 


\section{PROPOSITIONS}

1. Tuna fishers that do not have the capability to improve will be excluded by all incentive mechanisms.

(this thesis)

2. The least risk averse fishers are the most willing to adopt sustainable fishing practices. (this thesis)

3. The environmental issues dealt with by ecological sciences require an interdisciplinary approach that involves social sciences.

4. Theoretical research without empirics can contribute to scientific knowledge, but empirical research without theory cannot lead to scientific knowledge.

5. A woman's investments in a family and in a career are not mutually exclusive.

6. The European Union (EU) can drive sustainability change in developing countries by creating tailored rather than blueprint solutions.

Propositions belonging to the thesis, entitled

“Towards sustainable tuna fishing: Understanding the role of private incentive mechanisms"

Frazen Tolentino-Zondervan

Wageningen, 9 October 2017 


\section{Towards sustainable tuna fishing: \\ Understanding the role of private incentive mechanisms}

Frazen Tolentino-Zondervan 


\section{Thesis committee}

\section{Promotors}

Prof. Dr A.G.J.M. Oude Lansink

Professor of Business Economics

Wageningen University \& Research

Prof. Dr S.R. Bush

Professor of Environmental Policy

Wageningen University \& Research

\section{Co-promotor}

Dr P.B.M. Berentsen

Associate professor, Business Economics Group

Wageningen University \& Research

\section{Other members}

Prof. Dr A.D. Rijnsdorp, Wageningen University \& Research

Prof. Dr H. Uchida, University of Rhodes Island, Kingston, United States of America

Dr R.A. Groeneveld, Wageningen University \& Research

Dr R. Hille Ris Lambers, World Wide Fund for Nature Netherlands, Zeist

This research was conducted under the auspices of the Wageningen School of Social Sciences. 


\title{
Towards sustainable tuna fishing: Understanding the role of private incentive mechanisms
}

\author{
Frazen Tolentino-Zondervan
}

Thesis

submitted in fulfilment of the requirements for the degree of doctor

at Wageningen University

by the authority of the Rector Magnificus,

Prof. Dr A.P.J. Mol,

in the presence of the

Thesis Committee appointed by the Academic Board

to be defended in public

on Monday 9 October 2017

at 1:30 p.m. in the Aula. 
Frazen Tolentino-Zondervan

Towards sustainable tuna fishing: Understanding the role of private incentive mechanisms, 205 pages.

$\mathrm{PhD}$ thesis, Wageningen University, Wageningen, the Netherlands (2017)

With references, with summary in English

ISBN 978-94-6343-623-6

DOI https://doi.org/10.18174/419424 


\section{Table of Contents}

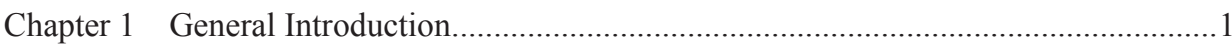

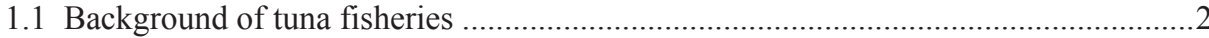

1.2 Private incentive mechanisms to improve sustainability of Filipino tuna fisheries ......4

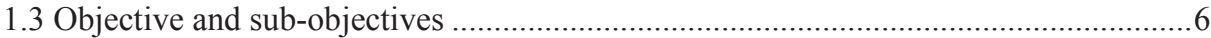

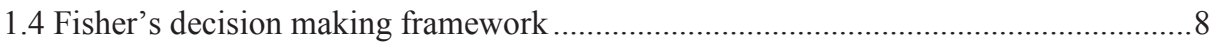

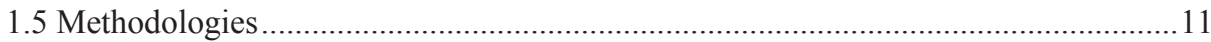

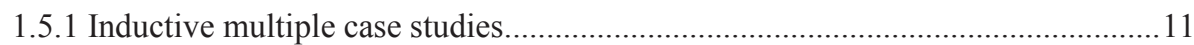

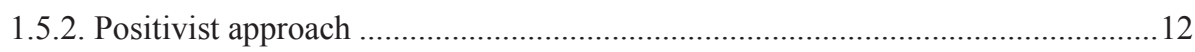

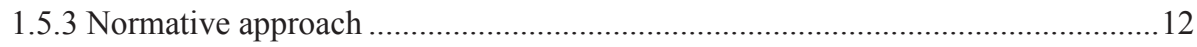

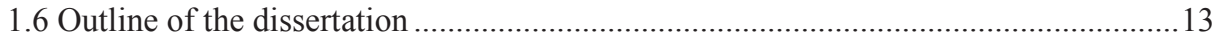

Chapter 2 Comparison of private incentive mechanisms for improving sustainability of Filipino

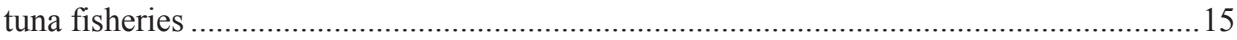

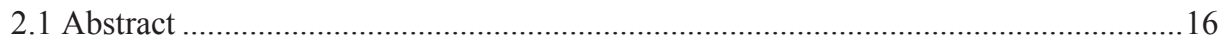

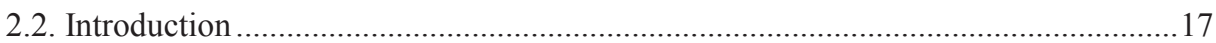

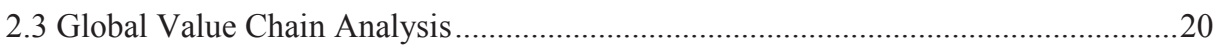

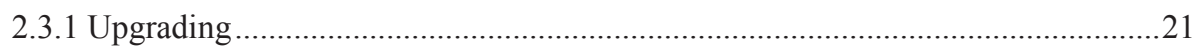

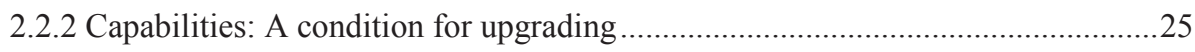

2.2.3 The vertical and horizontal dimensions of the value chain influencing upgrading26

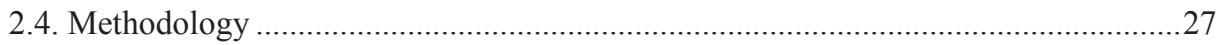

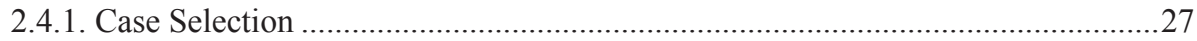

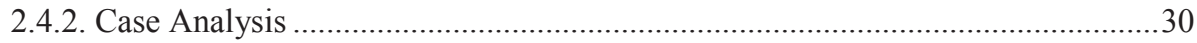

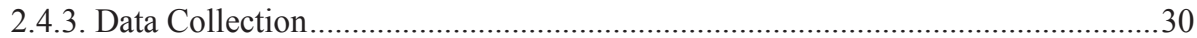

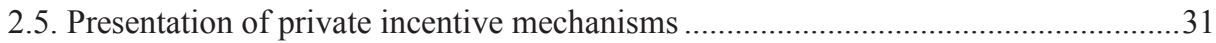

2.5.1 FIP: The Partnership Programme Towards Sustainable Tuna ..............................32

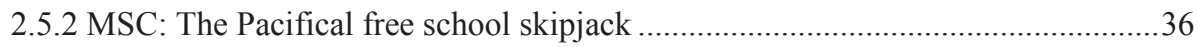

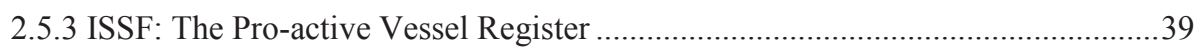

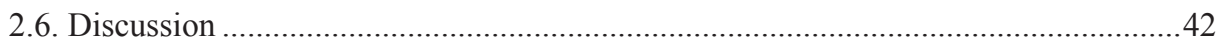

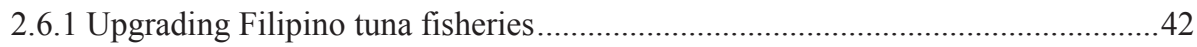

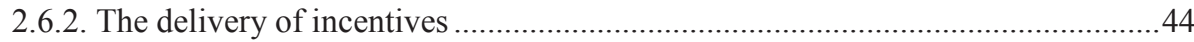

2.6.3 Goals of fishers and of private incentive mechanisms ........................................46

2.6.4 Mechanisms' selectiveness regarding type of fishers ........................................47

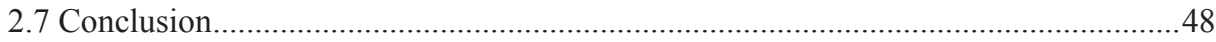


Chapter 3 Fisher-level decision making to participate in Fisheries Improvement Projects (FIPs)

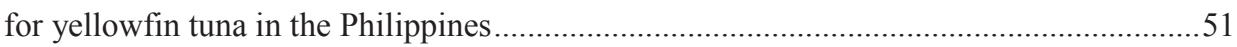

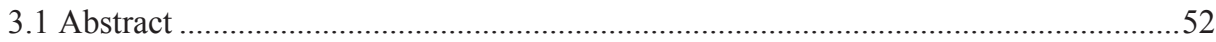

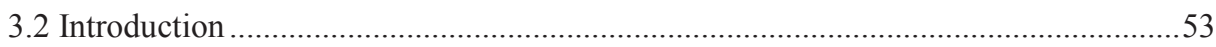

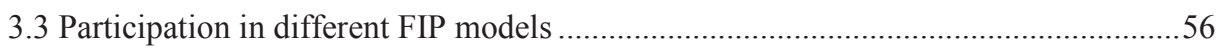

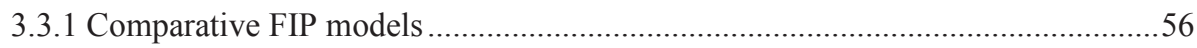

3.3.2 Fishers' participation decision framework .......................................................6 60

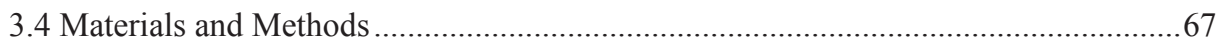

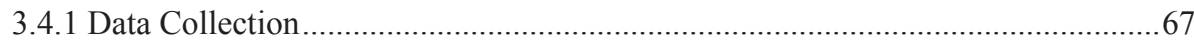

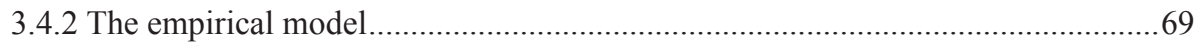

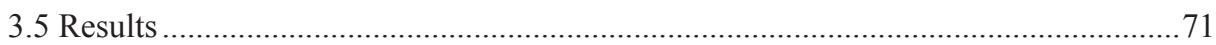

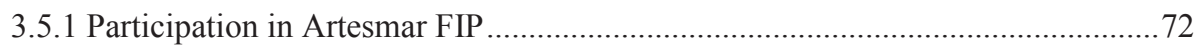

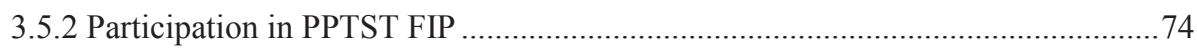

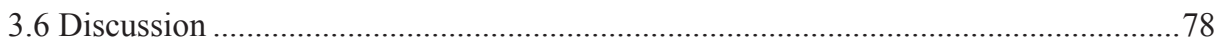

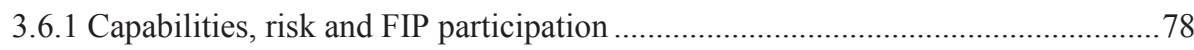

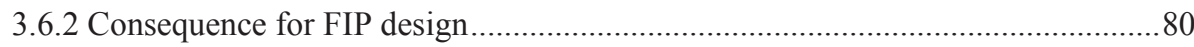

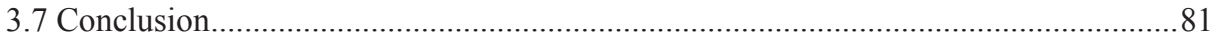

Chapter 4 FAD vs. free school: Effort allocation by Marine Stewardship Council compliant

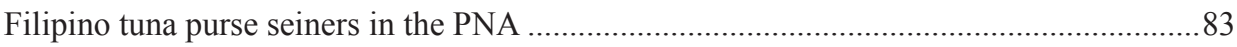

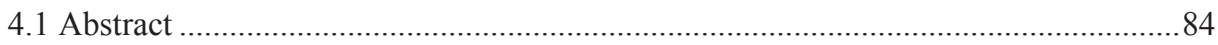

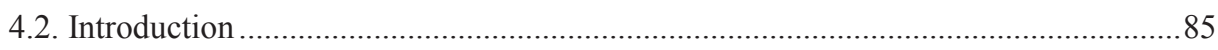

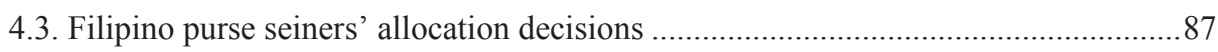

4.3.1 Filipino tuna purse seiners fishing in Papua New Guinea (PNG) ........................87

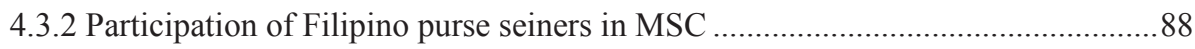

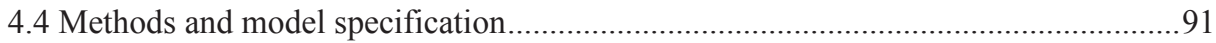

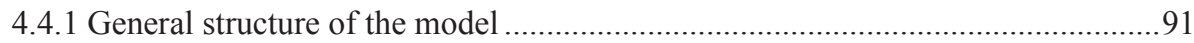

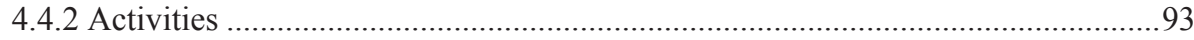

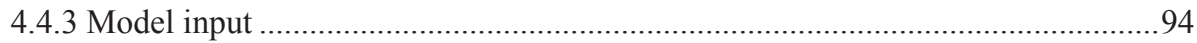

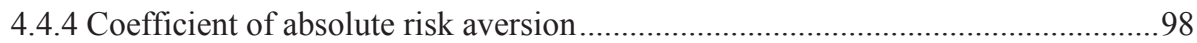

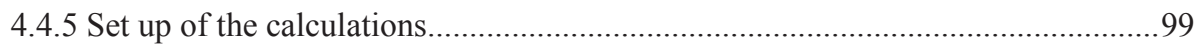

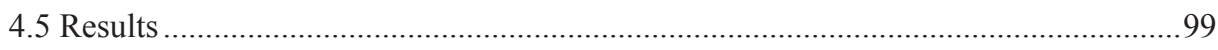

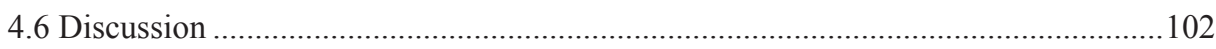

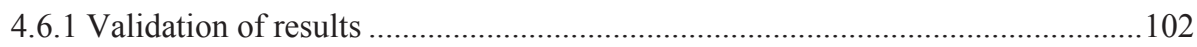

4.6.2 Risk aversion and allocation of fishing days of fishers ......................................103

4.6.3 Effectiveness of MSC as incentive mechanism .................................................104 
Chapter 5 Profitability of investments in private incentive mechanisms by Filipino purse seiners

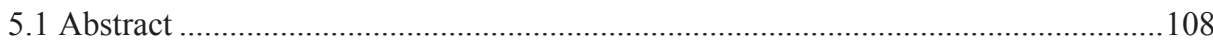

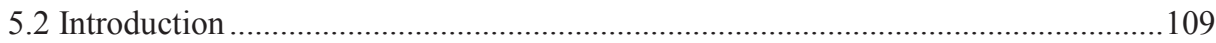

5.3 The participation of Filipino purse seine fishers in private incentive mechanisms ...111

5.3.1 International Seafood Sustainability Foundation (ISSF)...................................111

5.3.2 Marine Stewardship Council (MSC) ................................................................ 113

5.3.3 Strategic decisions for Filipino fishing companies ........................................... 114

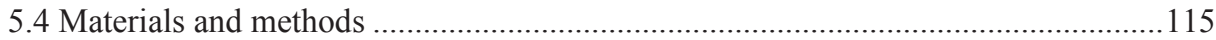

5.4.1 NPV and Equivalent Annual Profit (EAP) Approach ........................................115

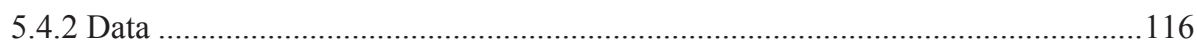

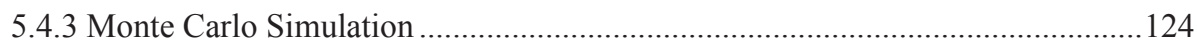

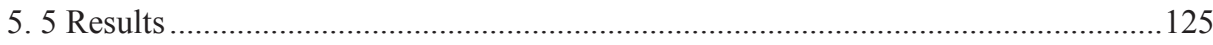

5.5.1 Statistical results of NPVs of investment on incentive mechanisms per risk aversion 125

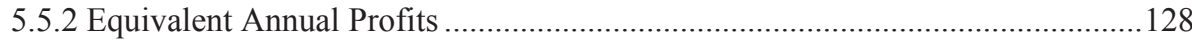

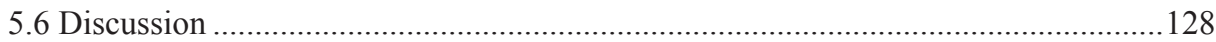

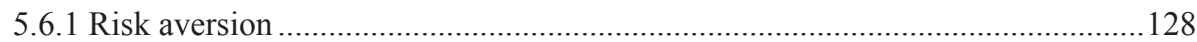

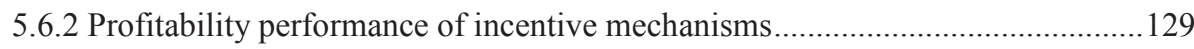

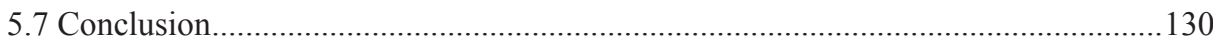

Chapter 6 General Discussion and Conclusion............................................................ 133

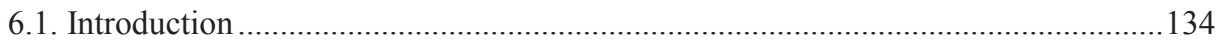

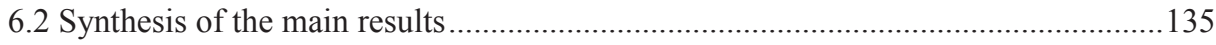

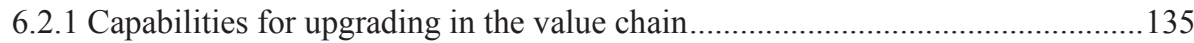

6.2.2 Tactical and strategic decision making under uncertainty .................................138

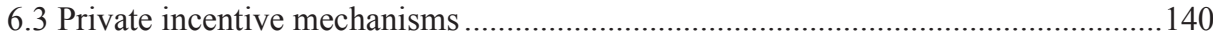

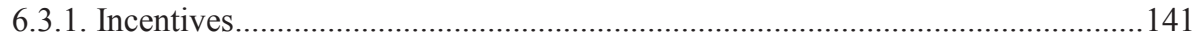

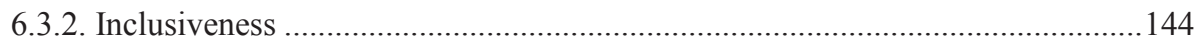

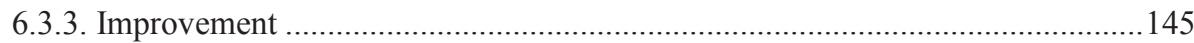

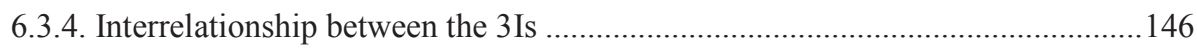

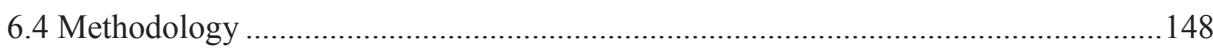

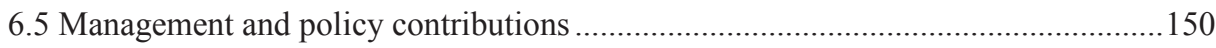

6.5.1. Recommendations for private incentive mechanisms ..................................... 150

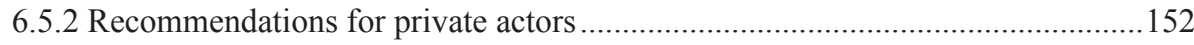


6.5.3 Recommendations for policy makers/government

6.5.4. Recommendations for future research 155

6.6 Concluding Remark 156

References .157

Summary 175

Appendices..... .183

Appendix A. Estimation of the sample size 184

Appendix B. Survey forms on household fishers. 185

Appendix C. Testing the explanatory variables for multi-collinearity using a Variance Inflation Factor (VIF) 191

Appendix D. Testing the explanatory variables for heteroskedasticity 191

Appendix E. Summary of the marginal effects of ordered probit model in second stage decision making 192

Appendix F. Ordered probit model of fisher data from Sablayan and Mamburao, Occidental Mindoro, with inverse Mills ratio .193

Appendix G. Ordered probit model of fisher data in Occidental Mindoro without inverse Mills ratio 194

Appendix H. Calculation of daily skipjack catches using FADs and free school fishing in PNG's archipelagic and EEZ waters 195

Appendix I. Detailed fishing vessels operation on FADs and on free school (2014) .....196 Appendix J. Variable costs of Vessel Monitoring System valued at 2015 196

Acknowledgements 197

About the Author 201

About the author. 202 


\section{List of Figures}

Figure 1.1 The research framework regarding methods used.

Figure 1.2 Framework for understanding fisher's decision making using the decision making theory

and upgrading in global value chain

Figure 2.1 The analytical framework links the horizontal and vertical dimensions of the chain to producer's upgrading strategies. Based on Riisgaard et al. (2010) ...............................................22

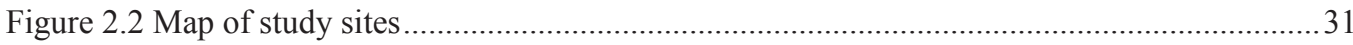

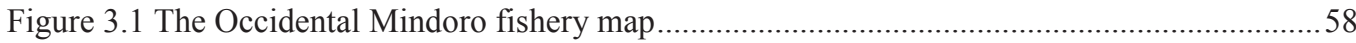

Figure 3.2 The decision model for fisher participation.............................................................61

Figure 3.3 The marginal effects of significant variables in second stage decision after ordered probit

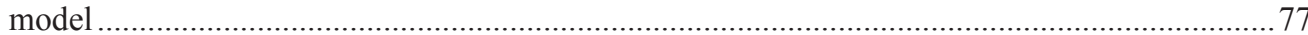

Figure 4.1 The archipelagic baseline and EEZ coverage of PNG waters .......................................8 89

Figure 4.2 The decision making framework of Philippine-owned chartered purse seine vessels in PNG

Figure 5.1 An example of FAD that uses non-entangling design (left picture) and of FAD that uses biodegradable materials (right picture)

Figure 5.2 An example design of non-entangling FAD that uses nettings (from old purse seine nets)

Figure 5.3 Projection of regular skipjack prices and skipjack prices caught on eco-FADs (top) and of skipjack catches using FADs in archipelagic and EEZ waters (bottom), 2016-2017 120

Figure 5.4 Projection of skipjack prices without and with MSC (top) and of free school skipjack catches for vessels with old engine and with upgraded engine (bottom), 2016-2020.

Figure 6.1 Framework for understanding how private incentive mechanisms can drive sustainability 


\section{List of Tables}

Table 2.1 The summary of GVC analytical concepts and how they are applied in the case of tuna value chains

Table 2.2 The different private incentive mechanisms fisheries and the example cases in WCPO tuna fisheries.

Table 2.3 Coordination of different private incentive mechanisms 32

Table 2.4 Institutional setting and support of the different private incentive mechanisms ...............33

Table 3.1 The explanatory variables for fishers' participation in Artesmar and PPTST FIPs ..........62

Table 3.2 The distribution of samples in each municipality .......................................................... 68

Table 3.3 Descriptive statistics of variables based on four groups of fishers' participation in FIP ..68

Table 3.4 Results of the probit model in the first stage using data from Sablayan and Mamburao fishers

Table 3.5 Results of the estimation of the ordered probit model in six municipalities of Occidental Mindoro .75

Table 4.1 Fisher-level requirements for MSC fishing in PNA

Table 4.2 Daily catches, prices, gross margin, and costs of Philippine-owned purse seine vessels flagged as PNG based on 2012-2014

Table 4.3 The monthly skipjack prices for years 2012-2014 in US\$ using Bangkok price index, inflated to 2014

Table 4.4 Variance-covariance matrix of gross margins (2012-2014) of Philippine-owned purse seine vessels flagged as PNG, with MSC (in '000)

Table 4.5 Model results for Philippine-owned purse seine vessels flagged as PNG for different values of absolute risk aversion coefficient

Table 5.1 The cost and revenues using traditional FADs versus using eco-FADs, per risk aversion, 2015

Table 5.2 The cost and revenues with and without MSC free school per risk aversion, 2015 .......118

Table 5.3 The types of distribution and parameters used for uncertain variables in Monte Carlo simulation

Table 5.4 NPV results and statistics for ISSF's eco-FADs, MSC free school fishing, and both mechanisms, per risk aversion based on simulation with 1000 iterations.

Table 5.5 EAP for comparing NPV of investments in ISSF's eco-FADs, MSC free school, and both mechanisms 
aFAD anchored Fish Aggregating Devices

BFAR Bureau of Fisheries and Aquatic Resources

CASS Conservation Alliance for Sustainable Seafood

CEA California Environmental Associates

COC Chain of Custody

DCF Developing Country Fisheries

dFAD drifting Fish Aggregating Devices

DWFN Distant Water Fishing Nation

EEZ Exclusive Economic Zones

EII Earth Island Institute

FAD Fish Aggregating Devices

FIP Fishery Improvement Project

FSMA Federated States of Micronesia Arrangement

GDP Gross Domestic Product

GVC Global Value Chain

ISSF

IUU

International Seafood Sustainability Foundation

LGU

MCS

Illegal Unreported Unregulated Fishing

Local Government Unit

MSC

Monitoring Control and Surveillance

NGO Non-Government Organisation

NPV Net Present Value

PNA Parties to Nauru Agreement

PNG Papua New Guinea

PPTST Partnership Programme Towards Sustainable Tuna

PVR Pro-active Vessel Register

RFMO Regional Fisheries Management Office

UVI Unique Vessel Identifier

VDS Vessel Day Scheme

VMS Vessel Monitoring System

WCPFC Western and Central Pacific Fisheries Commission

WCPO Western and Central Pacific Ocean

WWF World Wide Fund for Nature 

Chapter 1

General Introduction 


\subsection{Background of tuna fisheries}

The sustainability in tuna fisheries has been an interest both in scientific and management levels (Barclay \& Cartwright, 2007; Hilborn, 2007a; Langley et al., 2009; Pauly et al., 2002). Research on the sustainability of tuna fisheries has mostly focused on the two ends of a broad spectrum of fishers represented by small and large-scale fishers (Chand et al., 2003; Froese et al., 2011; Haward \& Bergin, 2001; Kaczynski \& Fluharty, 2002). This skewed focus has meant that the middle scale fishers along this scale have received less attention, while they too have an impact on the sustainability of tuna fisheries.

Representative of this 'missing' middle-scale, the majority of Filipino tuna fishers operate neither at the small-scale subsistence level, nor at a large industrial scale as seen in countries like Europe and the United States. The Philippines is the $4^{\text {th }}$ largest tuna producer in the world (Vera \& Hipolito, 2006). Some of these middle scale Filipino tuna companies have established fishing operations and canneries in countries like Indonesia and Papua New Guinea (Lewis, 2004). With their fishing practices, Filipino tuna fishers have an impact on the sustainability of the fishery. For instance around $75 \%$ of the Philippine fishing grounds are considered to be overfished due to the unsustainable fishing practices of Filipino fishers (Oceana, 2015), while many of the Filipino tuna fishers that have access to the international waters of Western and Central Pacific Ocean (WCPO) contribute to the pressure on tuna stocks in this region (Miyake et al., 2010).

Sustainability issues in tuna fisheries include the use of unsustainable fishing methods and the illegal, unreported, and unregulated (IUU) fishing. Filipino tuna fishers employ different kinds of gears ranging from handline to purse seine in catching three important tuna species in WCPO; namely skipjack (Katsuwomis pelamis), yellowfin (Thunnus albacares), and bigeye tuna (Thunnus obesus). Skipjack tuna, a low value species caught in higher volume for the canneries market, is not overfished and is also not subject to overfishing. Yellowfin and bigeye tunas, two high valued 
species targeted to fresh and sashimi markets, however, are perceived to be nearly overfished and are subject to overfishing (Bailey et al., 2012; Hampton, 2010; Langley et al., 2008). These latter species are threatened by, among others, unsustainable fishing practices of fishers in the WCPO. For instance, purse seining, which is the most dominant fishing practice in WCPO, heavily relies on the use of Fish Aggregating Devices (FADS), floating objects that increase the efficiency and catchability of skipjack tuna but at the same time, results in by-catch of juvenile yellowfin and bigeye tunas (Dagorn et al., 2007; Dagorn et al., 2013; Dempster \& Taquet, 2004; Macusi et al., 2015). With many fishing nations trying to increase their effort to further utilize the skipjack fishery, the yellowfin and bigeye stocks might face further decline (Langley et al., 2008). Moreover, the WCPO tuna fisheries are also challenged by Illegal Unreported and Unregulated (IUU) fishing, which is any activity of fishing vessels and fishers that violates fishery laws. IUU fishing includes the use of unlicensed fishing vessels, use of prohibited fishing techniques, and fishing in restricted areas. IUU fishing contributes to the depletion of fish stocks, to food security issues of developing countries, and to millions of dollars loss in revenue by the governments (Agnew et al., 2009).

Putting an end to unsustainable fishing methods and IUU fishing in tuna fisheries requires effective fishery governance. Government regulations, such as catch quotas, restrictions in fishing gears and licenses, and seasonal closures of fishing areas (see for e.g. O'Keefe et al., 2013; Oosterveer, 2008; Stefansson \& Rosenberg, 2005; Townsend, 1990), have been traditionally used to address conservation challenges in WCPO tuna fishery. However, the widely perceived failure of the government has led to a shift towards private incentive mechanisms as an innovative form of fishery governance (Grafton et al., 2006; Greiner et al., 2000; Oosterveer, 2008; Pascoe et al., 2010). 


\subsection{Private incentive mechanisms to improve sustainability of Filipino tuna}

\section{fisheries}

Private incentive mechanisms aim to change the behaviour of value chain actors through price premiums and/or preferential market access to voluntarily change their fishing practices (Jack et al., 2008; Van Riel et al., 2015). Private incentive mechanisms in tuna fisheries include a range of certification schemes, industry and NGO funded fishery improvement projects (FIPs), and industrial coalitions between fishing and/or trading firms, and use the market to incentivise the change in fishing practices of fishers. The increase in use of these mechanisms is partly due to the increasing demand for sustainable tuna from the Western markets such as Europe and America, as part of the strategy of brand members and retailers to ensure sustainability along the global chain (Iles, 2007; Oosterveer, 2008; Parkes et al., 2010; Ponte, 2008b). They may also provide fishers access to global chains through upgrading, or improving their production and positions in the value chain (Humphrey \& Schmitz, 2000, 2002a). However, it is unclear to what extent private incentive mechanisms influence fishers' decision to upgrade, which is to move towards sustainable fishing practices, either in the short- or in the long-run.

As the range and scope of private incentive mechanisms expands, there is a need to review private incentive mechanisms for two reasons. First, private incentive mechanisms are selective in nature because they determine who will participate or not, among developing country fishers, in global chains (Bolwig et al., 2010b; Gibbon et al., 2008; Ponte, 2008a). For instance, one of the major criticisms of the Marine Stewardship Council (MSC) is that it excludes developing country fishers due to the structural deficits in data management, the failure to set harvest control rules, and the high cost of auditing both for the fisheries and the chain of custody (Constance \& Bonanno, 2000; Gulbrandsen, 2009; Jacquet \& Pauly, 2008; Pérez-Ramírez et al., 2012a). Second, existing incentive mechanisms may differ in their definition of what constitutes a 'sustainable' fishery. For example, the MSC criteria for sustainable fisheries include the presence of sustainable fish stocks, 
use of fishing practices that minimise environmental impacts, and the presence of effective fishery management (Marine Stewardship Council, 2014b). By benchmarking these MSC criteria, FIP, a step-wise approach for improving fisheries practices and management of developing country fisheries, may enable fishers to achieve MSC certification at the end of a FIP program. However, while a fishery is currently improving its progress towards achieving similar or exactly the MSC principles, FIP participants can already access high value markets in the global chains while not fully complying with MSC standards (Bush et al., 2013; Sampson et al., 2015).

Understanding whether and to what extent private incentive mechanisms are effective in bringing sustainable improvements in the fishery requires a deeper insight into the decision making of fisher on changes in their practices (Charles, 1995; Hilborn, 1985; Opaluch \& Bockstael, 1984; Wilen, 1979). Most studies on private incentive mechanisms focus on the different kinds of incentives that might motivate fishers to improve their fishing practices (Costello et al., 2010; Grafton et al., 2006; Greiner et al., 2000; Pascoe et al., 2010). Some studies analysed the failure and successful cases of private incentive mechanisms in the fishery (Christian et al., 2013; Hilborn, 2007b; Ponte, 2012). However, there are hardly any studies that have analyzed the extent to which private incentive mechanisms influence the decision making of fishers to improve their fishing practices.

Analysing the effect of private incentive mechanisms on the decision making of tuna fishers to improve their fishing practices brings useful insights to different stakeholders in tuna fishery. Policy makers and fisheries management involved in the implementation of incentive mechanisms obtain information into which fishers are able and are not able to participate in incentive mechanisms, and based on this knowledge, determine the kind of rules and support that might enhance fisher's participation. By focusing on fishers' decision making, both participating (and yet to be participating) fishers can assess the effects of incentive mechanisms to their short- and long-term decisions, and therefore can implement upgrading decisions in the chain. 


\subsection{Objective and sub-objectives}

The main objective of this dissertation is to evaluate the extent to which private incentive mechanisms influence Filipino fishers' decisions to improve their fishing practices. In order to reach the main objective, four sub-objectives that represent the next four chapters of this dissertation in scientific article format, are formulated (see Figure 1.1).

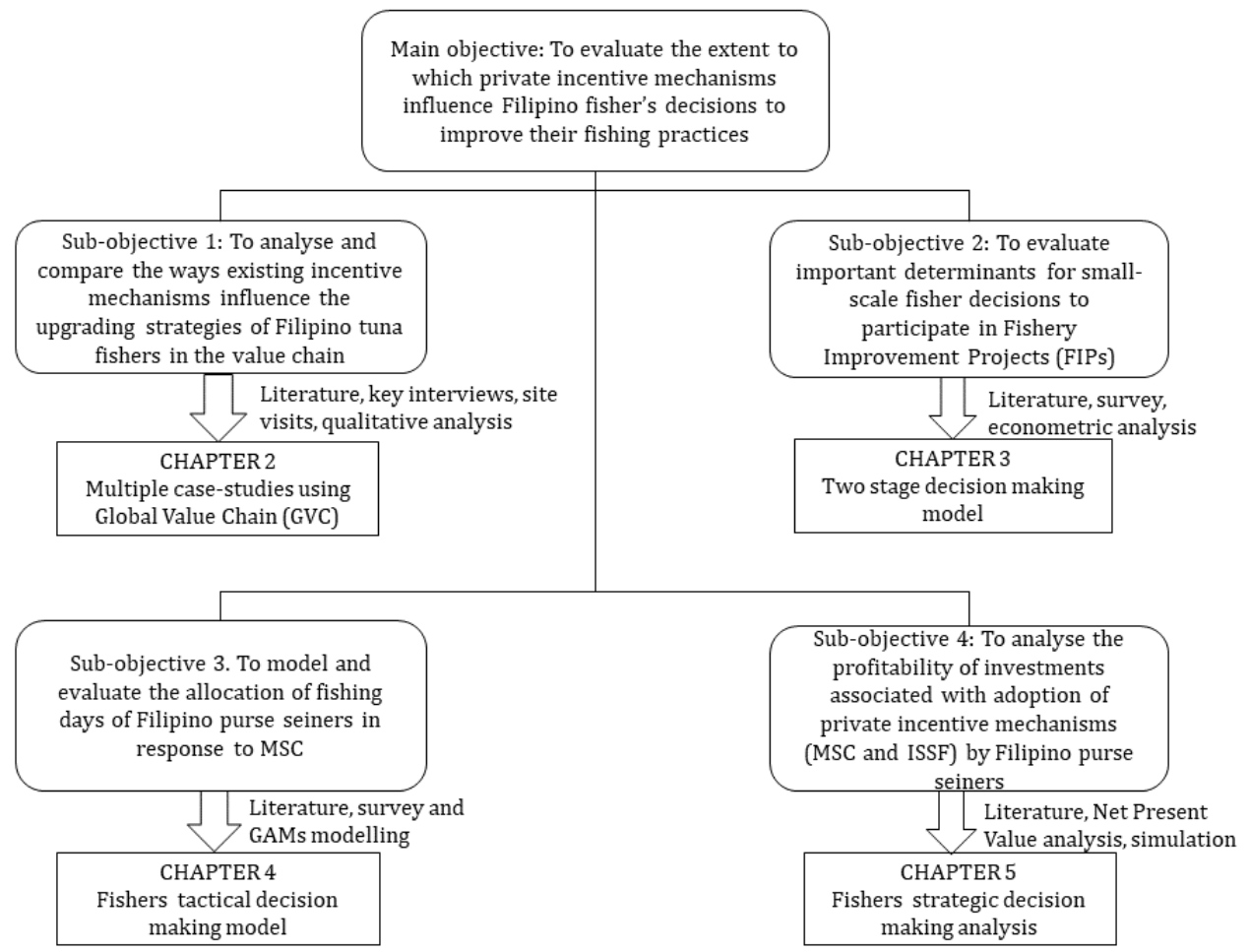

Figure 1.1 The research framework regarding methods used

The first sub-objective is to analyse and compare the ways existing incentive mechanisms influence the upgrading strategies of Filipino tuna fishers in the value chains. This sub-objective assesses whether the existing capabilities of the target Filipino tuna fishers, as a condition of fishers' upgrading in the value chain, match with the requirements set by existing private incentive mechanisms in tuna fisheries that include FIPs, MSC, and International Seafood Sustainability 
Foundation (ISSF). Moreover, this sub-objective explores the ways public and private actors outside the chain influence the capabilities of fishers in order to allow fishers to upgrade in the chain. By analysing the capabilities of fishers, this sub-objective can then provide insights into the different types of incentives for improving fishing practices, and whether these fishers are able to adopt specific upgrading strategies based on their capabilities. This will then provide clarity about the degree of inclusiveness for developing country fishers of the private incentive mechanisms.

The second sub-objective is to evaluate small-scale handline fishers' decisions to participate in FIPs. The case of FIPs is selected because the majority of the fishers participating in this program are less capable and disadvantaged than other actors in the value chain. This sub-objective further assesses the issue of inclusiveness in incentive mechanisms by providing insights into the factors that are needed for fishers to upgrade in the value chain using FIPs and into the fishers that are currently participating in FIPs.

The third sub-objective is to model and evaluate the allocation of fishing days of Filipino purse seiners in response to MSC. The outcome of this chapter will provide insight into the ways MSC influences the income, risks, and tactical decisions of fishers in terms of allocating fishing days based on fishing locations and on whether to use MSC free school fishing method or not by Filipino purse seine fishers. Having that knowledge leads to a better understanding of the extent to which fishers improve their fishing practices in response to MSC and the extent MSC incentivises purse seine fishers given the risks in tuna fishery.

The fourth sub-objective is to analyse the profitability of investments in private incentive mechanisms such as ISSF eco-FADs and MSC free school by Filipino purse seine fishers. This subobjective provides insights into the question whether fishers should invest in measures to fulfil the requirements of incentive mechanisms based on the economic benefits associated with investments 
of fishers. By focusing on two incentive mechanisms in purse seine fishery that differ in required fishing practices, level of investments, and institutional support, this chapter contributes to an understanding of the differences in defining a 'sustainable' fishery by each incentive mechanism and how these differences can be complementary to each other.

Based on these four sub-objectives, this dissertation contributes to the literature on 'missing' middle-scale fishers and provides insights into how fishers make decisions in the context of private incentive mechanisms, and how to improve the participation of fishers in order for private incentive mechanisms to achieve more sustainable fishery.

\subsection{Fisher's decision making framework}

This dissertation provides a decision making framework that integrates the decision making process and the kinds of improvement decisions made by fishers in short- and in long-run time horizons, in response to private incentive mechanisms (see Figure 1.2). The framework combines concepts from global value chain analysis and economic decision making theory. This framework is in line with the notion that the behavior of an individual is not simply influenced by economic factors, but also by the individual's social interaction with society (Granovetter, 1985). The analytical concepts underlying the decision making framework include upgrading and capabilities (in chapters 2 and 3), risk attitude, income, and risks (in chapters 3, 4, and 5), and tactical and strategic decisions (in chapters 4 and 5).

The decision making of fishers to adopt sustainable fishing practices using private incentive mechanisms is referred to as the 'upgrading' in the global value chain literature (Ponte \& Ewert, 2009; Ponte \& Gibbon, 2005). There are at least four different upgrading strategies that fishers can adopt. They can improve their product, the process of production, the functions they perform in a value chain or combine any of these strategies (Riisgaard et al., 2010). There are a number of 
frameworks for assessing the decisions of producers, like fishers to adopt a particular upgrading strategy for ultimately contributing to a goal like sustainable fishing (Antunes et al., 2006; Ostrom, 2009). This dissertation focuses on two specific factors that run through the GVC and economic decision making literature.

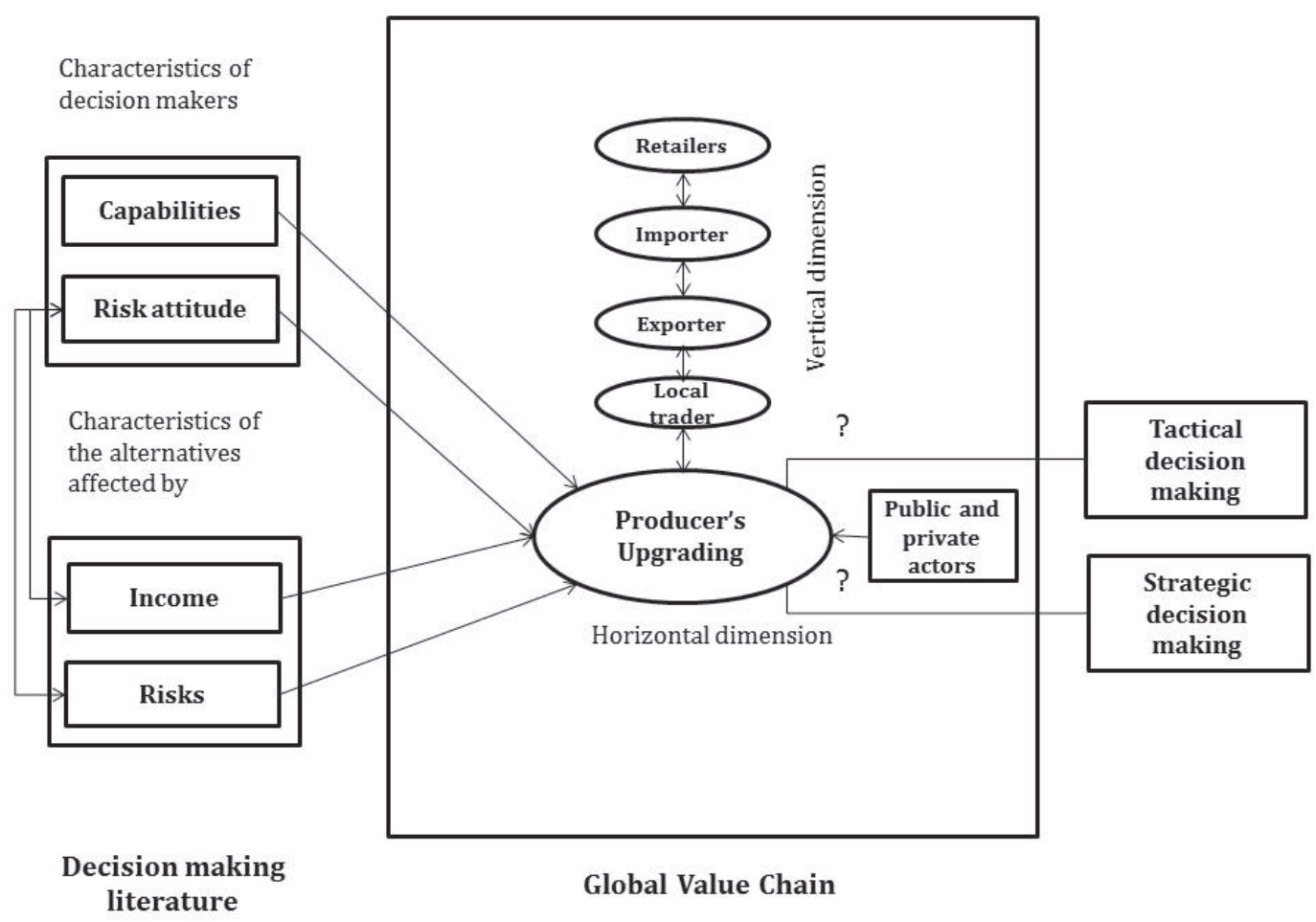

Figure 1.2 Framework for understanding fisher's decision making using the decision making theory and upgrading in global value chain

First, upgrading requires producers to be capable of making changes in their fishing practices. A capability is a specific skill or competence of an individual to achieve the necessary functions and strategies to realize an endowment (Sen, 1993). In the GVC literature, it is recognised that these capabilities are not inherent to an individual but are influenced by the relations of a producer in the 
value chain, as well as wider state and community institutions in which they are embedded (Giuliani et al., 2005; Robeyns, 2005). To understand the capabilities of a fisher, both these relations and the use or availability of firm-level resources, specific knowledge and skills, and forms of social organisations need to be considered (e.g. Helfat et al., 2009; Nussbaum, 2003; Robeyns, 2005). By characterising these capabilities, the extent to which producers are able to build and follow through with an upgrading strategy can be assessed.

The second factor that influences upgrading is the level of income and risk associated with upgrading, which are among others determined by the risk attitude of fishers (Rohrmann, 2008). Capabilities and risk attitude in decision making literature constitute the "characteristics of decision makers', which are the first variable group in Figure 1.2 that influence the decision making of producers. In general, fishers with lower risk aversion are expected to choose a strategy that generates a higher expected income with higher associated risk, such as upgrading (Abadi Ghadim \& Pannell, 1999; Lindner, 1987). Based on their risk attitude and the characteristics of the choice alternatives, fishers make decisions on whether or not to upgrade, which type of upgrading strategies to pursue, and to what extent to upgrade. The characteristics of the choice alternatives that vary in levels of income and risks, are external to the decision maker and constitute the second group of variables (in Figure 1.2) that influence decision making. Together, the characteristics of decision makers and the characteristics of the alternatives are the two important components of the decision making theory (McFadden, 1973) .

A cross cutting element of upgrading is time. Fishers can build an upgrading strategy through a combination of short- and long-run decisions. Short-run or tactical decision making refers to decisions within a time horizon of one year, while long-run or strategic decision making refers to decisions within a time horizon of more than a year (Kay et al., 2005). In this dissertation, the tactical decisions of fishers involve the allocation of fishing days using different types of fishing 
gear at different fishing ground. The strategic decisions focus on investing or not in equipment that is needed to comply with incentive mechanisms such as FIPs, MSC certified free school tuna fishing and/or the adoption and use of ISSF eco-FADs.

\subsection{Methodologies}

In order to address the main- and sub-objectives using the theoretical concepts outlined above, this dissertation employs multiple approaches that combine qualitative and quantitative forms of data collection (Figure 1.1). The multiple approaches used in this dissertation are: (multiple) inductive case studies, positivist approach, and normative modelling. The choice of an approach to be used in each chapter is based on a combination of three factors: the objective of the chapter, the available data, and the gap in literature. The advantage of using multiple approaches is that each approach can validate or strengthen the results of other approaches and can also address the limitation of other approaches (Byrne \& Humble, 2007). By applying multiple approaches, this dissertation makes a stronger analysis of private incentive mechanisms.

\subsubsection{Inductive multiple case studies}

Inductive research is based on and iteratively amends theory based on empirical data, while case studies also specifically address the 'hows' and 'whys' of research in contemporary events and use either a single or multiple cases approach (Eisenhardt, 1989; Yin, 2009). The advantage of using inductive multiple case study is that a researcher can have a wider understanding of the existing case phenomenon and can make more convincing generalisations based on the differences and similarities between the cases (Eisenhardt \& Graebner, 2007; Yin, 2009). The use of inductive multiple case study perfectly fits in understanding the new and innovative phenomena of private incentive mechanisms and in further advancing the relatively recently emerging theories of global value chain. Thus, this approach is employed in chapter two, which analysed and compared three private incentive mechanisms (FIPs, MSC, and ISSF) that Filipino tuna fishers participate with. 
In chapter two, the data used for doing inductive multiple case studies are extensive and the information are from wide range of value chain and institutional actors that are involved in incentive mechanisms. The qualitative techniques that are employed in this chapter are: key informant interviews, on-site visits, attendance and participation in the conferences, literature reviews, and desk research.

\subsubsection{Positivist approach}

The positivist approach starts with a hypothesis or assumption, which is tested using quantitative forms of data gathering such as survey and experiments (Crowther \& Lancaster, 2008). This approach is employed in chapter three employing data obtained from small scale fishers in Occidental Mindoro, Philippines. The data set has a large number of observations and a wide range of variables that might explain fisher participation in FIP; hence an econometric analysis is a suitable method in this chapter. By doing this analysis, this chapter addresses the gap in literature in terms of the availability of highly quantitative and empirical research in FIP.

\subsubsection{Normative approach}

The normative approach uses subjective and value based research and determines which aspect of the subject area requires improvement based on these set criteria/values (Hardin, 2008). The normative approach is used in this dissertation for two reasons.

The first reason is derived from the specific sub-objectives. For instance, chapter four models the effect of risk aversion of fishers on their allocation of fishing days in response to MSC. This chapter uses the Mean-Variance Approach because this normative modelling approach accounts for the risk aversion while determining the optimal allocation of fishing days of fishers. Chapter five assesses the profitability of investments associated with the adoption of private incentive mechanisms. The 
use of Monte Carlo simulation in calculating the profitability of investments is a suitable method for achieving the objective of this chapter.

The second reason for using normative approaches in this dissertation is the challenge of getting empirical and highly quantitative data of purse seine vessel based on the sensitivity of information and on time constraint in data collection. Not all fishing companies are willing to give information regarding their vessel activities because they consider this information as crucial for competing with other industry players. At the same time, the skippers stay at sea for a long period of time (average of one year), thus doing a quantitative sampling that is similar to the one done in chapter three will require a longer time horizon and will involve higher costs. These data include time series quantitative data of prices and catches at an aggregate level and information on published literature and websites of government, industry, and NGOs engaged in incentive mechanisms.

\subsection{Outline of the dissertation}

The rest of this dissertation is organised as follows. Chapter two discusses the general overview and overall comparison of the three incentive mechanisms (FIPs, MSC, and ISSF) in Philippine tuna fisheries. Chapter three focuses on the important factors that influence small-scale handline tuna fishers participation in FIPs. Chapter four analyses the influence of MSC on short-term decision making and on level of gross margins and risks of Filipino purse seine fishers who are fishing in PNA. Chapter five evaluates the level of profitability related to the adoption of incentive mechanisms (MSC and ISSF) by Filipino purse seine fishers. Finally, chapter six synthesizes the results from chapters two to five and recommends improvements in the design of incentive mechanisms and discusses the theoretical implications of this dissertation. 


\section{Chapter 2}

\section{Comparison of private incentive mechanisms for improving sustainability of Filipino tuna fisheries}

This chapter has been published as:

Tolentino-Zondervan, F., Berentsen, P., Bush, S., Idemne, J., Babaran, R., \& Oude Lansink, A. (2016). Comparison of private incentive mechanisms for improving sustainability of Filipino tuna fisheries. World Development, 83, 264-279. 


\subsection{Abstract}

This paper analyses the influence of three private incentive mechanisms over decision making related to improved sustainability of fishing practices in Filipino tuna fisheries. The three mechanisms compared are the World Wide Fund for Nature's fishery improvement project model, Marine Stewardship Council certification, and the International Seafood Sustainability Foundation pro-active vessel register. The main question addressed in this paper is how and to what extent the private incentive mechanisms support the development of fisher capabilities to respond to the requirements set out by these mechanisms. Applying a global value chain approach to analyse results collected from key actors involved in Philippine tuna fishers contributing to both domestic and regional economic development in the Western Pacific, we explore the structure and function of these private incentive mechanisms in achieving both environmental and economic development outcomes. Our results show that these private incentive mechanisms deliver different direct and indirect incentives for changing to more sustainable fishing practices, and that the success of these mechanisms is dependent on the extent to which the mechanisms support the development of target fisher capabilities to comply with their sustainability requirements. We conclude that the future success of these incentive mechanisms depends for a large part on stricter sustainability requirements, but also on the capacity of the mechanisms to incentivise the inclusion of more developing country fishers. These findings contribute to a wider understanding of how the capabilities of developing country producers are influenced by their relationship with chain and non-chain actors, and with the wide institutional arrangements that the producers operate in.

Keywords: Philippines; private incentive mechanisms; sustainability; tuna fishery; value chain 


\subsection{Introduction}

Improved management and more equitable distribution of benefits from tuna fisheries is widely recognised as fundamental to the long-term sustainability of tuna fisheries in Western and Central Pacific Ocean (WCPO) (Barclay, 2010; Barclay \& Cartwright, 2007). However, achieving both development and resource sustainability goals has been complicated by the complex interaction of different fishing gears with three main species; yellowfin (Thunnus albacares), bigeye (T. obesus), and skipjack tuna (Katsuwonus pelamis). While skipjack tuna remains underexploited, both juvenile yellowfin and bigeye tuna, both of which associate with skipjack, are more vulnerable to overexploitation; with bigeye already in an overfished state and with ongoing overfishing taking place (Hampton, 2010; Harley et al., 2011; Langley et al., 2008). Fisheries surrounding these tuna species account for up to half of the gross domestic product (GDP) of some Pacific island countries (Havice, 2010), and make up 20\% of total fisheries production in archipelagic countries such as the Philippines (Bailey et al., 2012). Finding governance mechanisms that can successfully steer fishers towards improved resource stewardship while maintaining an important source of regional, national and local income, is therefore a clear policy imperative for both national and regional sustainability and development.

State-led fisheries management and control, such as restrictions in fishing licenses, gears, and harvest, have been traditionally applied to addressing conservation challenges in WCPO tuna fisheries. However, the perceived limitations of state regulation have led to a shift towards regulation through private incentive mechanisms (Grafton et al., 2006; Hilborn et al., 2005; Oosterveer, 2008). Private incentive mechanisms aim to change the production and consumption behaviour of value chain actors towards sustainability by delivering economic incentives, such as price premiums and/or market access, while allowing actors to decide the extent to which they will adopt changes to their practices (Jack et al., 2008; Van Riel et al., 2015). The use of private incentive mechanisms in the value chain to motivate fishers to improve their fishing practices has 
increased considerably over the last decade and is often presented as a new opportunity for creating sustainability outcomes (Iles, 2007; Parkes et al., 2010). However, the impact of private incentive mechanisms in developing countries such as the Philippines has been widely debated given their potential adverse effect on poor or disadvantaged primary producers (e.g. Fairhead et al., 2012). Questions therefore remain about the extent to which these different mechanisms stimulate so called 'developing world' fishers to improve their fishing practices in order to achieve sustainability goals (see Stratoudakis et al., 2015).

Existing studies on private incentive mechanisms for fisheries have focused predominantly on ecolabels, including the MSC, Krav-Eco, Friends of the Sea (FOS), Naturland, and Marine Ecolabel Japan. These studies have focused on the ways in which standards or criteria for fishery sustainability are developed, introduced, and adopted by fisheries in different parts of the world (Gulbrandsen, 2009; Parkes et al., 2010; Ponte, 2008b; Ponte \& Cheyns, 2013; Potts \& Haward, 2007). Some studies highlight how private incentive mechanisms improve the management of developing country fisheries, resulting in economic- and non-economic benefits for producers (Bolwig et al., 2009; Lopuch et al., 2008; Pérez-Ramírez et al., 2012a; Warning \& Key, 2002). Other studies, however, show how private incentive mechanisms have limited and marginalised developing country fisheries' participation in the global chain (Pérez-Ramírez et al., 2012b; Ponte, 2008a; Tran et al., 2013). To the best of our knowledge, there are no studies that systematically compare different types of private incentive mechanisms in a single commodity, nor whether these mechanisms incentivise fishers to shift towards more sustainable production practices.

This study compares the effects of three private incentives mechanisms - the World Wide Fund for Nature (WWF)-led Fishery Improvement Projects (FIPs), the Marine Stewardship Council (MSC) certification, and the International Seafood Sustainability Foundation's (ISSF) pro-active vessel register (PVR) - and their effect on the domestic and international involvement of the Philippines in 
WCPO tuna fisheries. We have chosen these mechanisms because of their emerging influence over tuna fisheries in the WCPO and the range of institutional, social and economic challenges that have emerged around their implementation in developing countries (e.g. Kirby et al., 2014). We have chosen to focus on Filipino tuna fisheries for five reasons. First, tuna has been an important source of livelihoods and economic development in the Philippine economy, contributing around \$681 million of export revenue in 2013 (Bureau of Fisheries and Aquatic Resources, 2013). Second, the Philippines is the fourth major tuna producer in the world behind China, Japan, and Indonesia (Food and Agriculture Organisations, 2005). Third, the sustainability challenges faced in the Philippines have reached an acute stage, where domestic stocks of tuna are significantly depleted (BFAR, 2012; Vera \& Hipolito, 2006), forcing Filipino investment offshore within the WCPO region. Fourth, the Filipino tuna fishers range from small-scale nearshore handline fishers to industrial scale offshore purse-seine fishers, so both different type and scale of tuna fisheries are included. And fifth, there are at least four private incentive mechanisms currently implemented in the Philippines that aim to create change towards sustainability of tuna fisheries.

The objective of this paper is to compare the ways in which different types of private incentive mechanisms influence upgrading of Filipino tuna fishers in the value chain. In order to achieve this objective, we analyse how the capacity of fishers to make decisions related to upgrading is influenced by prevailing value chain governance arrangements and the local institutional arrangements that structure the practices of fishers. We compare these incentive mechanisms through the analytical lens of 'upgrading' in global value chains (GVCs). By doing so we analyse the conditions under which producers can capture more value for their products through compliance to market requirements, while at the same time balancing a range of economic, environmental, and social benefits and risks (Humphrey \& Schmitz, 2000; Ponte \& Ewert, 2009). Building directly on the GVC literature (Gibbon \& Ponte, 2005; Humphrey \& Schmitz, 2002b; Mitchell \& Coles, 2011), we contribute to a wider understanding on how the interaction between firm and non-firm actors 
involved in these incentive mechanisms influences the capabilities of developing countries producers to upgrade in globally traded products such as tuna.

The following section provides an explanation of GVC analysis and of upgrading, before outlining the methods used in this study. The paper continues by presenting the private incentive mechanisms and comparing and discussing them in the context of globally commodified natural resources. Finally, conclusions are drawn related to upgrading of fishers under each mechanism.

\subsection{Global Value Chain Analysis}

Governing sustainability 'through' value chains involves a set of normative and regulatory practices that use the chain as a medium for influencing producer decision-making, and strategies for upgrading their practices for sustainable production (Bush et al., 2014). But while considerable attention has been given to the structural dimensions of GVCs, including lead-firm strategy and state support to private incentive mechanisms such as certification (e.g. Foley, 2013; Ponte, 2008b), less has been given to how these strategies enable producers to improve their capability for upgrading to more sustainable production practices (e.g. Giuliani et al., 2005; Marchi et al., 2013). The relationship between private incentive mechanisms and producer capabilities in GVCs raises important development-related questions, such as how the governance of value chains in tuna fisheries enable developing country producers to access markets, how incentives for participation in these markets are distributed among participating countries, and in how far producers are exposed to economic, social and environmental risk as a consequence of their participation (Barrientos et al., 2011; Perez-Aleman, 2012). A particularly underexplored question is how and to what extent incentive mechanisms support the development of capabilities of fishers to respond to the requirements they set out for market compliance. Addressing this gap, we now turn to an explanation of how the GVC framework enables a more precise elaboration of producers capabilities and how capabilities are influenced by the interactions of producers with chain actors, 
with private and public actors outside the chain, and with the existing institutional arrangements of the operating environment.

\subsubsection{Upgrading}

Firms are expected to upgrade their practices towards specified goals such as more sustainable production, when the benefits of upgrading exceed maintaining existing practices (Jack et al., 2008). Private incentive mechanisms are therefore designed with the purpose of coordinating (or enabling firms to coordinate) the conditions in the value chain and the incentives to be delivered, which force other firms to comply with the pre-determined standards or requirements.

The different ways in which producers and other firm actors upgrade their position or process of production in value chains, have been variously classified (Gibbon \& Ponte, 2005; Humphrey \& Schmitz, 2002b; Mitchell \& Coles, 2011). Following Riisgaard et al. (2010), these ways can be summarised into four main strategies. First, upgrading the process, the product characteristics and the volume, which can improve the quality, yield and value per unit sold. Second, either increasing or decreasing the number of chain functions, which corresponds in broad terms to functional integration or specialisation. Third, changing the level of coordination set out in contracts, either in terms of vertical business relationships or horizontal business relationships with firms in the same chain node (e.g. forming a cooperative or association). And fourth, combining any of the three upgrading strategies in order to achieve specific production related goals.

While this upgrading typology can be used to explain strategies post hoc, it does not provide a means of analysing the conditions under which firms are able to respond to private incentive mechanisms in order to upgrade. We therefore argue that any comparison of these private incentive mechanisms requires focusing on the relations firms have with other firm and non-firm actors that facilitate and constrain the willingness and capacity of those they target to adopt pre-defined or 
standardised upgrading strategies. In doing so, we focus on three broad dimensions of the value chain, as shown in Figure 2.1. First, the vertical dimension of value chains, with attention given to the movement of products downstream from suppliers to buyers, and information and more specific production requirements flowing back upstream from buyers to suppliers. Second, the horizontal dimension of value chains, made up of both public and private institutions that set rules and norms over the conduct of producers, while at the same time providing institutional support that enables producers to implement their upgrading strategy. And third, at the confluence of vertical and horizontal dimensions of value chains, the capabilities of producers, which are a function (as well as constituent part) of the conditions in the vertical and horizontal dimensions of the value chain.

We now turn to a breakdown of these three dimensions into a set of analytical variables (as outlined in Table 2.1), starting in reverse order.

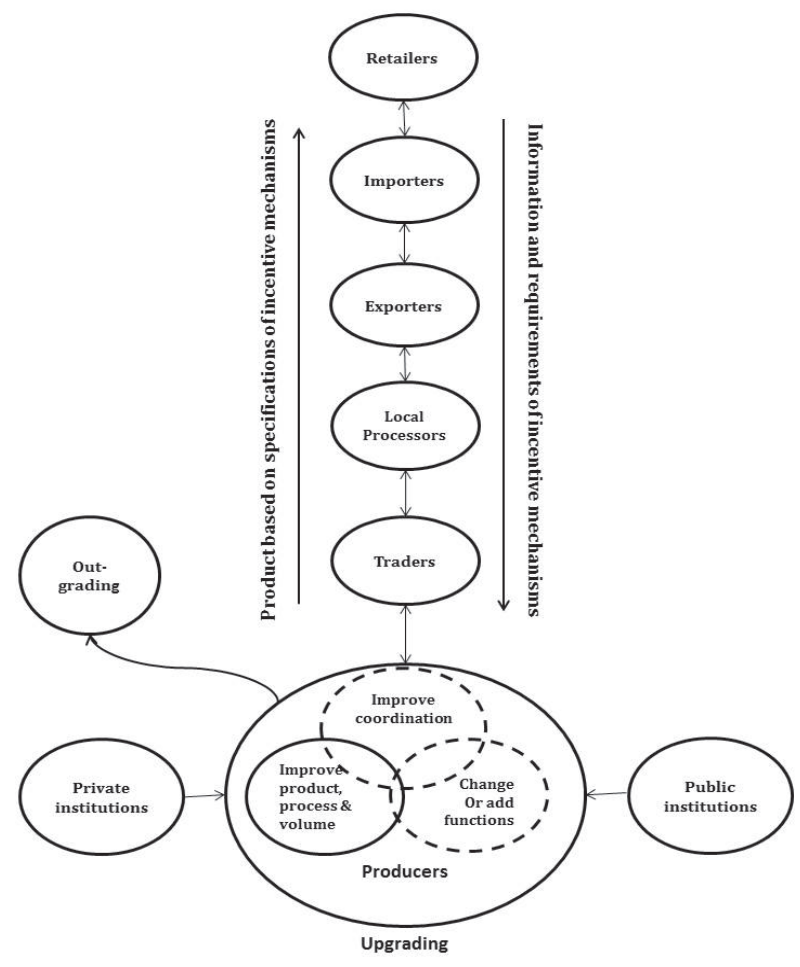

Figure 2.1 The analytical framework links the horizontal and vertical dimensions of the chain to producer's upgrading strategies. Based on Riisgaard et al. (2010) 


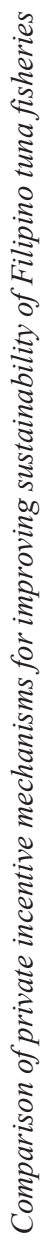

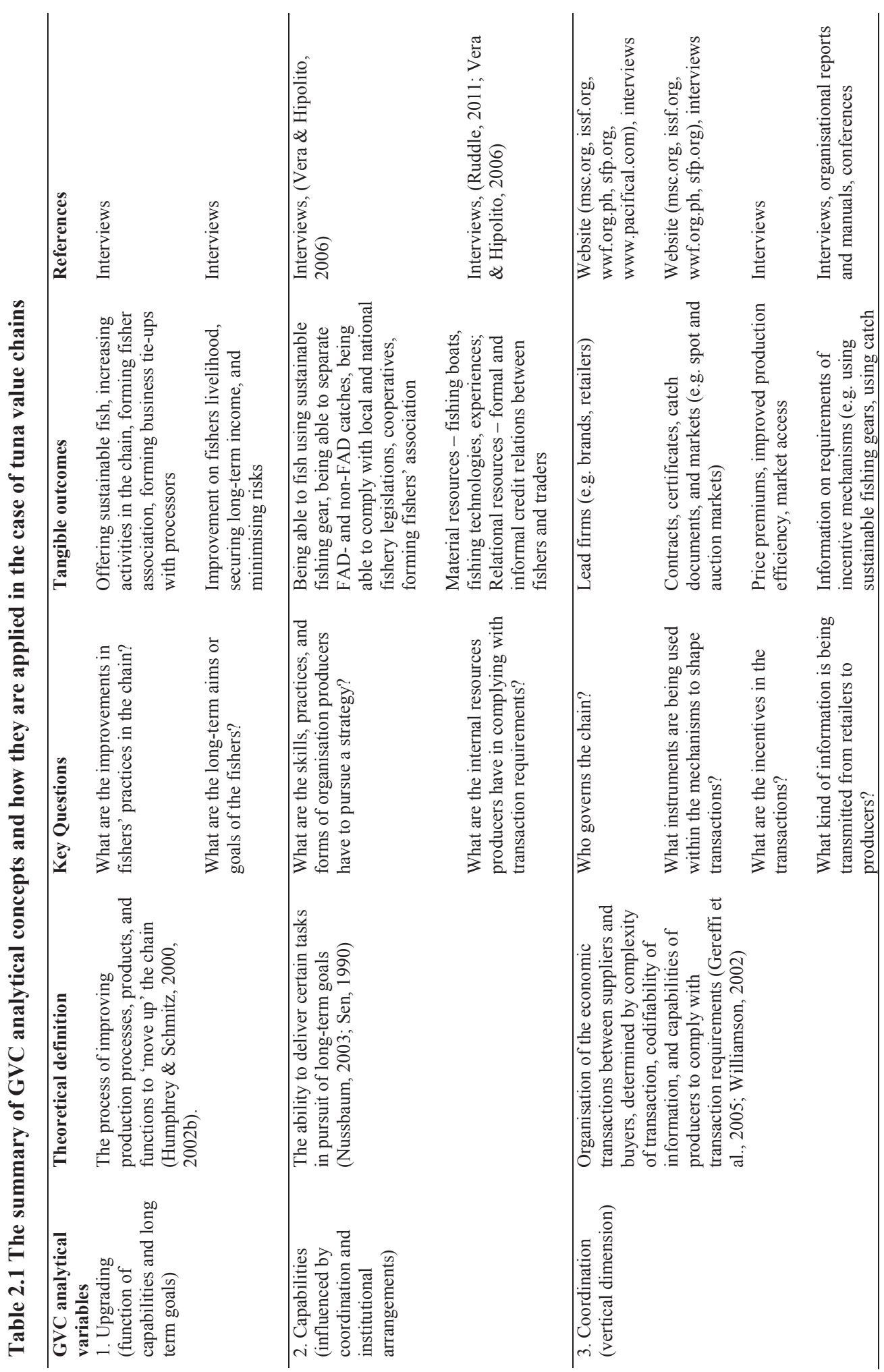




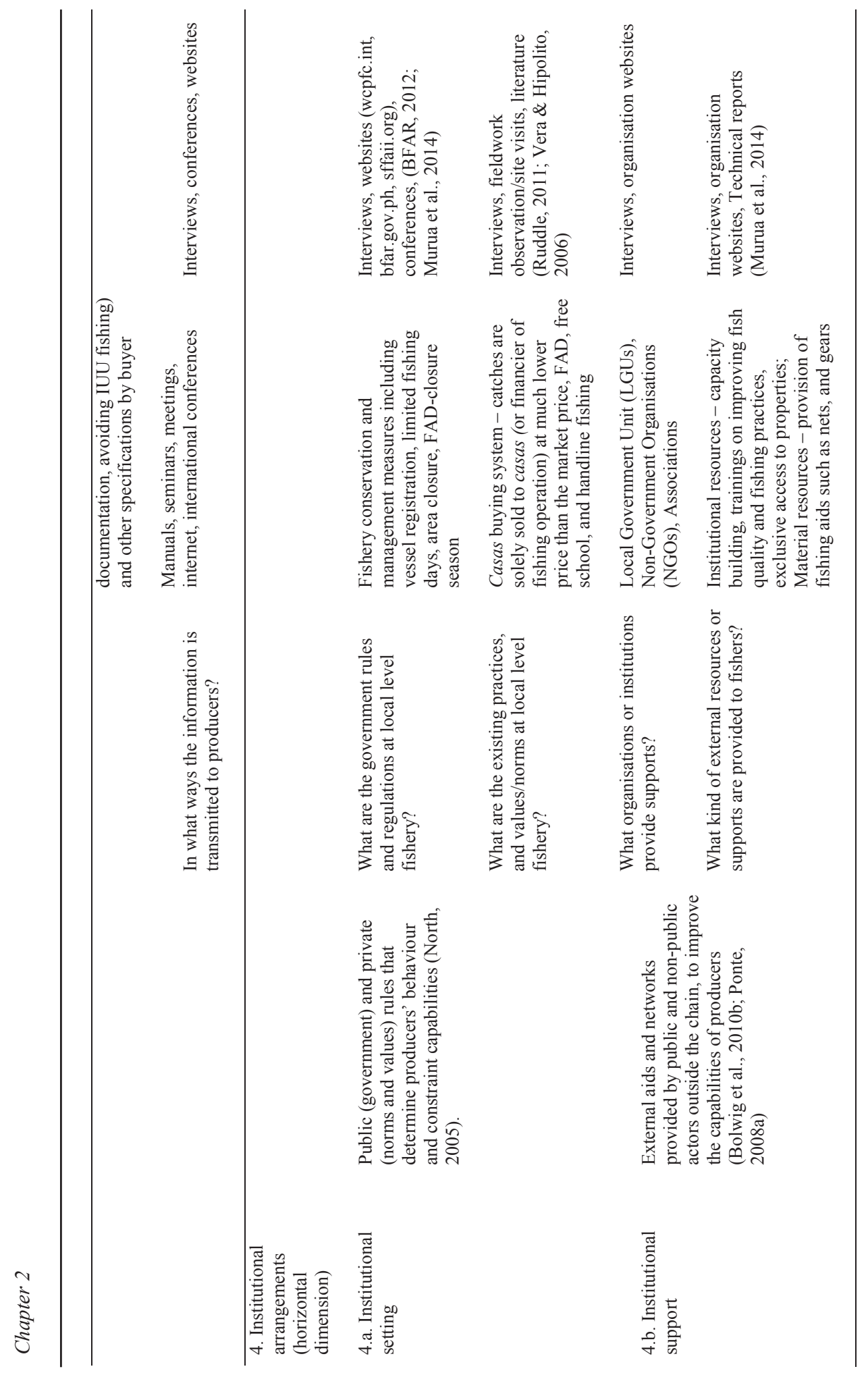




\subsubsection{Capabilities: A condition for upgrading}

Defined broadly as "what people are able to do or to be" (Sen, 1993p. 271), the capabilities of a given firm determine whether and to what extent they can pursue upgrading strategies dependent on specific skills, practices, experiences, and forms of social organisation, such as improved livelihoods or resource sustainability (Nussbaum, 2003; Sen, 1990). Translated to tuna fisheries, examples of capabilities that are required by fishers to respond to the requirements of private incentive mechanisms include the ability to chase and set nets around schools of fish, to analyse fishing technologies, to comply with local and national fishery legislations, to cooperate to form fishers' associations or cooperatives, and to separate non-fish aggregating device (FAD) catches from FAD catches. The latter is of particular importance to tuna fisheries given the role of FADs in increasing the efficiency of fishers (Macusi et al., 2015), but also their impact on attracting threatened and endangered marine species that often end up as by-catch such as sea turtles, sharks and juvenile big-eye tuna.

Developing capabilities to respond to private incentive mechanisms also requires a firm to gain access to and to apply material and social (or relational) resources. Material resources refer to natural or material capital, such as fishing boats and gears, and also firm specific knowledge, man power, and experiences gained through time (Collis, 1994; Morrison et al., 2008; Prahalad \& Hamel, 1990). Relational resources are those that emerge from social capital, including formal and informal relationships and organisational arrangements that results in access to credit, technical support and legal advice (Davis \& Mentzer, 2008). Building again on Sen (1993), the local institutional setting within which an individual is embedded also affects their ability to develop these capabilities, especially if public or private institutions limit or enable access to the resources necessary to realise a capability. For example, if access to credit is limited, the option to change is also constrained. Therefore, capabilities, coupled with producers goals, influence whether and how upgrading 
decisions are made. Conversely, an individual's material and social resources may also be influenced by the level of requirements set by private incentive mechanisms.

\subsubsection{The vertical and horizontal dimensions of the value chain influencing upgrading}

As indicated in Figure 2.1, the capabilities of producers do not exist in isolation but are instead influenced by actors and institutions in both the vertical and horizontal dimensions of value chains (Giuliani et al., 2005; Riisgaard et al., 2010). The vertical dimension describes the locations and relationships between value chain actors, the information and product flow in the value chain, and the distribution of functional labour and incentives along the chain (e.g. Dolan \& Humphrey, 2000; Gereffi, 1999; Nadvi, 2008; Schmitz \& Knorringa, 2000). This dimension also focuses on how lead firms, often from developed countries, 'coordinate' the production and trade by setting conditions over the terms of incorporation of producers into a given chain (Bolwig et al., 2010b; Gereffi et al., 2005; Humphrey \& Schmitz, 2000; Kaplinsky, 2000a; Riisgaard et al., 2010).

A number of coordination types have been identified in the GVC literature, ranging from free market exchange to chains where lead firms play an increasingly greater role in the activities of producers - from relational to captive and hierarchical forms of coordination (see Gereffi et al., 2005 for detail). But more importantly this literature also identifies a range of factors that influence the degree of lead firm coordination, often using rules, standards and norms of private incentive mechanisms (Gereffi et al., 2005; Nadvi, 2008; Ponte \& Cheyns, 2013). First, the complexity of transaction refers to the kind of product or production practice that is requested. Second, how codifiable that product or practice is will determine the level of information that needs to be passed down to producers. Third, how capable a producer is to respond to the complexity and codification set out by a firm and/or incentive mechanism determines whether they will ultimately be able to comply with the requirements for market inclusion. Depending on the kind of coordination, apparent compliance with these requirements may provide incentives to producers in the form of 
higher product prices, market-access, or improved company image (Humphrey \& Schmitz, 2002a). However, given that investments are often needed to meet these requirements, producers also have to balance cost against the risk of recovering any investments made associated with upgrading. As variously argued (Amekawa, 2013; Khiem et al., 2010; Riisgaard et al., 2010), inability to satisfy higher requirements or the lack of incentives for upgrading may also lead to producers exiting the chain (as illustrated in Figure 2.1).

Building on the definition of capabilities and of coordination discussed previously, we assume that producers' capability is also influenced by the horizontal dimension in the chain in which they are embedded. The horizontal dimension is made up of the institutional setting in which producers operate, including both the public (government) and private (norms and values) rules that determine producers' behaviour and constrain capabilities (North, 2005). The horizontal dimension is also made up of what we term 'institutional support', or the external support given by private and public actors outside the chain that help develop and improve producers' capabilities (Bolwig et al., 2010a; Perez-Aleman, 2012; Ponte, 2008a). Both these horizontal factors influence if and how the producers can access resources necessary to upgrade their practices in order to participate in a value chain (Bush \& Oosterveer, 2007; Bush \& Oosterveer, 2012) and to achieve long-term goals such as improvements in producers' livelihoods and fishery sustainability.

\subsection{Methodology}

\subsubsection{Case Selection}

From an inventory of private incentive mechanisms in WCPO fishery presented in Table 2.2 , the cases in this study are selected based on three criteria. First, the private incentive mechanisms must address tuna sustainability. Second, Filipino tuna fishers must be the target fishers of private incentive mechanisms due to their high involvement in WCPO tuna fishery and given the acute state of tuna sustainability in the Philippines. Third, the private incentive mechanisms must be 
currently operational, as it would make no sense comparing an incentive operating in practice with an incentive existing only on paper. 'Currently operational' is understood as being open to the participation of tuna fishers. Based on these criteria, three private incentive mechanisms are chosen for comparison. The first is the FIP approach developed by a group of NGOs currently collaborating under the banner of the Conservation Alliance for Sustainable Seafood (CASS) (see Sampson et al., 2015). FIPs are broadly defined as a stepwise framework known for guiding fisheries towards providing certified products to international markets. The second is the MSC, a private standard based on the three principles for certifying sustainable fishing practices and management and rewarding fisheries with either preferential market access or price premium (Marine Stewardship Council, 2011). The third is the PVR, a tool used by ISSF (a private conservation organisation established by nine of the largest tuna brands in partnership with WWF-US in 2009, (see International Seafood Sustainability Foundation, 2012a) to promote long-term conservation and sustainable use of tuna stocks, reducing by-catch, and promoting ecosystem health. 


\subsubsection{Case Analysis}

The collection of information for this study is guided by a list of analytical questions aimed at understanding the vertical and horizontal dimensions of upgrading production practices. Based on a qualitative case study method (Yin, 2009), addressing the hows and whys of research in contemporary events, the cases are analysed by iteratively cross checking, and comparing theory and empirical data (Eisenhardt, 1989; Yin, 2009). First, each of the three private incentive mechanisms is presented using the analytical variables in Table 2.1: starting from coordination, followed by institutional supports, institutional setting, capabilities, and upgrading. Second, the cases are compared by identifying patterns, congruencies, and differences in terms of how the conditions in vertical and horizontal dimensions influence the capabilities of fishers to upgrade, as well as how these capabilities contribute to the upgrading decisions of fishers. Finally, based on a comparison of these three mechanisms, we generalise our findings in relation to upgrading of Filipino tuna fishers in the global value chains.

\subsubsection{Data Collection}

Multiple methods were employed in collecting data. First, a review of scientific literature and technical reports was undertaken. Second, a total of 158 in-depth interviews were conducted from July 2013 to May 2014 with hand line fishers (43), master fishermen and carrier vessel captains (25), traders (21), representatives from fishing companies (7), processors and retailers (26), NGOs (27), government (5) and academics (4). The first five groups of respondents provided firsthand information on the way private incentive mechanisms operate in the chain, while the last three groups provided extended and expert information on the mechanisms. The interviews were based predominantly on open-ended questions that were adapted to the different profiles of respondents. Third, observations regarding the actual production processes, the welfares of the fishers, and the existing institutional settings were made at landing sites, ports, and fishing communities where the private incentive mechanisms are present (see Figure 2.2). The focus fisheries are Lagonoy Region 
and Occidental Mindoro Philippines for FIP, Lae Papua New Guinea for MSC, and General Santos City and Navotas Manila Philippines for ISSF. Other information was also collected from a series of seminars and conferences, including the 2013 Fishery Improvement Project workshops in Manila and Bicol, the 2012 and 2013 Tuna Congress in General Santos, the 2013 European Tuna Conference in Brussels, and the 2014 InfoFish Tuna Conference in Bangkok.

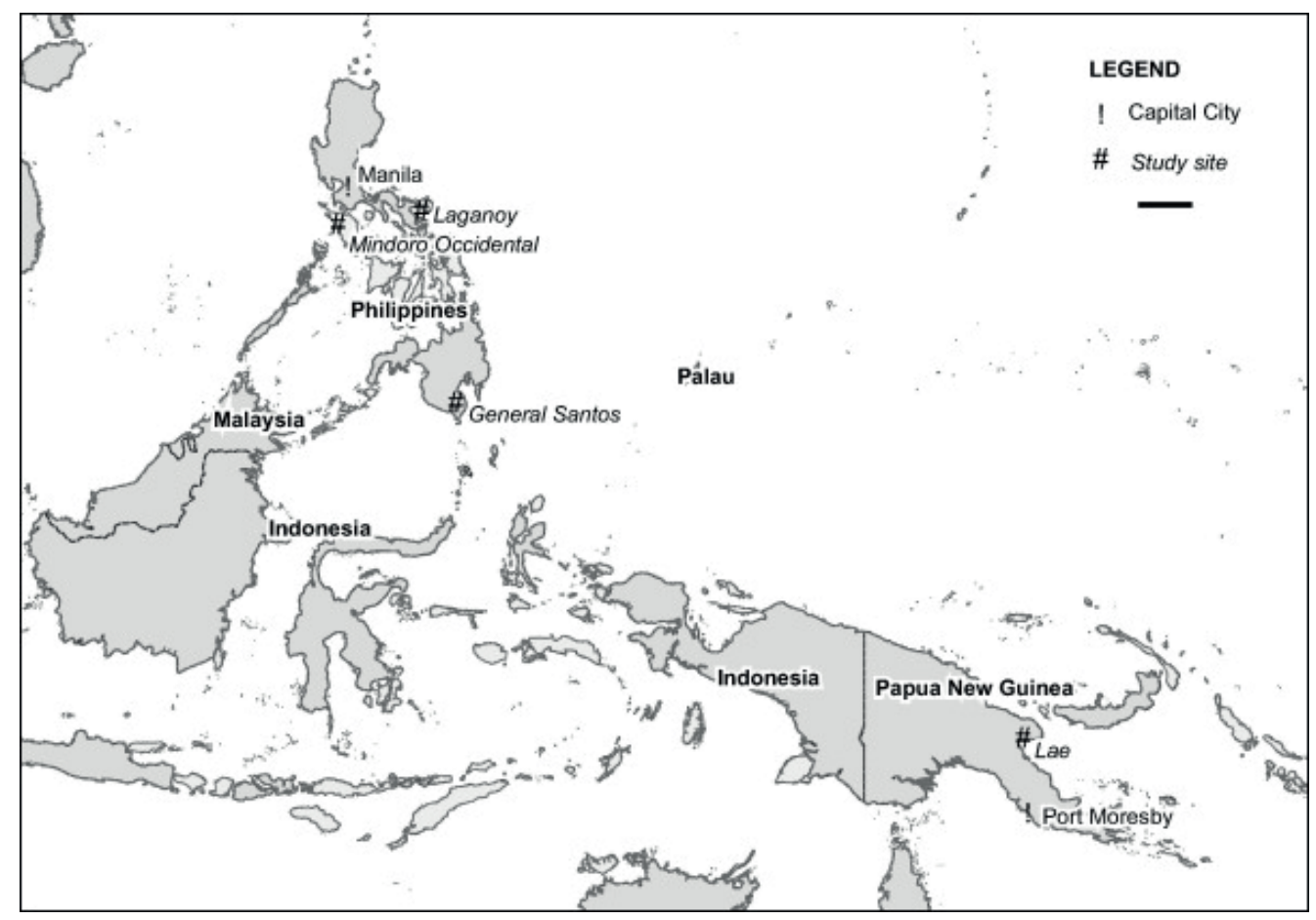

Figure 2.2 Map of study sites

\subsection{Presentation of private incentive mechanisms}

We now present each of the cases by starting with an overview of each incentive mechanism followed by an outline of the three analytical value chain dimensions. Table 2.3 summarizes the vertical dimensions of the value chain, comparing the private incentive mechanisms with regard to species traded, incentives, lead firms, coordination mechanisms, and fisher-level and specific product requirements. Regarding the horizontal dimension, Table 2.4 compares the different private 
incentive mechanisms with regard to the public and private institutions involved, the institutional settings, and the types of institutional supports. The improved capabilities at the confluence of vertical and horizontal dimensions and the resulting upgrading strategies are included in the case descriptions.

Table 2.3 Coordination of different private incentive mechanisms

\begin{tabular}{|c|c|c|c|}
\hline $\begin{array}{l}\text { Coordination in vertical } \\
\text { dimension }\end{array}$ & FIP & MSC & ISSF \\
\hline Species traded & Yellowfin & Skipjack & Skipjack \\
\hline Incentives & $\begin{array}{l}\text { Preferential market } \\
\text { access } \\
1.5 \text { time higher ex- } \\
\text { vessel price for tuna }\end{array}$ & $\begin{array}{l}20 \% \text { price premium } \\
(10 \% \text { to fishers })\end{array}$ & $\begin{array}{l}\text { Higher ex vessel price } \\
\text { and priority sourcing }\end{array}$ \\
\hline Lead Firms & $\begin{array}{l}\text { European retailers } \\
\text { (SeaFresh, Coop, Bell } \\
\text { Seafood) }\end{array}$ & Pacifical (distributor) & $\begin{array}{l}\text { ISSF member brands } \\
\text { and processors }\end{array}$ \\
\hline $\begin{array}{l}\text { Coordination } \\
\text { mechanism }\end{array}$ & $\begin{array}{l}\text { Catch certificates } \\
\text { Accreditations of } \\
\text { landing sites and } \\
\text { processing plants }\end{array}$ & $\begin{array}{l}\text { MSC certificate } \\
\text { Chain of Custody } \\
\text { (CoC) }\end{array}$ & $\begin{array}{l}\text { Pro-active Vessel } \\
\text { Register (PVR) }\end{array}$ \\
\hline $\begin{array}{l}\text { Fisher (or vessel)-level } \\
\text { requirements }\end{array}$ & $\begin{array}{l}\text { Catch certificates } \\
\text { Hand line fishing }\end{array}$ & $\begin{array}{l}\text { Catch documentation } \\
\text { Free school fishing } \\
\text { Registration in Vessel } \\
\text { Monitoring System } \\
\text { (VMS) }\end{array}$ & $\begin{array}{l}\text { Unique Vessel } \\
\text { Identifier, not enlisted } \\
\text { in RFMO's IUU lists, } \\
\text { with human or } \\
\text { electronic observer, } \\
\text { shark finning policy, } \\
\text { trained skippers, } \\
\text { sustainable FAD } \\
\text { fishing }\end{array}$ \\
\hline Product requirements & $\begin{array}{l}\geq 35 \text { kilos tuna, } \\
\text { Grade A or export } \\
\text { quality }\end{array}$ & $\begin{array}{l}\text { Separate MSC- and } \\
\text { non-MSC fish, } \\
\text { Canning grade quality }\end{array}$ & $\begin{array}{l}\text { Canning grade quality } \\
\text { Meet fish size } \\
\text { requirement }\end{array}$ \\
\hline
\end{tabular}

Source: Fieldwork, 2013

\subsubsection{FIP: The Partnership Programme Towards Sustainable Tuna}

Starting in 2011 as a partnership between WWF-Philippines and Local Government Units (LGUs) in Occidental Mindoro and Lagonoy fisheries, the aim of the Partnership Programme Towards 
Sustainable Tuna (PPTST) FIP is to enhance the sustainability of yellowfin tuna. The explicit goal of this WWF-led FIP is to move both fisheries towards MSC certification by the end of the program in 2016 .

Table 2.4 Institutional setting and support of the different private incentive mechanisms

\begin{tabular}{|c|c|c|c|}
\hline & FIPs & $\mathrm{MSC}$ & ISSF \\
\hline $\begin{array}{l}\text { Public and private } \\
\text { institutions involved }\end{array}$ & $\begin{array}{l}\text { LGUs, WWF- } \\
\text { Philippines }\end{array}$ & $\begin{array}{l}\text { PNA and } \\
\text { PNG government }\end{array}$ & ISSF, BFAR, WCPFC \\
\hline Institutional settings & $\begin{array}{l}\text { Casas, fisher } \\
\text { registration, and boat } \\
\text { licensing }\end{array}$ & $\begin{array}{l}\text { Vessel registration, } \\
\text { Vessel Day Scheme } \\
\text { (VDS), area closure, } \\
\text { FAD-closure season }\end{array}$ & $\begin{array}{l}\text { FAD and area closures, } \\
\text { sanctions for IUU } \\
\text { fishing, Philippine } \\
\text { Fisheries Observer } \\
\text { Program, and } \\
\text { Monitoring, Control } \\
\text { and Surveillance } \\
\text { (MCS) activities such } \\
\text { as deployment of patrol } \\
\text { vessels, logbook } \\
\text { systems, transhipment } \\
\text { declaration, Vessel } \\
\text { Monitoring System, } \\
\text { and port State control }\end{array}$ \\
\hline $\begin{array}{l}\text { Types of institutional } \\
\text { supports }\end{array}$ & $\begin{array}{l}\text { Trainings (grading } \\
\text { catch, proper } \\
\text { slaughtering and icing } \\
\text { techniques), organising } \\
\text { fishers, management } \\
\text { and leadership } \\
\text { seminars and } \\
\text { workshops, provision } \\
\text { of fishing aids, nets, } \\
\text { gears }\end{array}$ & $\begin{array}{l}\text { Observers-on-board } \\
\text { programs, Vessel } \\
\text { Monitoring System } \\
\text { (VMS), electronic } \\
\text { catch documentation } \\
\text { scheme }\end{array}$ & $\begin{array}{l}\text { Skippers training on } \\
\text { improved FAD design, } \\
\text { handbooks, courses }\end{array}$ \\
\hline
\end{tabular}

Source: Fieldwork, 2013

Consistent with the market logic of FIPs, the PPTST seeks to incentivize upgrading through both preferential market access as well as an ex-vessel price for tuna 1.5 times above local market value price (see Table 2.3). In order to capture these market benefits, fishers must comply with specific fisher-level requirements set by the lead firms composed of European retailers such as Coop Switzerland, Bell Seafood (Germany), and Seafresh (The Netherlands). To satisfy the European 
Union's Illegal Unreported and Unregulated (IUU) legislation, these lead firms require catch certificates, recording the place, time, and name of vessel and fisher who caught the fish. They also need to meet food safety requirements for import to the European Union (EU). For this, landing sites and processing plants need to be accredited. Additional sustainability requirements set by WWF include the use of handline fishing gear (one hook, one catch) by fishers to reduce the incidence of bycatch associated with other gears, a minimum size requirement of 35 kilos, and Grade A or export quality fish (freshly caught, iced, red tinge to the meat) to reduce wastage and inefficiencies.

Institutional support is provided by WWF-Philippines in partnership with LGUs, by means of assisting fishers to comply with PPTST requirements (see Table 2.4). Attention has been given to strengthening fisher registration and boats licensing in order to officially verify information provided in catch certificates. The WWF-PPTST team also became highly involved in forming a fisher core group called Barangay Fishery Aquatic Resources Management Council (BFARMC), to arrange fisher members' access to management and leadership training, information, and support from both the LGUs and WWF-Philippines. Furthermore, BFARMC facilitates proposals from fishers to LGUs for providing budget and in-kind help, such as fishing aids, nets, and gears. Finally, WWF-PPTST and LGUs further invested in trainings aimed at changing fishers' values and mindset towards improving their fishery management, practices, and income.

The institutional support provided by WWF-PPTST and LGUs improves the capabilities of fishers and provides incentives for participation in the FIP. For example, fishers that participate in FIP and are registered in the municipality are prioritised by LGU programs providing livelihood assistance and training. This has been proven a highly effective approach, given that $90 \%$ of the population is actively engaged in fisheries in these two sites (with the remaining 10 percent have other incomegenerating activities such as local goods stores, farming, pottery, and construction in urban areas). 
In addition, the fisher association assists fishers to strengthen the management of their fisheries and to access external supports for their fishing activities. As a result fishers have established stronger local arrangements to support the civilian led 'marine guards' (bantay dagat) to stop IUU fishing. Lastly attention has been given to assisting fishers with upgrading their vessels (bancas), to improve the handling of fish at sea, including grading their catch, proper slaughtering and icing techniques, to maintain quality. Despite the effort put into these project activities the decision of fishers to upgrade their production practices is almost entirely dependent on the vertical coordination of middlemen or Casas. Similar to many other fisheries in Southeast Asia (Ferse et al., 2012; Kusumawati et al., 2013; Ruddle, 2011), fishers in the PPTST FIP are highly dependent on these Casas who control local financing arrangements and serve as fish traders in the vertical dimension of the chain. The high degree of control exercised by Casas on fish prices hinders the transmission of any price incentive to fishers. However, this hindrance is at least in part offset by the provision by Casas of what can be termed ('horizontal') social welfare benefits to fishers, such as health care and education assistance to family of fishers, which are important in the absence of strong state support. As such, Casas are a typical example of patron-client relationship, providing an informal source of credits for fishers in exchange for lower ex-vessel fish prices. The influence of Casas is strong in both Occidental Mindoro and Lagonoy. Overall, ninety three percent of interviewed fishers in both fisheries rely on financing by Casas and are obliged to land their tunas to their respective Casas at a lower price than the market price. The rest of the interviewed fishers personally finance their fishing operations and have the option to sell their fish to a Casa or a market that offers a higher price. In order to deal with fishers' high dependency on Casas and to increase tuna prices, the WWF-PPTST team provided trainings on proper handling, grading, and icing of tuna to fishers.

Around a quarter of interviewed fishers from both PPTST sites have been able to upgrade their fishing practices so far, which is promising. However, the majority of fishers have chosen not to 
upgrade because they either saw no direct benefit or because of the limitations they face in making autonomous decisions through their relationship with Casas. To continue satisfying those fishers already engaged, and to extend participation to other fishers, PPTST has to ensure that the incentives promised are delivered. In the short term, fishers interviewed from both PPTST sites are complaining that higher ex-vessel prices are not being delivered, which in turn runs the risk that they will exit the programme. However, there is also evidence that these interviewed fishers are able to improve their efficiency based on improved handling techniques, which increases the quality and therefore value of the tuna landed. To extend participation to the $75 \%$ of fishers not yet participating, it seems longer term goals also need to be met by the programme, such as improving the overall well-being of fishers like housing and children's education, increasing ownership of fishing vessels, and improving health of fish stocks. Aligning these wider goals with the immediate incentives of fishers appears to dictate the long term success of the FIP. Finally, in terms of development, the PPTST aims for an on-going improvement in the fishery, beyond the life of the project.

\subsubsection{MSC: The Pacifical free school skipjack}

The MSC certification of skipjack purse seine fisheries using free school or non-FAD techniques in the waters of the Parties of Nauru Agreement (PNA) is the largest single certified fishery in the world in terms of potential landed volume. The certification was awarded in 2011 to Pacifical BV, a 50/50 public-private partnership between the PNA countries and the Dutch-based company Sustunable BV and is valid for five years. Fishers changing their practices to comply with the MSC non-FAD requirement are rewarded by lead firm Pacifical through a 20\% price premium; divided among cannery (5\%), fishing company (10\%), and PNA/Pacifical (15\%) (Table 2.3). There are currently around 314 purse seine vessels operating in the PNA that are potentially MSC-eligible, of which 54 are Filipino vessels. 
The institutional setting of the PNA sets clear regulatory requirements with which all fishers must comply, and which the MSC certifies. The regulation of the non-FAD fishery comes under the Vessel Day Scheme (VDS), in which fishing companies buy fishing days, currently at a cost of $\$ 6000 /$ day/vessel. Vessels also have to invest in a monitoring system to continuously improve PNA's conservation and management measures such as their harvest control rules, reference points, and harvest strategies (Forum Fisheries Agency, 2015b). In the case of Papua New Guinea (PNG), a member country of PNA where three major Filipino fishing companies operate, fishing companies are also obliged to land their catches in PNG cannery as a condition for issuing fishing licenses. In addition, the MSC Chain of Custody $(\mathrm{CoC})$, designed for verifying that fish sold from fishers to retailers (Marine Stewardship Council, 2013) are from an MSC certified fishery, is also in place. The MSC CoC requires training of vessel crews and master fishermen, as well as fulfilling a number of requirements including a trip number from the PNA office, the presence of on-board observers, and enrolment of the vessel in Vessel Monitoring System (VMS), all of which are instituted in the conservation and management measures of the PNA. In addition MSC and nonMSC skipjack must be separated on board and after being caught, and transferred from catcher to carrier vessels with the presence of MSC-certified observer. Lastly, processing of MSC skipjack for canning must be done separately from non-MSC skipjack.

Faced with these conditions, Filipino fishing companies have taken steps to improve their capabilities to meet MSC and PNA requirements. First, Filipino fishing companies establish joint venture companies with locally owned processors in PNG, in addition to existing vertically integrated companies, meaning a company owning the fishing fleets and canneries. The vertical integration and new joint ventured companies means these companies meet PNG requirements for maintaining fishing licenses, they facilitate the traceability of MSC skipjack, and they meet the national requirements of the PNG government to meet the zero percent duty of PNG canneries to EU. Second, Filipino fishing companies hired Korean, Japanese, and Taiwanese master fishermen 
due to their formal schooling (including university degrees) in fishing. According to interviews, learning from foreign master fishermen improves the Filipino master fishermen's knowledge and fishing techniques. Third, fishing companies invested in learning how to use helicopters and advanced GPS tracking devices to aid catcher vessels in detecting schools of tuna. Executives of fishing companies strongly believe that the fishing skills of master fishermen and the free school fishing technologies are the keys in fishing success. Development of these capabilities also serves as a coping strategy of fishers for dealing with assumed higher fuel costs of non-FAD fishing (Parker et al., 2015).

Benefits from investing in upgrading strategies to comply with MSC requirements, as well as those of PNG, are recognised by Filipino companies. Company executives note that the quality of fish from non-FAD catches is also in their interest, because of the larger size of fish and the more homogenous schools being caught. Not only are larger fish more valuable, they are more efficient to process compared with juveniles and small fish caught on FADs. However, despite the launching of Pacifical's first MSC canned skipjack in November 2013 by an Austrian retailer, only 400 metric tons (MT) out of potentially 440,000mt (less than $0.1 \%$ ) of MSC skipjack reached the market, for three reasons. First, fishing companies and industry players remain hesitant to participate in MSC as they perceive that the MSC price premium may be insignificant, given the high costs and high risks in catching and getting MSC skipjack to the port. In contrast, catches on FADs are more predictable and provide assured income. MSC also requires additional time and effort for training crews, for extra documentation, and for extra care when handling fish. Second, the industry players including fishing companies seem to lack confidence in the PNA-Pacifical set-up. Some industry players see Pacifical as a broker in the chain that is cutting their margin, while other brands are not open for any offer of 'co-branding' because they see Pacifical as potential brand competitor. Finally, the industry has also been reluctant to join as a result of the dispute between Pacifical and Earth Island Institute 
(EII), another certification body in fishery (as outlined by Miller and Bush (2014), EII has threatened action against those companies that support (MSC certified) Pacifical traded tuna.

Overall it appears that the MSC certification of the PNA non-FAD skipjack fishery has offered a series of requirements and incentives for fishers to upgrade their practices to participate in a 'sustainable' value chain. However, the participation of one of the three Filipino fishing companies currently operating in PNG demonstrates a wider set of apparent limitations. Irrespective of the developed capabilities, fishing companies are limited in their participation because the majority perceive the cost of participation to be too high, the price premium offered to be relatively weak, and the conflict between non-chain actors and the PNA-Pacifical set-up as high risk.

\subsubsection{ISSF: The Pro-active Vessel Register}

ISSF promotes sustainability in FAD fisheries by incorporating association membership and market power to change fishing practices. Fishing companies of member brands and retailers ${ }^{1}$ (lead firms) of International Seafood Sustainability Association (ISSA), an affiliate of ISSF, and fishers supplying to members are urged to enroll their vessels in the Pro-Active Vessel Register (PVR). The incentives for registering vessels in the PVR are the priority sourcing for tuna and the higher ex-vessel price per ton of fish supplied, which is negotiated between vessel owners and buyers (see Table 2.3). The PVR as a coordination mechanism in the chain, allows vessel owners to publically demonstrate steps towards upgrading of their fishing practices in order to indicate their progress towards becoming a full compliant to the ISSF (International Seafood Sustainability Foundation, 2014b). The PVR seeks to complement and supplement the conservation and management measures of the Regional Fisheries Management Organizations (RFMOs). For example, the PVR can facilitate centralized data collection on FAD fishing, a requirement that supports but goes further

\footnotetext{
${ }^{1}$ The ISSA members include Bumble Bee Foods, Clover Leaf Seafoods, Bolton Alimentari, MW Brands, Princes, Sea Value Company, Starkist Company, Chicken of the Sea International, TriMarine International, and Thai processors such as Sea Value, Thai Union, CMC, King Fisher, Siam International, and Pattaya. Retailers such as Walmart and Loblaw.
} 
than the requirements set out by the RFMO. As Filipino fishers and processors are directly involved in the value chains that supply skipjack to the ISSA members, they are also subject to ISSF commitments.

For enrolment in the PVR, the requirements at vessel level include having a Unique Vessel Identifier (UVI) number, having a shark finning policy, having skippers trained through the ISSF (including improved FAD design for more selective fishing practices), no listing in any RFMO's IUU vessel registers, and the presence of either human or electronic on-board observers (Murua et al., 2014). By December 31, 2015, purchasing from PVR registered vessels will be a requirement for all ISSA members. To encourage enrolment and scaling up of the system, annual fees for the PVR are waived for first two years. After that, vessels are required to pay an annual fee of US\$5,000 for vessels larger than 2000MT, US\$4,000 for vessels between 1,200 to 2,000MT, US $\$ 3000$ for vessels between 800 to $1199 \mathrm{MT}$, US\$2,000 for vessels between 350 to $799 \mathrm{MT}$, and US $\$ 1,000$ for vessels less than 350 MT. Any tuna landed must be of canning grade quality and meet the fish size requirements of processors.

The institutional setting in the Philippines supports the measures of the PVR, which are designed to align with existing management arrangements under the Bureau of Fisheries and Aquatic Resources (BFAR) and the Western and Central Pacific Fisheries Commission (WCPFC) (see Table 2.4). BFAR's management measures, following from its membership to the WCPFC, include FAD and area closures, sanctions for IUU fishing, the Philippine Fisheries Observer Program, and Monitoring, Control and Surveillance (MCS) activities such as the deployment of patrol vessels, the use of logbook systems, transhipment declarations, VMS, and port state controls. As a full member of the WCPFC, the Philippines through the representation of BFAR, has to comply with all the conservation and management measures related to overcapacity, non-target species, IUU fishing, and data transparency (Western and Central Pacific Fisheries Commission, 2014). To further 
strengthen the capabilities of fishers to comply with PVR, ISSF also provides institutional support to fishers such as handbooks, courses, and trainings to support compliance to WCPFC measures.

Despite several Filipino fishing companies having the capabilities to meet the PVR requirements, only 24 fishing vessels (including those that are PNG flagged) of one fishing company, out of 309 Filipino-owned purse seine and carrier vessels (Western and Central Pacific Fisheries Commission, 2014) initially enrolled in the PVR. An addition of 15 more vessels from three Filipino fishing companies joined the PVR in 2015, thus generating a total of 39 PVR enrolled Filipino-owned vessels. The increase in number of vessels enrolled is driven by ISSF resolution on solely purchasing from PVR enrolled vessels and by one Filipino processing company becoming a fullfledged member of ISSF in 2014. Moreover, two important events have contributed to vessel enrolment in PVR. First, the granting of a Generalised Scheme of Preferences (GSP+) status to Philippines that allows the country to export with zero percent tariff to EU motivates Filipino fishing companies to comply with EU regulations in order to access European market. Second, the European Commission handed an IUU Red Card to the Philippines in 2014, which provided an extra incentive for Filipino vessels to demonstrate regulatory compliance. A Red Card is issued to countries which have not taken sufficient action to control IUU activity in their waters or by their flagged vessels and enforces economic and trade sanctions, including banning imports to the EU market.

Non-enrolment of the majority of Filipino fishing vessels in the PVR is due to three reasons. First, Filipino fishing companies are concerned that the incentive for compliance cannot offset the annual fees of enrolment in PVR, particularly since the PVR is at its introductory stage and there is a decreasing marginal profits caused by declining skipjack prices. After a number of years with high skipjack prices (with a peak of US\$ 2,400/MT in 2013) in 2014 the price of skipjack reached a record low of US\$ 1150/MT (Atuna, 2015). According to interviewed industry players, the fall in 
skipjack prices was assumed to be caused by the high capacity in skipjack fishing which was boosted in the years before with high skipjack prices. Interviewed fishing companies and traders are also concerned that ISSF associated processors and brands will capture any market benefits, while a few of these interviewees also argued that consumers are not willing to pay more for 'PVR compliant fish'. Second, some respondents are concerned about the path dependency of adopting PVR requirements making the adoption of alternative mechanisms, such as MSC certification, overly complicated. Third, the goals of fishing companies that include sustaining their long-term income through improved fishing process, do not necessarily match with the possible outcomes sought by ISSF. For example, two big Filipino fishing companies are already preparing to shift from FAD to free school fishing in order to reduce their risks in case of stricter FAD regulation at either RFMO or national level. The investment made in free school fishing is a movement away from sustainable FAD fishing, which the ISSF pursues.

\subsection{Discussion}

We now compare the three private incentive mechanisms based on how the vertical and horizontal dimensions of the value chain influence the capabilities of fishers to upgrade their fishing practices. We then extend the discussion on the effectiveness of the mechanisms in the value chain by looking at the delivery of incentives to fishers, the extent to which the goals of fishers and the mechanisms are aligned, and how selective these mechanisms are on different types of fishers.

\subsubsection{Upgrading Filipino tuna fisheries}

In support of our framework (Figure 2.1), the three cases show how specific capabilities enable producers to respond to the incentives offered by the mechanisms and therefore invest in different upgrading strategies. Overall, fishers are able to develop capabilities that are necessary to upgrade, and the choice of these fishers to both engage in process and functional upgrading is determined by their goals and by their capabilities (Humphrey \& Schmitz, 2002b; Riisgaard et al., 2010). Fishers 
involved in the PPTST FIP improved the quality of the tuna being caught, and were partly enabled to do so by drawing on the 'horizontal coordination' of the tuna fishers association, which was supported directly by WWF as the FIP provider. Fishers involved in MSC certified skipjack chain were able to benefit from their participation by not only complying with MSC regulation, but also improving their post-harvest handling practices, thus increasing the value of their tuna. At the same time, these MSC fishers functionally upgraded by establishing a joint venture company with local processors. The capabilities required for upgrading are supported by MSC through training of vessel crews and master fishermen and through provision of observers-on-board. Finally, fishers complying with the ISSF PVR demonstrated a clear potential to benefit from greater degrees of vertical coordination by strengthening their relations with ISSF processors and related traders further down the chain. In this case, ISSF supports this compliance by supporting the development of capabilities of fishers through training.

The cases also show that how incentive mechanisms are implemented in the value chain is important for understanding the extent to which capabilities are developed for upgrading in order to meet the requirements set by these mechanisms. The greater the degree of coordination of lead firms, the more control they have in setting the terms of participation for fishers to strengthen lead firms positions in the value chain (Gereffi et al., 2001; Kaplinsky, 1998). In all three cases, the vertical coordination of the chain differed considerably in terms of forms of coordination and degree of control by lead firms. Both the MSC and ISSF cases demonstrate the use of hierarchical forms of coordination by lead firms. In the fishery certified by MSC there is even a strong hierarchical form of coordination given the degree of control held by Pacifical BV. Consistent with the literature (Gereffi et al., 2005; Ponte \& Cheyns, 2013; Riisgaard et al., 2010), information exchange and deliverance of sustainability requirements is evident with strong lead firm coordination and control. In contrast, the FIP case demonstrates a captive form of coordination as manifested through the strong role of Casas in capturing fishers in economic 
'contracts' through provision of credits and social security (Bush, 2004; Platteau \& Abraham, 1987; Ruddle, 2011). This coordination of lead firms in the chain reveals a potential paradox outcome. The strong coordination of lead firms requires fishers to develop more specialised capabilities that allow them to upgrade and later on receive incentives from the mechanisms. However, the extent to which this specialised capabilities are beneficial to fishers still remains unclear in case lead firms withdraw their support from the chain or do not pass up benefits up the chain, particularly if there is less or no alternative for fishers under greater lead firm coordination. Whether these lead firms will continue to contribute to both sustainability and development outcomes from their employment of incentive mechanisms is at the current stage unclear.

In addition to the implementation of the mechanisms, our result also shows how these mechanisms themselves tend to reinforce control of the value chain by lead firms. The WWF and ISSF have strengthened the coordinating role of lead firms in FIP and ISSF cases respectively, although to varying degrees, given the strength of existing relationships and contracts between fisher and lead firms. Only in the MSC case, a new entrant (Pacifical BV) is playing the coordinating role of lead firm in the chain. In none of the cases, the various mechanisms foster greater coordinating power by fishers, indicating that capabilities are driven by the requirements of lead firms using these mechanisms rather than in response to any form of empowerment.

\subsubsection{The delivery of incentives}

Contrary to much of the literature focussing on creating change through incentive based mechanisms, the incentives in the value chain do not reach fishers in a linear fashion as is often assumed (Grafton et al., 2006; Jack et al., 2008). Instead, the forms of vertical coordination of the value chain appear to determine whether and how incentives are to be delivered to fishers. The vertical dimension of these chains seems to provide the structure and requirements for delivering incentives to fishers and thereby stimulating fishers to upgrade towards more sustainable production 
practices. However, the delivery of incentives is influenced by existing social and economic relationships between actors in the vertical and horizontal dimensions of the value chains.

Our results show that two related processes determine how incentives are delivered. On the one hand the incentives in the vertical dimension are influenced by the rent-seeking (income) behaviour of chain actors, but on the other hand they are deemed inadequate by fishers to invest in a corresponding upgrading strategy. For example, Casas and exporters in the FIP case capture many of the price premiums associated with export requirements, while in the ISSF case, member processors and brand firms are more likely to capture the benefits associated with upgrading. A price premium has been made explicit in the MSC case by Pacifical, but fishing companies have not seen this premium as adequate enough to offset the higher costs and risk of fishing free-school skipjack tuna.

The results also reveal that looking only at the delivery of a price premium obscures other incentives that are delivered to fishers engaging with these incentive mechanisms. For example, in the MSC case, the improved processing efficiency afforded by larger size tuna caught in free school purse seine is seen as a measurable incentive of supporting greater volumes of certified fish. Likewise, preferential sourcing of ISSF member brands and processors for tuna supply provides a potential incentive for fishers to upgrade their vessels to comply with PVR. However, in both cases it was observed that producers do not simply change their practices in line with what might be described as the 'economics of upgrading'; i.e. an evaluation on whether the incentives outweigh the costs and risks of investment. Instead their decisions are dependent on their capabilities and on their perception of costs and risks to receive and respond to these incentives.

Finally, it appears in support of our framework (Figure 2.1) that the delivery of more indirect incentives from institutions in horizontal dimension develops the necessary capabilities of fishers to 
make decisions around upgrading. As identified in other value chains (Bolwig et al., 2010a; Giuliani et al., 2005; Riisgaard et al., 2010), the institutions deliver similar indirect incentives to producers under private incentive mechanisms. These include in-kind support such as fishing aids provided to fishers in FIPs or indirect support derived from: 1) income generated as an outcome of conserving the fishery by local fishers (e.g. ecotourism); 2) subsidies and external funding as a result of fisher associations' project proposals; or 3) trainings, capacity buildings, and information (Kiss, 2004; McNeely, 1988). However, it appears that indirect incentives will only be considered as an incentive from the horizontal dimension if these also develop the capability of fishers to achieve their goals.

\subsubsection{Goals of fishers and of private incentive mechanisms}

In support of Grafton et al. (2006) and Hilborn et al. (2005), all three cases demonstrate evidence that the better the incentives are matched to the goals of the fishers, and the better the institutions support the capability of fishers to upgrade, the more likely fishers will upgrade their production practices under private incentive mechanisms. The short-term goals of fishers are the food security and income goals, while their long-term goals include securing long-term income and minimising risks. When incentives are delivered to fishers and their short-term goals are realised, fishers are more inclined to make future investments needed for continued or full participation in order to support their long-term goals. However, this is not yet realized by most of fishers as illustrated in the cases. For example, in the FIP case, the 'social contracts' (Bush, 2004; Platteau \& Abraham, 1987; Ruddle, 2011) established with Casas enable fishers' to meet short term food security goals, but the lack of an ongoing price premium due to control of Casas in prices appears to limit the willingness of fishers to make long-term investments. In the MSC case, the perceived high risk and high costs of providing MSC certified products to the market, limit the delivery of MSC skipjack in the market, thus making fishing companies unable to satisfy their profit goals. Similarly in ISSF, 
the perceived weak incentives in PVR may not deliver the income goals of fishers, thus restraining fishing companies to make future investments related to PVR.

It is also apparent in these cases that the time bounded nature of incentive mechanisms limits fishers' decision to invest in long-term upgrading investments. Both in the FIP and the MSC cases show that these mechanisms are at least initially set for period of five years, with an unknown continuation. Both developing capabilities and participating in a mechanism that will exist for a short period of time increase uncertainty and the risk for fishers of losing any investment they make in upgrading. This negatively contributes to realisation of the goals and it results in less participation.

\subsubsection{Mechanisms' selectiveness regarding type of fishers}

The results indicate that there is no single type of private incentive mechanism that works in all fisheries (Christensen \& Raakjær, 2006; Poos et al., 2010; Turner, 1997). Philippine tuna fisheries, just like other fisheries in the world, are highly heterogeneous. The important component in explaining the differences in capabilities of different fishers is the level of institutional supports in the horizontal dimension, which supplements the existing level of coordination of fishers in the vertical dimension.

As outlined in the results, the level of coordination of fishers differs based on their numbers, investment capabilities, scale of operation, and strength of relationships between actors in the value chains. In support of our framework, varying levels of institutional support were observed that assist fishers to develop their capabilities to upgrade. In the FIP case, the high level of institutional support include the provision of fishing aids, funding, and training. In both MSC and ISSF cases, the institutional supports are mainly based on trainings and education with strengthened regulations 
given the availability of capabilities of fishing companies, therefore enabling fishers to comply with MSC and PVR requirements, respectively.

\subsection{Conclusion}

This study has evaluated and compared the ways different private incentive mechanisms influence upgrading of Filipino tuna fishers in the value chain. Overall, the private incentive mechanisms stimulate fishers to improve their fishing practices. Yet, these mechanisms still face challenges in terms of improving both environmental and development outcomes. Each mechanism differs in terms of strengths (and weaknesses) in delivering incentives, in building capabilities of fishers, and in incorporating fishers in their regulation of sustainability. From this, three conclusions can be drawn. First, it appears that some of the mechanisms have to do more than delivering direct benefits to fishers in the form of higher ex-vessel fish prices; they also have to develop the capabilities of those fishers they wish to engage with these incentives. This applies to fishers involved in FIPs in developing countries in general. Second, as shown in the cases of MSC and ISSF, the incentives delivered by the mechanisms must be able to offset the additional costs and risks of upgrading in order to increase and sustain the participation of fishers. Third, our analysis shows that while all three mechanisms have had made inroads to promoting sustainable tuna fisheries, there remains room for improvement in terms of incorporating the fishers that they are targeting and ultimately leading to significant sustainability impact in developing country fisheries.

To be more effective in changing the behaviour of fishers in developing countries, these mechanisms have to involve a wide set of actors both within and outside the value chains. Moreover, the mechanisms have to initiate investment in institutional means of support for fisheries to realise the benefits any incentive has to offer in order to stimulate changes to their practices on the water. In support of this, the interaction between firm and non-firm actors involved in the application of private incentive mechanisms, and the wide institutional arrangements that include 
regulatory and normative institutions operating at and beyond local-level production, need closer consideration in the design and implementation of private incentive mechanisms.

This study contributes to a wider understanding of the impact of private incentive mechanisms and their role in developing countries. Bringing these mechanisms into sharper focus reveals that incentive-based approaches have a role to play in fostering natural resource sustainability in different kinds of developing world fisheries. But in doing so we need to consider the degree to which they expose fishers to both benefits and risk based on their participation. By focusing on capabilities and upgrading in the global value chains, we are able to show how these benefits and risks differ between incentive mechanisms, based on the influence of both vertical value chain coordination and horizontal institutional support. The extent to which fishers can respond to incentives by upgrading is therefore dependent on the combined effects of these value chain dimensions. Further research is called for to assess the relevance of this framework beyond tuna, including other fisheries and other food and non-food value chains involving developing world producers subject to private forms of sustainability governance. 


\section{Chapter 3}

\section{Fisher-level decision making to participate in Fisheries Improvement Projects (FIPs) for yellowfin tuna in the Philippines}

This chapter has been published as:

Tolentino-Zondervan, Frazen, Paul Berentsen, Simon R. Bush, Larry Digal, and Alfons Oude Lansink. "Fisher-Level Decision Making to Participate in Fisheries Improvement Projects (FIPs) for Yellowfin Tuna in the Philippines." PloS one 11, no. 10 (2016): e0163537. 


\subsection{Abstract}

This study identifies the capabilities needed by small-scale fishers to participate in Fishery Improvement Projects (FIPs) for yellowfin tuna in the Philippines. The current literature provides little empirical evidence on how different models, or types of FIPs, influence the participation of fishers in their programs and the degree which FIPs are able to foster improvements in fishing practices. To address this literature gap, two different FIPs are empirically analysed, each with different approaches for fostering improvement. The first is the non-governmental organisation-led Partnership Programme Towards Sustainable Tuna, which adopts a bottom-up or development oriented FIP model. The second is the private-led Artesmar FIP, which adopts a top-down or market-oriented FIP approach. The data were obtained from 350 fishers surveyed and were analysed using two separate models run in succession, taking into consideration full, partial, and non-participation in the two FIPs. The results demonstrate that different types of capabilities are required in order to participate in different FIP models. Individual firm capabilities are more important for fishers' participation in market-oriented FIPs, which use direct economic incentives to encourage improvements in fisher practices. Collective capabilities are more important for fishers to participate in development-oriented FIPs, which drive improvement by supporting fishers, fisher associations, and governments to move towards market requirements.

Keywords: capabilities; decision making; fishery improvement projects; Philippines; small-scale fishers 


\subsection{Introduction}

The sustainability of fisheries is driven in large part by the alignment of fisher practices with management goals (Botsford et al., 1997; Pauly et al., 2002). State regulations, such as restrictions on fishing gears, harvest control rules, and access restrictions have traditionally been applied to change fisher behavior. However, the perceived weakness of these state regulations, or total absence in many developing country fisheries (DCFs), has led to the emergence of private incentive mechanisms, which are designed to improve compliance with existing rules and management approaches (Grafton et al., 2006; Hilborn et al., 2005; Oosterveer, 2008). The design and objectives of these private incentive mechanisms differ, but most commonly involve incentivising changes in fishing practices through value chain based arrangements such as industrial coalitions, improvement projects, and eco-certification (e.g. Tolentino-Zondervan et al., 2016a).

The most dominant private incentive mechanisms for sustainable fisheries is the Marine Stewardship Council (MSC) standards, against which fisheries practices, the health of stocks and habitats, and the capacity of management to deliver sustainable outcomes are measured and certified (Cummins, 2004). However, one of the main criticisms of the MSC is its limited capacity to adequately include DCFs. As of 2015, only $8 \%$ MSC-certified fisheries are from developing countries (Marine Stewardship Council, 2015). This limited inclusion is attributed to the high cost of certification, the lack of data on fish stocks available for assessment, and the inadequate or absence of effective governance and regulatory systems (Constance \& Bonanno, 2000; Jacquet \& Pauly, 2008; Pérez-Ramírez et al., 2012a; West et al., 2011). Recognising the difficulties of DCFs to move towards certification, a range of Non-Government Organisations (NGOs) and private consultancy firms have developed Fishery Improvement Projects (FIPs), a step-wise methodology for improving fisheries practices and management that originally started in developed world contexts but is also focused on DCFs (Bush \& Oosterveer, 2015; Deighan \& Jenkins, 2015; Sampson et al., 2015). 
FIPs utilize the market incentives in seafood value chains to stimulate sustainability improvements, which may or may not lead to MSC certification (Sampson et al., 2015). For example, retailers and food companies can push fishers towards improvements by directly funding a FIP or purchasing products (with or without a premium) from a fishery in a FIP (Conservation Alliance for Seafood Solutions). The six stages FIP model proposed by the Sustainable Fisheries Partnership is as follows: 1. the identification of improvement goals and engagement of corporate partners; 2. agreement on work plans for improvement between fishers and participating partners; 3. engagement of regulators by FIP partners to improve regulation and market partners to adopt better product specification and procurement policies; 4. measurement of improvements to policy and practice; 5 . key scientific indicators demonstrating a positive trend towards management goals; and 6. (optional) certification against the MSC standards (Sustainable Fisheries Partnership, 2012). While differing in substance, other FIP models demonstrate a similar logic (see World Wide Fund for Nature, 2014) and are predicated on facilitating access to high end markets under the notional condition (Sampson et al., 2015) that the fishery is working towards improvement.

Despite convergence around the type of steps required, the mix of organisations involved, the kinds of fishers targeted, and the extent of institutional support provided in FIPs differ considerably. This is especially the case in the estimated 130-plus developing country FIPs (Sampson et al., 2015). Based on a recent attempt to create a general classification of FIP implementation (California Environmental Associates, 2015) we define two general categories: 'bottom-up' developmentoriented FIPs, often led by NGOs stimulating general improvements to government support and regulation; and 'top-down' market-oriented FIPs, led by firms focused on direct economic benefits for fishers in return for strict compliance (California Environmental Associates, 2015). It is assumed that these FIP models have consequences for the way fishers are included in FIP programs, especially in terms of the decision of fishers to change their practices in accordance with 
improvement criteria. Yet, there is little empirical evidence to verify this (Deighan \& Jenkins, 2015; Sampson et al., 2015).

We argue that the decisions made by fishers to participate in a FIP depend on the type of capabilities they have and whether these capabilities match with the requirements for participation. These capabilities refer to the specific skills, practices, and forms of social organisations (Nussbaum, 2003; Sen, 1990). This study classifies these capabilities into individual capabilities at personal level, individual capabilities at firm-level, and collective capabilities at the fishery or community level. By identifying these capabilities we build a clearer understanding of the specific factors that influence fisher decisions to comply with requirements that seek to improve fishing practices.

The objective of this paper is to determine which decision making factors are important for small scale Filipino tuna fishers' decisions to participate in two FIPs for yellowfin tuna (Thunnus albacares) in the Philippines. The first is the market-oriented Artesmar FIP, which is run by the private-company Meliomar and the consultancy firm BlueYou (Switzerland). This FIP sets a high sustainability requirement and provides economic incentives to encourage fishers participation. The second is the development-oriented Partnership Programme Towards Sustainable Tuna (PPTST) FIP, which is run by the World Wide Fund for Nature (WWF) Philippines, and seeks improved local governance of tuna fisheries to meet global value chain requirements. Both FIPs are focused on yellowfin tuna because of its market value and importance to the local economy, the scalability of these FIPs to other sites in the Philippines and beyond targeting yellowfin tuna, and because yellowfin is a species subject to overfishing in recent years (Davies et al., 2014; Langley et al., 2008; Langley et al., 2009). 
To understand the factors that influence fisher's decisions to participate in FIPs, we employ a two stage framework including two models which are run separately. The following section describes both FIP models and the theoretical basis of capabilities and decision making. This is followed by an outline of the empirical data collection and of the probit and ordered probit models used for the two stage modelling. We then provide a justification for the variables adopted to explain fisher participation in FIPs. The paper concludes with a discussion of the key variables that are important for participation in different models of FIPs and recommendations for enhancing fisher participation in FIPs.

\subsection{Participation in different FIP models}

\subsubsection{Comparative FIP models}

In line with defining the different FIP models, the California Environmental Associates (CEA) (California Environmental Associates, 2015) created four archetypes based on combination of two characteristic dimensions. The first dimension focuses on the structure of FIPs, ranging from 'basic' to 'comprehensive'. Basic FIPs are characterised as a simple, low-cost model which provides small incremental improvements through time, while comprehensive FIPs are considered those that are resource intensive model and aimed at achieving MSC certification. The second dimension focuses on supply chain engagement along a spectrum of bottom-up vs. top-down. Bottom-up FIPs are those that develop improvements first and only later attempt to access high end markets and major buyers who have made sustainability commitments (California Environmental Associates, 2015). In contrast, top-down FIPs are those that start with the demand of major buyers and retailers to put pressure on fisheries to engage in sustainability in exchange for market access. The four possible archetypes from these two dimensions allow us to classify Artesmar as a top-down comprehensive FIP and PPTST as a bottom-up comprehensive FIP. 
Beginning in 2013, the goal of Artesmar is to provide market recognition and incentives for improved business and fishing practices of small scale fishers in the Philippines. Artesmar works in different regions of the Philippines, trading yellowfin from Occidental Mindoro, Albay, Quezon and Infanta, Antique, and Eastern Samar, Palawan, Batangas, Subic, Negros Occidental, and Zamboanga. Our research focused on Sablayan and Mamburao municipalities in Occidental Mindoro (see Figure 3.1) because the export chain for yellowfin tuna has been established since 2010 and full participation in the FIP is observable. Both of these municipalities are characterised by a higher concentration of fishers with larger tuna boats and higher tuna landings than the other municipalities of Occidental Mindoro. The two municipalities also have good access to tuna processing plants due to improved roads, proximity to landing sites for easier tuna transfer, and the availability of transportation and major services such as communication and electricity which facilitates improved business transactions.

The Artesmar FIP supports fishers to be compliant with legal catch documentation requirements, as well as enhancing fishery data, and fishery co-management; all of which are necessary to prepare the fishery for MSC certification. Artesmar also sets chain of custody requirements, including strict quality standards for tuna, and traceability requirements such as vessel registration and full catch documentation to verify the absence of Illegal Unreported Unregulated (IUU) fishing. Fishers participating in the Artesmar FIP are more likely to receive higher prices for their fish compared to fishers who do not participate because they are trained in how to handle their catch in such a way that improves the quality of the meat. They also have more certainty of having a buyer and receiving timely payment for the fish they land. These benefits of participation in the Artesmar FIP lower the risk of having a highly variable income, but are offset by the investment required for participation including time and effort allocated to training, additional effort and investment to satisfy traceability requirements and upgrading facilities to meet fish safety and quality requirements. The cost of training is particularly high because of the structure of boat ownership, 
with fishers owning several boats having to extend new equipment, practices, and knowledge to their multiple boats and boat captains.

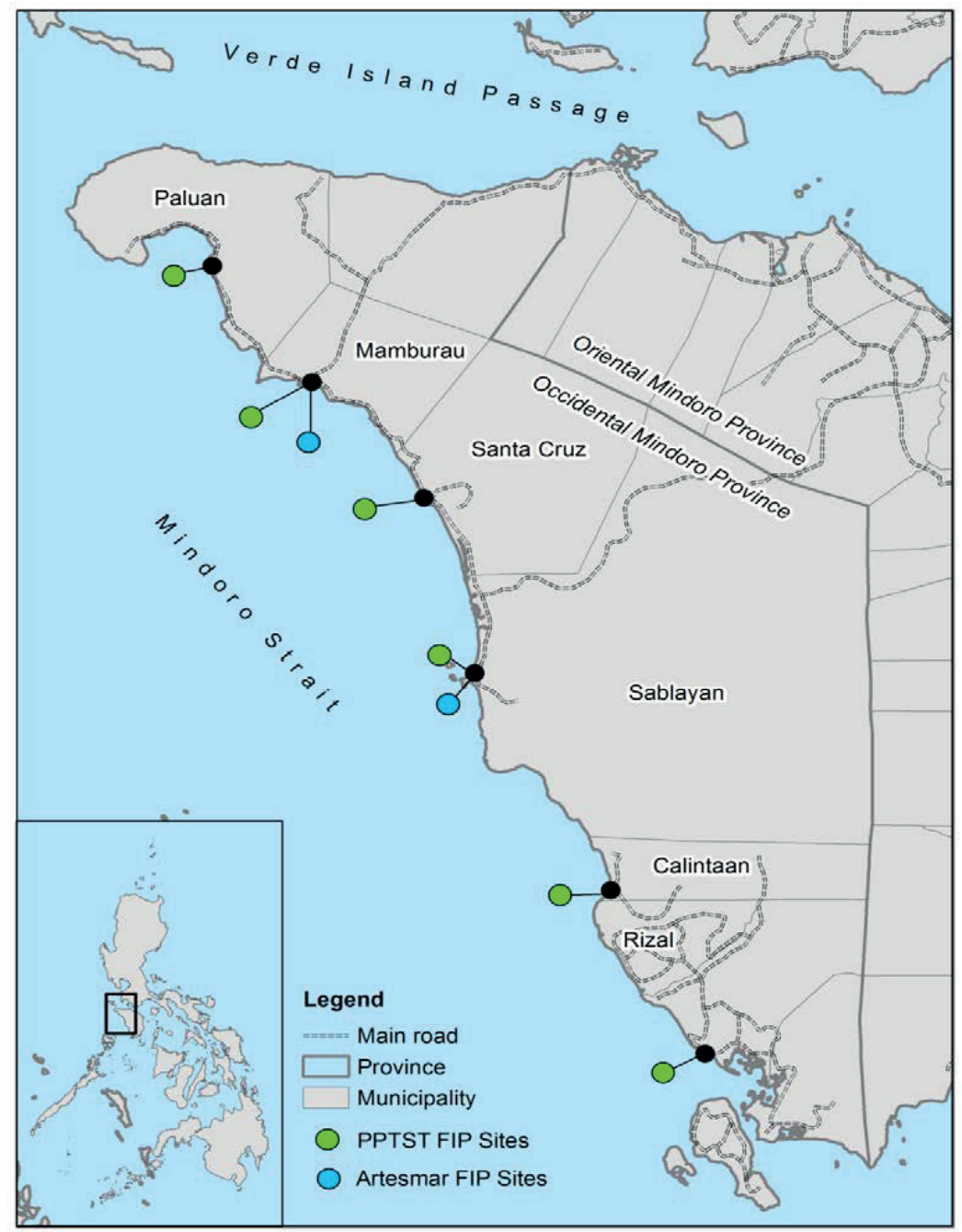

Figure 3.1 The Occidental Mindoro fishery map

The PPTST FIP is based on a public-private partnership established in 2011 to develop sustainable practices of yellowfin tuna fishers in Lagonoy and in Occidental Mindoro. Although funded by WWF Germany and European retailers such as Seafresh (Netherlands), Bell Seafood (Germany), 
and Coop (Switzerland), neither higher landing prices nor market access is currently used as an incentive to participate in the FIP. Instead the PPTST FIP can be classified as a bottom-up comprehensive FIP, with day-to-day management of the FIP carried out by the WWF-Philippines and the municipal governments to improve the wider conditions of legal compliance and fisher safety in the fishery. Implementation of the PPTST FIP by WWF and the municipal governments focuses primarily on the organisation of fishers in associations, before engaging them in a consultative decision making process in order to comply with chain requirements similar to the Artesmar FIP (e.g. Cudney-Bueno \& Basurto, 2009; Pomeroy, 1995).

The PPTST FIP targets a very wide range of fishers across the six municipalities of Sablayan, Mamburao, Paluan, Sta. Cruz, Calintaan, and Rizal, Occidental Mindoro (see Figure 3.1). Fishers in Sablayan and Mamburao are large scale and have adequate capital to meet requirements set by buyers in Metro Manila. Fishers in the other four municipalities have smaller scale operations, target species other than yellowfin tuna, and have other forms of livelihoods such as rice farming, carpentry, and grocery stores. Unlike the Artesmar FIP which sets strict requirements for inclusion in the FIP, fishers can partially participate in the PPTST FIP by attending trainings related to fishery governance, without delivering tuna to the chain. Full participation requires the preparation of catch documents and providing export quality tuna based on their attendance at training sessions. In general, institutional support such as training, subsidies, and in-kind help are recognised as important indirect incentives for the improvement of fisher practices (see Tolentino-Zondervan et al., 2016a). Contrary to the trainings in the Artesmar FIP, the trainings in the PPTST FIP are organized and funded completely by external actors such as the WWF and the municipalities. The PPTST trainings are not only limited to complying with tuna quality and traceability requirements, but also extend to improving the governance of the fishery, such as putting in place anti-IUU measures, and supporting the development of alternative livelihoods (such as ecotourism). Moreover these trainings reach different types 
of fishers ranging from small- to large-scale, including those fishers in remote areas of the municipalities. The trainings, subsidies, and in-kind help are considered indirect incentives of the bottom up comprehensive FIPs because they are not directly associated with the market incentives of increased market access or a price premiums (Tolentino-Zondervan et al., 2016a).

\subsubsection{Fishers' participation decision framework}

This study analyses fishers' decisions to participate in the two FIPs (Figure 3.2). The first stage decision concerns the choice to opt for participation in the Artesmar FIP or not. In principle, the Artesmar FIP delivers higher returns and lowers the risk of fishers in terms of fluctuation in fish prices. However, higher investments for participation are required. The basic assumption here is that fishers who can fulfil the requirements of Artesmar FIP will choose this alternative because this option is expected to lead to a higher utility. As explained by the Utility Maximisation (UM) framework, a rational individual will maximise his/her income and will minimise risks (Hanemann, 1984; McFadden, 1973; Schoemaker, 1982). The second assumption is that participation in the Artesmar FIP, though preferred by fishers, is not feasible for many fishers due to their lack of capabilities to comply with the requirements of the Artesmar FIP. Fishers that find themselves unable to participate in the Artesmar FIP might then opt for participation in the PPTST FIP as a second best option. Participation of a fisher in the PPTST FIP can be partial or full, depending on the fulfilment of requirements. As an extension of the utility framework, the third assumption is that the perceived social benefits of community membership (see Gintis, 2000; Jager \& Mosler, 2007; Ostrom, 1994), adds to the utility of fishers when joining the PPTST FIP. The final option is that a fisher does not participate in any FIP.

Testing the participation choices requires identifying significant variables that affect income and risks of fishers. The literature on decision making has extensively described the characteristics of decision makers that affect their level of income and risk (Abadi Ghadim \& Pannell, 1999; Lindner, 
1987; Marra et al., 2003; Pannell et al., 2006). For this study, we divide these characteristics into four groups: individual capabilities at personal level, individual capabilities at firm-level, collective capabilities, and individual risk attitude and socio-demographic characteristics. Table 3.1 shows this grouping of characteristics, which are also used as the explanatory variables used to analyse decisions for FIP participation in the empirical model explained below.

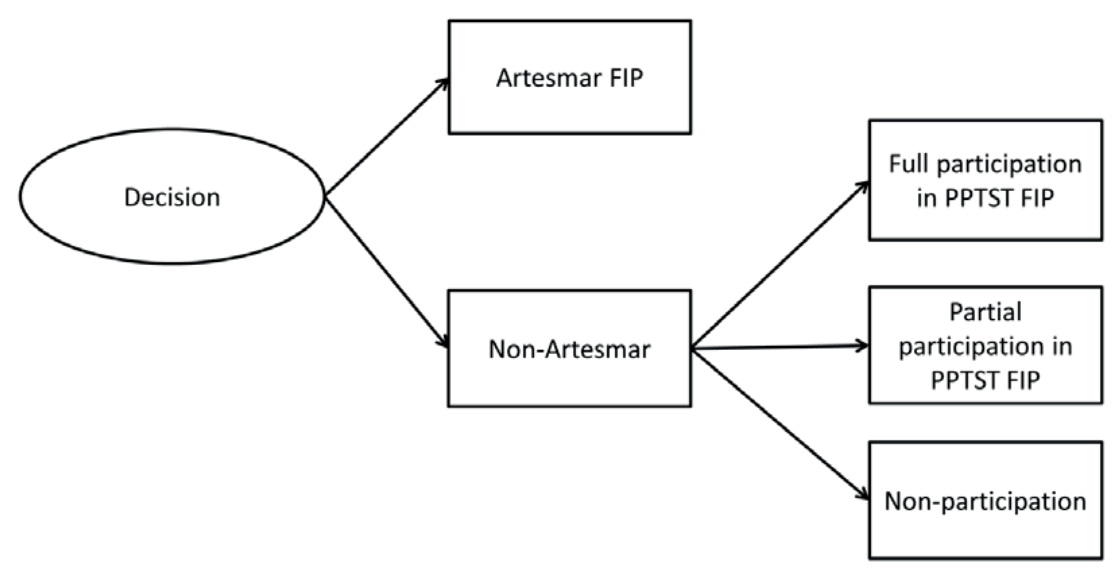

Figure 3.2 The decision model for fisher participation

Capabilities are defined as the specific skills, practices, and forms of social organisations required to deliver certain tasks in pursuit of long-term goals (Nussbaum, 2003; Sen, 1990). The level of capabilities of individuals or firms influences the amount of risk they can handle and the income they can generate (Murphy C \& P., 2008). For instance, a fisher that is more capable of adopting a certain fishing technology will find the risk of adoption lower than a fisher who still needs to build his/her capability to adopt the fishing technology. Moreover, the adoption of a fishing technology by a more capable fisher increases the likelihood of gaining a higher income (Abadi Ghadim \& Pannell, 1999; Marra et al., 2003; Tsur et al., 1990). 


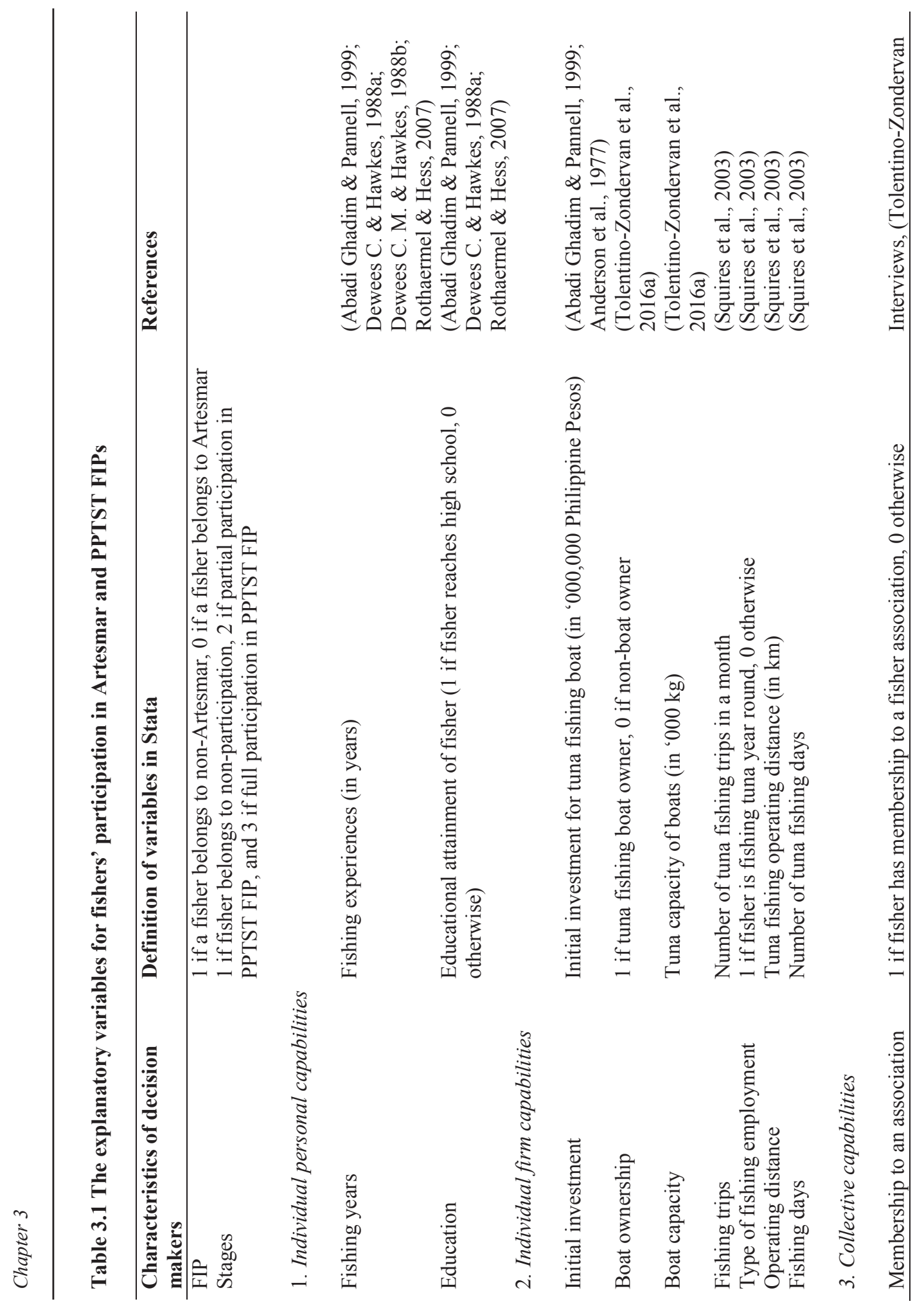




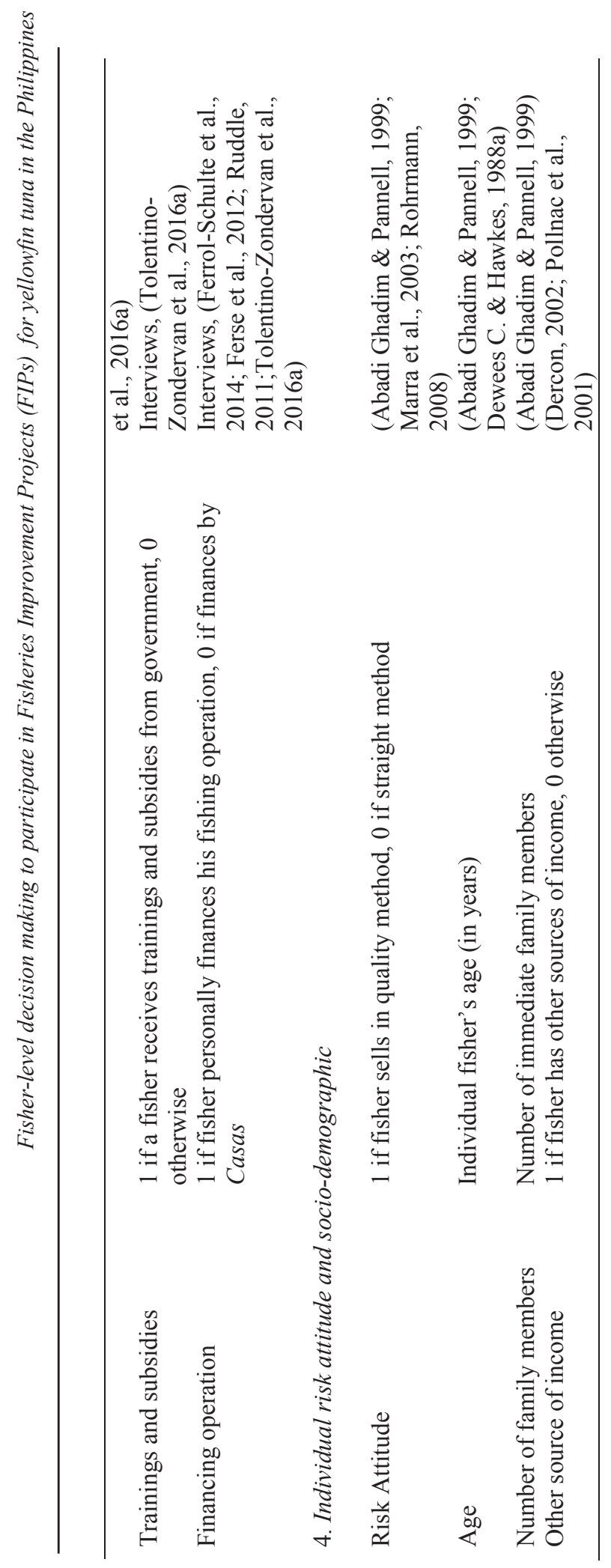


The capabilities are expressed at the individual, firm and collective levels. As shown in Table 3.1, individual capabilities of the fishers correspond to what others have termed human capital, including the experiences and education of an individual, and can be used as a proxy for the competences and skills either inherent or acquired by that individual (Rothaermel \& Hess, 2007). Firm capabilities refer to the collection of competences of the organisation to which the individual belongs (Prahalad \& Hamel, 1990; Rothaermel \& Hess, 2007; Teece \& Pisano, 1994) and reflect the use of material resources in order to comply with transaction requirements (TolentinoZondervan et al., 2016a). In this study boats are considered as the unit of a firm operated by individuals. The material resources that are translated to individual firm capabilities include initial investments, boat ownership, boat capacity, type of fishing employment, number of fishing trips, operating distance, and fishing days (Tolentino-Zondervan et al., 2016a). These last three factors represent the input variables used by fishers, including gasoline/fuel, ice, and labor costs (Squires et al., 2003). Collective capabilities correspond to what others refer to as social capital, including shared resources acquired through external relationships and networks that improve personal- and firm-level capabilities (Rothaermel \& Hess, 2007). In practical terms this extends to membership to a fisher association, institutional support such as trainings and subsidies, and financing business operations through loans either from an association or from Casas-local elites or patrons who control trade and provide credit for fishing, as well as for household needs such as education and health (see Ferse et al., 2012; Kusumawati et al., 2013; Ruddle, 2011). Based on compliance with market requirements the Artesmar FIP demands a higher level of capabilities for participation. This study hypothesizes that individual capabilities at firm-level will increase the likelihood of fisher participation to the Artesmar FIP because these variables reflect the higher capabilities of fishers.

The individual risk attitude and socio-demographic variables influence the required income and acceptable risk for the decision maker (Abadi Ghadim \& Pannell, 1999; Marra et al., 2003). This group of variables includes risk attitude, age, number of family members, and other sources of 
income (Table 3.1). The risk attitude reflects the extent to which decision makers value risks (Rohrmann, 2008). A value of 1 in the variable 'risk attitude' (Table 3.1) corresponds to the risk fishers take on by having a preference for what is termed locally as 'quality buying' - a method that requires quality inspection of tuna and assigns higher price for export quality tuna while lower price for rejected quality tuna. In this study, fishers with lower risk aversion (i.e. risk takers) will more likely choose the alternative that will give a higher expected income (Abadi Ghadim \& Pannell, 1999; Lindner, 1987; Tsur et al., 1990). This study assumes that socio-demographic variables may result in two opposite effects, which can influence the significance of these variables in the model. For instance, the age of the fisher affects the time horizon with which an investment can be recovered (Abadi Ghadim \& Pannell, 1999; Dewees C. \& Hawkes, 1988a). A higher age is therefore expected to decrease the likelihood for participation in the Artesmar FIP. At the same time, a higher age may also mean fishers have more fishing experience to improve their compliance with market requirements and could therefore increase the likelihood of participation in the Artesmar FIP (Abadi Ghadim \& Pannell, 1999). Similarly a higher number of family members may reduce the risk of a fisher or firm by increasing the availability of labour, thus increase the likelihood of participation in the Artesmar FIP (Abadi Ghadim \& Pannell, 1999). However, the number of family members also places greater pressure to remain economically viable and food secure, which can lead to a lower probability of participation in the Artesmar FIP. Additional sources of income may reduce this risk by providing alternative sources of finance to firms, which in turn may increase the funds available and the likelihood of participation in the Artesmar FIP (Dercon, 2002). At the same time, other sources of income are also assumed to increase risk due to the allocation of time and resources to other activities, thus decreasing the likelihood of participation in the Artesmar FIP (Pollnac et al., 2001).

In the second-stage decision, collective capabilities such as membership to an association, and subsidies from the government enable fishers to comply with the requirements of the development- 
oriented FIP, while the financial dependency on Casas is either improving or limiting the participation of fishers. These collective capabilities reduce the exposure of fishers to risks by acquiring parts of investments to external actors and developing fishers' capabilities through bottom-up comprehensive FIPs, and thus improve their income. We assume that membership to a fisher association strengthens the social relationships among fishers, enables fishers to improve the management of their fisheries, and allows access to the external resources that help fishers to improve their fishing activities in order to comply with FIP requirements (Tolentino-Zondervan et al., 2016a). Fishers, therefore, will perceive higher utility in joining a bottom-up comprehensive FIP given their focus on establishing fisher associations. Finally, we assume that the financial dependency of fishers to Casas can motivate fishers to participate in these FIPs because of (1) fishers feelings of indebtedness to Casas and/or (2) the (mis)trust of Casas that prices are correlated with the quality of fish. At the same time, the financial dependency of fishers to Casas may limit their freedom in joining a FIP in which they are not involved, because Casas may lose control over fishers which is based on a mix of familial and debt-tied relations (Ferrol-Schulte et al., 2014; Ferse et al., 2012; Ruddle, 2011).

The non-participation of fishers in all FIPs may not only be attributable to a lack of capabilities only, but also to a higher perceived risk of participating in a FIP. Field results indicate that the risk perception of fishers is mainly influenced by four factors: 1) the existing tied-credit relation of fishers to Casas that results to lower fish price, while leaving no alternative higher markets to fishers for selling their fish; and by 2) the lack of trusts of fishers in those assessing quality at landing sites (Ferrol-Schulte et al., 2014); (3) the increasing temperature that results to low tuna quality; and (4) the decreasing tuna catches in the recent years that causes fluctuation in income (Van Putten et al., 2010). 
Based on the assumptions outlined here, the rest of the paper addresses two key questions. First, which variables are important for fishers participation in the Artesmar and PPTST FIPs? Second, based on these variables, to what extent do top down and bottom up comprehensive FIPs facilitate participation of fishers in their programs?

\subsection{Materials and Methods}

\subsubsection{Data Collection}

Individual fisher data were obtained from a survey covering the six municipalities of Occidental Mindoro. The Wageningen School of Social Sciences (WASS) at Wageningen University assessed and approved the research proposal in 2013 before fieldwork commenced in 2014. Verbal consent was sought from fishers by first explaining to them the objective of this study, the kind of information this study requires, and the use of the information they will provide. The interviews commenced after verbal consent was given and recorded by including the name of the fishers in the survey form. Written consent was not obtained due to the illiteracy of most of the fishers and the sensitivity of some fishers in terms of signing any form of what they perceive to be formal documentation containing their names.

The total fisher population in Occidental Mindoro is 3584 fishers, according to the database of WWF Philippines as of June 2014. Following Field (Field, 2013), a total of 350 randomly selected surveys were carried out with the target of $10 \%$ of the population across spatially dispersed areas per municipality (see Table 3.2). The number of complete responses was 316 , which can be divided into four groups according to their participation in the Artesmar FIP (6.3\%), full participation in the PPTST FIP (17.4\%), partial participation in the PPTST FIP (34.2\%), and non-participation (42.1\%) (see Table 3.3). The number of Artesmar FIP fishers is partly limited since the Artesmar FIP started two years later than the PPTST FIP and only covered two out of six FIP municipalities in Occidental Mindoro. 
Table 3.2 The distribution of samples in each municipality

\begin{tabular}{lll}
\hline Municipality & Total population** & Number of samples* \\
Sablayan & 1656 & 165 \\
Mamburao & 850 & 85 \\
Paluan & 113 & 12 \\
Sta. Cruz & 350 & 25 \\
Calintaan & 315 & 33 \\
Rizal & 300 & 30 \\
Total & 3584 & 350 \\
\hline
\end{tabular}

*Total number of surveys carried out is 350 . However, the number is reduced to 316 due to incomplete and nonresponses of some fishers.

**Source: WWF Philippines, June 2014

Table 3.3 Descriptive statistics of variables based on four groups of fishers' participation in FIP

\begin{tabular}{|c|c|c|c|c|}
\hline Variables & $\begin{array}{l}\text { Artesmar FIP } \\
(n=20) 6.3 \%\end{array}$ & $\begin{array}{l}\text { Full PPTST } \\
\text { FIP }(n=55) \\
17.4 \%\end{array}$ & $\begin{array}{l}\text { Partial PPTST } \\
\text { FIP }(n=108) \\
34.2 \%\end{array}$ & $\begin{array}{l}\text { No } \\
\text { Participation } \\
(n=133) 42.1 \%\end{array}$ \\
\hline \multicolumn{5}{|l|}{ Scale variables } \\
\hline Fishing years & $23.95(2.7410)$ & $21.50(1.6487)$ & $19.03(1.09)$ & $18.81(0.9835)$ \\
\hline Initial investments & $3.79(2.2136)$ & $1.98(0.3295)$ & $0.61(0.1090)$ & $0.74(0.1423)$ \\
\hline Boat capacity & $1.74(0.3172)$ & $1.25(0.1280)$ & $0.90(0.1575)$ & $0.90(0.0948)$ \\
\hline Number of fishing trips & $3.9(1.0709)$ & $3.60(0.3349)$ & $8.96(0.8252)$ & $7.67(0.7033)$ \\
\hline Operating distance & $46.25(9.9331)$ & $50.27(5.3346)$ & $35.10(2.8944)$ & $35.54(2.6733)$ \\
\hline Number of fish days & $6.6(0.6257)$ & $6.05(0.3571)$ & $4.15(0.2737)$ & $4.69(0.2309)$ \\
\hline Age & $44.75(2.8533)$ & $42.45(1.3530)$ & $41.81(1.1230)$ & $40.53(0.9858)$ \\
\hline Number of family members & $6.25(0.5020)$ & $4.96(0.2854)$ & $5.35(0.2245)$ & $5.16(0.1801)$ \\
\hline Nominal variables & $\begin{array}{l}\text { Frequency count } \\
(\%)\end{array}$ & $\begin{array}{l}\text { Frequency count } \\
(\%)\end{array}$ & $\begin{array}{l}\text { Frequency count } \\
(\%)\end{array}$ & $\begin{array}{l}\text { Frequency count } \\
(\%)\end{array}$ \\
\hline Reach Hs (1) & $10(50)$ & $55(50.9)$ & $57(42.9)$ & $30(54.5)$ \\
\hline Do not reach Hs $(0)$ & $10(50)$ & $53(49.1)$ & $76(57.1)$ & $25(45.5)$ \\
\hline $\begin{array}{l}\text { Membership to } \\
\text { an association }\end{array}$ & $4(20)$ & $67(62.0)$ & $12(9.0)$ & $44(80.0)$ \\
\hline No $(0)$ & $16(80)$ & $41(38.0)$ & $121(90.10)$ & $11(20.0)$ \\
\hline $\begin{array}{l}\text { Trainings and } \\
\text { subsidies }\end{array}$ & $3(0.15)$ & $55(50.9)$ & $17(12.8)$ & $22(40.0)$ \\
\hline No $(0)$ & $17(0.85)$ & $53(49.1)$ & $116(87.2)$ & $33(60.0)$ \\
\hline $\begin{array}{l}\text { Boat } \\
\text { ownership }\end{array}$ & $8(40)$ & $78(72.2)$ & $71(53.4)$ & $42(76.4)$ \\
\hline Not owner (0) & $12(60)$ & $30(27.8)$ & $62(46.6)$ & $13(23.6)$ \\
\hline $\begin{array}{l}\text { Financing } \\
\text { operation }\end{array}$ & $8(0.4)$ & $61(56.5)$ & $70(52.6)$ & $18(32.7)$ \\
\hline Casa (0) & $12(0.6)$ & $47(43.5)$ & $63(47.4)$ & $37(67.3)$ \\
\hline \multirow[t]{2}{*}{ Season } & $8(40)$ & $34(31.5)$ & $51(38.3)$ & $46(83.6)$ \\
\hline & $12(60)$ & $74(68.5)$ & $82(61.7)$ & $9(16.4)$ \\
\hline Risk attitude & $9(0.45)$ & $13(12.0)$ & $11(8.3)$ & $18(32.7)$ \\
\hline $\begin{array}{r}\text { Straight }(0) \\
\text { buying }\end{array}$ & $11(0.55)$ & $95(88.0)$ & 122 (91.7) & $37(67.3)$ \\
\hline \multirow{2}{*}{$\begin{array}{l}\text { Source of } \\
\text { income }\end{array}$} & $10(50)$ & $78(72.2)$ & $67(50.4)$ & $25(45.5)$ \\
\hline & $10(50)$ & $30(27.8)$ & $66(49.6)$ & $30(54.5)$ \\
\hline
\end{tabular}


Table 3.3 also shows descriptive statistics of the independent variables that were used to explain fisher participation. In general, the scale variables such as fishing years, initial investments, boat capacity, operating distance, number of fish days, age, and number of family members show an increasing trend with increasing levels of participation, while the number of fishing trips shows a decreasing trend. The distribution of fishers is also shown for each nominal variable. The education level of fishers is evenly distributed across four fisher participation options. The membership to a fisher association and the boat ownership of fishers both increase from non-participation to full participation in the PPTST FIP. Artesmar FIP has the highest fraction of risk taking fishers. Also the percentage of fishers that prefers quality buying increases with the degree of participation in the PPTST FIP.

\subsubsection{The empirical model}

In modelling fishers' decision making to participate in FIPs, fishers decisions are structured in the two stages as explained above (Figure 3.2). The initial explanatory variables to explain fisher's decision making are outlined in Table 3.1 and are coded in Stata 13, the statistical program used in this paper.

We employed a two-stage modelling approach, similar to the concept of Heckman's two-stage sample selection model (De Luca \& Perotti, 2011; Greene, 2012; Heckman, 1979; StataCorp, 2005), because it enables us to assess fisher's participation in FIPs in two stages (Greene \& Hensher, 2010; Tucker, 2010). The first stage is a sample selection equation that uses a probit model. In this study, the sample selection deals with fishers options to choose between Artesmar FIP or non-Artesmar, which works for the two municipalities of Sablayan and Mamburao. The sample selection equation is represented by: 


$$
\begin{aligned}
& z^{*}=\alpha^{\prime} \mathrm{w}+\mathrm{u} \\
& z=1\left[z^{*}>0\right] .
\end{aligned}
$$

The variable $\mathrm{Z}^{*}$ is a shadow variable ruling the fisher participation in Artesmar FIP, $\alpha^{\prime}$ is a coefficient of the selection process, $w$ is the explanatory variables known to influence the selection decision, and $\mu$ is the random error term of sample selection equation that is normally distributed. When $z=1$, the fisher belongs to the category 'non-Artesmar' (and $\mathrm{z}=0$ for the Artesmar FIP) since further analysis will be done for a group of fishers not involved in the Artesmar FIP. All variables in Table 3.1 are used in the selection equation.

Next is to use the result in the first equation to calculate the inverse Mills ratio, a selection hazard that is added as an explanatory variable in the second equation to remove the sample selection bias. Similar to Heckman's two-stage sample selection model and to other studies (e.g. Cohen \& Zarowin, 2010; Henson et al., 2013; Ngaruko \& Lwezaula, 2013; Weber \& Willenborg, 2003; Wu \& Zang, 2009) that employed the same methodology, the second stage is an ordered probit equation. Since the second stage applies for the six regions where PPTST FIP operates (excluding Artesmar FIP in the analysis), individual fishers in Mamburao and Sablayan have values in their inverse Mills ratio while fishers in the remaining four municipalities have inverse mills ratio set to zero. The ordered probit equation is:

$$
\begin{gathered}
y^{*}=\beta^{\prime} x+\gamma \cdot \lambda+\varepsilon, \\
y=j \text { if } \mu_{i-j}<y^{*} \leq \mu_{j} .
\end{gathered}
$$

The $\mathrm{y}^{*}$ represents a shadow variable ruling the ordered stages of participation to which nonArtesmar fishers belong: $\beta$ ' represents the coefficient of outcome explanatory variables $x, \gamma$ is the selectivity bias, $\lambda$ is the inverse Mills ratio, and $\varepsilon$ is the random error term for the ordered probit 
equation. The $\mathrm{y}=\mathrm{j}$ corresponds to the exact stage of participation in non-Artesmar, and is decomposed as follows: $1(\mathrm{y}=1)$ for non-participation, 2 for partial participation in the PPTST FIP, and 3 for full participation in the PPTST FIP. The variables in Table 3.1 are used in the ordered probit equation.

Before running the probit and the ordered probit models, two steps were conducted. First, all independent variables were checked for multicollinearity using the Variance Inflation Factor (VIF), which in this case gave values well below 10 for all explanatory variables (see Appendix C). This means that all explanatory variables exhibit low multicollinearity so all variables are retained in the model. Second, the heteroskedasticity of the model was tested using the Breusch-Pagan test to determine whether the variance of the error terms increases or decreases with explanatory variables. The heteroskedasticity test shows a significant result (see Appendix D), implying that running the model using robust standard errors reduces the variance of the error terms.

Finally we added two extra steps to the model to test the robustness of our result, as shown in the supplementary information (see Appendix F and Appendix G). First, we checked for the significance of the inverse Mills ratio using the samples in Mamburao and Sablayan. Second, we ran a separate ordered probit model in the second stage that does not account for inverse Mills ratio for comparison with the one that does account for inverse Mills ratio.

\subsection{Results}

First the modelling results will be presented for the first stage decision on participation in the Artesmar FIP, followed by the results for the second stage decision on participation in the PPTST FIP and the ordered outcome of non-participation in FIP, partial and full-participation in PPTST FIP. 


\subsubsection{Participation in Artesmar FIP}

Table 3.4 shows all independent variables that might explain participation of fishers in the Artesmar FIP, together with the corresponding coefficients, standard error, and Z-value. The coefficients are interpreted based on the direction of the effect of the variables (Greene, 2012). For instance, a positive coefficient means that a variable increases the participation of fishers in Artesmar FIP while a negative coefficient reduces the participation of fishers in Artesmar FIP. It is not possible to use the value of these coefficients in estimating the increase or decrease of participation because the coefficients are not derived using a linear model. The inverse Mills ratio shows insignificant result which means that there is no evidence that selection bias is quantitatively important.

The results presented in Table 3.4 show that some explanatory variables have significant effects on fishers' choice for Artesmar FIP over non-Artesmar. The fit of the model based on the probit equation is $\mathrm{P}>\chi^{2}=0.00$, which implies a good model fit at $\alpha=0.01$. Consistent with our hypothesis, the initial investment for fishing boats, risk attitude, and number of family members are significant and positively contribute to the fishers' choice to participate in the Artesmar FIP. Increasing initial investment for fishing boat reflects higher capabilities of fishers in terms of boat size, boat engine, and fishing equipment. These capabilities enable fishers to deliver tuna in the chain, therefore increasing their likelihood of choosing the Artesmar FIP and their chances of gaining higher income to recover their investments. A higher value for risk attitude of fishers as manifested by fishers preference to sell through quality buying, increases the likelihood of fishers to participate in the Artesmar FIP. A higher number of family members indicates that fishers also have an increase likelihood to participate in the Artesmar FIP. Based on field observations and interviews, fishers participating in Artesmar FIP often operate as part of a large scale family business. As shown in the literature (Zahra, 2005), family members in the fishing business reduce fishers' risks by having trusted employees, by developing the capabilities of the family members in order to succeed the 
business in the future, and by having confidence that a fisher contributes to the welfare of the family member.

Table 3.4 Results of the probit model in the first stage using data from Sablayan and

\section{Mamburao fishers}

\begin{tabular}{|c|c|c|c|}
\hline & Coefficients & Standard Error & Z \\
\hline \multicolumn{4}{|l|}{ FIP $^{\mathrm{a}}$} \\
\hline \multicolumn{4}{|l|}{ Individual personal capabilities } \\
\hline Fishing years & 0.005 & 0.014 & -0.35 \\
\hline Education & 0.156 & 0.303 & -0.51 \\
\hline \multicolumn{4}{|l|}{ Individual firm capabilities } \\
\hline Initial investment & $0.089 * * *$ & 0.029 & -3.082 \\
\hline Boat ownership & -0.391 & 0.351 & 1.11 \\
\hline Boat capacity & 0.035 & 0.085 & -0.42 \\
\hline Fishing trips & 0.011 & 0.044 & -0.25 \\
\hline Type of fishing employment & $-0.836 * * *$ & 0.300 & 2.78 \\
\hline Operating distance & -0.003 & 0.005 & 0.53 \\
\hline Fishing days & 0.070 & 0.053 & -1.32 \\
\hline \multicolumn{4}{|l|}{ Collective capabilities } \\
\hline Membership to Association & -0.269 & 0.330 & 0.82 \\
\hline Financing operation & -0.276 & 0.279 & 0.99 \\
\hline Trainings and subsidies & -0.549 & 0.414 & 1.33 \\
\hline \multicolumn{4}{|c|}{ Individual risk attitude and socio demographic } \\
\hline Risk attitude & $1.132 * * *$ & 0.293 & -3.86 \\
\hline Age & 0.017 & 0.018 & -0.98 \\
\hline Number of family members & $0.259 * * *$ & 0.069 & -3.78 \\
\hline Other sources of income & 0.119 & 0.279 & -0.42 \\
\hline Constant & $3.80 * * *$ & 0.941 & 4.03 \\
\hline \multicolumn{4}{|c|}{$\begin{array}{l}N=220 \text {; Wald chi }(16)=47.60 ; \text { prob }>(\text { chi }) 2=0.000 ; \text { inverse mills ratio }=0.16 \\
\quad * \text { Statistical significance at } \alpha=0.10 \\
\quad * * \text { Statistical significance at } \alpha=0.05 \\
\quad * * \text { Statistical significance at } \alpha=0.01 \\
{ }^{a} \text { For reading the result, let } 1=\text { Artesmar FIP and } 0=\text { non-Artesmar }\end{array}$} \\
\hline
\end{tabular}

Contrary to what was expected, the type of fishing employment has a negative effect on participation in the Artesmar FIP. The results show that the more fishers operate part-time or target species aside from tuna, the more likely it is that they will participate in the Artesmar FIP. Most 
part-time tuna fishers shift from tuna fishing to catching other species during the low season for tuna catches in order to recover their costs of operation. Moreover, based on field interviews, some fishers believe that tuna stocks are declining over time, and therefore search for alternative catch to balance the risks of going out to sea.

\subsubsection{Participation in PPTST FIP}

The results of the ordered probit model on the degree of participation of fishers in the PPTST FIP are presented in Table 3.5. Variables such as type of fishing employment, operating distance, membership to an association, and risk attitude have positive and significant effects on the degree of fishers' participation. The type of fishing employment increases the likelihood of full-participation in PPTST FIP when fishers target tuna on a full-time basis. Fishers specializing in tuna may have better skills in catching and improving tuna as compared to diversified fishers, thus enabling them to comply with the product requirements of PPTST FIP and therefore increasing their chance of generating higher income. As the operating distance increases, the likelihood of full participation in the PPTST FIP also increases. Fishers also note that the declining catch in municipal water $(<15 \mathrm{~km}$ from seashore) drives them further seaward to search for better fishing grounds. Doing so increases their chances of catching and delivering tuna in the PPTST FIP, which in turn increase their chances of gaining higher income.

The membership to a fisher association also increases the likelihood of fishers to move from nonparticipation to full-participation in PPTST FIP. Based on interviews, fishers in the PPTST FIP perceive that joining a fisher association will help them improve the quality of their tuna, and will finally lead to higher tuna prices. The fisher association increases the perceived benefits of fishers since the association helps fishers to generate funding and subsidy such as fishing aids from the government, which improves their fishing activities. Moreover, a fisher association also organises activities such as the marine guards to prevent illegal fishing and conservation activities as part of 
the improvement process in the FIP. Finally, the risk attitude of fishers shows a positive effect in terms of pushing fishers to fully participate in the PPTST FIP. This means that fishers are willing to sell more through quality buying because these fishers are confident that they acquired the knowledge and skills to improve the quality of tuna catches, which in turn increases the probability of getting higher prices for the fish they land.

Table 3.5 Results of the estimation of the ordered probit model in six municipalities of Occidental Mindoro

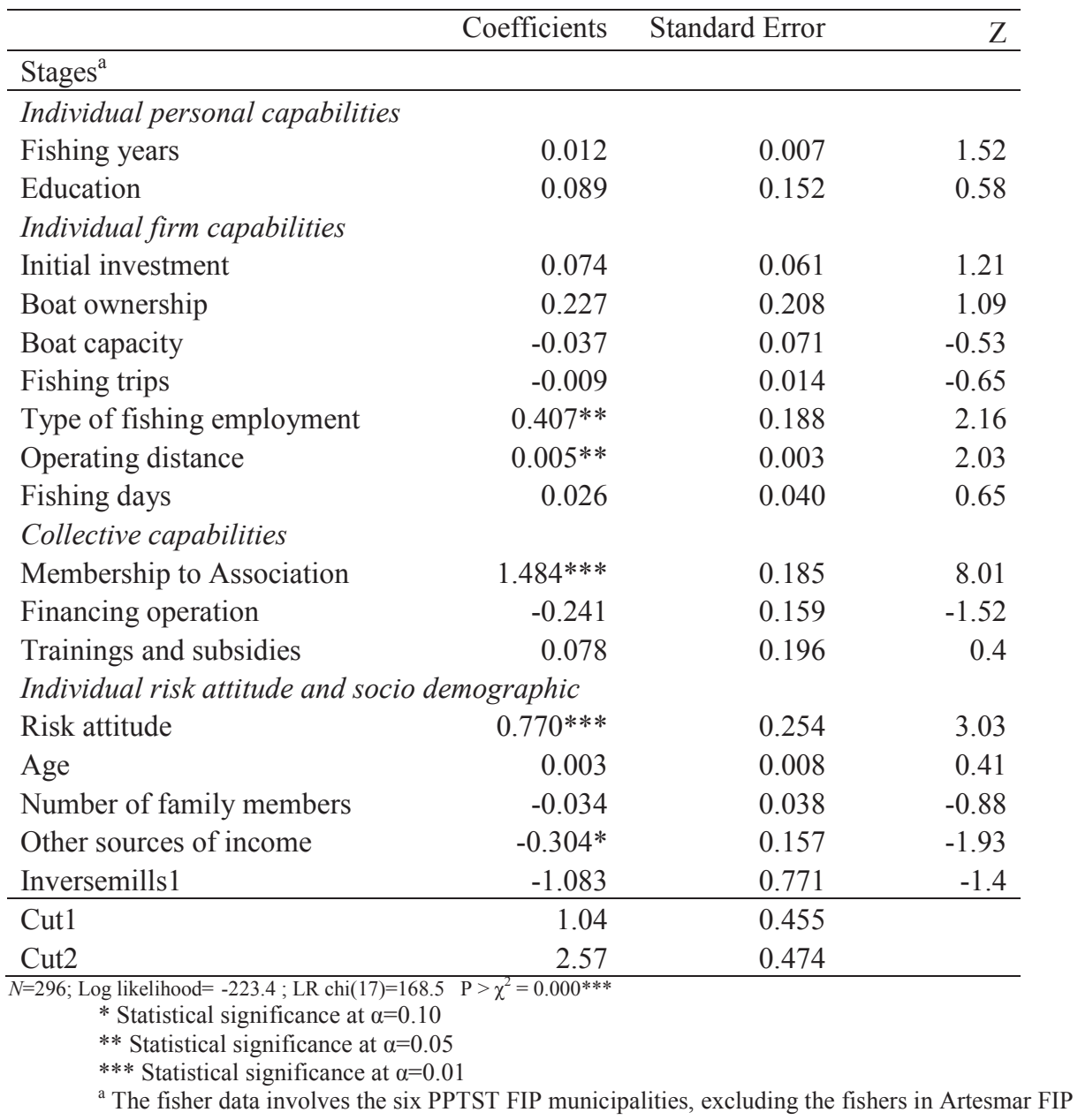


Having alternative sources of income has a negative and significant effect on the participation of fishers in the PPTST FIP as compared to those fishers who solely rely on fishing as a source of income. Based on interviews, and consistent with literature related to fishing as a form of employment (e.g. Pollnac et al., 2001), some fishers consider fishing as the poorest among other forms of employment and would like to move away from fishing if possible. Therefore, having other sources of income such as farming and small enterprises leads them to prioritize alternative sources of income rather than improving their fishing practices to satisfy FIP requirements.

Finally, the significant variables in the ordered probit model are further analysed by deriving their marginal effects, which show the change in probability when an independent variable increases by one unit. Calculating marginal effects in the second stage decision shows both the patterns and requirements for fishers to move from one participation stage to another. Figure 3.3 shows these marginal effects of the type of fishing employment, operating distance membership to an association, risk attitude, and other sources of income based on non-, partial-, and full-participation in the PPTST FIP (also refer to Appendix E for detailed information). The vertical axis of the graph represents the values of marginal effects from low to high, while the data labels or numbers in bold represent the significance of marginal effects at $\alpha=0.05$. Taking the membership to a fisher association as an example, the graph shows that when any fisher is a member of a fisher association, the probability of not participating reduces by $51.5 \%$, while the probability of partial participation increases by $21.4 \%$, and of full participation increases by $22.7 \%$. In another example, an addition of one $\mathrm{km}$ to the $35.5 \mathrm{~km}$ average operational distance will reduce the non-participation of fishers by $0.2 \%$ (see Figure 3.3).

Aside from the direct interpretation of the marginal effects, the graph also shows the trends of marginal effects in selecting for partial or full participation in the PPTST FIP. The five variables show an increasing trend, which means that they generally enhance the participation of fishers from non- to full-participation in the PPTST FIP. The variables membership to a fisher association and 
risk attitude are highly significant in non, partial, and full-participation in PPTST FIP at $\alpha=0.01$. This means that both variables are highly important in improving the participation of fishers in the PPTST FIP. The type of fishing employment, operating distance, and financing operation are significant at $\alpha=0.05$ and at 0.10 . It is also notable that among the five variables, the membership to a fisher association shows the highest marginal values, making it highly important for both partial and full participation. The majority of the partial participants are able to get funding from the government to improve their livelihoods through a fisher association. Full participants also benefit by being members of a fisher association by having regulatory support to fight IUU fishing in their area, thus ensuring greater legality of fish caught and traded.

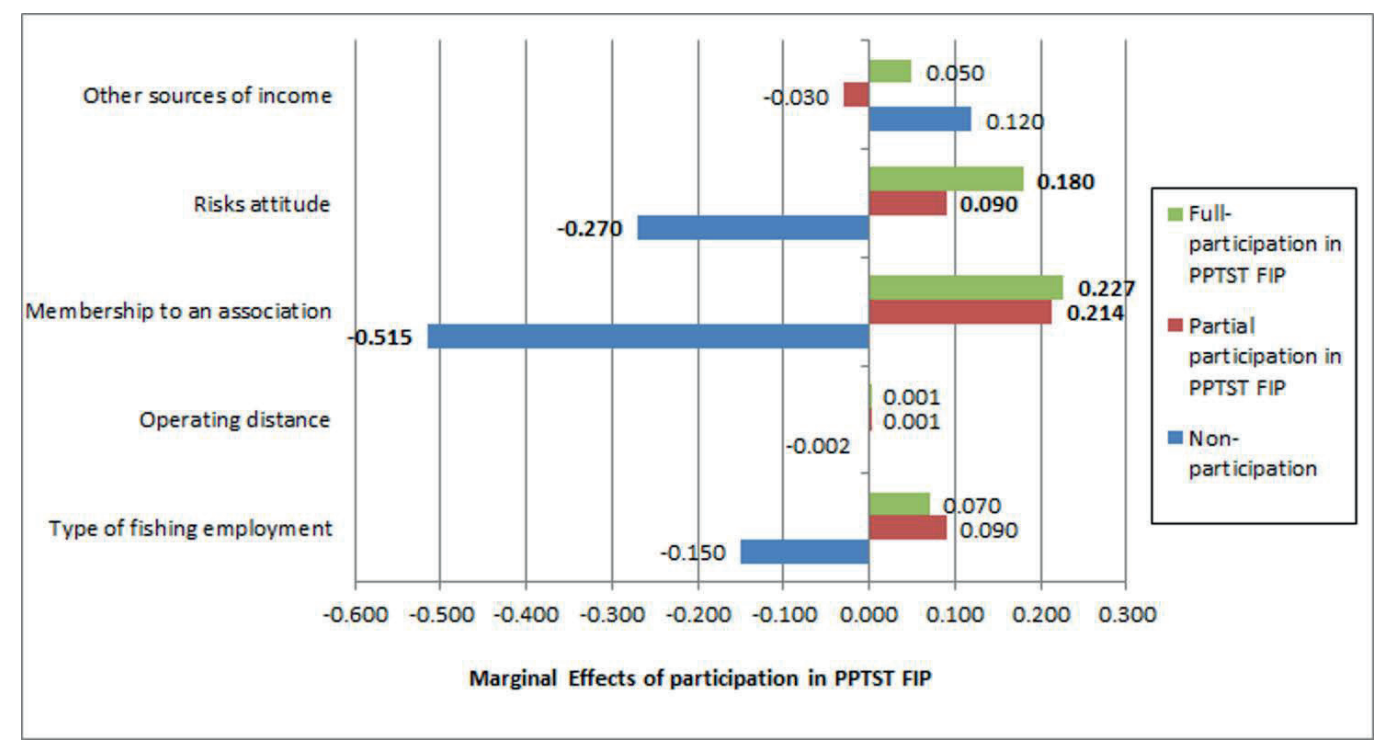

Figure 3.3 The marginal effects of significant variables in second stage decision after ordered probit model

Note: The numbers in bold represent the marginal effects significant at $\alpha=0.05$. 


\subsection{Discussion}

Based on these results we now further elaborate on how the capabilities of fishers influences fisher decision making for different levels of participation in top-down and bottom-up comprehensive FIPs, and on the influence these factors have on the design of different FIPs as a means of reaching goals of improved fishery practices and fisheries management.

\subsubsection{Capabilities, risk and FIP participation}

The results show that different types of capabilities influence the decision of fishers to join different kinds of FIPs. First, individual firm capabilities, such as initial investment and type of fishing employment, increase the likelihood for fisher participation in response to market-oriented FIPs, which provide economic incentives through dock side transactions based on quality. These individual firm capabilities are more likely to be exhibited by those with considerable financial capacity, owning and financing several fishing boats. Moreover, these fishers are also more likely to be engaged in other chain-related activities. However, consistent with now wider observations of how economic decisions are embedded in wider social or community relations (Granovetter, 1985; Platteau \& Abraham, 1987), the results also show that these individual firm capabilities are not independent from wider social relations in which these firm actors find themselves in fishing communities. For example, socio-demographic variables, such as the higher number of family members, are also shown to play a role in the probability of participating in market-based FIPs possibly because familial ties reduce the risk associated with individual choices to invest in complying with FIP requirements (Gomez-Mejia et al., 2001; Zahra, 2005).

Second, collective capabilities, such as membership to an association, are more likely to increase participation in the bottom-up PPTST FIP. The results also show that full participation in development-oriented FIPs remains dependent on the characteristics of the individual fishing firm. The results indicate that fishers fully participating in PPTST FIP have a greater degree of operation, 
for instance by their large capacity to finance high costs of operation at a farther distance and through their capability to cope with risks associated with full-time tuna fishing particularly from March to September where catches are lower (see for example Herrero, 2004). However, partial participation is dominated by those fishers with smaller 'one-man, one-boat' operations, characterised by fishing at shorter distance from shore, and who are dependent on collective capabilities supported by fishing associations and Casas (see Bailey et al., In Press for comparable results). The consequence appears to be that despite the bottom-up oriented nature of the PPTST FIP, targeting a wider group of smaller scale and relatively poorer fishers, full participation appears to remain linked to those with higher individual firm level capabilities. This supports the idea of “elite capture" of benefits (MacNeil \& Cinner, 2013), meaning that fishers with a high level of individual capabilities, in general, benefit from participation in FIPs.

In addition to capabilities, the results indicate that risk attitude also influences the decision of fishers to participate in the two FIPs. First, the results indicate that less risk averse fishers are more likely to participate in the top-down Artesmar FIP. Building on work around fisher behaviour in response to economic risk (Prahalad \& Hamel, 1990; Rohrmann, 2008; Rothaermel \& Hess, 2007) this finding indicates that those fishers choosing for Artesmar FIP do so in order to not only generate higher income, but more importantly to reduce the lack of transparency and high price volatility inherent in the landing sites controlled by Casas. This means that the high price in Artesmar FIP reduces the risks of fishers against lower fish prices, as long as these fishers satisfy the fish quality requirement. In contrast, those choosing for the bottom-up PPTST FIP were not able to reduce this risk, as seen in many small-scale developing country fisheries (Pérez-Sánchez \& Muir, 2003; von Essen et al., 2013), because most buyers involved were not moving to quality buying and maintained many of the same debt-tied relations. 


\subsubsection{Consequence for FIP design}

Our results hold consequences for the design of FIPs, as well as the relationship between different FIP models. First, reflecting wider discussions on market-based approaches to environmental improvement [such as eco-certification, see (Bush et al., 2013)], top down comprehensive FIPs requiring high level of individual capabilities have a higher risk of being selective of those fishers who can more easily comply with sustainability standards in exchange for immediate market access (Tolentino-Zondervan et al., 2016a) - with the consequence of reducing the potential for overall fishery improvement. In contrast, bottom up comprehensive FIPs fostering collective capabilities appear to be more inclusive of a larger group of fishers, but with the potential consequence of delivering lower overall improvements to the fishery as a whole. Balancing these trade-offs is at the core of the differentiation on how different FIP models are evolving (California Environmental Associates, 2015).

Second, the results indicate that the design of FIPs also influences the delivery of incentives to fishers, which also affects inclusiveness and overall impact. As argued above, top-down FIPs appear to be better able to deliver more transparent price signals to fishers. The case of the Artesmar FIP shows that companies like Meliomar invest in vertical coordination and in doing so control the chain from production to export. They are thus better able to set higher prices for higher quality fish and to transmit this price incentive to fishers (Gulati et al., 2007; Suzuki et al., 2011). On the other hand, bottom-up FIPs with weaker relationships between retailers and fishers may result in weaker control over chain coordination. In addition, the on-ground implementation by actors operating outside the chain such as WWF, appears to result in weaker delivery of price-related incentives. Based on field interviews and observation, WWF serves as a facilitator outside the chain that links fishers to other seafood stakeholders. However, WWF does not have influence over the price of fish. Nevertheless, supporting other observations (Deighan \& Jenkins, 2015; Tolentino-Zondervan et al., 
2016a), bottom-up comprehensive FIPs do appear to offer more durable support from government given their closer relationship during implementation.

Finally, these results open up questions around the degree of complementarity and competition that might exist between FIP models in relation to inclusion and improvement. While the results point to the differences between top-down or bottom-up comprehensive FIPs, it may not necessarily be the case that these or other FIP models are opposed or in competition. Instead, building on nascent ideas of FIP design (California Environmental Associates, 2015), two FIP models operating in one place points to a range of potential complementarities in terms of delivering incentives to fishers and improving the governance of the fishery. Here the more stringent top-down market-oriented approach could target fishers with individual firm capabilities, while bottom up 'developmentoriented' FIPs could provide a more inclusive approach. By targeting different capabilities, and setting different incentives, the two models could work in tandem to provide overall greater gains in fishery improvement.

\subsection{Conclusion}

Our results indicate the overall importance of considering fisher capabilities in understanding decisions of fishers to participate in different kinds of FIPs. The individual firm capabilities stimulate fishers to participate in strongly market oriented top-down FIPs while collective capabilities enable fishers to improve their practices and to participate in bottom-up FIPs aimed at wider fishery and community development goals. These types of capabilities and FIP models have consequences for the inclusiveness of different fishers, for which three insights are generated in this study. First, the top-down FIPs appear to be more exclusive, given that there are a few numbers of fishers who have the capabilities and lower risk aversion to comply with its requirements. Second, bottom-up FIPs appear to be more inclusive, aiming to provide broad support to the development of fisher capabilities and the institutional support provided to them to improve their practices on the 
water. Third, the two FIP models exhibit competing inclusion when implemented in the same fishery, yet also exhibit potential complementarity in terms of delivering incentives and improving governance of the fishery.

We also conclude that in order to increase the participation of fishers, those designing FIPs need to not only recognize the economic utility that a fisher could derive from participation, but also to identify and build fishers capabilities to participate in a FIP. Moreover, FIPs must also balance both the deliverance of incentives to individual fishers and the improvement in the governance of the fishery in order to enhance participation of fishers and thus achieve high sustainability impact. Future research may elaborate on the implementation of FIPs to poor and well performing fishers and to different fisheries (e.g. tuna or other species), and on their consequences to the inclusiveness and fishery improvement. Finally, focusing on ways to enhance the participation of fishers in FIPs and in other private incentive mechanisms is also relevant to achieve higher sustainability outcomes. 


\section{Chapter 4}

\section{FAD vs. free school: Effort allocation by Marine Stewardship Council compliant Filipino tuna purse seiners in the PNA}

This chapter has been submitted to Marine Policy as Tolentino-Zondervan, F. Berentsen, P. Bush, S.R., and Oude Lansink, A. FAD vs. free school: Effort allocation by Marine Stewardship Council compliant Filipino tuna purse seiners in the PNA. 


\subsection{Abstract}

This paper assesses the effect of Marine Stewardship Council certification on the allocation of fishing effort by Filipino purse seine fishers operating in the waters of the Parties of the Nauru Agreement. Targeting skipjack tuna, these purse seiners allocate effort under a vessel day scheme to either MSC certified free school fishing or non-MSC certified fishing on fish aggregating devices (FADs). Based on historical catch and price data, the optimal set of fishing activities are determined in terms of the mean and variance of fishers' gross margin at given levels of risk aversion. The results show that MSC certification stimulates fishers to reduce their allocation of effort on nonMSC compliant FADs, and consequently convert this effort to MSC compliant free school purse seining. In general, the MSC also increases the yearly gross margin of fishers as compared to the situation without MSC certification. The MSC therefore appears to be effective to a certain extent in promoting a transition to more sustainable fishing practices. However, the results also indicate that the risk profile of fishers is a key but underexplored dimension of assessing the potential impact of MSC certification on effort allocation.

Keywords: effort allocation; Filipino; Marine Stewardship Council; purse seine; risk aversion 


\subsection{Introduction}

The skipjack (Katsuwomis pelamis) purse seine fishery in the waters of the Parties to Nauru Agreement (PNA) accounts for $60 \%$ of the tuna supply in the Western and Central Pacific Ocean (Parties to Nauru Agreement Office, 2015). Acting collectively the eight Pacific island member states of the PNA have implemented two management measures designed to secure a greater share of the value of this tuna resource (Barclay, 2010; Barclay \& Cartwright, 2007; SPC, 2010). The vessel day scheme (VDS) sets a price on fishing days within the Exclusive Economic Zones (EEZ) of the PNA member states, with the intention of controlling access and fishing effort by fishing fleets owned almost exclusively by distant water fishing nations (for details see Havice, 2013). In addition these fleets can voluntarily comply with the Marine Stewardship Council (MSC) certification by fishing on 'free school' tuna either in parallel to or replacing fishing on tuna associated with Fish Aggregating Devices (FADs).

The MSC certification of free school purse seine fishing in the PNA aims to reduce the observed negative effects of FADs on: (1) non-target juvenile yellowfin (Thunnus albacares) and bigeye tuna (T. obesus), both of which are considered overexploited; and (2) the by-catch of endangered and threatened species (Bailey et al., 2009; Bailey et al., 2013; Hampton, 2010; Langley et al., 2008). In support of the MSC certification, the PNA has set measures for reducing fishing effort on FADs, including seasonal FAD closure in the EEZs of the PNA countries and an annual limit on the number of FAD sets by purse seine vessels (Gilman \& Lundin, 2010). During the seasonal FAD closures, vessels are limited to MSC compliant free school fishing. However, during the FAD fishing season vessels can elect to either set on free school tuna or on FADs during a voyage as long as there is an MSC registered observer on board (Hamilton et al., 2011). With measures in place to separate tuna from FAD and free school sets on-board, vessels can land both MSC and non-MSC tuna from a single trip. If the vessel carries a PNA member state flag it can fish either on free school or on FADs in the archipelagic waters of these nations under the Federated States of Micronesia 
(FSM) Arrangement (see Yeeting et al., 2016). This fishing activity then falls outside the VDS and does not qualify for MSC certification.

The possibility to make allocation decisions based on location and fishing gear on any given voyage is unlike other MSC certified fisheries, where all fishing activities within the 'unit of certification' are MSC compliant. Despite the flexibility this brings to purse seine fishers in the PNA, the choice of effort allocation also forces fishers to make tactical decisions. A key determinant of this tactical decision to allocate fishing days to MSC or non-MSC compliant fishing is therefore also influenced by their risk attitude (see for example Brick et al., 2012). For tuna fishing, these risks include the variation of catches on FADs and/or free schools and the variation in the price of MSC and non-MSC compliant tuna. By better understanding risk attitude, fishery managers may therefore better understand the motivation of fishers to change their fishing practices and in doing so enhance the sustainability of the fishery.

The relationship between effort allocation and risk attitude is understudied. Some studies have looked at the effect of risk aversion on effort allocation in terms of both gear and location (Dupont, 1993; Eggert \& Tveteras, 2004; Mistiaen \& Strand, 2000). However, the majority of studies have focused on effort allocation decisions without taking the risk attitude of fishers into account (Bastardie et al., 2010; Béné \& Tewfik, 2001; Pet - Soede et al., 2001; Poos et al., 2010; Poos \& Rijnsdorp, 2007; Rijnsdorp et al., 2000). No study has yet assessed the influence of risk attitude on the allocation of fishing days in response to incentive mechanisms such as the MSC, nor assessed the effectiveness of MSC in promoting sustainable fishing practices based on effort allocation by fishers in a multi-gear fishery.

This study fills this gap by examining the mean and variance of gross margins resulting from different effort allocation by more and less risk averse MSC compliant Filipino purse seine vessels 
in the PNA. The analysis uses a Mean-Variance Approach to account for both the allocation of fishing days and the risk aversion of fishers. The analysis is limited to the Filipino tuna purse seine fishing in PNA for two reasons. First, these vessels are currently complying with MSC at varying rates of effort allocation. Second, they have the widest set of options in terms of fishing in both archipelagic waters and the EEZ of PNA countries based on the Palau Agreement. The results provide insights on the extent to which the MSC can affect the allocation of 'compliant' fishing days by fishers, as well as provide guidance to managers seeking to increase the voluntary participation of fishers in MSC compliant fishing across the full risk-attitude spectrum.

The following section describes the Filipino purse seine vessels and their participation in MSC compliant free school fishing. Section three then outlines the effort allocation framework of purse seiners in the PNA and the Mean-Variance Approach used to model this allocation. Section four presents the effects of MSC on the gross margin and effort allocation and section five discusses the effectiveness of MSC in affecting effort allocation. The paper concludes by outlining the recommendations for both fishery managers and the MSC seeking to incentivise fishers to shift to more sustainable practices in multi-gear fisheries.

\subsection{Filipino purse seiners' allocation decisions}

\subsubsection{Filipino tuna purse seiners fishing in Papua New Guinea (PNG)}

Filipino purse seine vessels have fished in the waters of the PNA, including interstitial High Seas Pockets, for more than three decades (Vera \& Hipolito, 2006). Today, Filipino owned purse seine vessels flying a domestic Papua New Guinea (PNG) flag or chartered vessel flying a Philippines flag have access to PNA waters. Domestic vessels fish primarily in the PNG waters while chartered vessels have access to all PNA EEZs under the FSM Arrangement. PNG has introduced this flagging arrangement in an attempt to attract investment from vertically integrated Filipino firms who own both vessels and processing plants. By domesticating processing capacity the PNG 
government hopes to increase domestic fishing capacity and in turn increase the volume of tuna being landed, processed, and exported from the country (Barclay, 2014).

In 2014 there were 12 Filipino-owned domestically-flagged PNG vessels and 18 Filipino-owned chartered vessels in PNG (Usu et al., 2014). Philippine flag vessels chartered by PNG fished exclusively in the PNG waters until 2014 (Usu et al., 2013, 2014). This study focuses on Philippineowned domestic and chartered vessels by PNG because these vessels are included in the lists of MSC certified vessels regulated by the PNA (Marine Stewardship Council, 2014a). However, no further distinction is made between these vessels given they have the same options for fishing activities in PNG waters.

The majority of Filipino-owned vessels are between 50-80 meters in length. This is significant because vessel length determines the type of fishing license and the coverage of operation in PNG waters and also qualifies vessels for fully equivalent fishing days under the VDS (Forum Fisheries Agency, 2015a). Vessels this size are also able to engage in both FADs and free school fishing (Barut \& Garvilles, 2005; Vera \& Hipolito, 2006). FAD fishing includes both anchored FADs, which are stationary floating objects, and drifting FADs, which are moving FADs that contain satellite buoys that transmit their location to fishing vessels (Dagorn et al., 2013; Fonteneau et al., 2013). Free school fishing uses technologies such as fish finders, GPS, and sonar, to scan for tuna in the open ocean. Some vessels fishing free schools are also aided by a helicopter that search for tuna and then radio coordinates to the closest catcher vessel.

\subsubsection{Participation of Filipino purse seiners in MSC}

Under the PNA's vessel day scheme, distant water fishing nation vessels are limited to fishing in the collective EEZ of the PNA members, but have the further choice of employing MSC compliant free-school fishing and/or fishing on FADs. However, domestic and chartered vessels by PNG have 
the added choice of free-school and/or FAD fishing in the archipelagic waters of PNA countries as agreed under the FSM Arrangement. The archipelagic waters of PNG are dominated by the Bismarck Sea, delimited by the 12 nautical mile boundary of territorial waters to the start of the EEZ (see Figure 4.1). As of 2015 these archipelagic waters are accessible to PNG domestic and chartered vessels only (National Fisheries Authority, 2015c).

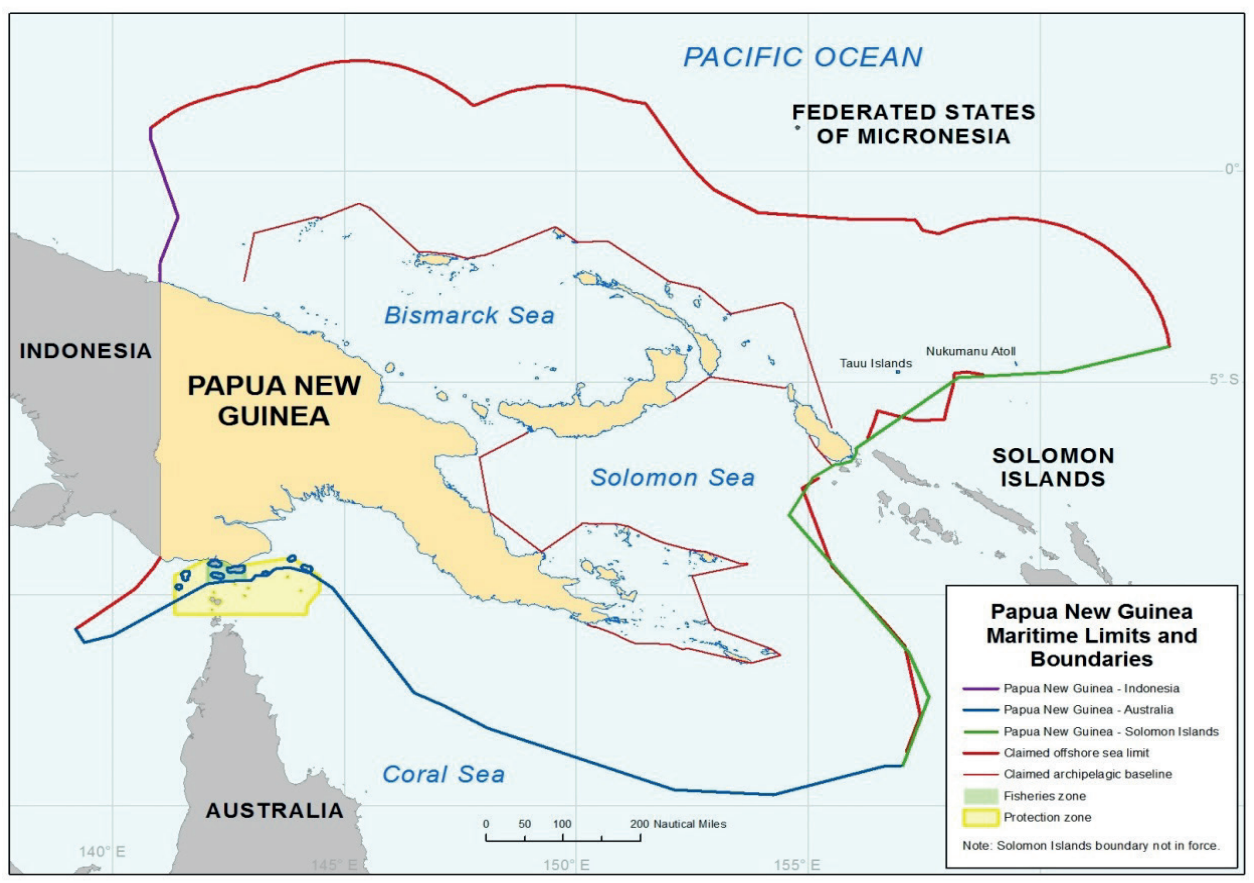

Figure 4.1 The archipelagic baseline and EEZ coverage of PNG waters

Source: (Bureau of Oceans and International Environmental and Scientific Affairs, 2014)

Fisher's compliance with MSC free-school fishing in the EEZ is incentivised through a 20\% price premium controlled by Pacifical B.V., a 50/50 joint venture company between the PNA and the Dutch trader Sustunable (Adolf et al., 2016; Miller \& Bush, 2014). This premium is divided among the cannery (5\%), fishing company (10\%), and PNA/Pacifical (5\%) (Tolentino-Zondervan et al., 
2016a). Since Filipino firms have integrated fishing and processing, they receive a combined price premium of $15 \%$.

To qualify for MSC free school fishing, vessel crews and captains have to undergo MSC training and register the vessel for an MSC trip with the PNA office (see Table 4.1). Both carrier and catching vessels also have to carry a trained observer on-board to verify catch is MSC compliant. Fishers must also comply with the VDS as one of the main harvest control measure of the PNA (Yeeting et al., 2016). In addition to paying for VDS days at a rate of US $\$ 4,000$ per fishing day, vessels in the EEZ zone fishing on free-school or FAD associated tuna have to carry a Vessel Monitoring System (VMS) that tracks the activities of a fishing vessel. The VMS is made up of electronic tracking, electronic monitoring, and electronic reporting (Poseidon Aquatic Resource Management Ltd, 2016). Finally, the catch of fishers must be documented through skippers' logbook and observers' data.

Table 4.1 Fisher-level requirements for MSC fishing in PNA

\begin{tabular}{lll}
\hline Fisher-level requirements & $\begin{array}{l}\text { Description } \\
\text { 1. MSC training }\end{array}$ & $\begin{array}{l}\text { Parties Involved } \\
\text { Vessel crews and captains, } \\
\text { PNA office, and MSC. }\end{array}$ \\
$\begin{array}{ll}\text { 2. Enrol the vessel for MSC } \\
\text { fishing trip and for VMS }\end{array}$ & $\begin{array}{l}\text { Vessel captains, PNA office } \\
\text { 3. Separate MSC (free } \\
\text { school) to non-MSC catch } \\
\text { (FADs, floating objects) }\end{array}$ & Purse seine fishers \\
$\begin{array}{ll}\text { 4. MSC trained observer on } \\
\text { board for both catcher and } \\
\text { carrier vessels }\end{array}$ & $\begin{array}{l}\text { MSC observers from PNA } \\
\text { office }\end{array}$ \\
$\begin{array}{l}\text { 5. Documentation of the } \\
\text { catch }\end{array}$ & $\begin{array}{l}\text { Fishing companies } \\
\text { MSC observers, National }\end{array}$ \\
& $\begin{array}{l}\text { Fisheries Authority, Forum } \\
\text { Fisheries Agency, and } \\
\end{array}$ & $\begin{array}{l}\text { Secretariat of the Pacific } \\
\text { Community, Vessel captain }\end{array}$ \\
\hline
\end{tabular}


The overall effort allocation framework of Filipino purse seiners (as illustrated in Figure 4.2) includes whether to fish on FADs in archipelagic water, FADs in the EEZ, free schools in archipelagic water, and/or MSC free school fishing in the EEZ. Fishers make these decisions based on the risks and the expected gross margin associated with different fishing activities. Risk in tuna production is characterized by the variation in tuna catches from different fishing grounds using different fishing methods and by fluctuations in tuna prices. Fishers that are exposed to these production risks have different levels of risk aversion, which in turn influence their choice of fishing activities. It is assumed that a decrease in an individual's risk aversion tends to increase the likelihood of adoption of innovation, which may not only have high expected gross margin but also high costs and risk (Marra et al., 2003). Following this assumption, this study hypothesises that less risk averse fishers are more likely to adopt MSC fishing than the highly risk averse fishers. Less risk averse fishers are able to make this decision to engage with MSC since they have more wealth, measured by the total value of assets owned by an individual, more experience and knowledge to employ free school fishing, and more established social connections to support their decisions, as compared to highly risk averse fishers (Guiso \& Paiella, 2008; Pratt, 1964).

\subsection{Methods and model specification}

\subsubsection{General structure of the model}

Effort allocation is modelled using a representative Philippine-owned purse seine vessel operating in PNG. Skippers are considered the decision maker on these vessels because they manage the fishing operation of the vessels, including when and where to fish at sea (Libre et al., 2015). The general structure of the purse seine model includes the objectives, activities, and constraints of purse seine fisher as outlined above. The model covers a period of one year (365 days). 


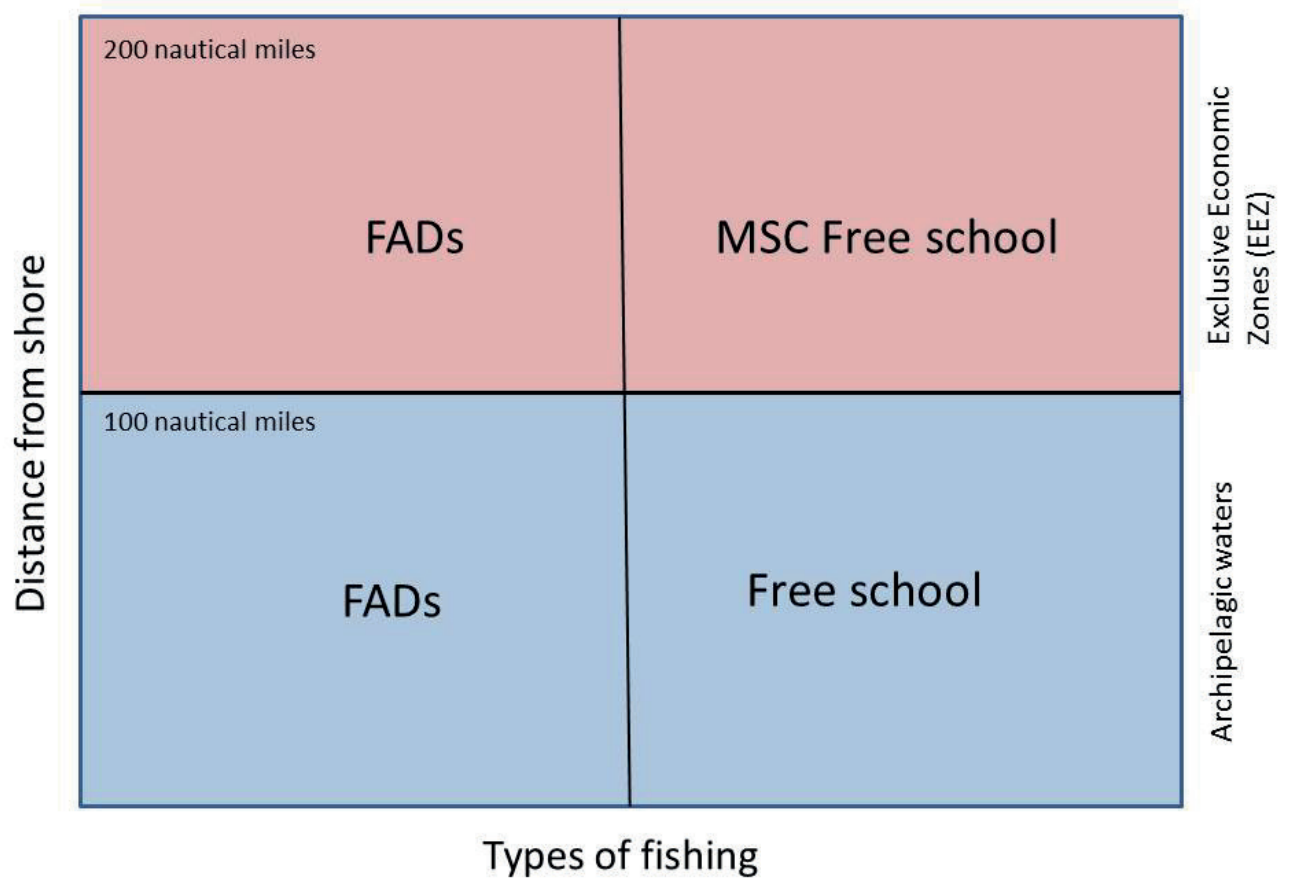

Figure 4.2 The decision making framework of Philippine-owned chartered purse seine vessels in PNG

The optimization model (e.g. Acs et al., 2009; Berentsen \& Giesen, 1995; Chavez et al., 2014) uses the Mean-Variance Approach to determine the combination of different outputs produced given the inputs used by decision makers, while explicitly accounting for the risk attitude of decision makers. The objective is to maximise the utility at the level of the vessel. The general formulation of the model (Hazell \& Norton, 1986; Scott J. T. J. \& Baker, 1972) is:

$\operatorname{Max} Z=C^{\prime} X-0.5 \alpha X^{\prime} W X$

Subject to $A X \leq B$

And $x \geq 0$. 
where $Z$ is the expected utility to be maximized, $C$ is the vector of gross margins for activities $X, \alpha$ is the absolute risk aversion coefficient, $W$ is the variance-covariance matrix of activities gross margins, $A$ is the matrix of input-output coefficients, and $B$ is the vector of the resource constraints.

The utility of fishers is defined as revenues from sales of skipjack catches (in metric tons) minus variable costs that include costs of fuels, labours, costs of fishing days, observer costs, and costs of VMS, minus the risk premium $0.5 \alpha X^{\prime} W X$. The output of the model includes the optimal catch plan, which is the optimal number of fishing days in each fishing activity at the assumed risk aversion level of fishers, and the gross margins of purse seiners.

\subsubsection{Activities}

Following from section 2, the activities of fishers are (1) FAD fishing in archipelagic water, (2) free school fishing in archipelagic water, (3) FAD fishing in EEZ, and (4) MSC (and non-MSC) free school fishing in the EEZ.

\subsubsection{Constraints}

The constraints that are included in the model are as follows:

(1) The total number of fishing days in PNG archipelagic water is limited to 5,500 fishing days per year (National Fisheries Authority, 2015a). The fishing days in archipelagic water is allocated based on the actual processing tonnage of different processing plants in PNG (McCoy, 2014). Fifty percent of the actual processing tonnage of processing plants in PNG is from Philippine-owned canneries (McCoy, 2014). A figure of 106 fishing days per year per vessel in archipelagic water is therefore estimated $[(5,500$ archipelagic water fishing days*50\%)/26 domestic and chartered vessels of Philippine-owned canneries]. 
(2) Filipino-owned domestic and chartered vessels with a PNG flag fall under the VDS scheme through the FSM Arrangement. Such PNA flagged vessels pay a lower price for fishing days compared to vessels flagged to distant water fishing nations because of their assumed contribution to the local development of PNA member states. The limit in fishing days in the PNG EEZ under the FSM Arrangement is 1,732 fishing days (Yeeting et al., 2016). There are 36 PNG flagged vessels under FSM Arrangement in 2014 (McCoy, 2014). The FSM Arrangement fishing days in the EEZ are set at 48 per vessel at a cost of US\$ 4,000 per day based on 2014 figures. Vessels can obtain additional fishing days in PNG waters outside the FSM Arrangement after it has used its EEZ days at a cost of US\$6000 per fishing day (National Fisheries Authority, 2015c).

(3) The FAD closure during the months of July, August, September in the EEZ is equivalent to 92 calendar days (Parris, 2010). In addition to the seasonal FAD closure, fishing vessels also face an additional one month (equivalent to 30 fishing days) FAD-ban in the EEZ, as part of an extra measure imposed on vessels since 2014 by the WCPFC to further conserve bigeye tuna (Western and Central Pacific Fisheries Commission, 2015a). So the maximum number of fishing days for FAD fishing in EEZ is 243.

\subsubsection{Model input}

The model requires daily catches per fishing activity, output prices, variable costs per day per fishing activity, and variances and covariances of gross margins of all fishing activities. The daily catches and the prices of outputs and of inputs in the model are based on data from 2012-2014 since fishers started MSC fishing in 2012.

The catch per fishing method in archipelagic water and in the EEZ of PNG is not directly available, and therefore calculated in multiple steps using different sources (Usu et al., 2013, 2014, 2015; Western and Central Pacific Fisheries Commission, 2015b) (refer Appendix H for detailed 
calculations). The resulting skipjack catches per fishing day are presented in Table 4.2. The daily skipjack catches per fishing method per fishing ground were validated with data on the average effort of Philippine purse seiners in archipelagic and EEZ waters of PNG (National Fisheries Authority, 2015b). Based on the input of two regional experts (Personal communication, November 14, 2016), the resulting catches are assumed to be representative of the age and the performance of Philippine-owned purse seine vessels for the years these data represent.

Table 4.2 Daily catches, prices, gross margin, and costs of Philippine-owned purse seine vessels flagged as PNG based on 2012-2014

\begin{tabular}{|c|c|c|c|c|c|c|}
\hline & Unit & $\begin{array}{l}\text { FAD } \\
\text { fishing in } \\
\text { archipelagic } \\
\text { water }\end{array}$ & $\begin{array}{l}\text { Free school } \\
\text { fishing in } \\
\text { archipelagic } \\
\text { water }\end{array}$ & $\begin{array}{l}\text { FAD } \\
\text { fishing } \\
\text { in EEZ }\end{array}$ & $\begin{array}{l}\text { Non-MSC } \\
\text { free school } \\
\text { fishing in } \\
\text { EEZ }\end{array}$ & $\begin{array}{l}\text { MSC free } \\
\text { school } \\
\text { fishing in } \\
\text { EEZ }\end{array}$ \\
\hline Catches & $\begin{array}{l}\text { mt fish day }{ }^{-1} \\
\text { vessel }^{-1}\end{array}$ & 20.81 & 17.82 & 32.47 & 19.68 & 19.68 \\
\hline Prices (in ‘000) & $\mathrm{US} \$ \mathrm{mt}^{-1}$ & 1.931 & 1.931 & 1.931 & 1.931 & 2.221 \\
\hline $\begin{array}{l}\text { Revenue (in } \\
\text { '000) } \\
\text { Variable costs } \\
\text { (in ‘000) }\end{array}$ & US\$ vessel $^{-1}$ & 40.18 & 34.39 & 62.70 & 38.00 & 43.71 \\
\hline $\begin{array}{ll}\text { - } & \text { Fuels } \\
\text { - } & \text { Labour }\end{array}$ & US\$ vessel ${ }^{-1}$ & 3.60 & 7.20 & 3.60 & 7.20 & 7.20 \\
\hline $\begin{array}{l}\text { (share of } \\
\text { crews) }\end{array}$ & US\$ vessel ${ }^{-1}$ & 8.04 & 6.88 & 12.54 & 7.60 & 8.74 \\
\hline $\begin{array}{l}\text { - Share of } \\
\text { skippers and } \\
\text { mechanics }\end{array}$ & US\$ vessel ${ }^{-1}$ & 7.14 & 5.08 & 11.64 & 5.80 & 9.72 \\
\hline $\begin{array}{l}\bullet \quad \text { MSC } \\
\text { observer }\end{array}$ & US\$ vessel ${ }^{-1}$ & 0 & 0 & 0 & 0 & 0.03 \\
\hline $\begin{array}{l}-{ }_{\text {VDS }} \text { Cost of } \\
\end{array}$ & US\$ vessel ${ }^{-1}$ & 0 & 0 & 4.0 & 4.0 & 4.0 \\
\hline$\dot{V}^{\text {VMS }}{ }^{\text {Cost of }}$ & US\$ vessel ${ }^{-1}$ & 0 & 0 & 0.106 & 0.106 & 0.106 \\
\hline $\begin{array}{l}\text { Total variable } \\
\text { cost }\end{array}$ & US\$ vessel ${ }^{-1}$ & 18.78 & 19.16 & 31.89 & 24.71 & 29.80 \\
\hline $\begin{array}{l}\text { Gross margin } \\
\text { (in '000) }\end{array}$ & US\$ vessel ${ }^{-1}$ & 21.40 & 15.23 & 30.81 & 13.29 & 13.91 \\
\hline $\begin{array}{l}\text { Standard } \\
\text { deviation of } \\
\text { gross margin } \\
\text { (in'000) }\end{array}$ & $\mathrm{US} \$ \mathrm{mt}^{-1}$ & 5.08 & 17.84 & 16.94 & 6.72 & 6.73 \\
\hline $\begin{array}{l}\text { Coefficient of } \\
\text { variation of } \\
\text { gross margin } \\
(\%)\end{array}$ & & 0.24 & 1.17 & 0.55 & 0.51 & 0.48 \\
\hline
\end{tabular}


The output price data covers the monthly price of skipjack tuna from 2012 to 2014 (Atuna, 2014). In order to make consistent observations, skipjack prices were converted to 2014 US dollars using the Consumer Price Index (CPI) of the Bangko Sentral ng Pilipinas (Bangko Sentral ng Pilipinas, 2016). Table 4.3 shows the deflated monthly skipjack tuna prices, which exhibits fluctuation due to the influence of both quality and quantity of supply of fish in the market (Jeon et al., 2008). The deflated monthly skipjack prices were averaged to obtain the annual skipjack prices for the period 2012 to 2014. The average skipjack price for 2012-2014 is used in the model for all non-MSC compliant fishing. The price of MSC compliant free school skipjack is the average price plus the $15 \%$ price premium.

Table 4.3 The monthly skipjack prices for years 2012-2014 in US\$ using Bangkok price index, inflated to 2014

\begin{tabular}{lcccc}
\hline Months & $\mathbf{2 0 1 2}$ & $\mathbf{2 0 1 3}$ & $\mathbf{2 0 1 4}$ & Average \\
\hline January & 2203.6 & 2178.6 & 1430 & 1937.4 \\
February & 2151.4 & 2263.7 & 1250 & 1888.4 \\
March & 2144.9 & 2374.7 & 1200 & 1906.5 \\
April & 2351.3 & 2447.3 & 1250 & 2016.2 \\
May & 2315.9 & 2456 & 1400 & 2057.3 \\
June & 2369.8 & 2297.1 & 1750 & 2139.0 \\
July & 2426.3 & 1998.3 & 1800 & 2074.9 \\
August & 2425.7 & 1993.4 & 1850 & 2089.7 \\
September & 2518.0 & 2003.9 & 1350 & 1957.3 \\
October & 2305.3 & 2003.8 & 1170 & 1826.4 \\
November & 2062.7 & 1783.3 & 1170 & 1672.0 \\
December & 2035.9 & 1643.3 & 1150 & 1609.7 \\
Average & $\mathbf{2 2 7 5 . 9}$ & $\mathbf{2 1 2 0 . 3}$ & $\mathbf{1 3 9 7 . 5}$ & $\mathbf{1 9 3 1 . 2}$ \\
\hline MSC price (average & $\mathbf{2 6 1 7 . 3}$ & $\mathbf{2 4 3 8 . 3}$ & $\mathbf{1 6 0 7 . 1}$ & $\mathbf{2 2 2 0 . 7}$ \\
price + 15\% premium) & & & & \\
\hline Source: Atuna 2014 & & & &
\end{tabular}

Fishing revenues are calculated based on the daily skipjack catches and average prices (see Table 4.2). The cost of fuel is calculated based on ten face-to-face interviews by the first author with skippers (7) and mechanics (3) in Lae, PNG in 2014. The interviews include the fuel consumption of the vessel per fishing day using the FAD and free school fishing techniques (refer 
to Appendix I for more details). The fuel consumption of FAD fishing is on average 3,000 Liters (L) per fishing day, while fuel consumption for free school fishing is on average $6000 \mathrm{~L}$ per fishing day. The prices of fuel in 2012, 2013, and 2014 were US\$1.17 per L, US\$1.30 per L, and US\$1.12 per L, respectively (Department of Energy, 2016). The 2012 and 2013 fuel prices were inflated to 2014. The three year (2012-2014) fuel price is on average US\$1.20 per L. Therefore, the average fuel consumption of purse seine fishers using FAD fishing is US\$3600 per fishing day and the average fuel consumption for free school fishing is US\$7200 per fishing day.

The cost of labour is based on the traditional catch sharing system of the Philippine purse seine fishery (Vera \& Hipolito, 2006). In this sharing system, 20\% of the gross revenue goes to crews, while $25 \%$ of the net sales (gross revenue minus the costs of labour and fuel) go to skippers and mechanics. Interviews with skippers also revealed that skippers and mechanics on MSC compliant trips receive on average an extra $10 \%$ of the net sales. The fishing days in the EEZ cost US\$ 4,000 for the first 48 days, with additional fishing day costing US\$6,000. The cost of MSC observers is US\$30.60 per day based on 2014 figures, while the costs of the VMS in EEZ amounts to US\$109.24 per day in 2015 (equivalent to US\$ 106.8 in 2014) (Poseidon Aquatic Resource Management Ltd, 2016). The breakdown of these costs can be found in Appendix J.

Given the fishing revenues and total variable costs, the gross margins, standard deviation and the coefficient of variation of gross margins are calculated (Table 4.2). The gross margins for three years are the resulting skipjack prices in 2012-2014 multiplied by the annual skipjack catches in 2012-2014, minus the total variable costs in each year. It is notable that FAD fishing in the EEZ has the highest gross margin, while free school fishing in the EEZ has the lowest gross margin among the four fishing activities. FAD fishing in archipelagic waters has the lowest standard deviation among the four fishing activities. This is followed by the MSC and free school fishing in the EEZ. Overall, FAD fishing in archipelagic waters has the lowest coefficient of variation of gross margins. 
The next lowest coefficient of variation of gross margins (in ascending order) are MSC fishing in EEZs, free school fishing in EEZs, FAD fishing in EEZs, and free school fishing in archipelagic water.

The gross margins per fishing activity from 2012 to 2014 are used to calculate the variancecovariance matrix. In order to compute for the variance of gross margins, the gross margins over this time period are averaged for each fishing activity, and the deviations, which represent the individual gross margin of each fishing activity minus the average gross margin, are calculated. The variance in each fishing activity is the sum of the squared deviations divided by three. The covariance is the sum of the product of deviations of two fishing activities for three years, divided by three. Table 4.4 shows the variance-covariance matrix of gross margins with MSC. Values are the same for the variance-covariance matrix of gross margins without MSC, except for a one unit increase in covariance of FAD fishing in archipelagic waters and of free school fishing in the EEZ without MSC.

\subsubsection{Coefficient of absolute risk aversion}

This study derives the coefficient of absolute risk aversion $(\alpha)$ from the coefficient of relative risk aversion ( $\mathrm{Rr})$, which is a dimensionless value that corresponds to the level of risk averseness of an individual. The $R r$ takes the value of 0 (risk neutral person); 0.5 (hardly risk averse person), 1.0 (somewhat risk averse person), 2.0 (rather risk averse person); 3.0 (very risk averse person); 4.0 (extremely risk averse person) (Acs et al., 2009; Anderson \& Dillon, 1992). The coefficient of absolute risk aversion $(\alpha)$ is calculated by dividing the relative risk aversion (Rr) by wealth (D), represented by the owner's equity. The owner's equity is assumed to be US $\$ 1,700,000$ based on the average investment on a large-scale tuna vessel (Libre et al., 2015). Therefore, the value of the coefficient of absolute risk aversion ranges from 0 to 0.0000024 . 
Table 4.4 Variance-covariance matrix of gross margins (2012-2014) of Philippine-owned purse seine vessels flagged as PNG, with MSC (in '000)

\begin{tabular}{lcccc}
\hline & $\begin{array}{l}\text { FADs } \\
\text { Archipelagic } \\
\text { water }\end{array}$ & $\begin{array}{l}\text { Free school } \\
\text { Archipelagic } \\
\text { water }\end{array}$ & FADs EEZ & $\begin{array}{l}\text { Free school } \\
\text { MSC }\end{array}$ \\
$\begin{array}{l}\text { FADs archipelagic } \\
\text { water }\end{array}$ & 26 & 89 & 79 & 26 \\
$\begin{array}{l}\text { Free school } \\
\text { archipelagic water }\end{array}$ & 89 & 318 & 247 & 75 \\
FADs EEZ & 79 & 247 & 287 & 109 \\
Free school MSC & 26 & 75 & 109 & 45 \\
\hline
\end{tabular}

\subsubsection{Set up of the calculations}

The model was run for two situations. The first is the control, i.e. without the possibility of MSC free school fishing. In this situation the price of free school skipjack caught in the EEZ is the same as for the other three alternatives. The second situation includes the possibility of MSC free school fishing. The price for MSC fishing is $15 \%$ higher than the price for fish caught using FAD and using free school fishing in archipelagic waters. The observer costs and the extra incentive for skippers fishing in MSC are included. Both situations are run with different level of risk aversion of fishers in order to determine the effect of risk aversion on the level of the fishing activities and on total gross margin.

\subsection{Results}

The effect of MSC certification is determined by comparing the gross margins of fishers with and without MSC compliant fishing under the different levels of risk aversion (Table 4.5). The changes in the level of fishing activity of fishers are also presented with and without MSC compliant fishing. 


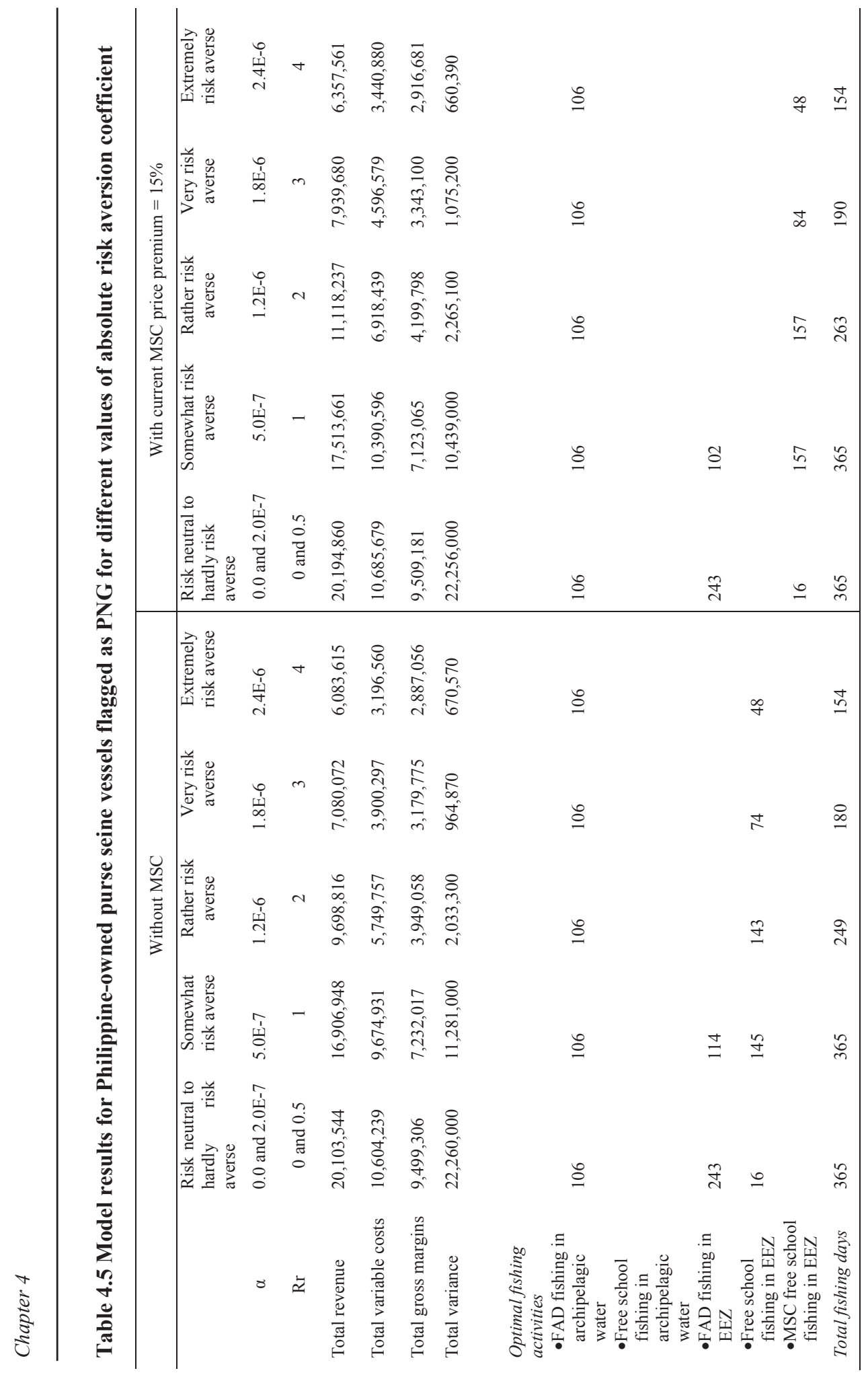


When fishers are not MSC compliant, the level of risk aversion affects their fishing activities, which in turn affects their total gross margin and total variance. The results show that risk neutral to hardly risk averse fishers will generate the highest gross margin and highest variance when they fish predominantly on FADs in both archipelagic waters and the EEZ, followed by a few days of fishing on free schools in the EEZ. In this case, the total available fishing days in archipelagic waters and FAD fishing days in the EEZ are completely utilized. Less risk averse fishers in general fully utilize available fishing days in archipelagic waters using FADs, while FAD fishing days in the EEZ reduce in exchange for free school fishing. When fishers are somewhat risk averse, the number of free school fishing days in the EEZ is higher than the number of FAD fishing days in the EEZ. When fishers are rather risk averse, FAD fishing in EEZ is no longer an option. Moreover, rather risk averse fishers only use 249 fishing days because the extra gross margin of an additional fishing day cannot cover the additional risk at this level of risk aversion. Very risk averse fishers continue to use their free school fishing in the EEZ at the level as extremely risk averse fishers. However, extremely risk averse fishers have the lowest total number of fishing days of fishers. The general observation drawn from these results is that with increasing level of risk averseness, gross margin and the variance decrease.

When fishers are MSC compliant their level of risk aversion affects the allocation of fishing effort and gross margin differently. Risk neutral to hardly risk averse fishers generate the highest gross margin when they fish most on FADs in archipelagic water and in the EEZ, followed by fishing using MSC compliant sets on free school tuna in the EEZ. Across all types of fishers, the available fishing days in archipelagic water using FAD fishing are used completely. When fishers are somewhat risk averse, FAD fishing days in the EEZ decline and are converted to MSC free school fishing days, ultimately at a higher allocation than FAD fishing days. The rather risk averse fishers maintain the same level of MSC fishing days in EEZ as the somewhat risk averse fishers and stop FAD fishing in the EEZ. The very risk averse and extremely risk averse fishers further reduce their 
MSC fishing days. The number of fishing days of extremely risk averse fishers is the lowest and similar to fishers who are not MSC compliant.

The comparison of fishing with and without the possibility of MSC compliant fishing as an incentive for allocating fishing effort reveals three further observations. First, the gross margins of fishers under different levels of risk aversion are generally higher when they are MSC compliant as compared to when they are not MSC compliant. Second, the number of FAD fishing days in the EEZ reduce and are converted to free school fishing in the EEZ when MSC is introduced. Vessels that are not MSC compliant do not reduce and convert FAD fishing effort to free school fishing effort. Third, none of the fishers change in effort allocated to FAD fishing days in archipelagic waters, including those who are MSC compliant. These observations indicate that overall MSC increases the revenues of fishers. However, in line with PNA regulations and the conditions of the MSC certification, MSC only incentivises a shift from FAD to free school fishing in the EEZ and not in archipelagic waters.

\subsection{Discussion}

\subsubsection{Validation of results}

The results of the model appear to be consistent with the existing practices of Filipino fishers in PNG waters. Based on the model results, FAD fishing in archipelagic water is the most preferred option by Filipino fishers across all different levels of risk aversion. As reflected in reality, the fishing effort of Filipino fishers are mainly concentrated in archipelagic waters using FADs (Pilling et al., 2014; Western and Central Pacific Fisheries Commission, 2015b). This has a dual explanation. First, fishers have essentially 'free access' to PNG's archipelagic waters given their investment in domestic processing capacity. Second, two Philippine-owned fishing companies own $88 \%$ of the FADs deployed in archipelagic waters of PNG between 1998 and 2012 (Pilling et al., 2014). 
The model also shows that Filipino fishers tend to increase their allocation of free school fishing days when they are MSC compliant. This is consistent with practice based on the increasing level of free school fishing observed in the PNG EEZ - and supported by PNA measures to support MSC compliance (Usu et al., 2012). Moreover, as validated by interviews, fishers increase their allocation of MSC free school fishing days during the seasonal FAD closures. To maximise catches during this closure Filipino fishers hire Koreans and Japanese skippers to educate and improve their free school fishing skills and use helicopters and advanced GPS tracking device to efficiently fish in free schools (Tolentino-Zondervan et al., 2016a). This in turn could suggest Filipino fishers might be in general less risk averse, giving further weight to the positive influence of MSC certification on free-school effort allocation.

\subsubsection{Risk aversion and allocation of fishing days of fishers}

The key result is that the level of risk aversion influences the allocation of fishing days, which in turn determines the extent to which the fishery as a whole will see a transition to more sustainable fishing practices. If a fishery is made up of risk neutral and/or hardly risk averse fishers, a greater effort allocation yielding the highest gross margins should be expected. In the case of the PNA this translates to predominant allocation of fishing effort to FADs in the EEZ followed by FADs in archipelagic water. Consequently there is minimal effort allocation to MSC compliant fishing by these types of fishers (see Table 4.5). Conversely, if a fishery is made up of less risk averse fishers, it should be expected that FAD fishing effort will be reduced and converted to MSC compliant free school fishing.

The results show that somewhat risk averse fishers convert 12 days from FAD to MSC compliant free school fishing in the EEZ. This corresponds to $3.3 \%$ of the total fishing effort of Filipino fishers over a one year period. However, over the same period there is no conversion of FAD fishing days in archipelagic water to MSC fishing by any category of fishers. The choice of fishers 
to allocate days to FAD fishing in archipelagic waters is because this fishing practice has the lowest coefficient of variation of gross margin (see Table 4.2) and variance (see Table 4.4) among the four fishing activities.

Finally, if a fishery is made up of more risk averse fishers, the result will be the persistence of nonMSC compliant FAD fishing in archipelagic waters and a lower allocation of effort to MSC compliant fishing practices. Given the different allocation decisions of fishers at different levels of risk aversion, this study clearly demonstrates that in a multi-gear fishery fishers should not be seen as one homogenous group. By identifying the level of risk aversion of different groups of fishers operating in a fishery, managers will be able to predict the likely effect of incentive based mechanisms like the MSC before its implementation.

\subsubsection{Effectiveness of MSC as incentive mechanism}

The MSC appears to be effective in motivating fishers to increase their allocation for free school fishing in the EEZ - the specified area of application. It therefore appears that the price premium for MSC compliant landings incentivises fishers to change their fishing practices. However, this price premium is not large to incentivise fishers to allocate effort currently allocated to FAD fishing in the archipelagic waters to MSC compliant free school fishing in the EEZ. In order to increase the fishing effort allocated both from FAD fishing in the EEZ and archipelagic waters, both the average gross margin would therefore need to be increased while the variance of gross margin would need to be reduced. This may already be observed in reality. Since the 2016 certification of free-school yellowfin tuna in the EEZ of the PNA, fishers appear to have both increased the probability of a higher overall gross margin as well as reduced the variance in gross margin (PNA, 2016). The certification of two free school fisheries may therefore reinforce the influence of MSC to incentivise an overall shift away from FAD fishing in both the EEZ and archipelagic waters. 
In line with the wider literature, the results also show that the success of MSC as a market-based incentive mechanism is dependent on both government regulation and market incentives (see for example Grafton et al., 2006; Mansfield, 2006). The four months FAD-closure in the PNA EEZs and limits on fishing in archipelagic waters enable fishers under different levels of risk aversion to choose for MSC free school fishing. However, FAD fishing in archipelagic water and in EEZ remains a key component of the daily operation of risk neutral and hardly risk averse fishers. Moreover, the FAD fishing in archipelagic water is the main choice of all fishers across different level of risk aversion. It therefore appears that without regulation limiting fishing days in archipelagic water, fishers will continue to prefer fish using FADs in archipelagic waters over the MSC free school fishing in EEZ. Similarly, limiting the use of FADs in the EEZ enables risk neutral and hardly risk averse fishers to fish using MSC free school. Therefore, the role of regulation in driving fishers to voluntarily comply with the MSC requirements should be recognized, since it appears that economic incentives alone are not enough to shift fishers to do more sustainable fishing practices.

It is notable, however, that the overall increase of both MSC and non-MSC compliant fishing effort in the PNA will place greater pressure on fishing stocks. The currently increased in capacity of fishing vessels that are doing MSC fishing in PNA puts pressure on skipjack and yellowfin tuna stocks (PNA, 2016), and therefore could undermine the MSC's principle of promoting sustainable fish stocks. To ensure that the goal of the MSC certification is ultimately met, the government must continuously monitor the change in fishing effort as well as stock status. A regulation is also necessary to address the discrepancy in the number of active vessels fishing, which this study uses in the model, and of registered vessels. The actual efforts of fishers may be more or may be less than the projected fishing effort, thus government regulations will resolve the issue of inactive vessels. 


\subsection{Conclusion}

This study shows the effects of MSC certification on the allocation of fishing effort in response to levels of gross margin and the risk aversion of Philippine purse seine fishers. Three conclusions can be made based on the findings of this study. First, the MSC is to some degree effective in incentivising a shift from one fishing practice to another by converting FAD fishing days in EEZ into MSC free school fishing in the EEZ. Second, the extent to which the current price premium of MSC incentivizes fishers is dependent on the degree of risk aversion of fishers. And third, both government regulations and the market incentive working together are necessary for MSC to effectively work as an incentive mechanism.

Fisheries employing MSC certification should take into account not only income but also the risk attitude of the fishers to determine the extent they are willing to change their fishing practices. Fishery managers that are involved in the application of MSC certification must therefore match the expected price premiums with the expected risk of these fishers. Only then can they increase the potential impact of incentive mechanisms such as the MSC to instigate transitions in fishing practices across a large enough number of fishers. Consequently the government must continuously monitor the effort of fishers for doing MSC fishing and the effect of this effort on the fish stocks. Future research may extend to the effect of risk aversion of short-term decisions to the long-term decision making of fishers in response to MSC and/or other incentive mechanisms. 


\section{Chapter 5}

\section{Profitability of investments associated with the adoption of private incentive mechanisms by Filipino purse seiners}

A modified version of this chapter will be submitted to a journal as Tolentino-Zondervan, F. Berentsen, P. Bush, S.R., and Oude Lansink, A. Profitability of investments associated with the adoption of private incentive mechanisms by Filipino purse seiners. 


\subsection{Abstract}

Private incentive mechanisms for promoting fisheries assume win-win outcomes for both fish and fishers. However, the economic return to fishers complying with these mechanisms remains unclear. This study assesses the economic benefits of complying with the International Seafood Sustainability Foundation's (ISSF) requirements for eco-FADs and the Marine Stewardship Council's (MSC) requirements for free school fishing by Filipino purse seine fishers with different level of risk aversions. Returns were calculated based on the Net Present Value (NPV) of investing in both ISSF and MSC compliance. The results show that investing in both ISSF eco-FADs and MSC certified free school fishing is the most profitable outcome for fishers with low risk aversion, but that MSC is the most robust investment option to fishers' with varying degree of risk aversion. Fishers with low risk aversion will have the highest return on investment, and the probability of a positive NPV decreases as the risk aversion of fishers increases. The paper concludes that increasing the adoption of private incentive mechanisms requires active risk reduction strategies such as future contracts, floor prices, and flexible taxation schemes. Only then will more risk averse fishers decide to participate in the programs, which in turn will contribute to the overall sustainability of a fishery.

Keywords: Filipino, International Seafood Sustainability Foundation, Marine Stewardship Council, Net Present Value, purse seine fishery 


\subsection{Introduction}

Purse seining is the most dominant fishing practice in the Western and Central Pacific Ocean (WCPO) skipjack tuna fishery by both volume and value. Conventional purse seining uses drifting and anchored Fish Aggregating Devices (FADs) to increase the catchability of tuna (Itano, 2007). However, FADs remain controversial because also they increase the catch of non-target juvenile yellowfin and bigeye tunas, two of the most valuable tuna species in the WCPO at maturity, as well as threatened and endangered marine organisms (Fonteneau et al., 2000). In addition, FADs have been linked to marine pollution (Ocean Studies Board, 2012).

In pursuit of the sustainable exploitation of skipjack tuna a series of effort controls have been implemented on FADs by regional fishery management regimes in the WCPO, including seasonal closures and vessel day limits (Gilman \& Lundin, 2010). However, a number of 'private' incentive mechanisms controlled by non-state actors have also emerged in support of these state measures and in response to market demand for sustainable seafood. They include third party certification, industrial coalitions and fishery improvement projects (Kirby et al., 2014; Tolentino-Zondervan et al., 2016b). Two main private incentive mechanisms used to improve the sustainability of purse seine tuna fisheries in the WCPO, and at the same time create marketable sustainability claims, are the Marine Stewardship Council's (MSC) certification of free school fishing and the International Seafood Sustainability Foundation's (ISSF) programme to develop so called eco-FADs .

Academic research has reviewed the effect of private incentive mechanisms on fishing practices (e.g. Costello et al., 2010; Pérez-Ramírez et al., 2012a; Yeeting et al., 2016), including quantitative assessments on fisher income (Msomphora \& Aanesen, 2015; Tolentino-Zondervan et al., 2017; Wakamatsu, 2014). Other studies have investigated the transmission of price premiums of incentive mechanisms to fishers (Blomquist et al., 2015; Goyert et al., 2010; Uchida et al., 2014), while others still have focused on the capabilities, challenges, and opportunities of developing 
country fishers to adopt private incentive mechanisms (Gulbrandsen, 2009; Ponte, 2008b; Tolentino-Zondervan et al., 2016a). However, none of these studies has quantitatively assessed the required level of investments for fishers in private incentive mechanisms, nor the profitability of their investments given the number of fishing days allocated to different available fishing methods.

This study fills this knowledge gap by assessing the profitability of investments in private incentive mechanisms. In doing so it contributes to a clearer understanding of the 'business-case' for improving the sustainability of fishing practices. The analysis uses Net Present Value (NPV) as a method for evaluating investment options (Myers, 1984). The model for calculating NPV compares the outcomes for fishing strategies of fishers with different levels of risk aversion and includes the uncertainty by allowing for stochasticity of catches, prices, and several types of costs. The four investment options by fishing companies included in the analysis are: (1) ISSF compliant eco-FADs, (2) MSC compliant free school fishing, (3) both eco-FADs and MSC free school fishing, and (4) business-as-usual. This research also limits the scope of analysis to Filipino fishing companies who have a license agreement to access Papua New Guinea (PNG) waters as a Distant Water Fishing Nation (DWFN). The focus on Filipino fishing companies in PNG is because they use both FAD and free school in purse seine fishing and have both the possibility to voluntarily employ ISSFs programme for eco-FADs and be a compliant with MSC free school fishing (see TolentinoZondervan et al., 2016a).

The following outlines ISSF's recommendations for eco-FADs and the criteria for MSC free school certification of the Parties of the Nauru Agreement (PNA) that includes PNG. The NPV method is then outlined, as well as the data required and the Monte Carlo simulation used to capture uncertainty in the NPV calculation. We then present the results before turning to a discussion of the profitability of investment in incentive mechanisms. Conclusions are drawn on factors that can influence investment strategies given returns on shifting to more sustainable fishing practices. 
Finally, recommendations are given to encourage greater voluntary participation of fishers in these incentive mechanisms.

\subsection{The participation of Filipino purse seine fishers in private incentive}

\section{mechanisms}

Filipino fishers operating under a Philippine flag in the waters of the PNA do so under bilateral access agreements. In 2014 there were 36 Philippine DWFN vessels registered in the PNA. These fishers can voluntarily participate in ISSFs eco-FAD programme as well as fish in compliance with the MSC free school certification. Both ISSF and MSC offer different incentives, but also require different levels of investment to realise the technical changes needed to move away from the 'business as usual' mode of FAD fishing.

\subsubsection{International Seafood Sustainability Foundation (ISSF)}

The ISSF was formed in 2009 through a coalition of major seafood industries and World Wide Fund for Nature. One of its core goals is to promote the sustainability of FAD fisheries (International Seafood Sustainability Foundation, 2017). Fishers are incentivised to voluntarily adopt ISSF recommendations through priority sourcing by ISSF member processors, who make up $75 \%$ of the worlds canned tuna, an assumed price premium for tunas caught on eco-FADs, and free enrolment of vessels on a 'pro-active vessel registry' maintained by ISSF. This study assumes a 10\% price premium based on the average premium given to producers for sustainably caught skipjack tuna, such as on fair trade tuna (Campling \& Havice, 2015), MSC free school tuna (Adolf et al., 2016), and pole-in-line caught tuna (Barclay, 2015). To facilitate wider uptake of their programme the ISSF has invested US\$ 3.6 million in 2014 in research on the design of eco-FADs that are nonentangling and/or are made from biodegradable materials (see Figure 5.1) (International Seafood Sustainability Foundation, 2014a). 


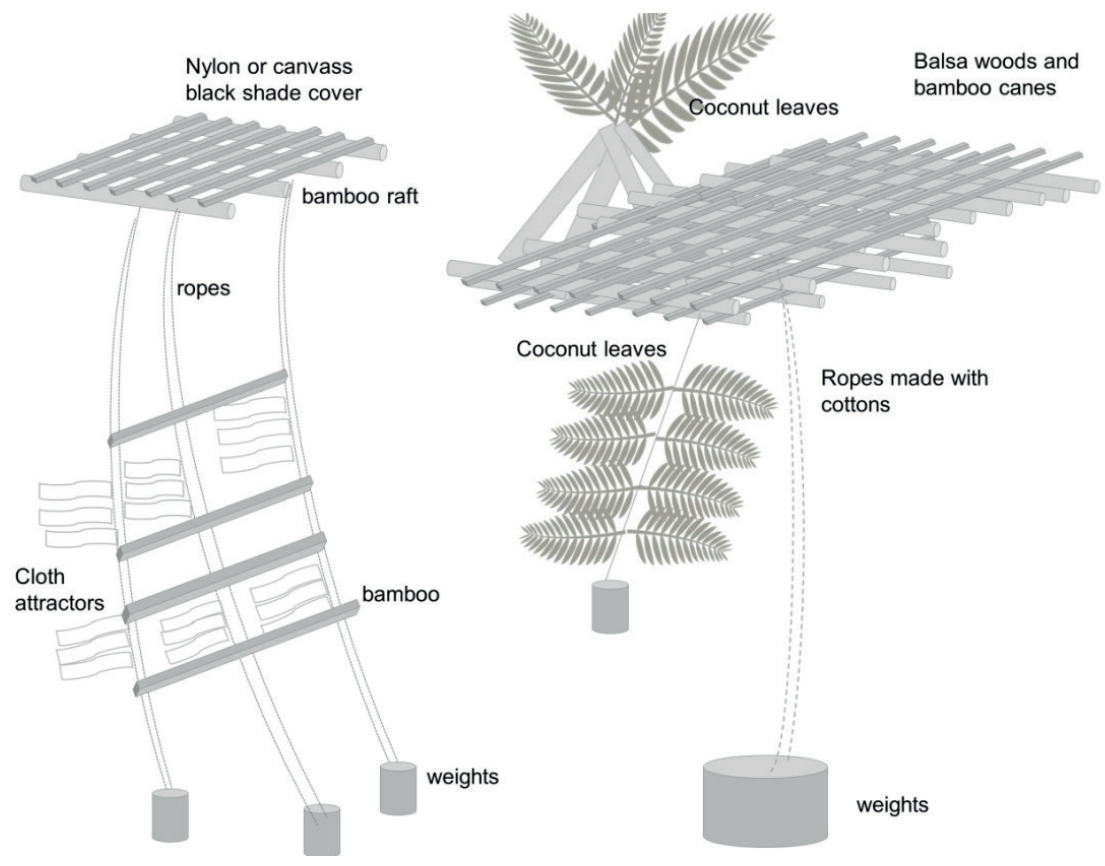

Figure 5.1 An example of FAD that uses non-entangling design (left picture) and of FAD that uses biodegradable materials (right picture)

Non-entangling FADs (see Figure 5.1) do not use nets that are prone to trapping non-target species such as turtles and sharks (see Figure 5.2 for reference) (Goujon et al., 2012; International Seafood Sustainability Foundation, 2012b; Moreno et al., 2016b). These designs are currently only used for drifting FADs (dFADs), a non-stationary type of FAD deployed in oceanic area that is tracked by satellite. Entanglement is less of an issue for anchored FADs (aFADs), which are stationary floating objects most often deployed in archipelagic waters (Itano et al., 2004). Biodegradable FADs are made with bamboo, palm leaves, cottons, coconut fiber, and yute with the aim of eliminating marine litter and pollution (MRAG, 2017). The use of biodegradable materials is currently accepted in aFADs since they are easier to monitor and maintain. There is less acceptance for biodegradable 
materials in dFADs due to their shorter lifetime and the cost of biodegradable materials, which is twice that of standard materials like plastic and nylon (MRAG, 2017).

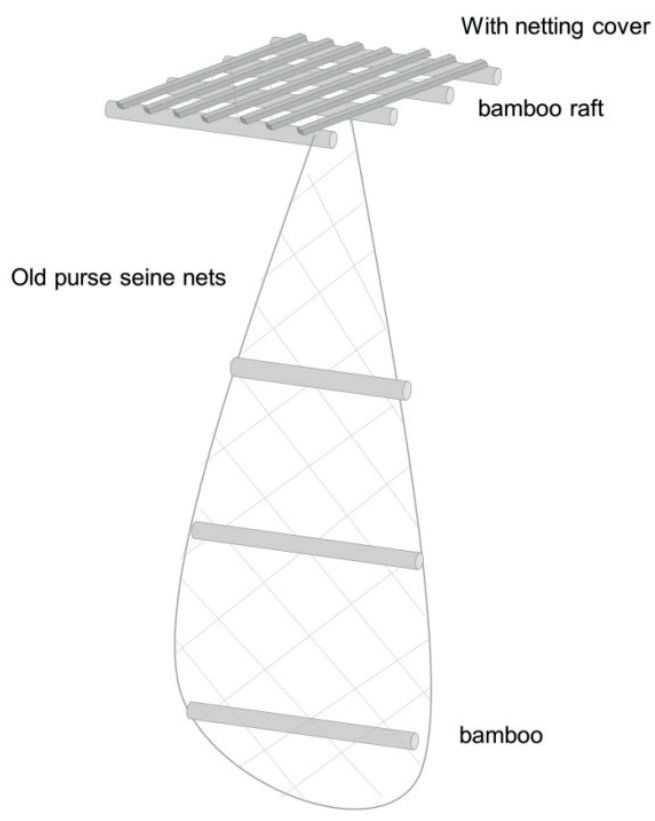

Figure 5.2 An example design of non-entangling FAD that uses nettings (from old purse seine nets)

\subsubsection{Marine Stewardship Council (MSC)}

The MSC certifies fisheries against their three principles, which focus on the sustainability of fish stocks, minimisation of environmental impacts associated with fishing, and the demonstration of an effective management system (Marine Stewardship Council, 2014a). The PNA obtained its MSC certification for skipjack caught in free schools in their EEZ waters in December 2011 (Marine Stewardship Council, 2012). 
The PNA, through their commercial partner Pacifical, incentivises fishers to participate in MSC compliant fishing through a $20 \%$ price premium, which is divided between the fishing company (10\%), cannery (5\%), and the PNA (5\%) (Adolf et al., 2016; Yeeting et al., 2016). The PNA secretariat further supports certification of the free school fishery in two ways. First, by investing in the MSC assessment, which is assumed here to be at the upper bound of assessment costs at around US\$500,000 (PNA, 2013). Second, by investing in electronic fisheries information system, including a Vessel Monitoring System (VMS) for tracking fishing vessels, MSC observers, and a catch documentation scheme, all of which are valued at US\$1.58 million (Poseidon Aquatic Resource Management Ltd, 2016).

In order to participate in MSC compliant free school fishing, Filipino fishers need to upgrade their vessel engines to improve chasing free school tuna and make technological investments that can potentially improve free school fishing such as on: (1) bird radar to detect birds that associate with school of tuna at a distance of 20-24 miles; (2) fish finder to locate the position of school of fish; and (3) depth sonar radar to analyse fish composition when fishers are near the school of fish.

\subsubsection{Strategic decisions for Filipino fishing companies}

Investment decisions are normally made at fishing company level (Libre et al., 2015). ${ }^{*}$ However, we assume that investment decisions are made at the vessel level since there are no economies of scale at a fishing company level when investing in compliance to incentive mechanisms like ISSF or the MSC. The rationales for this assumption are that (i) the investments of fishers are related on a per vessel basis and (ii), the investments at the fishery level, and therefore shared among vessels, are provided by the state. The investment options for fishers are considered to be mutually independent, meaning that accepting one investment does not affect the acceptance or rejection of

\footnotetext{
*Assessing the investment related to adoption of private incentive mechanisms by fishers can be done using either the private or societal perspective. This study takes the private perspective, which includes the investment, benefits, and costs made by fishers. The societal perspective includes investments, benefits, and costs made by the society that includes fishing company and government.
} 
other investments. In practice, vessel skippers have the freedom to employ different fishing techniques, such as FAD and free school fishing, at different fishing grounds during the year (Tolentino-Zondervan et al., 2017). Therefore, the possibility of adopting the two incentive mechanisms that targets FAD and free school fishing at the same time is feasible.

Assessing the profitability of the two incentive mechanisms determines whether the mechanisms have the potential to improve the financial performance of a fishing company. In case both investments are not profitable, rational fishers will maintain their current business operation. In the case a single investment or the two investments combined are profitable, the investment option that has the highest profitability is the recommended option for a fishing company.

\subsection{Materials and methods}

\subsubsection{NPV and Equivalent Annual Profit (EAP) Approach}

NPV is used to assess the profitability of investments in ISSF's recommended eco-FAD designs and compliance to MSC free-school. Due to the different life cycles of these investments their NPVs are made comparable by bringing them back to Equivalent Annual Profits (EAP).

The NPV is the difference between the present value of cash inflows and the present value of cash outflows. All projects that have a positive NPV are profitable and are recommended to be accepted. The formula for calculating NPV is followed from Barry et al. (2000) and Kay et al. (1994) and is presented as:

$$
N P V=-I N V+\sum_{t=1}^{T} \frac{N C F_{t}}{(1+i)^{t}}+\frac{V_{T}}{(1+i)^{T}}
$$

The INV is the initial investments, NCF is the net cash inflow during the period t, which is yearly additional fishing revenues generated from the investment in incentive mechanism minus annual 
additional operating cash expenses, $i$ is the discount rate, and $\mathrm{V}$ is the terminal value based on the life cycle of investments made on private incentive mechanisms.

The formula to calculate the EAP is:

$$
\mathrm{C}=\frac{i(N P V)}{1-(1+i)^{-n}}
$$

where $\mathrm{C}$ is the equivalent annual profit cash flows, NPV is the net present value, $i$ is the discount rate, and $n$ is the number of periods.

\subsubsection{Data}

Calculating the NPV requires information on the level of investment, cash inflows and cash outflows, the discount rate, and the terminal value of investment. The data collection is a combination of primary and secondary data. Primary data include interviews with five experts on sustainable FADs in 2017 and with 10 skippers and mechanics in PNG in 2014, and 55 skippers survey in General Santos in 2013-2014. Secondary data involve scientific literature, technical reports, and websites of government, tuna industry, and NGOs like MSC and ISSF.

NPV is calculated for fishers with different levels of risk aversion based on Tolentino-Zondervan et al. (2017). 'Somewhat risk averse' and 'very risk averse' classifications are used from that study to demonstrate the effect of risk aversion on the NPV. Somewhat risk averse fishers have a higher number of fishing days (208 FAD fishing days and 157 free school fishing days) than very risk averse fishers (106 FAD fishing days and 84 free school fishing days). Tables 5.1 and 5.2 summarise the cost and revenues which are needed for the computation of the NPV for eco-FADs and for MSC free school for initial year 2015. 


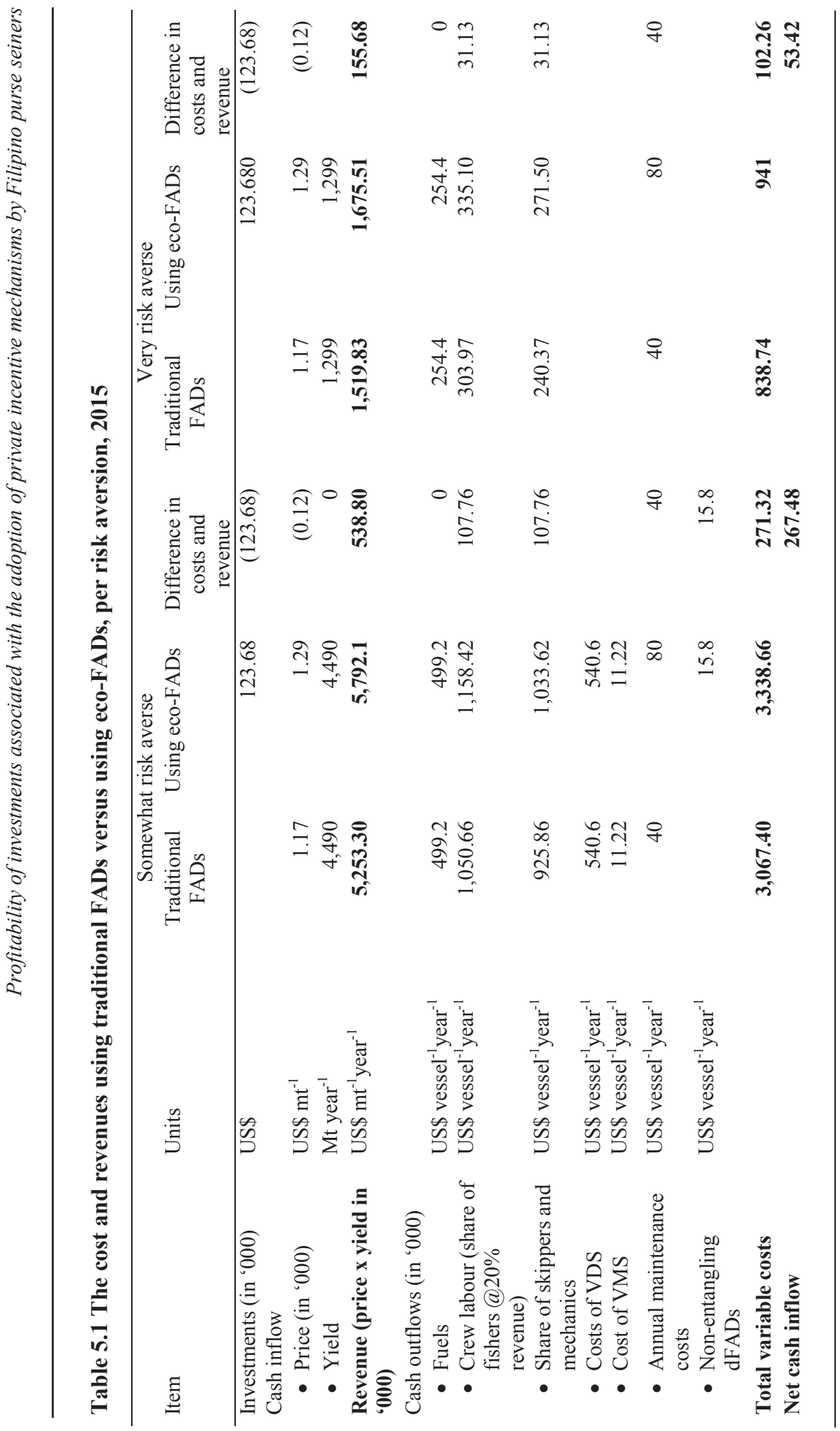




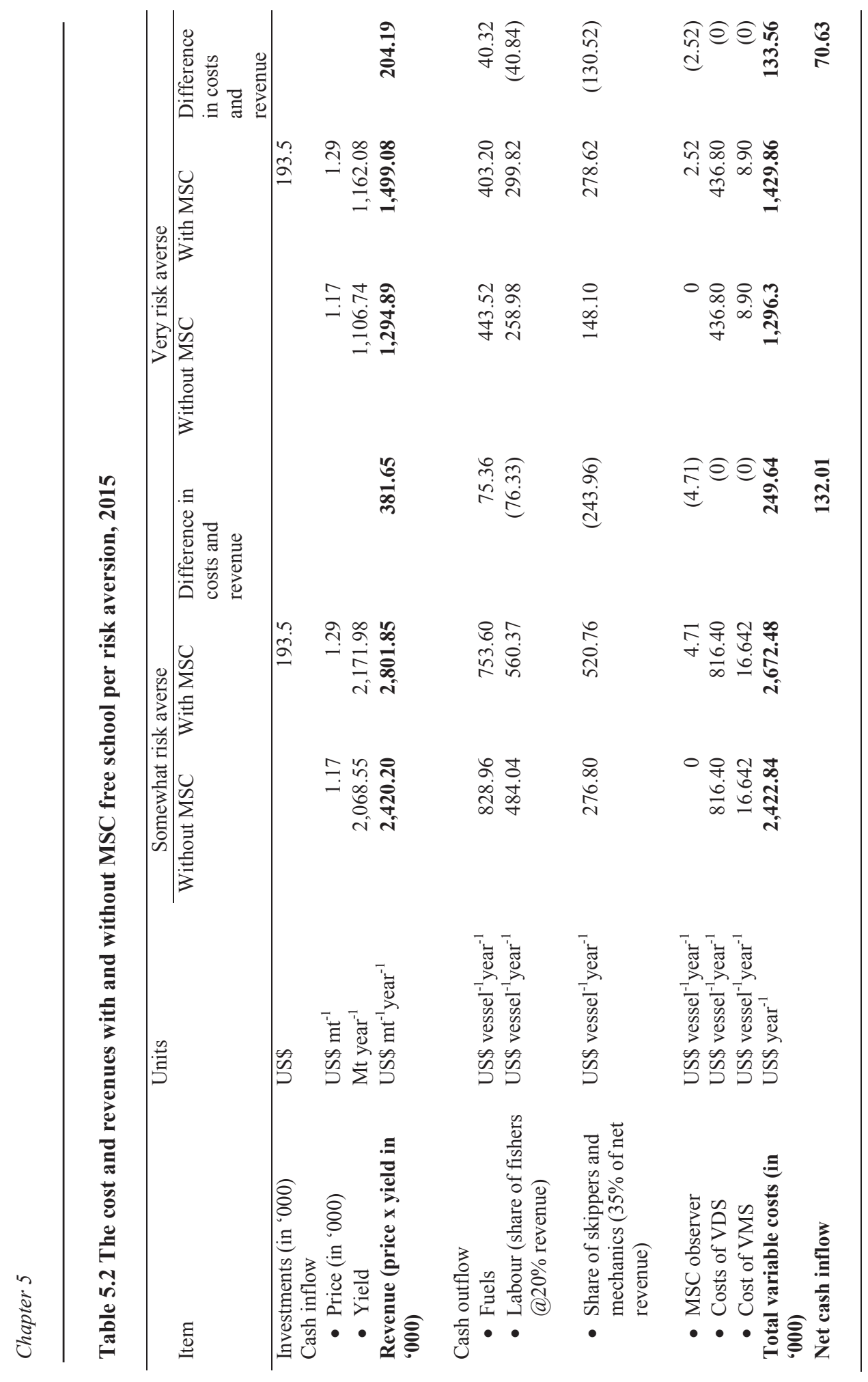




\subsubsection{ISSF eco-FAD investment}

The two types of eco-FADs promoted by ISSF have different lifespans. Non-entangling dFADs last for less than a year and biodegradable aFADs are usable for two years. Only investments with duration of more than one year are considered in this study, meaning that investments in biodegradable aFADs will be incorporated in the model, while non-entangling dFAD will be considered as annual costs. The investment for a biodegradable aFAD is twice as large as the investment required for a traditional aFAD (MRAG, 2017); the latter amounting to US\$3,092 based on data from fishers in General Santos in the Philippines. A purse seine vessel is allowed to have a maximum of 40 FADs, making the costs of transition to biodegradable aFADs to US\$123,680 per vessel.

The cash inflow from ISSF eco-FADs is the difference in revenue between using traditional FADs and ISSF recommendations for eco-FADs. In order to arrive at the cash inflow, multiple steps are taken. First, the price of regular skipjack tuna is projected for years 2016-2017 (Figure 5.3) based on a linear trend line from the average monthly skipjack prices from 2010-2015 (Atuna, 2014). Second, the price for skipjack caught on eco-FADs was calculated by adding $10 \%$ to the projected prices of regular skipjack tuna. Third, FAD catches from 2010-2015 from the Western and Central Pacific Fisheries Commission (Western and Central Pacific Fisheries Commission, 2016) were plotted and were fitted in a trend line, which is used to obtain the equation and to predict skipjack catches of 2016 and 2017 (refer to Figure 5.3). Based on interviews with experts and from Goujon et al. (2012), catches from both traditional and eco-FADs are considered equal. Fourth, yearly revenues were calculated for both using traditional and eco-FADs, by multiplying the product of skipjack catches and prices on the number of FAD fishing days allocated per year (TolentinoZondervan et al., 2017). 

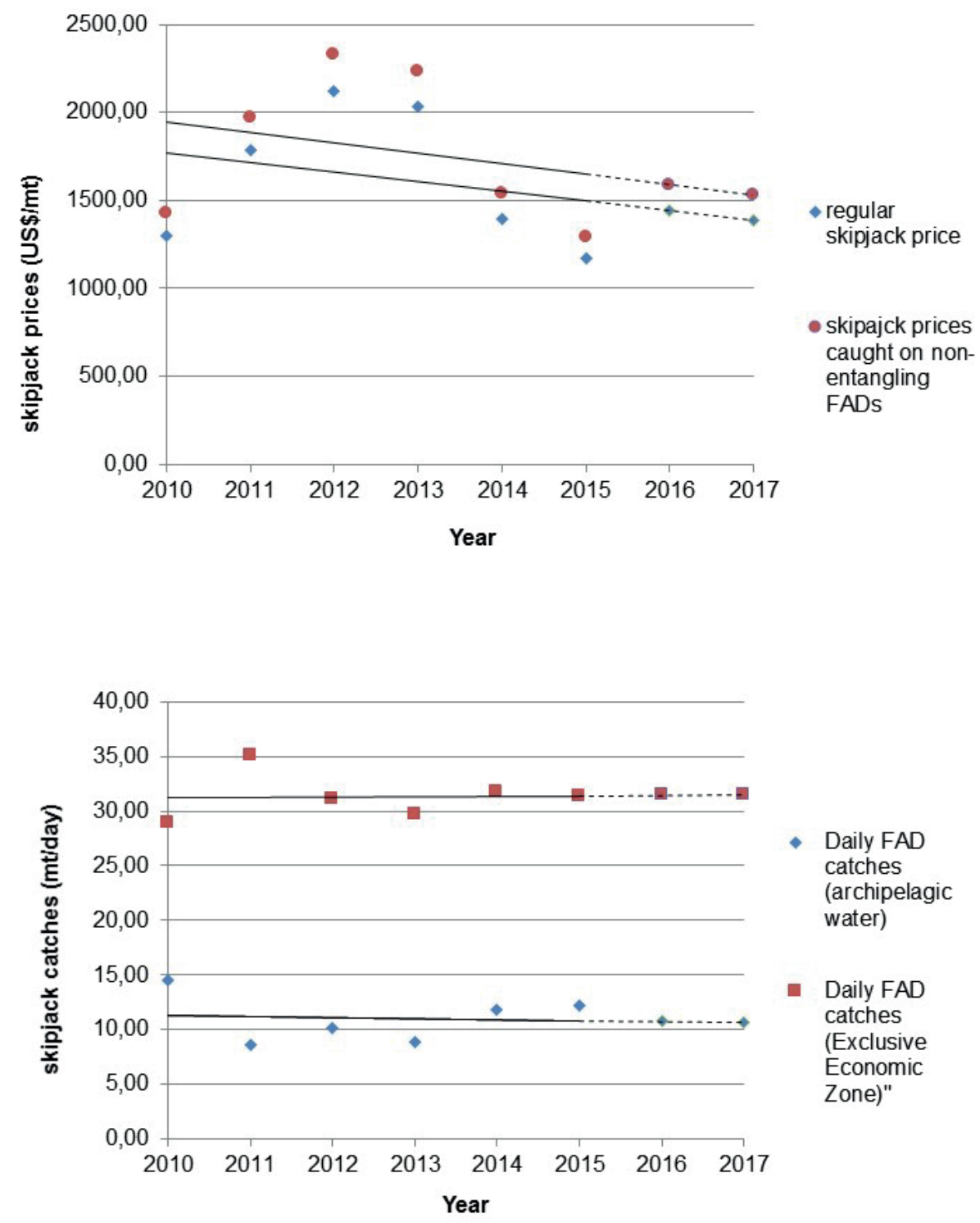

Figure 5.3 Projection of regular skipjack prices and skipjack prices caught on eco-FADs (top) and of skipjack catches using FADs in archipelagic and EEZ waters (bottom), 2016-2017 
Cash outflow was then calculated as the difference in total yearly costs of traditional versus nonentangling dFADs and biodegradable aFADs. The variable costs for fishing operation include (1) daily fuel costs at US\$2,400 (3,000L*US\$0.80/L) (Tolentino-Zondervan et al., 2017); (2) costs of labour (20\% of revenue) (Vera \& Hipolito, 2006); (3) share of skippers and mechanics (25\% of net revenue that is total revenue minus fuel and labour costs); (4) cost of a fishing day under the VDS estimated at US\$5,200 per day based on 30\% yearly growth rate of VDS (Les \& Clark, 2014); and (5) variable costs of VMS assumed to be US\$0.11 per fishing day (Tolentino-Zondervan et al., 2017). The variable costs related to FADs consist of two items. First, twice yearly repair and maintenance of biodegradable aFADs valued at US\$80,000 per year (US\$1000 per aFAD $\times 40$ aFADs $\times 2$ times per year) (Sharp, 2011). Second, improvements to non-entangling dFADs, which amount to US\$15,250 per year based on the difference in cost of non-entangling dFAD (US\$184) and of old entangling dFAD (US\$31) (Goñi et al., 2015), multiplied by the average dFAD usage per vessel of 100 dFADs per year (Morgan, 2011 p.p.2; Scott G. P. \& Lopez, 2014).

Investment in ISSF is assumed to be financed by the private equity of fishers' since the level of investment is relatively small compared to the yearly income generated by a Filipino purse seine vessel (Cruz-Trinidad, 2003). Following this assumption, the discount rate, which is subjective and varies per fisher, is assumed to be $10 \%$ in this study based on the consensus on required return on investment of fishers on sustainable fish (Lallemand et al., 2016). The investment is assumed to be fully depreciated after two years.

\subsubsection{MSC free school compliant participation}

Investment in MSC compliant fishing amounts to US\$193,395. This figure includes (1) an estimated US\$150,000 investment in upgrading the engine capacity of vessels to at least $2500 \mathrm{HP}$ $(2237.1 \mathrm{~kW})$ in order to efficiently move with free school tuna (World Wide Power Products, 2017); (2) investment in a bird radar estimated at US\$ 34,000 (based on interviews with vessel mechanics); 
(3) a fish finder estimated at US\$2,400 (Furuno brand); and (4) a scanning sonar valued at $\$ 6,995$ (Boating Magazine, 2001).

The cash inflow derived from MSC compliant fishing is calculated as the difference in revenues from yearly skipjack catches using upgraded engine and fishing technologies (receiving the nonMSC landing price with a $10 \%$ premium) minus the revenues from yearly skipjack catches using old vessel engine. The method for calculating cash inflow for ISSF eco-FADs is also employed for the MSC compliance. First, the trend line equation for regular skipjack prices in ISSF case is extended for years 2016-2020 to project the prices for non-MSC compliant fishing (see Figure 5.4) using the average annual skipjack prices from 2010 to 2015 (Atuna, 2014). The trend line equation obtained above is extended to the period 2016-2020 (see Figure 5.4). Second, the price for MSC caught skipjack tuna is calculated by adding an additional $10 \%$ to the projected prices of regular skipjack tuna. Third, daily free school catches of a DWFN Philippine vessels are predicted based on the yearly free school skipjack catches from 2010-2015 (Western and Central Pacific Fisheries Commission, 2016). Similar to skipjack prices, the daily free school skipjack catches were fitted in a trend line (in Figure 5.4) to determine the trend line equation for 2016-2020. Catches for vessels without an improved engine and free school fishing technologies is used as the basis of this calculation. It is assumed that renovated vessels have a 5\% increase in free school catch (Tidd et al., 2015). Finally, vessel revenues are calculated based on fishing days used for MSC free school fishing (see Table 5.2). 

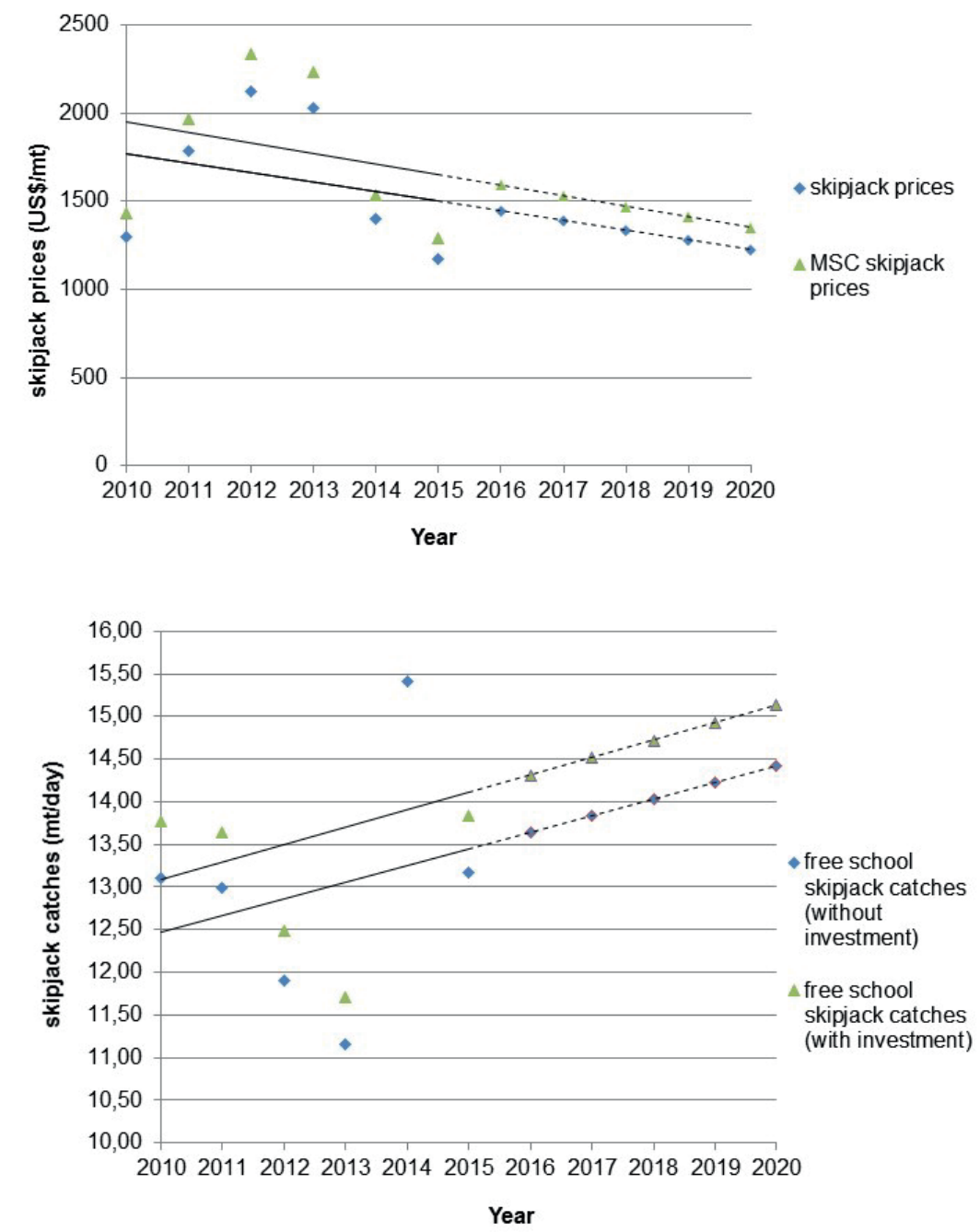

Figure 5.4 Projection of skipjack prices without and with MSC (top) and of free school skipjack catches for vessels with old engine and with upgraded engine (bottom), 2016-2020

The cash outflow for MSC compliant vessels is calculated as the difference between the variable costs for upgrading a vessel engine and fishing technologies and the costs incurred by preinvestment vessels (see Table 5.2). The variable costs follow from the costs of fishing operation outlined for the ISSF eco-FADs, with three modifications. First, the costs of fuel for free school 
fishing (with MSC) is assumed to be US $\$ 4,800 /$ day, based on $6,000 \mathrm{~L}$ fuel consumption on free school and US\$0.80/L fuel price in 2015. However, upgrading a vessel engine reduces fuel consumption by a reported $10 \%$ (Notti \& Sala, 2012), meaning the fuel price without MSC is US\$5280. Second, the share of skippers and mechanics on MSC compliance vessels is $35 \%$ of net revenue (Tolentino-Zondervan et al., 2017), or 10\% higher than FAD and non-MSC regular free school fishing. Third, the costs of MSC observer is US\$30/fishing day (Tolentino-Zondervan et al., 2017).

The assumed discount rate is similar to the case of ISSF, which is $10 \%$, based on the required return on investment of fishers on sustainable fish. The terminal value in the case of MSC is based on an assumed 5-year lifecycle of the vessel engine. The initial year for investment in MSC compliant fishing is 2015 , with the projection covering the renewed certification period of the fishery from 2016 to 2020.

\subsubsection{Investment in both ISSF's sustainable FADs and MSC free school}

The NPV of the combined investments in ISSF's eco-FADs and MSC free school are calculated based on the investments, prices, catches, costs, and discount rate for these two mechanisms. Combining these two investments required finding the least common multiple years for the two year time horizon of ISSF eco-FADs and five years horizon of MSC certification. This makes the time horizon of combined investments ten years. The investment for eco-FADs is then made every two years while for MSC free school fishing is made every five years. The projections for prices, catches, and costs are also extended for the period of 10 years from 2016 to 2025 .

\subsubsection{Monte Carlo Simulation}

To incorporate the uncertainty of revenues, initial investments, and operating expenses used in the NPV calculation, a Monte Carlo simulation is applied using @RISK in Excel. First, the type of 
distribution for all uncertain variables was assigned, as shown in Table 5.3. A normal distribution was used for evaluating uncertainties on time series data such as skipjack prices and catches. The standard deviations for both catches and prices based on historical data from years 2010-2015 (Western and Central Pacific Fisheries Commission, 2016) were 0.36 for prices and 219.02 for catches in the ISSF case, and 0.36 for prices and 173.73 for catches in the MSC case. Triangular distributions for assessing the uncertainty of operational costs are based on the minimum most likely value (i.e. the mean in this case) and the maximum investment value for operating costs such as fuel, VDS, and repair and maintenance of all types of FADs (Ngoc et al., 2016; Valderrama \& Engle, 2001). Second, Pearson correlation coefficients were calculated for price and catch in order to control for the values of these two uncertain variables based on the strength and direction of their relationships. Using the time series (2010-2015) data of prices and skipjack catches, a correlation coefficient of -0.75 was found between skipjack price and catches in ISSF case while it was -0.67 in MSC case. The values for costs of labour and share of skippers and mechanics, which are directly calculated from revenues (skipjack price*catch), are then also influenced by the correlation coefficients. The third step is to simulate the NPVs using 1000 iterations.

\section{5 Results}

\subsubsection{Statistical results of NPVs of investment on incentive mechanisms per risk} aversion

The mean NPV for investing in (1) ISSF's sustainable FADs, (2) MSC free school, and (3) both mechanisms for somewhat and very risk averse type of fishers are shown in Table 5.4. The mean NPVs for three cases of incentive mechanism for somewhat risk averse fishers are all positive, with either nearly or $100 \%$ probability of having positive NPV. The variation in NPVs based on the standard deviations is lowest for MSC, while the combined ISSF and MSC has the highest variation. The mean NPVs under the very risk averse type of fishers is positive for the MSC case, while negative for ISSF and combination of MSC and ISSF. MSC free school has a $100 \%$ probability of a 
positive NPV. However, for very risk averse fishers the probability of having positive NPV for the ISSF case decreases to $30.8 \%$ and to $13.2 \%$ for investments in both fishing methods.

Table 5.3 The types of distribution and parameters used for uncertain variables in Monte

\section{Carlo simulation}

\begin{tabular}{|c|c|c|c|c|c|c|}
\hline Variables & $\begin{array}{l}\text { Type of } \\
\text { distribution }\end{array}$ & $\begin{array}{l}\text { Mean } \\
\text { (standard } \\
\text { deviation) }\end{array}$ & $\begin{array}{l}\text { Minimu } \\
\mathrm{m}\end{array}$ & $\begin{array}{l}\text { Most } \\
\text { Likely }\end{array}$ & Maximum & Sources \\
\hline \multicolumn{7}{|c|}{ ISSF's sustainable FADS } \\
\hline Price (‘000) & Normal & $1.44(0.36)$ & & & & Atuna (2014) \\
\hline Yield & Normal & $\begin{array}{r}4,347.48 \\
(219.02)\end{array}$ & & & & $\begin{array}{l}\text { Western and } \\
\text { Central } \\
\text { Pacific } \\
\text { Fisheries } \\
\text { Commission } \\
\text { (2016) }\end{array}$ \\
\hline $\begin{array}{l}\text { Initial } \\
\text { investment } \\
\text { (‘000) }\end{array}$ & Triangular & & 100.00 & 123.68 & 175.80 & Survey \\
\hline Fuels ('000) & Triangular & & 468.00 & 499.20 & 624.00 & $\begin{array}{l}\text { Department } \\
\text { of Energy } \\
\text { (2016) }\end{array}$ \\
\hline $\begin{array}{l}\text { Costs of VDS } \\
\left({ }^{\circ} 000\right)\end{array}$ & Triangular & & 408.00 & 530.40 & 816.00 & $\begin{array}{l}\text { Les and Clark } \\
\text { (2014) }\end{array}$ \\
\hline $\begin{array}{l}\text { Costs of non- } \\
\text { entangling FADs } \\
\text { ('000) }\end{array}$ & Triangular & & 14.70 & 15.25 & 15.80 & $\begin{array}{l}\text { Goñi et al. } \\
\text { (2015) }\end{array}$ \\
\hline $\begin{array}{l}\text { Costs of FAD } \\
\text { maintenance } \\
\left({ }^{\prime} 000\right)\end{array}$ & Triangular & & 725.00 & $1,000.00$ & $1,150.00$ & $\begin{array}{l}\text { Beverly et al. } \\
\text { (2012); Sharp } \\
\text { (2011); } \\
\text { survey }\end{array}$ \\
\hline \multicolumn{7}{|l|}{ MSC free school } \\
\hline Yield & Normal & $\begin{array}{r}2,126.60 \\
(173.73)\end{array}$ & & & & $\begin{array}{l}\text { Western and } \\
\text { Central } \\
\text { Pacific } \\
\text { Fisheries } \\
\text { Commission } \\
(2016)\end{array}$ \\
\hline $\begin{array}{l}\text { Initial } \\
\text { investment }\end{array}$ & Triangular & & 134.38 & 193.50 & 234.49 & $\begin{array}{l}\text { Boating } \\
\text { Magazine } \\
\text { (2001); } \\
\text { Furuno USA } \\
\text { (2017) }\end{array}$ \\
\hline Fuels & Triangular & & 716.39 & 764.15 & 955.00 & $\begin{array}{l}\text { Department } \\
\text { of Energy } \\
\text { (2016) }\end{array}$ \\
\hline Costs of VDS & Triangular & & 628.00 & 816.40 & $1,256.00$ & $\begin{array}{l}\text { Les and Clark } \\
\text { (2014) }\end{array}$ \\
\hline
\end{tabular}



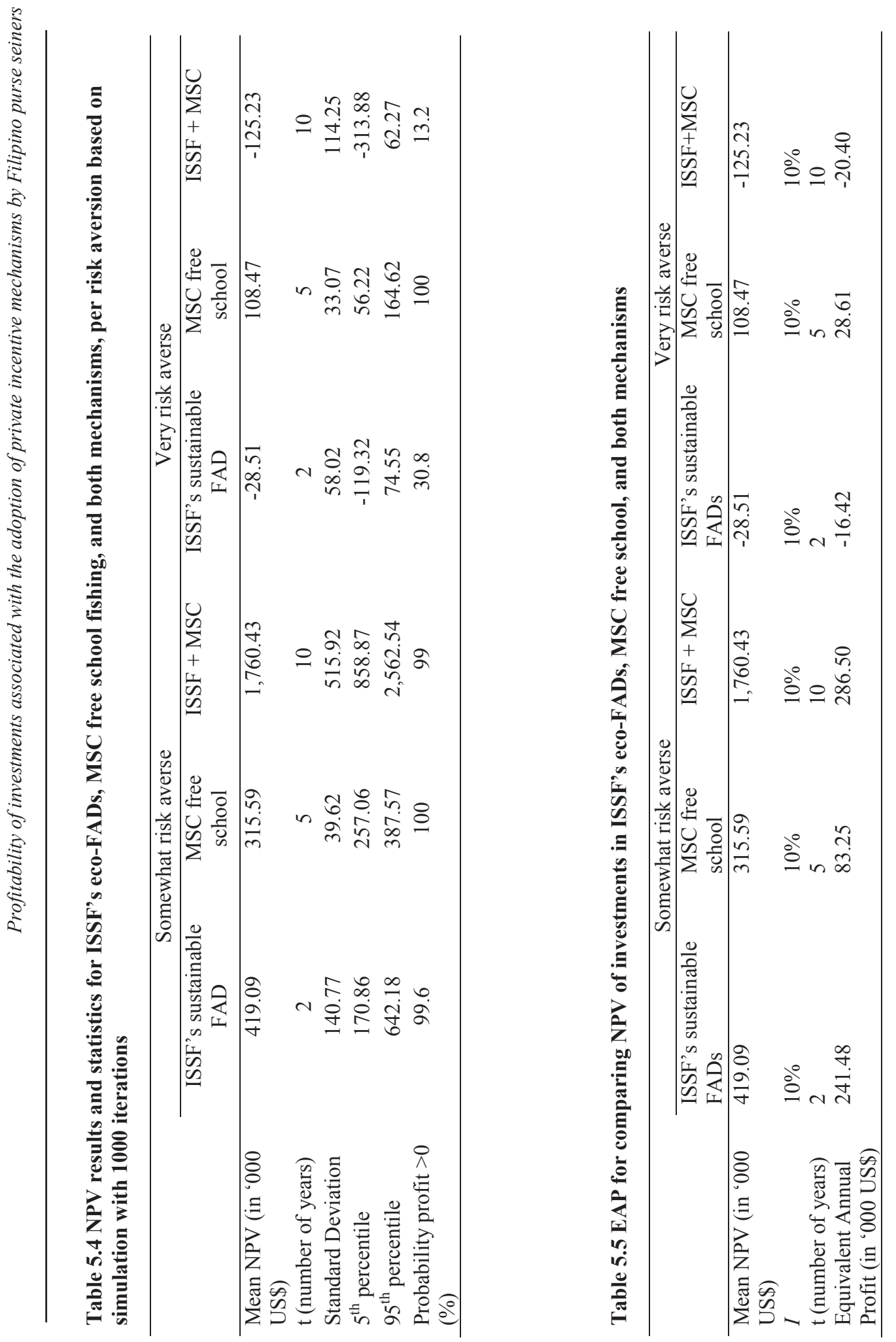


\subsubsection{Equivalent Annual Profits}

The three investments in incentive mechanism compliance with different life cycles are compared in terms of their EAP (Table 5.5). In general, the EAP of investments in incentive mechanisms by somewhat risk averse fishers are higher than those of the very risk averse fishers. The combined investment in ISSF and MSC has the highest EAP (US\$286,500) among the three investment options by somewhat risk averse fishers. Investment in MSC by very risk averse fishers will generate an EAP of US\$28,610, which is the highest and the only positive annual profit among the three investment options for this type of fisher.

\subsection{Discussion}

\subsubsection{Risk aversion}

This study has demonstrated the effects of risk aversion on the profitability of investments in incentive mechanism compliance, which in turn provides insights into the likelihood of adopting these mechanisms and ultimately the impact of these mechanisms on achieving sustainability outcomes. Somewhat risk averse fishers are more likely to have a higher NPV as compared to very risk averse fishers, and also have a $100 \%$ probability of a positive return. As a consequence, somewhat risk averse fishers are expected to be more inclined to adopt incentive mechanism and therefore improve their fishing practices. The NPV results for very risk averse fishers, which are generally lower than somewhat risk averse fishers and negative, would be even less attractive if the effect of risk aversion is also accounted for in the discount rate. The choice of discount rate reflects both the expected reward and risk premium of an investor (Guerard Jr \& Schwartz, 2007). Therefore, fishers that are more risk averse are therefore expected a higher underlying discount rate which takes into account compensation for the perceived risk of their investment. However, a higher discount rate means a lower NPV, because cash flows that occur further away in time carry less weight in the NPV calculation. This means that investments in incentive mechanisms will be generally less appealing than suggested by the results of this study for more risk averse fishers. 
To increase the adoption of incentive mechanisms like MSC and ISSF eco-FADs, associated actors such as states or firms can influence the initial fishing strategy of fishers by reducing the perceived risk of investment. Reducing the perceived risk of investment might be achieved by controlling for risk generated by fluctuating prices and income. Controlling for price risk can be done in at least two ways. First, by setting future contracts between two parties who agree on buying and selling an asset or a commodity such as fish at a fixed price but delivered and paid for at an agreed date in the future. And second, by setting a floor (minimum) price in order to decrease price volatility and to guarantee acceptable fish prices to fishers (Peterson \& Smith, 1982; Sethi, 2010). Controlling income risk can be done by providing a flexible taxation scheme that would allow fishers to cancel out low profits or losses through tax deductions in profitable years (Cunningham, 1994). These risk reducing strategies have been adopted in other species, for instance in white shrimp (Sanders \& Manfredo, 2002), demersal fish (Trondsen et al., 2003), and farmed Atlantic salmon (Simioni et al., 2013).

By reducing the riskiness of the incentive mechanisms, risk averse fishers may choose different fishing strategy to start with, which is in line with enhancing the adoption of incentive mechanism. Further research on who will implement decisions (e.g. government, value chain actors, or the fishers) and the extent of involvement of these actors in these risk reducing strategies, however, are still needed. Alternatively, influencing the NPV of investments such as the ISSF currently doing further research on improving the lifespan of eco-FADs while controlling for costs (Moreno et al., 2016b), will potentially lead to higher NPV and can also therefore encourage risk averse fishers to participate.

\subsubsection{Profitability performance of incentive mechanisms}

The results also show that a combination of different incentive mechanisms is the most profitable investment for less risk averse fishers. The combined investment in ISSF eco-FAD fishing and 
MSC free school fishing generates the highest return on investment for somewhat risk averse fishers. This finding builds on other observations that multiple gear changes can address the shortfalls of any one mechanism and can increase the benefits for both fishery and fishers (Chuenpagdee et al., 2003; Jenkins \& Garrison, 2013).

Concentrating on eco-FADs alone may address the by-catch of non-target species such as turtles and sharks and marine litter, but not the by-catch of juvenile bigeye and yellowfin tunas (MRAG, 2017). The goal of MSC free school fishing in specifically reducing the catch of associated juvenile tuna can therefore increase the sustainability scope of FAD related gear change. At the same time, concentrating on MSC free school fishing alone reduces the productivity of fishery due to a lower success rate of fishing on free school as compared to FAD fishing (Guillotreau et al., 2011). The flexibility of MSC compliant vessels to fish on both free schools and FADs in a single fishing trip also raises issues about the reliability of the MSC certification to address overall impact of purse seining (see Moreno et al., 2016a). However, purely undertaking MSC free school fishing may not be the most economically efficient strategy for fishers based on the success rate of free school fishing (Guillotreau et al., 2011), and may eventually lead to a lower adoption of MSC. Therefore using eco-FADs not only complements the limitations of MSC certification to deal with sustainability across the entire purse seine fishery, but also makes the fishing operation even more profitable than MSC compliant fishing alone. Given the $100 \%$ probability of a positive return for investment in MSC compliant fishing for somewhat and very risk averse fishers, it is likely to remain the most attractive investment option for fishers.

\subsection{Conclusion}

This study draws three new insights on the profitability of investments by Filipino fishers in ISSF's eco-FAD design and MSC compliant free school fishing. First, the level of risk aversion determines the extent that the NPV of investments in incentive mechanisms is profitable. Second, investing in 
different incentive mechanisms that target different fishing practices is the most profitable option for somewhat risk averse fishers. Third, the MSC has the potential to perform far better among other mechanisms based on the robustness of investments in this mechanism by fishers across a broader spectrum of risk attitude.

As a consequence of these findings, the value chain actors and the government supporting the implementation of these incentive mechanisms should incorporate risk reducing strategies in the design of incentive mechanisms to involve the broadest range of fishers. Risk reducing strategies could include using future contracts to reduce price volatility and improving the lifespan of investments in the mechanisms, such as the usability of FADs. Governments may intervene on fish prices, such as implementing floor prices to secure fishers from lower fish prices and/or may establish flexible taxation schemes to reduce the risk caused by fluctuation of fishers' income. By increasing the participation of different types of fishers, the application of different private incentive mechanisms will potentially improve the overall sustainability of the fishery.

Future research is needed to assess this model empirically and to evaluate the public benefits accrued from both state and private investments in incentive mechanisms, including both financial returns and the improved health of tuna stocks and other associated marine organisms. 
Chapter 6

General Discussion and Conclusion 


\subsection{Introduction}

This dissertation started from the premise that unsustainable fishing practices, including the use of non-selective fishing methods and IUU fishing, have contributed to the decline of tuna fish stocks globally. The perceived failure of the government to address unsustainable fishing practices of fishers has led to the rise of private incentive mechanisms as innovative instruments to enhance the sustainability of many fisheries including tuna (Grafton et al., 2006; Jack et al., 2008; Pascoe et al., 2010). However, research on private incentive mechanisms has been biased towards either large or small scale fishers (Chand et al., 2003; Froese et al., 2011; Haward \& Bergin, 2001; Kaczynski \& Fluharty, 2002). The so called 'missing' middle-scale fishers, which include much of the Filipino tuna vessels, have received far less attention. As such the main objective of this dissertation was to evaluate the extent to which private incentive mechanisms influence the decision of Filipino tuna fishers to improve their fishing practices.

The overall objective of the dissertation was addressed in four research chapters. Chapter two analysed and compared the ways existing private incentive mechanisms in tuna fisheries that include FIPs, MSC, and ISSF influence the upgrading strategies of Filipino tuna fishers in the value chain. Chapter three evaluated the important determinants for small-scale fishers' decision to participate in two FIPs in Occidental Mindoro, Philippines. Chapter four modelled and evaluated the allocation of fishing days of Filipino purse seiners in response to MSC and based on this allocation, the influence of MSC on the level of income and risk of fishers. Finally, chapter five evaluated the profitability of investments in MSC and ISSF by Filipino purse seine fishers.

This final chapter of the dissertation proceeds in the next section with a synthesis of the main results from the research chapters. Next, the chapter reflects on the theoretical insights offered by this dissertation on private incentive mechanisms using the decision making and global value chain theories, and on the methodological contribution of this dissertation. The final section then provides 
recommendations for fishery managers and value chain actors to improve the future design and implementation of incentive mechanisms; for policy makers this chapter recommends how to enhance the adoption of private incentive mechanisms by fishers. Finally, recommendations are given for future research.

\subsection{Synthesis of the main results}

Two key themes emerge from the results presented in the four research chapters. The first theme is the role of fisher capabilities as a requirement for responding to the goals of incentive mechanisms and in doing so upgrade their production through the value chain. This theme was dealt with directly in chapters two and three. The focus on capabilities enables an understanding of whether producers can upgrade in the value chain under private incentive mechanisms and what type of upgrading strategies these producers can implement based on their capabilities given that they are willing to upgrade. The second theme focuses on the influence of risk attitude on the tactical and strategic decision making of fishers under private incentive mechanisms in chapters four and five.

\subsubsection{Capabilities for upgrading in the value chain}

As outlined in the introduction chapter, the capabilities of an individual are key to their achievement of functions and/or strategies for realising endowments (Sen, 1993). These capabilities are not inherently intrinsic, they are also influenced by the internal structure of the value chain and the wider public and private institutions outside the value chain (Giuliani et al., 2005; Robeyns, 2005). This broader definition of capabilities in this dissertation opens up an improved understanding of how the different private incentive mechanisms work in tuna value chains and how private incentive mechanisms can improve the participation of fishers in transitions towards fishing techniques that are deemed desirable for achieving sustainable tuna production. 
In order to understand how private incentive mechanisms in tuna fishery operate in the value chain, chapter two evaluated and compared the existing capabilities of the target fishers against the requirements of private incentive mechanisms in tuna fisheries that include FIPs, MSC, and ISSF. The results in this chapter show that different types of fishers develop varying levels of capabilities based on the influence of chain and non-chain actors. Reflecting the findings of other studies, capabilities enable (or disable) fishers to participate in incentive mechanisms and ultimately determine the type of upgrading strategies that participating fishers can implement (Kaplinsky, 2000b; Morrison et al., 2008). The results of chapter two show that the majority of the target fishers in FIPs still lack the required capabilities to upgrade their production, while a few FIP participants developed capabilities through the support of the fisher association. Fishers involved in the MSC possess higher level capabilities to not only increase the value of their tuna by upgrading their product and processes, but also functionally upgrade through the establishment of joint venture company with local processors. Finally, fishers involved in the ISSF also demonstrably have the capabilities and potentially improved their vertical coordination by strengthening their relationships with ISSF processors and related traders.

Based on these results, chapter two provided three insights on how private incentive mechanisms work in the value chain. First, the incentives offered by these private mechanisms are not delivered to fishers in a linear way because: (i) the vertical actors determine whether and how the incentives will be delivered to fishers; and (ii) horizontal actors influenced fishers' capabilities to realise this incentive. This insight is contrary to literature that focuses on the role of market incentives as the main way of bringing about changes in the practices of producers (Grafton et al., 2006; Hilborn, 2007a). Second, private incentive mechanisms target different kinds of fishers that vary in their levels of capabilities. And third, the incentives built into these mechanisms are so far not able to match short-term food security and income goals, nor long-term income and risk minimization goals. The result is a lower overall participation by fishers. This finding is consistent with other 
research findings that also show that fishers receive incentives for participation in the mechanisms, but in doing so do not necessarily respond the way that the mechanism intended (Blomquist et al., 2015; Phillips et al., 2008; Ponte, 2012). These insights provide key considerations in the future implementation of private incentive mechanisms in tuna fisheries as well as other global commodities.

In further support of the literature on private incentive mechanisms (Giuliani et al., 2005; Kaplinsky et al., 2003; Pérez-Ramírez et al., 2012a), this dissertation argues that capabilities are key understanding why or why not fishers work towards sustainability. Chapter three analysed the factors and capabilities that influence handline fishers' decision to participate in two FIPs. The case of FIP is used because FIP participant fishers need the most attention in terms of improving the capabilities for participation based on the findings in chapter two, while fishers in the cases of MSC and ISSF already possess the capabilities to participate in incentive mechanisms. The outcome of chapter three shows that fishers possess different capabilities, which determines the types of FIPs that they participate in. The individual firm capabilities, which are possessed by few fishers in FIPs, strongly influence fishers to participate in market-oriented (top-down) FIPs while the collective capabilities that are possessed by the majority of fishers enable them to improve their fishing practices in order to participate in development-oriented (bottom-up) FIPs. Moreover, the majority of the fishers only partially participate in FIP because they do not possess the capabilities to a sufficient degree. Thus these fishers still need improvement in capabilities in order to fully participate in market-oriented FIPs, which will enable them to finally realise the incentives for participation and to contribute to fishery sustainability. This finding builds on studies (Giuliani et al., 2005; Kaplinsky et al., 2003; Perez-Aleman, 2013) that emphasize the importance of supporting the development of capabilities of more fishers, which in turn contributes to their decision to participate in incentive mechanisms and eventually lead to sustainability outcomes. 
Contrary to literature that focuses on the creation of economic incentives for changing practices of fishers (Grafton et al., 2006; Kremen et al., 2000), the outcome of chapters two and three clearly show that capabilities of fishers are an enabling and/or limiting factor in the fisher decision making. Therefore focusing on capabilities, in addition to the delivery of economic incentives to fishers, is an important step in understanding how to increase participation by fishers in private incentive mechanisms (Perez-Aleman, 2013; Perez-Aleman \& Sandilands, 2008).

\subsubsection{Tactical and strategic decision making under uncertainty}

The effects of risk attitude on the levels of income and risks and on the tactical (short-term) and strategic (long-term) decisions of fishers has been widely addressed in the fisheries literature (Bockstael \& Opaluch, 1983; Dupont, 1993; Eggert \& Tveteras, 2004; Mistiaen \& Strand, 2000; Nguyen \& Leung, 2009). However, none of these studies have analysed these effects in the context of private incentive mechanisms. This dissertation addressed this literature gap in chapters four and five. Chapter four evaluated the effect of incentive mechanisms on tactical decisions (choice of activity) of fishers that vary in risk aversion. Chapter five evaluated the profitability of investments (strategic decisions) in equipment that is needed to comply with incentive mechanisms. Together, these two chapters contribute to the literature on private incentive mechanisms and fisher decision making in two ways. First, these chapters provide a more elaborate understanding how fishers respond to incentives, in contrast to the traditional notion that fishers simply change practices based on the incentives of private incentive mechanisms (Grafton et al., 2006; Hilborn, 2007b). Second, they provide insight on the extent to which these mechanisms are effective in changing the fishing practices of fishers in the short- and in the long-term (e.g. Eliasen et al., 2013; Hicks \& Schnier, 2008; Lallemand et al., 2016).

The results of chapters four and five show that the extent to which private incentive mechanisms like MSC and ISSF incentivise fishers depends on the fisher's degree of risk aversion. Chapter four 
shows that adopting MSC free school generally increases the income of purse seine fishers with different levels of risk aversion, and therefore clearly incentivises fishers to adopt practices that are believed to contribute to sustainable fishery. The outcome of chapter five also strengthens the finding of chapter four by showing that in the long-run, the return on investments for fishers in MSC is positive regardless of risk aversion. This result is similar with the findings of Lallemand et al. (2016), who shows that fishers will receive the incentives to invest in new equipment in order to comply with MSC requirements. The results from the ISSF case, however, are more ambiguous as they suggest that only fishers with low risk aversion will benefit from positive returns on their investment in ISSF eco-FADs, while fishers with higher risk aversion face lower and even negative returns on their investments. This supports the fisheries literature, which suggests that the risk aversion of fishers is positively related to their compliance with sustainable standards and regulations (Brick et al., 2012; Smith \& Wilen, 2005), which enable them to realise the incentives of the mechanisms. In addition, the results of chapter five also show that investing in both mechanisms is the most profitable strategy for fishers that are less risk averse. Overall, these findings build on other observations that multiple gear changes can address the limitations of any one mechanism and at the same time can increase the benefits for both fishery and fishers (Chuenpagdee et al., 2003; Jenkins \& Garrison, 2013).

The results of chapters four and five also show that the risk attitude of fishers determines the decision of fishers on the extent to change their practices, which in turn influences the risk and the expected income of fishers. Consistent with studies that analyse the effect of risk aversion on compliance of fishers on sustainable measures (Brick et al., 2012; Cinner et al., 2011), the results of chapter four show that the less risk averse fishers (e.g. somewhat and rather risk averse) are those most willing to adopt MSC compliant free school fishing. Based on their level of risk aversion, fishers increase their MSC fishing days which at the same time leads to higher income and associated risk due to fluctuation in prices and catches. Conversely, the more risk averse fishers are 
the less likely to allocate fishing days to MSC compliant free school fishing. This leads to lower income and lower risk for these fishers. Similar to other studies (Christensen \& Raakjær, 2006; Gelcich et al., 2007), the results of chapter 4 suggest that in a multi-gear fishery, fishers should not be seen as an homogenous group.

In chapter five, the risk aversion of fishers to uncertainty in prices, catches, and other operating costs, are shown to influence the profitability of investing in compliance to private incentive mechanisms. The results suggest that fishers with low risk aversion are more likely to have high NPV of investments in incentive mechanisms. Therefore, they are more likely to adopt the incentive mechanisms. However, investing in incentive mechanisms for very risk averse fishers is less attractive since the probability of having positive NPV of investments is small for this type of fishers. Reducing the risks in implementing the incentive mechanisms will therefore attract these very risk averse fishers to change their initial fishing strategy into more sustainable fishing days.

The results of both chapters 4 and 5 run contrary to the wider literature on fisher decisions in response to market incentives (e.g. Antle \& Diagana, 2003; Grafton et al., 2006; Grafton et al., 2008). Instead of reacting to price and/or market access directly, the results show that the risk attitudes of fishers play a role in changing their practices in order to realise these incentives. When combined with capabilities, this dissertation presents a more nuanced understanding of how private incentive mechanisms work - especially in developing world fisheries.

\subsection{Private incentive mechanisms}

The results of this dissertation provide an improved understanding of the influence that private incentive mechanisms can have on fisher' decision making on upgrading to more sustainable fishing practices. In doing so this dissertation questions the assumption that private incentive mechanisms allocate adequate proper incentives to fishers to change the behaviour of fishers 
towards more sustainable fishing practices (Grafton et al., 2006; Hilborn, 2007a). The expectation that incentive mechanisms can shape sustainability related decisions through a narrow set of economic incentives is explained by Expected Utility theory, which assumes that fishers are rational individuals that are expected to improve their fishing practices in response to the incentives offered by these mechanisms (Schoemaker, 1982). In contrast, this dissertation argues that individual decision making is not only influenced by economic factors, but also by the social institutions of government, NGOs, and community within which individual operate (Granovetter, 1985). More specifically the results point to the extent to which fishers are capable to engage in private incentive mechanisms, given their wider institutional embeddedness, and their risk attitude to income and risks.

The use of these analytical concepts does not only contribute to understanding the decision making of fishers, but also to what constitutes a successful private incentive mechanism for sustainable primary production (e.g. Cocklin et al., 2007; Richards, 2000). The following section defines and explains the three key pillars that can drive the success of private incentive mechanisms for reaching its sustainability goals. These pillars are incentives, inclusiveness, and improvement, all of which are recurring themes in this dissertation and in the literature on private incentive mechanisms (e.g. Bush et al., 2013; Giovannucci \& Ponte, 2005; Hanley et al., 2012; Leadbitter et al., 2006). They also provide a basis for new insights on the role of private incentive mechanisms in guiding decision making for sustainability improvements in fisheries as well as other sectors.

\subsubsection{Incentives}

Much of the literature on private incentive mechanisms views incentive as the key driver for changing the practices of producers (Antle \& Diagana, 2003; Grafton et al., 2006; Jack et al., 2008; Pascual \& Perrings, 2007). Therefore, private incentive mechanisms are designed to create 'market' incentives as a reward for sustainably changing the practices of producers (Marine Stewardship 
Council, 2011). It is assumed that producers will respond and will get this incentive once they change their practices. As opposed to this argument, this dissertation found out that tuna fishers do not simply respond to incentives of private incentive mechanisms because two factors influence the way they see incentives.

The first factor is the delivery of incentives. This study has shown that the incentives are not delivered simply to producers responding to the requirements of private incentive mechanisms in the value chain. Instead, the delivery of incentives to producers is determined by the economic relationship between producers and value chain actors (see Bolwig et al., 2010a; Dolan \& Humphrey, 2000; Nadvi, 2008). As shown in chapter two, rent-seeking behaviour of value chain actors such as Casas and exporters in PPTST FIP case (chapters 2 and 3) and the brand members and processors in the ISSF case (chapter 2 and 5) make them more able to capture a higher portion of the incentive being offered by the private incentive mechanisms. As a consequence, fishers may find the economic value of the incentives insufficient to compensate for their costs and risks of upgrading.

The MSC case (chapters 2, 4 and 5) similarly demonstrates that the delivery of incentives is influenced by the support given to fishers to building the necessary capabilities to recognise and respond to economic incentives. By supporting the development of producer capabilities, either the producers are able to upgrade and receive the incentives or other forms of incentives are created at the fisher level; such as generation of extra income for conserving the fishery, trainings, capacity buildings, and information, and subsidies and funding generated by the fisher association (Kiss, 2004; McNeely, 1988; Robins et al., 2000). This has been shown in the case of FIP. Moreover, the FIP case also shows the importance of non-tangible benefits to producers based on their participation such as the feeling of inclusiveness, feeling of purpose, and emotional commitment for the community (e.g. Van Hecken \& Bastiaensen, 2010). Together these results build on a relatively 
marginal observation in the economic literature (e.g. Giuliani et al., 2005; Leimona et al., 2009) that private incentive mechanisms not only offer 'market' incentives but also non-economic incentives for producers.

The second factor is the risk attitude of producers, which determines the preference and extent fishers make changes in their fishing practices under private incentive mechanisms. Building on works that focus on fisher behaviour in response to economic risks (e.g. Branch et al., 2006; Fulton et al., 2011), all cases of private incentive mechanisms investigated in this dissertation show that only less risk averse fishers are able to capture the incentives offered by these mechanisms given their higher willingness to participate. For instance, chapter three shows that less risk averse fishers choose to participate in Artesmar FIP, therefore enabling them to realise the market incentive offered by this type of FIP. In contrast, highly risk averse fishers choose to partially participate in development-oriented FIPs, but are unable to realise the incentives on offer. This situation is highly observable in small-scale fisheries in developing countries because of the tied-credit relations of these fishers with Casas and the lack of motivation of buyers to move to quality form of buying (Pérez-Sánchez \& Muir, 2003; Ruddle, 2011; von Essen et al., 2013). In chapter four, the less risk averse fishers choose to increase their MSC fishing days, which leads to higher income and therefore allows them to materialise the incentives for participation. The results in chapter five suggest that less risk averse fishers decide to do more fishing days, which results in an increase in profitability of investments associated with private incentive mechanisms.

The third factor is an outcome of the influence of the institutions on building the capabilities of producers on the risk attitude of producers to adopt the mechanisms. Building the capabilities of producers reduces the perceived risk of producers to upgrade production (Murphy C \& P., 2008), which in turn can lead to an increased willingness of producers to participate in private incentive mechanisms. Coming full circle, this then allows them to realise the incentives for participation. At 
the same time, by improving capabilities and influencing the risk perception of fishers, more fishers could start adopting private incentive mechanisms which may further spread the adoption to other fishers.

\subsubsection{Inclusiveness}

Private incentive mechanisms seek to provide opportunities for developing country producers, to access higher value markets in the value chain (Buller \& Morris, 2004; Gullison, 2003; Lee et al., 2012; MacDonald, 2007). To realise this opportunity producers need the ability to comply with the requirements for participation in the value chain through which private incentive mechanisms are applied (Dolan \& Humphrey, 2000; Nadvi, 2008; Ponte, 2008a; Schmitz \& Knorringa, 2000; Tran et al., 2013). The extent to which a producer is able to participate or not in the value chain then determines the level of inclusiveness of private incentive mechanisms (Berdegué et al., 2008). Building on the findings of chapter 2 in this dissertation, the inclusiveness of producers is then a function of both the vertical and horizontal dimensions of coordination and institutional embedding in and around the value chain (Bolwig et al., 2010a; Bush \& Oosterveer, 2007; Bush \& Oosterveer, 2012).

The degree of inclusiveness is therefore determined by the requirements of incentive mechanisms and by the capabilities of producers. Inclusiveness influences the decision making of producers to adopt private incentive mechanisms. If private incentive mechanisms set high requirements for changing towards sustainable practices, more capable producers have the advantage of complying with these requirements while the less capable producers face difficulty that may results for their exclusion in the value chain (Bush et al., 2013; Pérez-Ramírez et al., 2012a). The danger of highly exclusive private incentive mechanisms is that they have the tendency to contribute less to sustainability because only few producers change their practices (California Environmental Associates, 2015). 
Next to inclusiveness in the value chain, private incentive mechanisms also manifest inclusiveness in the mechanisms themselves. The degree of inclusiveness of private incentive mechanisms increase when the mechanisms address a wider group of actors at institutional level. Private incentive mechanisms bring together chain and non-chain actors that include the government and NGOs in order to push for the sustainability of the production area (Miller, 2014). These institutional actors influence and enable the development of capabilities of producers to upgrade using private incentive mechanisms, which then enhances the inclusion of producers in the chain. In the case of tuna fisheries, NGOs such as WWF, government, value chain actors, and fisher associations in PPTST FIP work together in order to improve the fishers' capabilities that are needed for participation in the value chain. For MSC certification of the PNA, the PNA government made investments in certifications and VMS that enable producers to comply with the requirements of MSC. In the ISSF case, there is less involvement by the government but the ISSF themselves as an NGO invested in research for improving the sustainability of FAD fishery.

Inclusion is not necessarily good per se. Despite offering opportunity to producers, private incentive mechanisms at the same time expose producers to risks originating from the choice of mechanism, price and yield fluctuations, stringent market competition, and business transactions (Bolwig et al., 2010a). Building on the results of chapters four and five, the economic value of the incentive of private incentive mechanism should be able to compensate for the increase in risks and costs of upgrading practices by fishers, in order to be inclusive of a wider group of fishers that vary in risk aversion.

\subsubsection{Improvement}

There is a normative notion that private incentive mechanisms should lead to improvements of the environment and of the economic situation of producers (Engel et al., 2008; Fisher et al., 2008). The sustainable improvements in the environment depends on the environmental issues that private 
incentive mechanisms try to address, such as reduction in carbon emission by the energy and manufacturing sectors, long-term viability of fish stocks in the fishery, and conservation of soils in the agriculture sector (Antle \& Diagana, 2003; Kinzig et al., 2011). Improvements in the economic situation of producers can either be in the form of alleviating their poverty or improving their way of living and having a sustainable source of income in both the short- and long-term (Jack et al., 2008).

This dissertation argues that the pathway towards improvement is dependent on whether or not a fisher can improve their practices before they can reap the economic benefits before the fishery as a whole can become more sustainable. The notion of improvement in the production practices of producers under private incentive mechanisms is referred to as 'sustainable upgrading' strategy, because producers make improvements in their practices based on compliance with sustainability standards set by the wider institutions and the value chain actors (e.g. Jeppesen \& Hansen, 2004; Kaplinsky, 2010; Marchi et al., 2013). Producers make improvements in their practices in the shortterm (tactically) and in the long-term (strategically). Producers that are incorporated in the value chain through the incentive mechanisms will make continuous improvements in their practices as long as the economic incentive of their participation covers the increase in costs and risks associated with the dynamic and increasing requirements in the value chain. In case that the tradeoff between income and risks is not any more favourable to producers, producers might ‘functionally downgrade' (Ponte \& Ewert, 2009), which means that they go back to their traditional practices instead of doing improvements.

\subsubsection{Interrelationship between the 3Is}

The three I's presented - incentive, inclusiveness, and improvement - are interrelated with each other in terms of driving the success of private incentive mechanisms towards sustainability (Figure 6.1). As shown in Figure 6.1 (part A), the incentive is traditionally viewed to have a direct 
linear relationship with improvements in the environment (Jack et al., 2008; Marine Stewardship Council, 2011). However, this dissertation shows that this relationship is not direct, as explained by the analytical concepts capability, risk attitude, risks and income (see Figure 6.1, part B).

\section{A. Traditional approach to understanding private incentive mechanisms}

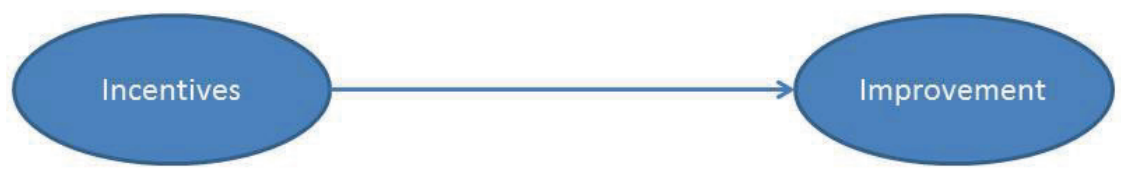

\section{B. A new approach to understanding private incentive mechanisms}

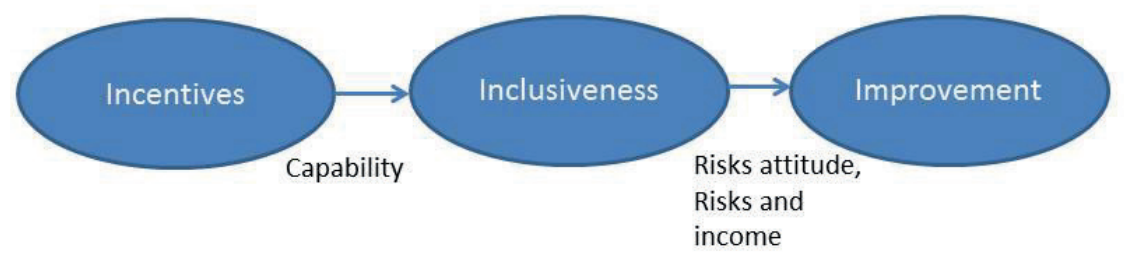

Figure 6.1 Framework for understanding how private incentive mechanisms can drive sustainability

First, private incentive mechanisms offer incentives to producers. In order for producers to realise economic value of the incentive of private incentive mechanisms, they first need to have capabilities that will enable them to satisfy the requirements of private incentive mechanisms (and in that way be inclusive). However, the availability of capability doesn't mean that producers will participate. Producers must also have the right attitude to take risks in order to make changes in 
their practices. Assuming that producers have the capabilities needed to upgrade and that they deem an incentive is sufficient to opt for participation based on their risk attitude, they may decide to improve their practices. Their improvement strategies, which can combine short- and long-term time horizon, eventually will contribute to the ultimate sustainability improvement goal of private incentive mechanisms. In order to allow producers to continuously make improvements, the economic incentive of the incentive must cover the additional costs and compensate for the increase of the risks of participation of currently participating producers. Therefore, at the core of these three pillars for a successful private incentive mechanism is the decision making of producers.

The implications of these findings are that private incentive mechanisms must take into consideration the capabilities, risk attitude of fishers, and risk and income in the current implementation and in the future design of private incentive mechanisms. By doing so, the mechanisms will be more inclusive of producers and eventually will increase the sustainability outcome for both the environments and producers.

\subsection{Methodology}

The various methodologies employed in this dissertation provide a comprehensive and rich understanding of the decision making of Filipino fishers in private incentive mechanisms. Chapter two uses an inductive multiple case study approach, which is capable of generating new theoretical insights (Eisenhardt \& Graebner, 2007; Yin, 2009). Chapter three uses a positivist (or deductive) approach, which tests a number of hypotheses that are derived from theory (Crowther \& Lancaster, 2008). Chapters four and five both use a normative approach, which is subjective and value based and determines which aspect of the focus of the study needs improvement based on an a priori determined set of criteria/values (Hardin, 2008). 
There are two advantages of using multiple methodologies in this dissertation. First multiple methodologies enable this dissertation to produce more coherent results because each different methodology triangulates and complements the results from other methodology (Byrne \& Humble, 2007). For example, chapter two theorizes the importance of capabilities in the upgrading of fishers in the value chain using inductive approach. The positivist approach in chapter three complements the importance of capabilities in upgrading by confirming the significant capabilities that influence fishers' participation in FIPs. Another example is that the inductive and positivist approaches use completely different forms of data collection and analysis. Inductive approach uses a highly qualitative form of data collection and analysis while the positive approach uses purely quantitative data and analytical methods. This diversity in methods of gathering and analysing data further triangulated and strengthened the results generated by chapters two and three.

Second, the use of multiple methods addresses the limitations or disadvantages of certain methods (Byrne \& Humble, 2007). In this dissertation, the inductive approach is applied in multiple case studies instead of single case study. Thus, the analysis of specific cases of private incentive mechanisms could have been richer and more insightful by using the inductive approach for single case study. However, this limitation has been cancelled out by using specific cases of incentive mechanisms while applying either positive or normative approaches in Chapters three, four and five. Another example is that the inductive approach using multiple case studies in chapter two has a generalisation issue on whether and on what extent fishers are incentivised from their participation in MSC and ISSF. This could be complemented by an empirical study to provide a deeper understanding of the extent fishers are incentivised from their participation. This dissertation addressed this research gap using normative modelling based on historical data on prices and catches in chapters four and five. This shows that 'in theory' these incentive mechanisms should incentivise fishers depending on fishers' level of risk aversion. However, the result of the normative 
modelling may still require comparing how the actual behaviours of the fishers may deviate from the behaviour assumed in the normative model.

Finally, this dissertation not only combined various methodological approaches but also employed an interdisciplinary approach in understanding fisher's decision making in the context of private incentive mechanisms. The implementation of private incentive mechanisms in fishery has been anchored in a single scientific discipline, such as the theory of change (Marine Stewardship Council, 2011). This leads to a lack of understanding of the role of factors other than incentives in determining the success of private incentive mechanism. In this dissertation, the use of an interdisciplinary approach brings together and connects concepts and theories from various disciplines such as global value chain, expected utility, capability, and sociological embeddedness. The interdisciplinary approach leads to a deeper understanding of the decision making of fishers in private incentive mechanisms and the role of inclusiveness and improvements in addition to incentives.

\subsection{Management and policy contributions}

The results of this research hold a series of recommendations for incentive mechanisms, private actors, policy makers in tuna fisheries and further research.

\subsubsection{Recommendations for private incentive mechanisms}

This dissertation has shown that in addition to incentives, the focus on inclusiveness and improvement in the decision making of fishers will enable private incentive mechanisms to achieve more sustainable impact. Existing private incentive mechanisms such as the MSC certification, FIPs, and ISSF pro-active vessel register (PVR) and recommendations on eco-FADs, should cover different groups of fishers in order to be more inclusive of fishers in their program and to bring the highest possible sustainability impact in the fishery. 
First, depending on their specific goals, private incentive mechanisms can either operate independently or work together with the fishers. For instance, the MSC is an independent, third party certification scheme and is considered as the 'gold' standard in fishery sustainability (Kaiser \& Edward-Jones, 2006; Pérez-Ramírez et al., 2012a). Given that the MSC is independent, it is not advisable for them to provide direct support to fishers for them to comply with their standards. This would undermine the credibility of their status and standards (Bush et al., 2013). Second, as a consequence of maintaining its independence, the MSC will still face challenges in being more inclusive of developing country fishers that generally lack capabilities to participate in this mechanism (Constance \& Bonanno, 2000; Jacquet \& Pauly, 2008; Pérez-Ramírez et al., 2012a). This justifies the existence of FIPs, which operate directly with fishers in order to address the limitation of MSC to include more fishers in its program. Third, the incentive mechanisms can also offer a different opportunity to fishers by improving the existing practices of fishers other than the alternative pathways towards improvement. For example, the MSC free school in PNA is implemented to address the FAD fishing of fishers. However, fishers still use FAD fishing in their fishing practices. As shown in chapter five, introducing the ISSF recommendations on eco-FADs through close collaborations with fishers and scientists, fishers are able to improve their existing FAD fishing practice.

The future design of private incentive mechanisms must take into account incentives, inclusiveness, and improvements. In order to deliver the highest sustainability coverage and impacts, private incentive mechanisms must develop or maintain a high level of sustainability standards, while at the same time allow for high inclusiveness of fishers. In order to do this, first private incentive mechanisms could be created through the collaboration of actors within the local fishery and the chain actors demanding the sustainable fish under the incentive mechanisms. The traditional approach of implementing incentive mechanism is through the demand from the markets and retailers (Bush et al., 2013; Perez-Aleman, 2013). However, this approach lacks understanding of 
the situation of the fishery and fishers, and could often not work effectively. But if the mechanisms are created through collaboration with local fishery and chain actors, the incentive mechanisms can be designed in such a way that they address the current capabilities of fishers and that they have lower risk of adoption by fishers. Second, in case that private incentive mechanisms has a marketoriented approach, the mechanisms must target the group of fishers that have the capabilities to comply with their requirements and must be able to deliver the incentives. By focusing on capabilities and delivery of incentives to fishers, these mechanisms will attract a large participation of fishers and may contribute to increase in sustainability of the fishery. For both future and currently operating private incentive mechanisms such as MSC, FIPs, and ISSF, the recommendations could be implemented via the set of private and public actors that engage in these mechanisms as will be discussed in the next section.

\subsubsection{Recommendations for private actors}

Private actors that engage in private incentive mechanisms include both value chain actors and NGOs. In order for these actors to attract more fishers to adopt the incentive mechanisms, they also have to assume certain roles in the implementation of incentive mechanisms in the fishery through the value chain.

First, downstream value chain actors that include retailers and marketers should not only focus on providing the financial means for creating and implementing private incentive mechanisms, but also on building the capabilities of fishers in order to enable the mechanisms to be more inclusive of fishers. In all cases of incentive mechanisms, chain actors such as retailers from Europe, Pacifical, and brand members and processors in ISSF make investments in the creation and implementation of incentive mechanisms in the fishery. However, their role as financier should also be extended into being a partner in building the capabilities of fishers either through direct interaction with fishers or through collaboration with wider institutional actors that include NGOs and the government. 
Assuming a partnership role with fishers or/and with NGOs and governments provide two benefits (Bitzer \& Glasbergen, 2015; Perez-Aleman, 2013). First, retailers and marketers that set requirements in the chain can transfer knowledge on how to increase the value of tuna, which includes using sustainable fishing practices and making fish traceable, to fishers. Second, through partnership with institutional actors, the challenges in the implementation of incentive mechanisms in the fishery that includes the lack of capabilities of producers and other social conditions such as interdependency of fishers with local financial providers (e.g. Casas), can be overcome. As a consequence, producers become more capable to participate in the value chain and ultimately upgrade their practices and contribute to the sustainability of fishery. At the same time, downstream actors can ensure sustainable source of fish.

Second, once fishers have the capabilities to improve their practices, the next step that downstream chain actors can implement is to reduce the risks in the adoption of private incentive mechanisms by fishers. Risks can be reduced by using different risk management strategies that include future contracts, individual and group insurance policies, and vertically integrating or establishing joint ventures with fishers (refer to Mumford et al., 2009; Sanders \& Manfredo, 2002; Sethi, 2010). By reducing the perceived risks in the adoption of the incentive mechanisms, more risk averse fishers could potentially participate in the incentive mechanisms and could contribute to overall benefit for the fishery.

NGOs such as WWF and ISSF should strengthen the build-up of partnerships with wide set of actors that include fishers, government, value chain actors, and scientist in order to facilitate the improvement in capabilities of fishers and to enable fishers to participate in private incentive mechanisms. However, these NGOs should not assume the roles of the actors that they partnered, such as the policy makers and value chain actors. Instead these NGOs presence should only focus on facilitating the capabilities of fishers to enable them to participate. 


\subsubsection{Recommendations for policy makers/government}

The government should not assume a single role in the implementation of private incentive mechanisms. As shown throughout the chapters of this dissertation, they have different positions in the operation of private incentive mechanisms in the fishery. This means that private incentive mechanisms do not simply exist in a vacuum and that these mechanisms need the help of the government to allow them to effectively work in the market (Engel et al., 2008).

First, the government as a partner in pushing for the sustainability goals of incentive mechanisms should support the implementation of these mechanisms through regulatory measures that focus on building the capabilities of producers (see Adolf et al., 2016; Foley, 2012; Gulbrandsen, 2014). As reflected in the case of FIPs, local government can push for the registration of fishers as the first step to organise fisher association, which later on help in the development of capabilities of majority of fishers. At the same time, local government can also provide institutional supports that include trainings, in-kind help, and strengthening of the fisher association through providing subsidies and grants on the projects of the association as found out in chapters two and three. The case of MSC shows that management measures such as VDS and seasonal FAD closures in the EEZ influence fishers to do MSC fishing as shown in the results of chapter four. Moreover, government also provided institutional supports such as investments in MSC certification and in VMS.

Second, the government should also facilitate reducing the risk inherent in the adoption of private incentive mechanisms by fishers. The risk reducing strategies that the government can implement could include reducing price risk through setting minimum price and developing a flexible taxation scheme that will protect fishers from fluctuating fishing income (Cunningham, 1994; Peterson \& Smith, 1982). For private incentive mechanisms that are operating with less involvement from the government, such as the ISSF case, the government should act as a watchdog in terms of the effects of these mechanisms in the fishery. 
And third, the government should exercise its 'command and control' role by continuously monitoring the behaviour of fishers in response to private incentive mechanisms, and based on this interaction, the government must adjust their policies to adopt with the changes in fisher's behaviour. For example, there is a currently observed increase in MSC fishing by fishers in the PNA region in response to the newly introduced MSC certification of yellowfin tuna caught in free school (Marine Stewardship Council, 2017). Since skipjack tuna caught on free school is also certified in this region, more fishers are encouraged to do MSC fishing. Therefore, the government must allocate properly the fishing effort to vessels in the forms of restricting fishing areas, influencing the price of vessel day scheme, and restricting fishing licenses.

\subsubsection{Recommendations for future research}

The recurring theme in this dissertation is how to engage more fishers to participate in private incentive mechanisms. This dissertation calls for a research that focuses on improving the implementation of incentive mechanisms, in order to be more effective in bringing wider impacts to fisheries. The improvement could focus on the ways these mechanisms make more inclusive of wider group of fishers. This could include ways on how to build the capabilities of fishers, how to ensure that the incentives within the value chains are delivered to fishers, and how to reduce the riskiness of adopting the incentive mechanisms in order to be more attractive to fishers.

This dissertation also has shown the importance of understanding the risk attitude of fishers in the implementation of the incentive mechanisms. Future research that focuses on the risk attitude of target and participating fishers in incentive mechanisms will be useful in understanding the actual level of risk aversion of fishers for participating and the level of acceptability of incentive mechanisms to fishers. Having this knowledge will aid in matching the right type of fishers for the incentive mechanisms or aid value chain and non-value chain actors to do the proper intervention in order to attract fishers to participate, and eventually to improve the sustainability of fishery. 
The decision making framework of this research has been applied to private incentive mechanisms in tuna value chains. Testing this framework in other 'missing middle' developing world fisheries, such as Indonesia, may strengthen the results of this dissertation or may also provide new insights in terms of the differences on how these fishers operate.

Finally, the analysis of the decision making in private incentive mechanisms is done in the context of tuna fisheries. Testing and extending the analysis of this study to mechanisms that are present to similar type of fisheries, aquaculture, and agricultural products could validate and provide richer understanding of these mechanisms.

\subsection{Concluding Remark}

This dissertation has evaluated the extent to which private incentive mechanisms influence the improvement in fishing practices of Filipino tuna fishers. Based on the findings of this study, private incentive mechanisms are able to influence the change in fishing practices of Filipino fishers, however, at limited effect based on the level of participation of fishers in the mechanisms. The broader challenge that remains in the successful implementation of private incentive mechanisms is how to increase the inclusiveness of developing country producers in these mechanisms in order to bring more sustainable outcome. By not only taking incentives into account and instead also account for inclusiveness and improvements in the design of private incentive mechanisms, the more likely that these mechanisms will succeed in bringing sustainable improvements in the fishery. 


\section{References}


Abadi Ghadim, A. K., \& Pannell, D. J. (1999). A conceptual framework of adoption of an agricultural innovation. Agricultural Economics, 21(2), 145-154.

Acs, S., Berentsen, P., Huirne, R., \& Van Asseldonk, M. (2009). Effect of yield and price risk on conversion from conventional to organic farming. Australian Journal of Agricultural and Resource Economics, 53(3), 393-411.

Adolf, S., Bush, S. R., \& Vellema, S. (2016). Reinserting state agency in global value chains: The case of MSC certified skipjack tuna. Fisheries Research, 182, 79-87.

Agnew, D. J., Pearce, J., Pramod, G., Peatman, T., Watson, R., Beddington, J. R., \& Pitcher, T. J. (2009). Estimating the worldwide extent of illegal fishing. PloS one, 4(2), e4570.

Amekawa, Y. (2013). Can a public GAP approach ensure safety and fairness? A comparative study of Q-GAP in Thailand. The Journal of Peasant Studies, 40(1), 189-217.

Anderson, J. R., \& Dillon, J. L. (1992). Risk analysis in dryland farming systems: Food \& Agriculture Org.

Anderson, J. R., Dillon, J. L., \& Hardaker, J. (1977). Agricultural decision analysis.

Antle, J. M., \& Diagana, B. (2003). Creating incentives for the adoption of sustainable agricultural practices in developing countries: the role of soil carbon sequestration. American Journal of Agricultural Economics, 85(5), 1178-1184.

Antunes, P., Santos, R., \& Videira, N. (2006). Participatory decision making for sustainable development - the use of mediated modelling techniques. Land use policy, 23(1), 44-52.

Atuna. (2014). Bangkok Skipjack price index Retrieved January 2015, 2014, from www.atuna.com

Atuna. (2015). SKJ1.8:BKK Retrieved January 20, 2015, from http://atuna.com/index.php/fishing/659-skj1-8-bkk

Bailey, M., Bush, S. R., Oosterveer, P., \& Larastiti, L. (In Press). Fishers, fair trade, and finding middle ground. Fisheries Research.

Bailey, M., Flores, J., Pokajam, S., \& Sumaila, U. R. (2012). Towards better management of Coral Triangle tuna. Ocean \& Coastal Management, 63, 30-42.

Bailey, M., Ingles, J., \& Sumaila, R. (2009). Economic tradeoffs in tuna fisheries management in the western and central Pacific Ocean. Presentation at NAAFE 2009.

Bailey, M., Ishimura, G., Paisley, R., \& Sumaila, U. R. (2013). Moving beyond catch in allocation approaches for internationally shared fish stocks. Marine Policy, 40, 124-136.

Bangko Sentral ng Pilipinas. (2016). Statistics Retrieved September 5, 2016, 2016, from www.bsp.gov.ph

Barclay, K. (2010). Impacts of tuna industries on coastal communities in Pacific Island countries. Marine Policy, 34(3), 406-413.

Barclay, K. (2014). History of industrial tuna fishing in the Pacific Islands Historical Perspectives of Fisheries Exploitation in the Indo-Pacific (pp. 153-171): Springer.

Barclay, K. (2015). Futures of governance ecological challenges and myths in tuna fisheries. In Jonathan Paul Marshall \& Linda H. Connor (Eds.), Environmental change and the world's futures: ecologies, ontologies and mythologies (pp. 65-80). Routledge.

Barclay, K., \& Cartwright, I. (2007). Governance of tuna industries: The key to economic viability and sustainability in the Western and Central Pacific Ocean. Marine Policy, 31(3), 348-358.

Barrientos, S., Gereffi, G., \& Rossi, A. (2011). Economic and social upgrading in global production networks: A new paradigm for a changing world. International Labour Review, 150(3-4), 319-340.

Barry, P. J., Ellinger, P. N., Hopkin, J. A., \& Baker, C. (2000). Financial management in agriculture. Danville, Ill. Interstate US.

Barut, N., \& Garvilles, E. (2005). Philippines fishery report: National Fisheries Research and Development Institute, Bureau of Fisheries and Aquatic Resources, Philippines. Prepared for the Scientific Committee of the Western and Central Pacific Fisheries Commission, Noumea, New Caledonia. 
Bastardie, F., Nielsen, J. R., Andersen, B. S., \& Eigaard, O. R. (2010). Effects of fishing effort allocation scenarios on energy efficiency and profitability: an individual-based model applied to Danish fisheries. Fisheries Research, 106(3), 501-516.

Béné, C., \& Tewfik, A. (2001). Fishing effort allocation and fishermen's decision making process in a multi-species small-scale fishery: Analysis of the conch and lobster fishery in Turks and Caicos Islands. Human Ecology, 29(2), 157-186.

Berdegué, J. A., Biénabe, E., \& Peppelenbos, L. (2008). Keys to inclusion of small-scale producers in dynamic markets-Innovative practice in connecting small-scale producers with dynamic markets. London: International Institute for Environment and Development (IIED).

Berentsen, P., \& Giesen, G. (1995). An environmental-economic model at farm level to analyse institutional and technical change in dairy farming. Agricultural Systems, 49(2), 153-175.

Beverly, S., Griffiths, D., \& Lee, R. (2012). Anchored fish aggregating devices for artisanal fisheries in South and Southeast Asia: benefits and risks. Bangkok, Thailand: RAP Publication 2012/20.

BFAR. (2012). Philippine Tuna Fisheries Profile. In West Pacific East Asia Oceanic Fisheries Management Project (Ed.).

Bitzer, V., \& Glasbergen, P. (2015). Business-NGO partnerships in global value chains: part of the solution or part of the problem of sustainable change? Current Opinion in Environmental Sustainability, 12, 35-40.

Blomquist, J., Bartolino, V., \& Waldo, S. (2015). Price Premiums for Providing Eco-labelled Seafood: Evidence from MSC-certified Cod in Sweden. Journal of Agricultural Economics, 66(3), 690-704.

Boating Magazine. (2001). Boating Retrieved March 4, 2017, 2017, from www.boatingmag,com

Bockstael, N. E., \& Opaluch, J. J. (1983). Discrete modelling of supply response under uncertainty: the case of the fishery. Journal of Environmental Economics and Management, 10(2), 125137.

Bolwig, S., Gibbon, P., \& Jones, S. (2009). The economics of small-holder organic contract farming in tropical Africa. World Development, 37(6), 1094-1104.

Bolwig, S., Ponte, S., Du Toit, A., Riisgaard, L., \& Halberg, N. (2010a). Integrating poverty and environmental concerns into value-chain analysis: a conceptual framework. Development Policy Review, 28(2), 173-194.

Bolwig, S., Ponte, S., Riisgaard, L., du Toit, A., \& Halberg, N. (2010b). A methodology for integrating development concerns into value chain analysis and interventions. In Jonathan Mitchell \& Christopher Coles (Eds.), Markets and Rural Poverty Upgrading in Value Chains. USA and Canada: Earthscan and IDRC.

Botsford, L. W., Castilla, J. C., \& Peterson, C. H. (1997). The management of fisheries and marine ecosystems. Science, 277(5325), 509-515.

Branch, T. A., Hilborn, R., Haynie, A. C., Fay, G., Flynn, L., Griffiths, J., Marshall, K. N., Randall, J. K., Scheuerell, J. M., \& Ward, E. J. (2006). Fleet dynamics and fishermen behavior: lessons for fisheries managers. Canadian Journal of Fisheries and Aquatic Sciences, 63(7), 1647-1668.

Brick, K., Visser, M., \& Burns, J. (2012). Risk aversion: experimental evidence from South African fishing communities. American Journal of Agricultural Economics, 94(1), 133-152.

Buller, H., \& Morris, C. (2004). Growing goods: the market, the state, and sustainable food production. Environment and Planning A, 36(6), 1065-1084.

Bureau of Fisheries and Aquatic Resources. (2013). Philippine Fisheries Profile 2013. PCA Compound, Elliptical Road, Diliman Q.C: Department of Agriculture BFAR.

Bureau of Oceans and International Environmental and Scientific Affairs. (2014). Limits in the seas no. 138 Papua New Guinea archipelagic and other maritime claims and boundaries. U.S. Department of State: Office of Ocean and Polar Affairs, Bureau of Oceans and International Environmental and Scientific Affairs. 
Bush, S. R. (2004). Scales and sales: Changing social and spatial fish trading networks in the Siiphandone fishery, Lao PDR. Singapore Journal of Tropical Geography, 25(1), 32-50.

Bush, S. R., \& Oosterveer, P. (2007). The missing link: intersecting governance and trade in the space of place and the space of flows. Sociologia Ruralis, 47(4), 384-399.

Bush, S. R., \& Oosterveer, P. (2012). Linking global certification schemes and local practices in fisheries and aquaculture. Traditional Marine Resource Management and Knowledge Information Bulletin, 29, 15-21.

Bush, S. R., \& Oosterveer, P. (2015). Vertically differentiating environmental standards: The case of the Marine Stewardship Council. Sustainability, 7(2), 1861-1883.

Bush, S. R., Oosterveer, P., Bailey, M., \& Mol, A. P. J. (2014). Sustainability governance of chains and networks: a review and future outlook. Journal of Cleaner Production( 0 ).

Bush, S. R., Toonen, H., Oosterveer, P., \& Mol, A. P. (2013). The 'devils triangle'of MSC certification: Balancing credibility, accessibility and continuous improvement. Marine Policy, 37, 288-293.

Byrne, J., \& Humble, A. (2007). An introduction to mixed method research. Atlantic Research Centre for Family-Work Issues, 1-4.

California Environmental Associates. (2015). Summary findings from the global landscape review of fishery improvement projects (FIPs).

Campling, L., \& Havice, E. (2015). Pacific Island Forum Fisheries Agency (FFA) trade and industry news (Vol. 8).

Chand, S., Grafton, R. Q., \& Petersen, E. (2003). Multilateral governance of fisheries: management and cooperation in the Western and Central Pacific tuna fisheries. Marine Resource Economics, 18(4), 329-344.

Charles, A. T. (1995). Fishery science: the study of fishery systems. Aquatic Living Resources, 8(3), 233-239.

Chavez, M. D., Berentsen, P. B., \& Lansink, A. O. (2014). Analyzing diversification possibilities on specialized tobacco farms in Argentina using a bio-economic farm model. Agricultural Systems, 128, 35-43.

Christensen, A.-S., \& Raakjær, N. J. (2006). Fishermen's tactical and strategic decisions: a case study of Danish demersal fisheries. Fisheries Research, 81(2), 258-267.

Christian, C., Ainley, D., Bailey, M., Dayton, P., Hocevar, J., LeVine, M., Nikoloyuk, J., Nouvian, C., Velarde, E., Werner, R., \& Jacquet, J. (2013). A review of formal objections to Marine Stewardship Council fisheries certifications. Biological Conservation, 161, 10-17.

Chuenpagdee, R., Morgan, L. E., Maxwell, S. M., Norse, E. A., \& Pauly, D. (2003). Shifting gears: assessing collateral impacts of fishing methods in US waters. Frontiers in Ecology and the Environment, 1(10), 517-524.

Cinner, J. E., Folke, C., Daw, T., \& Hicks, C. C. (2011). Responding to change: using scenarios to understand how socioeconomic factors may influence amplifying or dampening exploitation feedbacks among Tanzanian fishers. Global Environmental Change, 21(1), 7-12.

Cocklin, C., Mautner, N., \& Dibden, J. (2007). Public policy, private landholders: perspectives on policy mechanisms for sustainable land management. Journal of environmental management, 85(4), 986-998.

Cohen, D. A., \& Zarowin, P. (2010). Accrual-based and real earnings management activities around seasoned equity offerings. Journal of Accounting and Economics, 50(1), 2-19.

Collis, D. J. (1994). Research note: how valuable are organisational capabilities? Strategic Management Journal, 15(143-152), 45.

Conservation Alliance for Seafood Solutions. (2015). Guidelines for supporting fishery improvement projects, 2014, from http://www.solutionsforseafood.org/projects/fisheryimprovement/ 
Constance, D. H., \& Bonanno, A. (2000). Regulating the global fisheries: The world wildlife fund, unilever, and the marine stewardship council. Agriculture and Human Values, 17(2), 125139.

Costello, C., Lynham, J., Lester, S. E., \& Gaines, S. D. (2010). Economic incentives and global fisheries sustainability. Resource, 2.

Crowther, D., \& Lancaster, G. (2008). Research Methods: a Consice Introduction to Research in Management and Business Consultancy: Oxford: Butterworth-Heinemann.

Cruz-Trinidad, A. (2003). Socioeconomic and bioeconomic performance of Philippine fisheries in the recent decades. Paper presented at the Assessment, management and future directions for coastal fisheries in Asian Countries. Worldfish Center Conference Proceedings.

Cudney-Bueno, R., \& Basurto, X. (2009). Lack of cross-scale linkages reduces robustness of community-based fisheries management. PloS one, 4(7), e6253.

Cummins, A. (2004). The Marine Stewardship Council: A multi-stakeholder approach to sustainable fishing. Corporate Social Responsibility and Environmental Management, 11(2), 85-94.

Cunningham, S. (1994). Fishermen's incomes and fisheries management. Marine Resource Economics, 9(3), 241-252.

Dagorn, L., Holland, K. N., \& Itano, D. G. (2007). Behavior of yellowfin (Thunnus albacares) and bigeye (T. obesus) tuna in a network of fish aggregating devices (FADs). Marine Biology, 151(2), 595-606.

Dagorn, L., Holland, K. N., Restrepo, V., \& Moreno, G. (2013). Is it good or bad to fish with FADs? What are the real impacts of the use of drifting FADs on pelagic marine ecosystems? Fish and Fisheries, 14(3), 391-415.

Davies, N., Harley, S., Hampton, J., \& McKechnie, S. (2014, 6-14 August 2014). Stock assessment of yellowfin tuna in the Western and Central Pacific Ocean. Paper presented at the Scientific Committee 10th Regular Session, Majuro, Republic of the Marshall Island.

Davis, D. F., \& Mentzer, J. T. (2008). Relational resources in interorganizational exchange: the effects of trade equity and brand equity. Journal of Retailing, 84(4), 435-448.

De Luca, G., \& Perotti, V. (2011). Estimation of ordered response models with sample selection. Stata Journal, 11, 213-239.

Deighan, L. K., \& Jenkins, L. D. (2015). Fishing for recognition: Understanding the use of NGO guidelines in fishery improvement projects. Marine Policy, 51, 476-485.

Dempster, T., \& Taquet, M. (2004). Fish aggregation device (FAD) research: gaps in current knowledge and future directions for ecological studies. Reviews in Fish Biology and Fisheries, 14(1), 21-42.

Department of Energy. (2016). Oil Monitor Retrieved September 5, 2016, 2016, from http://www.doe.gov.ph

Dercon, S. (2002). Income risk, coping strategies, and safety nets. The World Bank Research Observer, 17(2), 141-166.

Dewees, C., \& Hawkes, G. (1988a). Technical innovation in the Pacific Coast trawl fishery: the effects of fishermen's characteristics and perceptions on adoption behavior. Human Organization, 47(3), 224-234.

Dewees, C. M., \& Hawkes, G. R. (1988b). Technical innovation in the Pacific Coast trawl fishery: the effects of fishermen's characteristics and perceptions on adoption behavior. Human Organization, 47(3), 224-234.

Dolan, C., \& Humphrey, J. (2000). Governance and trade in fresh vegetables: the impact of UK supermarkets on the African horticulture industry. Journal of development studies, 37(2), 147-176.

Dupont, D. P. (1993). Price uncertainty, expectations formation and fishers' location choices. Marine Resource Economics, 219-247. 
Eggert, H., \& Tveteras, R. (2004). Stochastic production and heterogeneous risk preferences: commercial fishers' gear choices. American Journal of Agricultural Economics, 86(1), 199212.

Eisenhardt, K. M. (1989). Building theories from case study research. Academy of management review, 14(4), 532-550.

Eisenhardt, K. M., \& Graebner, M. E. (2007). Theory building from cases: Opportunities and challenges. Academy of management journal, 50(1), 25-32.

Eliasen, S. Q., Papadopoulou, K.-N., Vassilopoulou, V., \& Catchpole, T. L. (2013). Socioeconomic and institutional incentives influencing fishers' behaviour in relation to fishing practices and discard. ICES Journal of Marine Science, 71(5), 1298-1307.

Engel, S., Pagiola, S., \& Wunder, S. (2008). Designing payments for environmental services in theory and practice: An overview of the issues. Ecological economics, 65(4), 663-674.

Fairhead, J., Leach, M., \& Scoones, I. (2012). Green Grabbing: a new appropriation of nature? The Journal of Peasant Studies, 39(2), 237-261.

Ferrol-Schulte, D., Ferse, S. C., \& Glaser, M. (2014). Patron-client relationships, livelihoods and natural resource management in tropical coastal communities. Ocean \& Coastal Management, 100, 63-73.

Ferse, S. C. A., Knittweis, L., Krause, G., Maddusila, A., \& Glaser, M. (2012). Livelihoods of rrnamental coral fishermen in South Sulawesi/Indonesia: Implications for management. Coastal Management, 40(5), 525-555.

Field, A. (2013). Discovering statistics using IBM SPSS statistics: SAGE.

Fisher, B., Turner, K., Zylstra, M., Brouwer, R., Groot, R., Farber, S., Ferraro, P., Green, R., Hadley, D., \& Harlow, J. (2008). Ecosystem services and economic theory: integration for policy-relevant research. Ecological applications, 18(8), 2050-2067.

Foley, P. (2012). The political economy of Marine Stewardship Council certification: Processors and access in Newfoundland and Labrador's inshore shrimp industry. Journal of Agrarian Change, 12(2-3), 436-457.

Foley, P. (2013). National government responses to Marine Stewardship Council (MSC) fisheries certification: insights from Atlantic Canada. New Political Economy, 18(2), 284-307.

Fonteneau, A., Chassot, E., \& Bodin, N. (2013). Global spatio-temporal patterns in tropical tuna purse seine fisheries on drifting fish aggregating devices (DFADs): Taking a historical perspective to inform current challenges. Aquatic Living Resources, 26(1), 37-48.

Fonteneau, A., Pallares, P., \& Pianet, R. (2000). A worldwide review of purse seine fisheries on FADs. Paper presented at the Pêche thonière et dispositifs de concentration de poissons, Caribbean-Martinique, 15-19 Oct 1999.

Food and Agriculture Organisations. (2005). FAOSTAT data Retrieved December 15, 2012, from http://www.faostat.fao.org

Forum Fisheries Agency. (2015a). Aims and Rules of VDS Retrieved December 04, 2015, 2015, from https://www.ffa.int/node/55

Forum Fisheries Agency. (2015b). FFA Vessel Monitoring System Retrieved January 20, 2015, 2015, from http://www.ffa.int/vessel_registration

Froese, R., Branch, T. A., Proelß, A., Quaas, M., Sainsbury, K., \& Zimmermann, C. (2011). Generic harvest control rules for European fisheries. Fish and fisheries, 12(3), 340-351.

Fulton, E. A., Smith, A. D., Smith, D. C., \& van Putten, I. E. (2011). Human behaviour: the key source of uncertainty in fisheries management. Fish and Fisheries, 12(1), 2-17.

Furuno USA. (2017). Furuno USA radars Retrieved March 23, 2017, 2017

Gelcich, S., Edwards-Jones, G., \& Kaiser, M. J. (2007). Heterogeneity in fishers' harvesting decisions under a marine territorial user rights policy. Ecological Economics, 61(2), 246-254.

Gereffi, G. (1999). International trade and industrial upgrading in the apparel commodity chain. Journal of International Economics, 48(1), 37-70. 
Gereffi, G., Humphrey, J., \& Kaplinsky, R. (2001). Introduction: Globalisation, value chains and development. IDS bulletin, 32(3), 1-8.

Gereffi, G., Humphrey, J., \& Sturgeon, T. (2005). The governance of global value chains. Review of International Political Economy, 12(1), 78-104.

Gibbon, P., Bair, J., \& Ponte, S. (2008). Governing global value chains: an introduction. Economy and Society, 37(3), 315-338.

Gibbon, P., \& Ponte, S. (2005). Trading down: Africa, value chains and the global economy. Philadelphia, USA: Temple University Press.

Gilman, E. L., \& Lundin, C. G. (2010). Minimizing bycatch of sensitive species groups in marine capture fisheries: lessons from tuna fisheries. Handbook of Marine Fisheries Conservation and Management, 150-164.

Gintis, H. (2000). Strong reciprocity and human sociality. Journal of theoretical biology, 206(2), 169-179.

Giovannucci, D., \& Ponte, S. (2005). Standards as a new form of social contract? Sustainability initiatives in the coffee industry. Food policy, 30(3), 284-301.

Giuliani, E., Pietrobelli, C., \& Rabellotti, R. (2005). Upgrading in global value chains: lessons from Latin American clusters. World development, 33(4), 549-573.

Gomez-Mejia, L. R., Nunez-Nickel, M., \& Gutierrez, I. (2001). The role of family ties in agency contracts. Academy of management Journal, 44(1), 81-95.

Goñi, N., Ruiz, J., Murua, H., Santiago, J., Krug, I., de Olano, B. S., de Zarate, A. G., Moreno, G., \& Murua, J. (2015). System of verification of the code of good practices on board ANABAC and OPAGAC tuna purse seiners and preliminary results for the Atlantic Ocean. In Indian Ocean Tuna Commission (Ed.), IOTC-2015-WPEB11-INF09.

Goujon, M., Vernet, A.-L., \& Dagorn, L. (2012). Preliminary results of the Orthongel program "eco-FAD" as June 30th 2012. In IOTC (Ed.).

Goyert, W., Sagarin, R., \& Annala, J. (2010). The promise and pitfalls of Marine Stewardship Council certification: maine lobster as a case study. Marine Policy, 34(5), 1103-1109.

Grafton, R. Q., Arnason, R., Bjørndal, T., Campbell, D., Campbell, H. F., Clark, C. W., Connor, R., Dupont, D. P., Hannesson, R., \& Hilborn, R. (2006). Incentive-based approaches to sustainable fisheries. Canadian Journal of Fisheries and Aquatic Sciences, 63(3), 699-710.

Grafton, R. Q., Hilborn, R., Ridgeway, L., Squires, D., Williams, M., Garcia, S., Groves, T., Joseph, J., Kelleher, K., \& Kompas, T. (2008). Positioning fisheries in a changing world. Marine Policy, 32(4), 630-634.

Granovetter, M. (1985). Economic action and social structure: the problem of embeddedness. American journal of sociology, 481-510.

Greene, W. H. (2012). Econometric Analysis. Upper Saddle River, NJ: Prentice Hall.

Greene, W. H., \& Hensher, D. A. (2010). Modeling ordered choices: a primer: Cambridge University Press.

Greiner, R., Young, M., McDonald, A., \& Brooks, M. (2000). Incentive instruments for the sustainable use of marine resources. Ocean \& Coastal Management, 43(1), 29-50.

Guerard Jr, J. B., \& Schwartz, E. (2007). Investing in Assets: Theory of Investment Decision Making Quantitative Corporate Finance (pp. 247-276): Springer.

Guillotreau, P., Salladarré, F., Dewals, P., \& Dagorn, L. (2011). Fishing tuna around Fish Aggregating Devices (FADs) vs free swimming schools: Skipper decision and other determining factors. Fisheries Research, 109(2), 234-242.

Guiso, L., \& Paiella, M. (2008). Risk aversion, wealth, and background risk. Journal of the European Economic association, 6(6), 1109-1150.

Gulati, A., Minot, N., Delgado, C., \& Bora, S. (2007). Growth in high-value agriculture in Asia and the emergence of vertical links with farmers.

Gulbrandsen, L. H. (2009). The emergence and effectiveness of the Marine Stewardship Council. Marine Policy, 33(4), 654-660. 
Gulbrandsen, L. H. (2014). Dynamic governance interactions: Evolutionary effects of state responses to non-state certification programs. Regulation \& Governance, 8(1), 74-92.

Gullison, R. E. (2003). Does forest certification conserve biodiversity? Oryx, 37(2), 153.

Hamilton, A., Elizabeth Havice, \& Campling, L. (2011). FFA Fisheries Trade News Volume 4. Retrieved January 23, 2017, 2017, from http://www.ffa.int/node/456

Hampton, J. (2010). Tuna fisheries status and management in the western and central Pacific Ocean: Secretariat of the Pacific Community, New Caledonia.

Hanemann, W. M. (1984). Discrete/continuous models of consumer demand. Econometrica: Journal of the Econometric Society, 52(3), 541-561.

Hanley, N., Banerjee, S., Lennox, G. D., \& Armsworth, P. R. (2012). How should we incentivize private landowners to 'produce'more biodiversity? Oxford Review of Economic Policy, 28(1), 93-113.

Hardin, R. (2008). Normative Methodology: The Oxford Handbook of Political Science

Harley, S., Williams, P., Nicol, S., \& Hampton, J. (2011). The Western and Central Pacific tuna fishery: 2010 overview and status of stocks Western and Central Pacific Commission 8th Regular Session. Koror Palau: SPC-OFP.

Havice, E. (2010). The structure of tuna access agreements in the Western and Central Pacific Ocean: lessons for vessel day scheme planning. Marine Policy, 34(5), 979-987.

Havice, E. (2013). Rights-based management in the Western and Central Pacific Ocean tuna fishery: economic and environmental change under the Vessel Day Scheme. Marine Policy, 42, 259267.

Haward, M., \& Bergin, A. (2001). The political economy of Japanese distant water tuna fisheries. Marine Policy, 25(2), 91-101.

Hazell, P. B. R., \& Norton, R. D. (1986). Mathematical Programming for Economic Analysis

in Agriculture: Macmillan Publishing Company.

Heckman, J. (1979). Sample selection bias as a specification error. Econometrica, 47, 153-161.

Helfat, C. E., Finkelstein, S., Mitchell, W., Peteraf, M., Singh, H., Teece, D., \& Winter, S. G. (2009). Dynamic capabilities: Understanding strategic change in organizations: John Wiley \& Sons.

Henson, S., Jaffee, S., \& Masakure, O. (2013). The Participation of smallholder farmers in highvalue export markets governed by standards: the role of exporter procurement practices. Non-tariff measures with market imperfections: trade and welfare implications, 12.

Herrero, I. (2004). Risk and strategy of fishers alternatively exploiting sea bream and tuna in the Gibraltar Strait from an efficiency perspective. ICES Journal of Marine Science: Journal du Conseil, 61(2), 211-217.

Hicks, R. L., \& Schnier, K. E. (2008). Eco-labeling and dolphin avoidance: A dynamic model of tuna fishing in the Eastern Tropical Pacific. Journal of Environmental Economics and Management, 56(2), 103-116.

Hilborn, R. (1985). Fleet dynamics and individual variation: why some people catch more fish than others. Canadian Journal of Fisheries and Aquatic Sciences, 42(1), 2-13.

Hilborn, R. (2007a). Managing fisheries is managing people: what has been learned? Fish and Fisheries, 8(4), 285-296.

Hilborn, R. (2007b). Moving to sustainability by learning from successful fisheries. AMBIO: $A$ Journal of the Human Environment, 36(4), 296-303.

Hilborn, R., Orensanz, J. L., \& Parma, A. M. (2005). Institutions, incentives and the future of fisheries. Philosophical Transactions of the Royal Society B: Biological Sciences, 360(1453), 47-57.

Humphrey, J., \& Schmitz, H. (2000). Governance and upgrading: linking industrial cluster and global value chain research IDS Working Paper No. 120. Brighton: Institute of Development Studies, University of Sussex. 
Humphrey, J., \& Schmitz, H. (2002a). Developing country firms in the world economy: Governance and upgrading in global value chains: Institut für Entwicklung and Frieden der Gerhard-Mercator-Universität Duisburg.

Humphrey, J., \& Schmitz, H. (2002b). How does insertion in global value chains affect upgrading in industrial clusters? Regional studies, 36(9), 1017-1027.

Iles, A. (2007). Making the seafood industry more sustainable: creating production chain transparency and accountability. Journal of Cleaner Production, 15(6), 577-589.

International Seafood Sustainability Foundation. (2012a). About ISSF Retrieved March 14, 2013, 2013, from http://iss-foundation.org/resources/downloads/?did=381

International Seafood Sustainability Foundation. (2012b). ISSF Guide For Non-Entangling FADs Retrieved December 12, 2016, 2016, from http://iss-foundation.org/download-monitordemo/download-info/issf-guide-for-non-entangling-fads/

International Seafood Sustainability Foundation. (2014a). Marine Mammal Commission Retrieved April 2, 2017, 2017, from https://iss-foundation.org/

International Seafood Sustainability Foundation. (2014b). Proactive Vessel Register Retrieved November 14, 2014, 2014, from https://iss-foundation.org/knowledgetools/databases/proactive-vessel-register/

International Seafood Sustainability Foundation. (2017). About ISSF enabling sustainability through science and collaboration Retrieved April 24, 2017, 2017, from http://issfoundation.org/who-we-are/about/

Itano, D. G. (2007). A summary of operational, technical and fishery information on WCPO purse seine fisheries operating on floating objects. Scientific Committee Third Regular Session of Western and Central Pacific Fisheries Commission (WCPFC). Honolulu, United States of America.

Itano, D. G., Fukofuka, S., \& Brogan, D. (2004). The development, design and recent status of anchored and drifting FADs in the WCPO. Information Paper INF-FTWG-3.17 TH. Standing Committee on Tuna and Billfish, Majuro, Republic of the Marshall Islands.

Jack, B. K., Kousky, C., \& Sims, K. R. (2008). Designing payments for ecosystem services: Lessons from previous experience with incentive-based mechanisms. Proceedings of the National Academy of Sciences, 105(28), 9465-9470.

Jacquet, J., \& Pauly, D. (2008). Funding priorities: big barriers to small-scale fisheries. Conservation Biology, 22(4), 832-835.

Jager, W., \& Mosler, H. J. (2007). Simulating human behavior for understanding and managing environmental resource use. Journal of Social Issues, 63(1), 97-116.

Jenkins, L. D., \& Garrison, K. (2013). Fishing gear substitution to reduce bycatch and habitat impacts: An example of social-ecological research to inform policy. Marine Policy, 38, 293-303.

Jeon, Y., Reid, C., \& Squires, D. (2008). Is there a global market for tuna? Policy implications for tropical tuna fisheries. Ocean Development \& International Law, 39(1), 32-50.

Jeppesen, S., \& Hansen, M. W. (2004). Environmental upgrading of third world enterprises through linkages to transnational corporations. Theoretical perspectives and preliminary evidence. Business Strategy and the Environment, 13(4), 261-274.

Kaczynski, V. M., \& Fluharty, D. L. (2002). European policies in West Africa: who benefits from fisheries agreements? Marine Policy, 26(2), 75-93.

Kaiser, M. J., \& Edward-Jones, G. (2006). The role of ecolabeling in fisheries management and conservation. Conservation Biology, 20(2), 392-398.

Kaplinsky, R. (1998). Globalisation, industrialisation and sustainable growth: The pursuit of the nth rent: Institute of Development Studies, University of Sussex.

Kaplinsky, R. (2000a). Globalisation and unequalisation: What can be learned from value chain analysis? Journal of development studies, 37(2), 117-146. 
Kaplinsky, R. (2000b). Spreading the gains from globalisation: what can be learned from value chain analysis. Institute of Development Studies Working Paper 110.

Kaplinsky, R. (2010). The role of standards in global value chains World Bank Policy Research Working Paper No. 5396. Available at: https://ssrn.com/abstract=1653682.

Kaplinsky, R., Memedovic, O., Morris, M., \& Readman, J. (2003). The global wood furniture value chain: What prospects for upgrading by developing countries.

Kay, R. D., Edwards, W. M., \& Duffy, P. A. (1994). Farm management: McGraw-Hill New York.

Kay, R. D., Edwards, W. M., \& Duffy, P. A. (2005). Farm management, 5th edition. New York: McGraw Hill International edition.

Khiem, N. T., Bush, S. R., \& Coles, C. (2010). Upgrading, downgrading and out-grading smallholders in the Vietnamese pangasius catfish value chain. In Jonathan Mitchell \& Christopher Coles (Eds.), Markets and Rural Poverty Upgrading in Value Chains. USA and Canada: Earthscan and IDRC.

Kinzig, A. P., Perrings, C., Chapin, F. S., Polasky, S., Smith, V. K., Tilman, D., \& Turner, B. (2011). Paying for ecosystem services - promise and peril. Science, 334(6056), 603-604.

Kirby, D. S., Visser, C., \& Hanich, Q. (2014). Assessment of eco-labelling schemes for Pacific tuna fisheries. Marine Policy, 43, 132-142.

Kiss, A. (2004). Is community-based ecotourism a good use of biodiversity conservation funds? Trends in ecology \& evolution, 19(5), 232-237.

Kremen, C., Niles, J. O., Dalton, M., Daily, G. C., Ehrlich, P. R., Fay, J. P., Grewal, D., \& Guillery, R. P. (2000). Economic incentives for rain forest conservation across scales. Science, 288(5472), 1828-1832.

Kusumawati, R., Bush, S. R., \& Visser, L. E. (2013). Can patrons be bypassed? Frictions between local and global regulatory networks over shrimp aquaculture in East Kalimantan. Society \& Natural Resources: An International Journal, 26(8), 898-911.

Lallemand, P., Bergh, M., Hansen, M., \& Purves, M. (2016). Estimating the economic benefits of MSC certification for the South African hake trawl fishery. Fisheries Research, 182, 98-115.

Langley, A., Williams, P. G., \& Hampton, J. (2008). The Western and Central Pacific tuna fishery: 2006 overview and status of stocks Tuna Fisheries Assessment Report 8. Noumea, New Caledonia: Secretariat of the Pacific Community.

Langley, A., Wright, A., Hurry, G., Hampton, J., Aqorua, T., \& Rodwell, L. (2009). Slow steps towards management of the world's largest tuna fishery. Marine Policy 33(2), 271-279.

Leadbitter, D., Gomez, G., \& McGilvray, F. (2006). Sustainable fisheries and the East Asian seas: Can the private sector play a role? Ocean \& coastal management, 49(9), 662-675.

Lee, J., Gereffi, G., \& Beauvais, J. (2012). Global value chains and agrifood standards: challenges and possibilities for smallholders in developing countries. Proceedings of the National Academy of Sciences, 109(31), 12326-12331.

Leimona, B., Joshi, L., \& Noordwijk, M. (2009). Can rewards for environmental services benefit the poor? Lessons from Asia. International Journal of the Commons, 3(1).

Les, \& Clark, S. (2014). The PNA Vessel Day Scheme. Paper presented at the A Presentation to the ANU Pacific Update 2014, Canberra, 16-17 June, 2014.

Lewis, A. (2004). Review of tuna fisheries and the tuna fishery statistical system in the Philippines. Oceanic Fisheries Programme, Secretariat of the Pacific Community, Noumea, New Caledonia.

Libre, S. V. D., George A.K. van Voorn, Guus A. ten Broeke, Megan Bailey, Paul Berentsen, \& Bush, S. R. (2015). Effects of social factors on fishing effort: The case of the Philippinetuna purse seine fishery. Fisheries Research, 172, 250-260.

Lindner, R. K. (1987). Adoption and diffusion of technology: an overview (Vol. 19): ACIAR Proceedings Series, Australian Centre for International Agricultural Research.

Lopuch, M., Ward, T., \& Phillips, B. (2008). Benefits of certification for small-scale fisheries. Seafood ecolabelling: Principles and practice, 307-321. 
MacDonald, K. (2007). Globalising justice within coffee supply chains? Fair Trade, Starbucks and the transformation of supply chain governance. Third World Quarterly, 28(4), 793-812.

MacNeil, M. A., \& Cinner, J. E. (2013). Hierarchical livelihood outcomes among co-managed fisheries. Global environmental change, 23(6), 1393-1401.

Macusi, E. D., Babaran, R. P., \& van Zwieten, P. (2015). Strategies and tactics of tuna fishers in the payao (anchored FAD) fishery from general Santos city, Philippines. Marine Policy, 62, 6373.

Mansfield, B. (2006). Assessing market-based environmental policy using a case study of North Pacific fisheries. Global Environmental Change, 16(1), 29-39.

Marchi, V. D., Maria, E. D., \& Micelli, S. (2013). Environmental strategies, upgrading and competitive advantage in global value chains. Business strategy and the environment, 22(1), $62-72$.

Marine Stewardship Council. (2011). Harnessing market forces for positive environmental change Retrieved June 6, 2018, 2017, from https://www.msc.org/documents/msc-brochures/msctheory-of-change

Marine Stewardship Council. (2012). The PNA Western \& Central Pacific skipjack tuna fishery's 'free school' set operations gains MSC certification Retrieved September 12, 2016, 2016, from www.msc.org

Marine Stewardship Council. (2013). MSC standards Retrieved March 1, 2013, from http://www.msc.org/about-us/standards/standards

Marine Stewardship Council. (2014a). MSC Fisheries Standard and Guidance v2.0 (Extracted from Annexes SA, SB, SC and SD of the Fisheries Certification Requirements v2.0) Retrieved April 24, 2017, 2017, from https://www.msc.org/documents/scheme-documents/fisheriescertification-scheme-documents/fisheries-standard-version-2.0

Marine Stewardship Council. (2014b). PNA Western and Central Pacific Skipjack Tuna (Katsuwonus pelamis) unassociated set purse seine fishery Retrieved September 9, 2016, 2016, from https://msc.org/track-a-fishery/fisheries-in-theprogram/certified/pacific/pna western_central pacific tuna unassociated nonFAD pursese ine/assessment-downloads-1/20141020_New_Cert_F-SCS-0090_TUN197.pdf

Marine Stewardship Council. (2015). Global impacts summary report 2015 Retrieved June 8, 2015, 2015, from https://www.msc.org/documents/environmental-benefits/global-impacts/mscglobal-impacts-summary-report-2015

Marine Stewardship Council. (2017). PNA Western and Central Pacific skipjack and yellowfin, unassociated / non FAD set, tuna purse seine Retrieved June 15, 2017, 2017, from https://fisheries.msc.org/en/fisheries/pna-western-and-central-pacific-skipjack-andyellowfin-unassociated-non-fad-set-tuna-purse-seine/@,@view

Marra, M., Pannell, D. J., \& Abadi Ghadim, A. (2003). The economics of risk, uncertainty and learning in the adoption of new agricultural technologies: where are we on the learning curve? Agricultural systems, 75(2), 215-234.

McCoy, M. A. (2014). Tuna Supply Chains and Regulatory Frameworks in Two Pacific Island Countries. In Preston and Associates Inc. Gillet (Ed.): WorldWildlife Fund-South Pacific, Suva, Fiji.

McFadden, D. (1973). Conditional logit analysis of qualitative choice behavior.

McNeely, J. A. (1988). Economics and biological diversity: developing and using economic incentives to conserve biological resources. https://portals.iucn.org/library/efiles/documents/1988-MacN-001.pdf.

Miller, A. (2014). Governance innovation networks for sustainable tuna: Wageningen University. Miller, A., \& Bush, S. R. (2014). Authority without credibility? Competition and conflict

between ecolabels in tuna fisheries. Journal of Cleaner Production, 1(9). 
Mistiaen, J. A., \& Strand, I. E. (2000). Location choice of commercial fishermen with heterogeneous risk preferences. American Journal of Agricultural Economics, 82(5), 11841190.

Mitchell, J., \& Coles, C. (2011). Markets and rural poverty: Upgrading in value chains: IDRC.

Miyake, M. P., Guillotreau, P., ChinHwa, S., \& Ishimura, G. (2010). Recent developments in the tuna industry: stocks, fisheries, management, processing, trade and markets. FAO fisheries and aquaculture technical paper(543).

Moreno, G., Herrera, M., \& Morón, J. (2016a). To FAD or not to FAD: A challenge to the Marine Stewardship Council and its Conformity Assessment Bodies on the use of Units of Assessment and Units of Certification for industrial purse seine tuna fisheries. Marine Policy(73), 100-107.

Moreno, G., Restrepo, V., Dagorn, L., Hall, M., Murua, J., Sancristobal, I., Grande, M., Couls, S. L., \& Santiago, J. (2016b). Workshop on the use of biodegradable fish aggregating devices (FAD). In International Seafood Sustainability Foundation (Ed.), ISSF Technical Report 2016-18A. Washington, D.C., USA.

Morgan, A. (2011). Fish aggregating devices (FADs) and tuna In The PEW Environment Group (Ed.), Impacts and management options.

Morrison, A., Pietrobelli, C., \& Rabellotti, R. (2008). Global value chains and technological capabilities: a framework to study learning and innovation in developing countries. Oxford development studies, 36(1), 39-58.

MRAG. (2017). An analysis of the uses, impacts and benefits of fish aggregating devices (FADs) in the global tuna industry. In A report produced for WWF-UK by MRAG Ltd (Ed.), (pp. pp.51). London, UK.

Msomphora, M. R., \& Aanesen, M. (2015). Is the catch quota management (CQM) mechanism attractive to fishers? A preliminary analysis of the Danish 2011 CQM trial project. Marine policy, 58, 78-87.

Mumford, J., Leach, A., Levontin, P., \& Kell, L. (2009). Insurance mechanisms to mediate economic risks in marine fisheries. ICES Journal of Marine Science: Journal du Conseil, 66(5), 950-959.

Murphy C, \& P., G. (2008). The acceptability and the tolerability of societal risks: A capabilitiesbased approach. Science and Engineering Ethics, 14(1), 77-92.

Murua, J., Moreno, G., Hall, M., Itano, D., Dagorn, L., \& Restrepo, V. (2014). ISSF skipper workshops: collaboration between scientists and fishing industry to mitigate bycatch in tuna FAD fisheries. In ISSF Technical Report 2014-06 (Ed.), International Seafood Sustainability Foundation, Washington, D.C., USA.

Myers, S. C. (1984). Finance theory and financial strategy. Interfaces, 14(1), 126-137.

Nadvi, K. (2008). Global standards, global governance and the organisation of global value chains. Journal of Economic Geography, 8, 323-343.

National Fisheries Authority. (2015a). National Fisheries Authority Public Notice Retrieved September 5, 2016, 2016, from http://www.fisheries.gov.pg/Portals/0/NFA\%20Public\%20Notice.pdf

National Fisheries Authority. (2015b). Optimizing economic returns for the tuna fishery sector within a sustainable fisheries environment in Papua New Guinea APEC 2015 Expert Consultation on Assessment Methodology of Fishery and Livestock Losses Taipei, Chinese Taipei.

National Fisheries Authority. (2015c). Papua New Guinea National Fisheries Authority Licensing Policy. http://www.fisheries.gov.pg/Portals/0/PNG\%20NFA\%20Licensing\%20Policy.pdf.

Ngaruko, D. D., \& Lwezaula, D. D. (2013). Determinants of farmers' group membership satisfaction in Mbozi district, Tanzania: Exploring farmers' opinions. International Journal of Economy, Management and Social Sciencies, 2(11), 919-923. 
Ngoc, P. T. A., Meuwissen, M. P., Cong Tru, L., Bosma, R. H., Verreth, J., \& Lansink, A. O. (2016). Economic feasibility of recirculating aquaculture systems in pangasius farming. Aquaculture Economics \& Management, 20(2), 185-200.

Nguyen, Q., \& Leung, P. (2009). Do fishermen have different attitudes toward risk? An application of prospect theory to the study of Vietnamese fishermen. Journal of Agricultural and Resource Economics, 518-538.

North, D. C. (2005). Understanding the process of economic change. Princeton: Princeton University Press.

Notti, E., \& Sala, A. (2012). Effects of engine replacement on the fuel consumption reduction in fisheries. In CNR-ISMAR (Ed.), Information Collection in Energy Efficiency for Fisheries (ICEEF). Ancona Italy.

Nussbaum, M. (2003). Capabilities as fundamental entitlements: Sen and social justice. Feminist economics, 9(2-3), 33-59.

O'Keefe, C. E., Cadrin, S. X., \& Stokesbury, K. D. (2013). Evaluating effectiveness of time/area closures, quotas/caps, and fleet communications to reduce fisheries bycatch. ICES Journal of Marine Science: Journal du Conseil, fst063.

Ocean Studies Board. (2012). Tackling Marine Debris in the 21st Century. Washington D.C.: The National Academies Press.

Oceana. (2015). Recent articles on overfishing shed light on Oceana's 'save the oceans, feed the world' campaign Retrieved May 4, 2017, 2017, from http://oceana.org/blog/recent-articlesoverfishing-philippines-shed-light-oceana $\%$ E2\%80\%99s- $\%$ E2\%80\%98save-oceans-feedworld $\%$ E2\%80\%99-campaign

Oosterveer, P. (2008). Governing global fish provisioning: ownership and management of marine resources. Ocean \& Coastal Management, 51(12), 797-805.

Opaluch, J. J., \& Bockstael, N. E. (1984). Behavioral modeling and fisheries management. Marine Resource Economics, 1(1), 105-115.

Ostrom, E. (1994). 6. Constituting Social Capital and Collective Action. Journal of Theoretical politics, 6(4), 527-562.

Ostrom, E. (2009). A general framework for analyzing sustainability of social-ecological systems. Science, 325(5939), 419-422.

Pannell, D. J., Marshall, G. R., Barr, N., Curtis, A., Vanclay, F., \& Wilkinson, R. (2006). Understanding and promoting adoption of conservation practices by rural landholders. Animal Production Science, 46(11), 1407-1424.

Parker, R. W., Vázquez-Rowe, I., \& Tyedmers, P. H. (2015). Fuel performance and carbon footprint of the global purse seine tuna fleet. Journal of Cleaner Production, 103, 517-524.

Parkes, G., Young, J. A., Walmsley, S. F., Abel, R., Harman, J., Horvat, P., Lem, A., MacFarlane, A., Mens, M., \& Nolan, C. (2010). Behind the signs - a global review of fish sustainability information schemes. Reviews in Fisheries Science, 18(4), 344-356.

Parris, H. (2010). Is the Western and Central Pacific Fisheries Commission meeting its conservation and management objectives? Ocean \& Coastal Management, 53(1), 10-26.

Parties to Nauru Agreement Office. (2015). Review of the PNA purse seine vessel day scheme In Parties to the Nauru Agreement Office (Ed.). Majuro, Marshall Islands.

Pascoe, S., Innes, J., Holland, D., Fina, M., Thébaud, O., Townsend, R., Sanchirico, J., Arnason, R., Wilcox, C., \& Hutton, T. (2010). Use of incentive-based management systems to limit bycatch and discarding. International Review of Environmental and Resource Economics, 4(2), 123-161.

Pascual, U., \& Perrings, C. (2007). Developing incentives and economic mechanisms for in situ biodiversity conservation in agricultural landscapes. Agriculture, Ecosystems \& Environment, 121(3), 256-268.

Pauly, D., Christensen, V., Guénette, S., Pitcher, T. J., Sumaila, U. R., Walters, C. J., Watson, R., \& Zeller, D. (2002). Towards sustainability in world fisheries. Nature, 418(6898), 689-695. 
Perez-Aleman, P. (2012). Global standards and local knowledge building: Upgrading small producers in developing countries. Proceedings of the National Academy of Sciences of the United States of America, 109(31), 12344-12349.

Perez-Aleman, P. (2013). Regulation in the process of building capabilities: strengthening competitiveness while improving food safety and environmental sustainability in Nicaragua. Politics \& Society, 41(4), 589-620.

Perez-Aleman, P., \& Sandilands, M. (2008). Building value at the top and the bottom of the global supply chain: MNC-NGO partnerships. California management review, 51(1), 24-49.

Pérez-Ramírez, M., Phillips, B., Lluch-Belda, D., \& Lluch-Cota, S. (2012a). Perspectives for implementing fisheries certification in developing countries. Marine Policy, 36(1), 297-302.

Pérez-Ramírez, M., Ponce-Díaz, G., \& Lluch-Cota, S. (2012b). The role of MSC certification in the empowerment of fishing cooperatives in Mexico: The case of red rock lobster co-managed fishery. Ocean and Coastal Management, 63, 24-29.

Pérez-Sánchez, E., \& Muir, J. F. (2003). Fishermen perception on resources management and aquaculture development in the Mecoacan estuary, Tabasco, Mexico. Ocean \& coastal management, 46(6), 681-700.

Pet-Soede, C., Van Densen, W., Hiddink, J., Kuyl, S., \& Machiels, M. (2001). Can fishermen allocate their fishing effort in space and time on the basis of their catch rates? An example from Spermonde Archipelago, SW Sulawesi, Indonesia. Fisheries Management and Ecology, 8(1), 15-36.

Peterson, S., \& Smith, L. J. (1982). Risk reduction in fisheries management. Ocean Management, $8(1), 65-79$.

Phillips, B., Ward, T., \& Chaffee, C. (2008). Eco-labelling in fisheries: what is it all about? : John Wiley \& Sons.

Pilling, G. M., Thomas Usu, Brian Kumasi, Shelton J. Harley, \& Hampton, J. (2014). Purse seine CPUE for skipjack and yellowfin in the Papua New Guinea purse seine fishery. In Western and Central Pacific Fisheries Commission (Ed.), Scientific Committee Tenth Regular Session, WCPFC-SC10-2014/SA-WP-03. Majuro, Republic of the Marshall Islands

Platteau, J. P., \& Abraham, A. (1987). An inquiry into quasi-credit contracts: The role of reciprocal credit and interlinked deals in small-scale fishing communities. The Journal of Development Studies, 23(4), 461-490.

PNA. (2013). PNA Western \& Central Pacific skipjack tuna fishery's 'free school' set operations gain MSC certification. Retrieved April 14, 2017, 2017, from http://www.pnatuna.com/node/75

PNA. (2016). Sustainably caught tuna tonnage forecast to double in 2017 Retrieved June 17, 2017, 2017, from http://www.pnatuna.com/node/391

Pollnac, R. B., Pomeroy, R. S., \& Harkes, I. H. (2001). Fishery policy and job satisfaction in three southeast Asian fisheries. Ocean \& Coastal Management, 44(7), 531-544.

Pomeroy, R. S. (1995). Community-based and co-management institutions for sustainable coastal fisheries management in Southeast Asia. Ocean \& Coastal Management, 27(3), 143-162.

Ponte, S. (2008a). Developing a vertical dimension to chronic poverty research: Some lessons from global value chain analysis.

Ponte, S. (2008b). Greener than thou: The political economy of fish ecolabeling and its local manifestations in South Africa. World Development, 36(1), 159-175.

Ponte, S. (2012). The Marine Stewardship Council (MSC) and the making of a market for 'sustainable fish'. Journal of Agrarian Change, 12(2-3), 300-315.

Ponte, S., \& Cheyns, E. (2013). Voluntary standards, expert knowledge and the governance of sustainability networks. Global Networks, 13(4), 459-477.

Ponte, S., \& Ewert, J. (2009). Which way is "up" in upgrading? Trajectories of change in the value chain for South African wine. World Development, 37(10), 1637-1650. 
Ponte, S., \& Gibbon, P. (2005). Quality standards, conventions and the governance of global value chains. Economy and society, 34(1), 1-31.

Poos, J.-J., Bogaards, J. A., Quirijns, F. J., Gillis, D. M., \& Rijnsdorp, A. D. (2010). Individual quotas, fishing effort allocation, and over-quota discarding in mixed fisheries. ICES Journal of Marine Science: Journal du Conseil, 67(2), 323-333.

Poos, J.-J., \& Rijnsdorp, A. D. (2007). An" experiment" on effort allocation of fishing vessels: the role of interference competition and area specialization. Canadian Journal of Fisheries and Aquatic Sciences, 64(2), 304-313.

Poseidon Aquatic Resource Management Ltd. (2016). Analysis of the costs and benefits of electronic fisheries information systems applied in FFA countries and identification of the legislative, regulatory, and policy supporting requirements. Port Douglas, Australia.

Potts, T., \& Haward, M. (2007). International trade, eco-labelling, and sustainable fisheries - recent issues, concepts and practices. Environment, Development and Sustainability, 9, 91-106.

Prahalad, C. K., \& Hamel, G. (1990). The core competence of the corporation (Vol. 68).

Pratt, J. W. (1964). Risk-Aversion in the Small and in the Large. Econometrica, 32(1-2), 122-136.

Richards, M. (2000). Can sustainable tropical forestry be made profitable? The potential and limitations of innovative incentive mechanisms. World Development, 28(6), 1001-1016.

Riisgaard, L., Bolwig, S., Ponte, S., Du Toit, A., Halberg, N., \& Matose, F. (2010). Integrating poverty and environmental concerns into value chain analysis: a strategic framework and practical guide. Development Policy Review, 28(2), 195-216.

Rijnsdorp, A., Dol, W., Hoyer, M., \& Pastoors, M. (2000). Effects of fishing power and competitive interactions among vessels on the effort allocation on the trip level of the Dutch beam trawl fleet. ICES Journal of Marine Science: Journal du Conseil, 57(4), 927-937.

Robeyns, I. (2005). The capability approach: a theoretical survey. Journal of human development, 6(1), 93-117.

Robins, N., Roberts, S., \& Abbot, J. (2000). Who Benefits?: A Social Assessment of Environmentally-driven Trade: IIED.

Rohrmann, B. (2008). Risk perception, risk attitude, risk communication, risk management: A conceptual appraisal. Paper presented at the Conferencia presentada en la Sociedad Internacional de Gerenciamiento de Emergencias, TIEMS, Universidad de Melbourne.

Rothaermel, F. T., \& Hess, A. M. (2007). Building dynamic capabilities: Innovation driven by individual-, firm-, and network-level effects. Organization Science, 18(6), 898-921.

Ruddle, K. (2011). Informal" credit systems in fishing communities: Issues and examples from Vietnam. Human Organisation, 70(3), 224-232.

Sampson, G. S., Sanchirico, J. N., Roheim, C. A., Bush, S. R., Taylor, J. E., Allison, E. H., Anderson, J. L., Ban, N. C., Fujita, R., Jupiter, S., \& Wilson, J. R. (2015). Secure sustainable seafood from developing countries. Science 348 (6234), 504-506. doi: [DOI:10.1126/science.aaa4639]

Sanders, D. R., \& Manfredo, M. R. (2002). The white shrimp futures market: lessons in contract design and marketing. Agribusiness, 18(4), 505-522.

Schmitz, H., \& Knorringa, P. (2000). Learning from global buyers. Journal of development studies, $37(2), 177-205$.

Schoemaker, P. J. (1982). The expected utility model: Its variants, purposes, evidence and limitations. Journal of economic literature, 529-563.

Scott, G. P., \& Lopez, J. (2014). The use of FADs in tuna fisheries. In Directorate General for Internal Policies (Ed.). European Union: Scott Fishery Consultants and Azti Tecnalia.

Scott, J. T. J., \& Baker, C. B. (1972). A practical way to select an optimum farm plan under

risk. Am. J. Agr. Econ., 54(4), 657-660.

Sen, A. K. (1990). Development as capability expansion. In in K. Griffin and J. Knight (Ed.), Human Development and the International Development Strategy for the 1990s. MacMillan, London. 
Sen, A. K. (1993). Capability and well-being (Vol. 3rd edition): Cambridge University Prress.

Sethi, S. A. (2010). Risk management for fisheries. Fish and Fisheries, 11(4), 341-365.

Sharp, M. (2011). Investment profile for anchored nearshore fish aggregating device. In SPC (Ed.), SPC Fisheries Newsletter.

Simioni, M., Gonzales, F., Guillotreau, P., \& Le Grel, L. (2013). Detecting asymmetric price transmission with consistent threshold along the fish supply chain. Canadian Journal of Agricultural Economics/Revue canadienne d'agroeconomie, 61(1), 37-60.

Smith, M. D., \& Wilen, J. E. (2005). Heterogeneous and correlated risk preferences in commercial fishermen: The perfect storm dilemma. Journal of Risk and Uncertainty, 31(1), 53-71.

SPC. (2010). Western and Central Pacific Fisheries Commission Tuna Fishery Yearbook Technical Report Secretariat of the Pacific Community.

Squires, D., Grafton, R. Q., Alam, M. F., \& Omar, I. H. (2003). Technical efficiency in the Malaysian gill net artisanal fishery. Environment and Development Economics, 8(03), 481504.

StataCorp, L. P. (2005). Stata base reference manual (Vol. 2).

Stefansson, G., \& Rosenberg, A. A. (2005). Combining control measures for more effective management of fisheries under uncertainty: quotas, effort limitation and protected areas.

Philosophical Transactions of the Royal Society of London B: Biological Sciences, 360(1453), 133-146.

Stratoudakis, Y., McConney, P., Duncan, J., Ghofar, A., Gitonga, N., Mohamed, K. S., Samoilys, M., Symington, K., \& Bourillon, L. (2015). Fisheries certification in the developing world: Locks and keys or square pegs in round holes? Fisheries Research.

Sustainable Fisheries Partnership. (2012). FIP overview. Fishery Improvement Project Retrieved June 6, 2015, from

http://cmsdevelopment.sustainablefish.org.s3.amazonaws.com/2012/01/12/FIP\%20Overvie w\%20Jan\%202012-d6749f2d.pdf

Suzuki, A., Jarvis, L. S., \& Sexton, R. J. (2011). Partial vertical integration, risk shifting, and product rejection in the high-value export supply chain: The Ghana pineapple sector. World Development, 39(9), 1611-1623.

Teece, D., \& Pisano, G. (1994). The dynamic capabilities of firms: an introduction. Industrial and corporate change, 3(3), 537-556.

Tidd, A. N., Pilling, G., \& Harley, S. (2015). Examining productivity changes within the tropical WCPO purse seine fishery. In Western and Central Pacific Fisheries Commission (Ed.), Scientific Committee Eleventh Regular Session WCPFC-SC11-2015/MI-WP-06. Pohnpei, Federated States of Micronesia.

Tolentino-Zondervan, F., Berentsen, P., Bush, S., \& Lansink, A. O. (2017). Modelling the effects of Marine Stewardship Council (MSC) to short-term decision making of Filipino purse seiners. (In press).

Tolentino-Zondervan, F., Berentsen, P., Bush, S. R., Digal, L., \& Lansink, A. O. (2016a). FisherLevel Decision Making to Participate in Fisheries Improvement Projects (FIPs) for Yellowfin Tuna in the Philippines. PLoS One, 11(10), e0163537.

Tolentino-Zondervan, F., Berentsen, P., Bush, S. R., Idemne, J., Babaran, R., \& Oude Lansink, A. (2016b). Comparison of private incentive mechanisms for improving sustainability of Filipino tuna fisheries. World Development, 83(July 2016), 264-279.

Townsend, R. E. (1990). Entry restrictions in the fishery: a survey of the evidence. Land Economics, 66(4), 359-378.

Tran, N., Bailey, C., Wilson, N., \& Phillips, M. (2013). Governance of global value chains in response to food safety and certification standards: The case of shrimp from Vietnam. World development, 45, 325-336. 
Trondsen, T., Helstad, K., \& Young, J. A. (2003). Market-oriented regional fisheries management - an analysis of four fish regions in the North Atlantic. Ocean \& coastal management, 46(9), 917-941.

Tsur, Y., Sternberg, M., \& Hochman, E. (1990). Dynamic modelling of innovation process adoption with risk aversion and learning. Oxford Economic Papers, 336-355.

Tucker, J. W. (2010). Selection bias and econometric remedies in accounting and finance research. Journal of Accounting Literature, Winter.

Turner, M. A. (1997). Quota-induced discarding in heterogeneous fisheries. Journal of Environmental Economics and Management, 33(2), 186-195.

Uchida, H., Roheim, C. A., Wakamatsu, H., \& Anderson, C. M. (2014). Do Japanese consumers care about sustainable fisheries? Evidence from an auction of ecolabelled seafood. Australian Journal of Agricultural and Resource Economics, 58(2), 263-280.

Usu, T., B., K., \& L., B. (2012). Annual report to the commission - Part 1: information on fisheries, research and statistics: Papua New Guinea [AR CCM 18]. In Western and Central Pacific Fisheries Commission (WCPFC). (Ed.), Scientific Committee Regular Session, (pp. 8th. 25 p). Busan, Republic of Korea.

Usu, T., Kumasi, B., \& Baje, L. (2013). Annual Report to the Commission Part 1: Information on Fisheries, Research and Statistics 2012 Papua New Guinea. In Western and Central Pacific Fisheries Commission (Ed.), Scientific Committee Seventh Regular Session. Pohnpei, Federated States of Micronesia 06th -14th August, 2012.

Usu, T., Kumasi, B., \& Baje, L. (2014). Annual report to the commission part 1: Information on fisheries, research and statistics Western and Central Pacific Fisheries Commission 10th Regular Session of the Scientific Committee. Majuro Republic of the Marshall Islands.

Usu, T., Kumasi, B., \& Baje, L. (2015). Annual report to the commission Part 1: Information on fisheries, research and statistics 2014 Papua New Guinea. Paper presented at the Western and Central Pacific Fisheries Commission 11th Regular Session of the Scientific Committee, Pohnpei, Federated States of Micronesia.

Valderrama, D., \& Engle, C. R. (2001). Risk analysis of shrimp farming in Honduras. Aquaculture Economics \& Management, 5(1-2), 49-68.

Van Hecken, G., \& Bastiaensen, J. (2010). Payments for Ecosystem Services in Nicaragua: Do Market-based Approaches Work? Development and Change, 41(3), 421-444.

Van Putten, I., Kulmala, S., Dowling, N., Hamon, K. G., Hutton, T., Pascoe, S., \& Thébaud, O. (2010). Towards Behavioural Models of Fleet Dynamics. Paper presented at the International Institute of Fisheries Economics and Trade 2010, Montpellier, France.

Van Riel, M. C., Bush, S. R., Zwieten, P. A., \& Mol, A. P. (2015). Understanding fisheries credit systems: potentials and pitfalls of managing catch efficiency. Fish and Fisheries, 16(3), 453-470.

Vera, C. A., \& Hipolito, Z. (2006). The Philippines tuna industry: a profile: International Collective in Support of Fishworkers.

von Essen, L.-M., Ferse, S. C., Glaser, M., \& Kunzmann, A. (2013). Attitudes and perceptions of villagers toward community-based mariculture in Minahasa, North Sulawesi, Indonesia. Ocean \& Coastal Management, 73, 101-112.

Wakamatsu, H. (2014). The impact of MSC certification on a Japanese certified fishery. Marine Resource Economics, 29(1), 55-67.

Warning, M., \& Key, N. (2002). The social performance and distributional consequences of contract farming: An equilibrium analysis of the Arachide de Bouche programme in Senegal. World Development, 30(2), 255-263.

Weber, J., \& Willenborg, M. (2003). Do expert informational intermediaries add value? Evidence from auditors in microcap initial public offerings. Journal of Accounting Research, 41(4), 681-720. 
West, R. J., Palma, M. A., Barut, N., Garvilles, E., \& Ayanan, D. (2011). Preliminary assessment of the handline (banca) fisheries in the Philippines Final Report (FIS/2009/033 ed.). Canberra, ACT: Australian Centre for International Agricultural Research.

Western and Central Pacific Fisheries Commission. (2014). WCPFC Records of fishing vessels Retrieved January 18, 2015, 2015, from http://www.wcpfc.int/record-fishing-vessel$\underline{\text { database }}$

Western and Central Pacific Fisheries Commission. (2015a). Conservation and management measure for bigeye, yellowfin and skipjack tuna in the Western and Central Pacific Ocean. In WCPFC (Ed.), Twelfth Regular Session of the Commission. Bali, Indonesia

Western and Central Pacific Fisheries Commission. (2015b). Information paper: Data summaries in support of discussions on the CMMs on tropical tunas (CMM 2013-01 AND CMM 201401): WCPFC.

Western and Central Pacific Fisheries Commission. (2016). Information paper: Data summaries in support of discussions on the CMMs on tropical tunas. In Western and Central Pacific Fisheries Commission (Ed.).

Wilen, J. E. (1979). Fisherman behavior and the design of efficient fisheries regulation programs. Journal of the Fisheries Board of Canada, 36(7), 855-858.

Williamson, O. (2002). The theory of the firm as governance structure: from choice to contract. Journal of Economic Perspectives, 16(3), 171-195.

World Wide Power Products. (2017). Industrial marine engines Retrieved February 16, 2017, 2017 , from http://www.wpowerproducts.com

World Wide Fund for Nature. (2014). Fisheries in transition Retrieved June 27, 2016, 2016

Wu, J. S., \& Zang, A. Y. (2009). What determine financial analysts' career outcomes during mergers? Journal of Accounting and Economics, 47(1), 59-86.

Yeeting, A. D., Bush, S. R., Ram-Bidesi, V., \& Bailey, M. (2016). Implications of new economic policy instruments for tuna management in the Western and Central Pacific. Marine Policy, 63, 45-52.

Yin, R. K. (2009). Case study research: Design and methods (Vol. 5): SAGE.

Zahra, S. A. (2005). Entrepreneurial risk taking in family firms. Family Business Review, 18(1), 23 40. 
Summary 
Unsustainable fishing practices, including the use of non-selective fishing methods and Illegal Unreported and Unregulated (IUU) fishing, contribute to the decline of tuna fish stocks in the Western and Central Pacific Ocean (WCPO). Addressing these unsustainable fishing practices requires improved fishery governance. Government regulations, such as catch quotas, restrictions in fishing gears and licenses, and seasonal closures of fishing areas, have been traditionally applied to address the conservation challenges in WCPO tuna fishery. The perceived failure of the government to address unsustainable fishing practices of fishers has led to a shift towards private incentive mechanisms as innovative instruments to enhance the sustainability of tuna fisheries.

Private incentive mechanisms are instruments that allow value chain actors to decide whether and to what extent to change fishing practices based on economic incentives (e.g. price premiums). Research on private incentive mechanisms has mostly focused on the extremely large and small scale fishers to tackle the sustainability issues in tuna fisheries. This has resulted in a lack of attention given to 'missing' middle-scale fishers such as Filipino tuna fishers. The majority of Filipino tuna fishers operates neither at a small-scale, nor at a large scale compared to fishers in countries in Europe and the United States. In addition, the analysis of private incentive mechanisms is mostly focused on the incentives and on the failures and successes of these mechanisms to bring sustainable improvements in the fishery. However, there is no study so far that analyses the influence of private incentive mechanisms on the decision making of fishers. These knowledge gaps lead to the main objective of this dissertation which is: to evaluate the extent to which private incentive mechanisms influence Filipino fishers' decisions to improve their fishing practices.

This thesis combines concepts from global value chain analysis and economic decision making theory to build an overall framework for analyzing private incentive mechanisms in tuna fisheries. The main assumption in the framework is that the behaviour of an individual is not simply influenced by economic factors, but also by the individual's social interaction with society. This 
means that the incentives of private incentive mechanisms do not directly lead to the change in behaviour of fishers because several factors could influence the decision making of fishers to improve their practices. These factors include their capability to comply with requirements of incentive mechanisms and their risk attitude to the income and risks inherent in private incentive mechanisms. The overall objective of this thesis is addressed through four sub-objectives represented by the four research chapters.

Chapter two analyses and compares the ways existing private incentive mechanisms influence the upgrading strategies of Filipino tuna fishers in the value chains. The three private incentive mechanisms analyzed in this chapter are Fishery Improvement Projects (FIPs), Marine Stewardship Council (MSC) certification, and International Seafood Sustainability Foundation's (ISSF) proactive vessel registry. This chapter starts by introducing the value chain analysis framework which includes producers' capabilities as a condition for upgrading. These capabilities are influenced by existing governance arrangements at the vertical dimension of the chain and by public and private institutions that set rules and norms and that provide institutional support at the horizontal dimension. The results of the three private incentive mechanism cases show that the majority of the target fishers in FIPs still lack the required capabilities to upgrade while a few FIP participants who developed capabilities with the help of fisher associations are able to upgrade their product and therefore realize the incentives for participation. Fishers involved in MSC possess capabilities, and one third of these fishers not only choose to upgrade their product and process, but also their functions in the chain through the establishment of joint venture companies with local processors. The rest of the fishers do not upgrade because it is unclear for them whether the economic value of the incentive in MSC is sufficient to cover their costs and compensate for the risks of doing MSC free school fishing. Finally, fishers involved in the ISSF also have the capabilities and can potentially improve their vertical coordination by strengthening their relationships with ISSF processors and related traders. Reflecting on these results, some fishers are able, while others are 
not able to upgrade their practices under private incentive mechanisms based on their capabilities. Moreover, the incentives offered by private incentive mechanisms are not simply delivered to fishers because (i) the vertical actors determine whether and how the incentives will be delivered to fishers, and (ii) the horizontal actors influence fishers' capabilities to realize this incentive.

Chapter three evaluates the important determinants for small-scale handline fishers' decisions to participate in two FIPs for yellowfin tuna in the Philippines. These include the market-oriented Artesmar and the development-oriented Partnership Programme Towards Sustainable Tuna (PPTST) FIPs. Based on the differences in requirements and performance in delivering market incentives to fishers, this chapter develops a two-stages participation decision making framework of fishers. The first stage decision assumes that fishers will choose to participate in Artesmar FIP because this FIP delivers higher returns and lowers the risk of fishers in terms of fluctuation in fish prices. In case fishers are not able to participate in Artesmar FIP, the next best option for fishers at the second stage is to choose for PPTST FIP, which offers partial and full participation depending on fishers' ability to fulfill the requirements. In case fishers do not participate in PPTST FIP, the final option for them is to not participate at all. The results of this chapter show that fishers possess different capabilities, which determine the types of FIPs that they participate in. The individual firm capabilities that are possessed by few fishers in FIPs strongly influence fishers' decision to participate in the top-down market-oriented Artesmar FIP. The collective capabilities, which are possessed by the majority of fishers, enable them to improve their fishing practices in order to participate in bottom-up development-oriented FIPs. Moreover, the majority of the fishers only partially participate in development-oriented FIP because they do not possess the capabilities to a sufficient degree. If the capabilities of these fishers improve, they may choose to fully participate in market-oriented FIPs, which will enable them to realize the incentives for participation and to contribute to fishery sustainability. In line with chapter two, this chapter shows that private incentive mechanisms should balance the delivery of incentives to fishers and should support the 
development of capabilities of fishers, in order to enhance the participation of wider group of fishers.

Chapter four examines the effect of MSC certification on the allocation of fishing days by Filipino purse seiners operating in Papua New Guinea (PNG), one of the member states of Parties to Nauru Agreement (PNA). As part of its management measures, the PNA employs Vessel Day Scheme (VDS) to set the price of fishing days in Exclusive Economic Zones (EEZ) and MSC free school for skipjack caught in their EEZ. Vessels doing MSC fishing are allowed to fish both in free school and in Fish Aggregating Devices (FADs) when there is no seasonal FAD closure in the EEZ. In addition, vessels can also fish in the archipelagic water of PNG under Federated States of Micronesia Arrangement, using FAD and free school fishing methods. The allocation decisions of fishers in these fishing grounds using different fishing methods are influenced by their risk attitude and by the level of income and risks caused by the fluctuation in prices and catches. This chapter determines the likely outcome of the allocation decisions of fishers in order to assess the effectiveness of MSC in reducing FAD fishing and increasing free school fishing practices of fishers. The results show that adopting MSC free school fishing generally increases the income of purse seine fishers with different levels of risk aversion, and therefore MSC clearly incentivizes fishers to adopt practices that are believed to contribute to sustainable fishery. The results show that somewhat and rather risk averse fishers are those most willing to adopt MSC compliant free school fishing. These fishers increase their MSC fishing days, which leads to a higher level of expected income and risk. The highly risk averse fishers on the other hand are less likely to adopt MSC and therefore allocate the least days to MSC free school fishing. This leads to lower income and lower risk for these fishers. This chapter shows the importance of understanding the risk attitude of fishers so that fishery managers or value chain actors employing the incentive mechanisms can match the expected premiums against the expected risks of these fishers. 
Chapter five analyses the profitability of investments in measures needed to comply with private incentive mechanisms by Filipino purse seiners. The two private incentive mechanisms that this chapter analyses are the ISSF eco-FADs and MSC free school fishing, both of which aim to address the FAD fishing practices of purse seiners. Using the Net Present Value (NPV) method, this chapter assesses the investment decisions in either one, or both mechanisms jointly. The results show that less risk averse fishers in general will benefit from positive returns on their investments in ISSF eco-FADs and MSC free school and that the investment in both mechanisms is the most profitable strategy for this type of fishers. Moreover, the findings show that the investments in MSC free school are more robust given the positive return on investments of fishers regardless of their risk aversion. The investments on both mechanisms and on ISSF eco-FADs of fishers with higher risk aversion lead to lower and even negative returns on their investments. Based on these findings, this chapter concludes that a combination of incentive mechanisms in multi-gear fishery can cover a wider set of sustainability issues and at the same time provide more economic benefits for less risk averse fishers. Moreover, reducing the perceived risks of investments through future contracts, floor prices, and flexible taxation schemes among others, are necessary to attract more fishers to adopt incentive mechanisms. The higher inclusiveness of a wider group of fishers that vary in risk aversion in the incentive mechanisms may further increase the sustainability of the fishery.

Chapter six reflects and synthesizes the results of chapters two to five and discusses the theoretical implications of this thesis on the future design of incentive mechanisms and on the set of actors who engage in these mechanisms. In the synthesis section, this chapter uses two themes, i.e. capabilities and risk attitude. The first theme focuses on capabilities to cover the insights from chapters two and three while the second theme focuses on tactical and strategic decision making under uncertainty to incorporate the insights in chapters four and five. Based on the results of chapter two and three, the first theme shows that the capabilities of producers are an enabling or limiting factor in the upgrading of producers. Therefore, focusing on capabilities of producers is an important step in 
understanding the participation of fishers in private incentive mechanisms. Based on the results of chapters four and five, the second theme shows that producers do not simply change their fishing practices in response to incentives offered by private incentive mechanisms. Instead, the risk aversion of fishers influences their decision making to adopt sustainable tuna fishing. Therefore, reducing the risks associated with the participation in private incentive mechanisms can increase the participation of fishers that vary in risk aversion.

The synthesis of the four chapters contributes to theoretical insights on the role that private incentive mechanisms in tuna fisheries and other commodity sectors in facilitating a transition to sustainable production practices. At the start of this dissertation, the initial assumption was that the incentives of private incentive mechanisms do not directly lead to improvements in fishing practices of fishers. This assumption is further elaborated using the analytical concepts of capabilities, risk attitude, risk and income. As shown in chapters two and three, producers first need to have the capabilities to meet the requirements of private incentive mechanisms, so that they can be included in the value chain and that they can realize the incentives offered by these mechanisms. However, being capable does not guarantee that producers will improve their practices. The producers must also have the willingness to upgrade, based on the ability of the economic incentive to cover the additional costs and to compensate for the increase of the risks of participation of producers. Given that producers have the capabilities to upgrade and that the benefit is sufficient to opt for participation, they may decide to improve their practices. And that decision to make improvements in their practices may contribute to the sustainability improvement goal of private incentive mechanisms. Based on these theoretical insights, the future design of incentive mechanisms must account for incentives, inclusiveness, and improvement in order to successfully bring sustainability improvements. Recommendations on ways to increase the participation of fishers that include focusing on the development of capabilities of fishers and reducing the perceived risks of adopting 
private incentive mechanisms by fishers are provided for different actors involved in the incentive mechanisms.

The overall finding of the thesis is that private incentive mechanisms are able to influence the change in fishing practices of Filipino fishers but only to a limited overall extent based on the participation of fishers. The broader challenge these mechanisms face is the limited inclusiveness of developing country fishers in its program. Private incentive mechanisms that build the capabilities of fishers and ensure that the economic value of the incentives covers the costs, and compensate for the risks, of participation of fishers, will attract a large participation of fishers and may contribute more to the sustainability of the fishery. 
Appendices 


\section{Appendix A. Estimation of the sample size}

The sample size was calculated starting from unknown population equation:

$$
s s=(Z \text {-score })^{2} * s d^{*}(1-s d) /(c)^{2}
$$

where Z-score is the standard score in statistics, $s d$ is the standard deviation, expressed as decimal, and $c$ is the confidence interval, also expressed as decimal. We use the $95 \%$ confidence level with Z-score of 1.96 and a confidence interval of $\pm 5 \%$. The recommended standard deviation of 0.5 is used before the survey is administered as it ensures that the samples will be large enough (REF). The recommended sample size for unknown population is 384 . Since the population of fishers in the area is known, the sample size is adjusted based on unknown population equation (Field, 2003):

$$
\text { new } s s=s s /(1+s s-1 / \text { population })
$$

In equation 2, the new ss represents new sample size while ss is the required sample size in equation 1. The adjusted sample size of for known population is 350 samples. 


\section{Appendix B. Survey forms on household fishers}

\section{SURVEY FORM FOR SHORT- AND LONG-TERM DECISION MAKING OF HOUSEHOLD/INDIVIDUAL FISHERS}

Dear Madame/Sir:

Good day!

I am Frazen Tolentino, Phd student at Wageningen University (The Netherlands). I am currently conducting research on the effects of incentive mechanisms such as MSC certifications, Fishery Improvement Projects or FIPs, and private branding strategy of ISSF member brands, to short- and long-term decision making of fishers. The goal of my research is to provide insights on which decisions, such as how much to catch, how much resources to use, and invest or disinvest in fishing technologies and fleets, will help fishers reach their objectives. In line with this, I would like to request for your participation in a survey. The survey may take an hour of your time. Please rest assured the information you provided will be used for academic and research purposes only. At the end of the survey, I'll kindly ask you to sign the form as proof of your participation in the survey and that you agree to use the information for academic and research purposes.

Thank you very much.

P.S.: In case of further information or clarification, provided is my contact information:

Frazen Tolentino

$+63927-248-1512$

Frazen.tolentino@wur.nl, frazentolentino@gmail.com

Business Economics Group

Wageningen University, The Netherlands 


\section{A. HOUSEHOLD FISHERS' CHARACTERISTICS}

\section{A.1. SOCIO-DEMOGRAPHIC ASPECT}

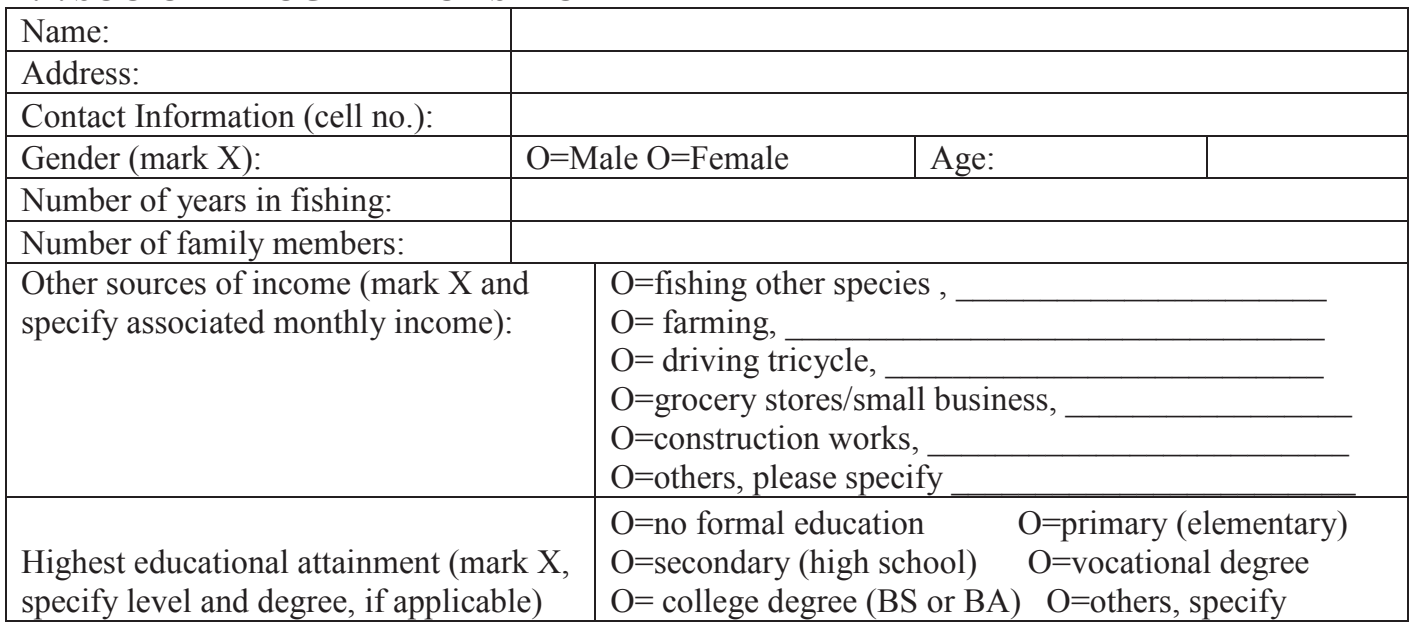

\section{B. MATERIAL RESOURCES}

\section{B.1. FISHING BOATS}

\begin{tabular}{|l|l|}
\hline No. of fishing boats & \\
\hline Name of fishing boats/vessels & \\
\hline Initial investment $(\mathrm{PhP})$ & \\
\hline Replacement value (PhP) & \\
\hline Boat repair (PhP/year) & \\
\hline Age of the boat (year) & \\
\hline $\begin{array}{l}\text { Number of boat crew (including } \\
\text { captains) }\end{array}$ & \\
\hline $\begin{array}{l}\text { Fishing licenses or registration } \\
\text { (PhP/year) }\end{array}$ & \\
\hline Vessel weight (metric tons) & \\
\hline Length size (m) & \\
\hline Fish capacity (in kg) & \\
\hline Number of compartments/bins &
\end{tabular}

\section{B.2. VESSEL OWNERSHIP (mark X)}

\begin{tabular}{|l|l|l|}
\hline $\mathrm{O}=$ owner & $\mathrm{O}=$ boat captain & $\mathrm{O}=$ passenger \\
\hline If owner, how did you finance your vessels? & $\mathrm{O}=$ fisher's cooperative \\
\hline $\mathrm{O}=$ personal savings & $\mathrm{O}=$ bank loans & \multicolumn{2}{|l|}{} \\
\hline $\mathrm{O}=$ through relatives & $\mathrm{O}=$ others, specify &
\end{tabular}

Amount loan: 
Interest Rate:

Monthly Payment:

\section{B.3. FISHING GEARS (What fishing gears do you use? Mark X)}

\begin{tabular}{|l|l|}
\hline Fishing gears & Costs: \\
\hline $\mathrm{O}=$ handline & \\
\hline $\mathrm{O}=$ hook-and-line & \\
\hline $\mathrm{O}=$ jigger & \\
\hline $\mathrm{O}=$ pole and line & \\
\hline $\mathrm{O}=$ others, specify & \\
\hline & \\
\hline Length size: & \\
\hline Number of traps: & \\
\hline
\end{tabular}

B.4. FISHING TECHNOLOGIES (mark $\mathrm{X}$ and determine the amount of investments, life span, number of years used, maintenance costs)

\begin{tabular}{|l|l|l|l|l|}
\hline & $\begin{array}{l}\text { Investment } \\
(\text { PhP) }\end{array}$ & Life span & $\begin{array}{l}\text { No. Of years } \\
\text { used }\end{array}$ & $\begin{array}{l}\text { Maintenance } \\
\text { costs }\end{array}$ \\
\hline $\mathrm{O}=$ sonar radar & & & & \\
\hline $\mathrm{O}=$ compass & & & & \\
\hline $\begin{array}{l}\mathrm{O}=\text { GPS tracking } \\
\text { device }\end{array}$ & & & & \\
\hline $\mathrm{O}=$ radio & & & & \\
\hline $\mathrm{O}=$ generator & & & & \\
\hline $\mathrm{O}=$ others, specify & & & & \\
\hline
\end{tabular}

\section{FIP REQUIREMENTS}

A. Fisherfolk and Vessel registration

A.1 Are you a registered fisherfolk in your respective municipality? $\mathrm{O}=\mathrm{No} \mathrm{O}=\mathrm{Yes}$ If not, reason why?

A.2 Vessel registration (in Table B1)

B. Traceability

B.1 Do you use catch documents $\mathrm{O}=\mathrm{No} \mathrm{O}=\mathrm{Yes}$

If yes, what are the information provided in catch documents?

B.2 Do you use tuna tags? $\mathrm{O}=\mathrm{No} \mathrm{O}=\mathrm{Yes}$

If yes, what are the information provided in tuna tags? 
C. Fish Quality

C.1. What's your mode of selling tuna? $\mathrm{O}=$ Straight buying $\mathrm{O}=$ Quality Buying

Price in Straight Buying (PhP)

Price in Quality Buying: Good quality: Reject:

D. Trainings

\begin{tabular}{|l|l|}
\hline Are you aware of FIP & $\mathrm{O}=$ No $\mathrm{O}=\mathrm{Yes}$ \\
\hline If yes, which FIP are you aware of? & $\mathrm{O}=$ PPTST O=Artesmar \\
\hline When did you join FIP? & \\
\hline Reasons for joining? & $\mathrm{O}=$ No $\quad \mathrm{O}=$ Yes \\
\hline $\begin{array}{l}\text { Are you a member of fishers } \\
\text { cooperative/association? (mark X) }\end{array}$ & \\
\hline If yes, name of association & $\mathrm{O}=$ provide credit \\
\hline Position in association & $\mathrm{O}=$ provide trainings \\
\hline Activities of association (mark X): & $\mathrm{O}=$ provide marketing services \\
\hline & $\mathrm{O}=$ others, specify \\
\hline &
\end{tabular}

C.2. Trainings and Education (please shade and identify the name of trainings)

O Capacity buildings,

$\mathrm{O}=$ Marketing and value-adding activities on tuna,

$\mathrm{O}=$ New fishing technology,

$\mathrm{O}=$ Seminars on fishery management,

C.3. Subsidies from the government (mark X those that are received)

\begin{tabular}{|l|l|}
\hline Subsidies from the government & $\mathrm{O}=$ fuel subsidy \\
\hline & $\mathrm{O}=$ new fishing gears \\
\hline & $\mathrm{O}=$ new boat motors \\
\hline & $\mathrm{O}=$ others, please specify, \\
\hline
\end{tabular}

SHORT-RUN OBJECTIVES (Maximise fishing income, minimise risks)

\section{A. FISHING TRIP INFORMATION}

\begin{tabular}{|l|l|}
\hline Name of fishing Ground & \\
\hline $\begin{array}{l}\text { Fishing trip (in hours or days, one } \\
\text { way) }\end{array}$ & \\
\hline Number of fishing days & \\
\hline Number of fishing trips in a month & \\
\hline Name of unloading port & \\
\hline
\end{tabular}


Distance of fishing ground to unloading port

\section{B. COSTS per FISHING TRIP}

\begin{tabular}{|l|l|l|}
\hline & Usage & Costs \\
\hline Fuel consumption for boat's motor (L) & & \\
\hline Gasoline consumption for generator (L) & & \\
\hline Ice (Blocks) & & \\
\hline Baits (bottles) & & \\
\hline $\begin{array}{l}\text { Workers expenses (include foods, cigarettes, } \\
\text { water, medicines) }\end{array}$ & & \\
\hline Total Fishing Costs $(\mathrm{PhP})$ & & \\
\hline
\end{tabular}

Worker's wage: If sharing system what are the percentages for:

boat owners captains crews

how much do you normally get per fishing trip?

How do you finance your fishing operation? $\mathrm{O}=\mathrm{O}$ wn financing $\mathrm{O}=$ Casas

\section{E. FISHING OUTPUTS}

\begin{tabular}{|l|l|l|l|l|l|l|l|}
\hline $\begin{array}{l}\text { Catches } \\
(2013 \text { and } \\
2014):\end{array}$ & \multicolumn{2}{|l|}{ Yellowfin } & \multicolumn{2}{|l|}{ Skipjack } & \multicolumn{2}{l|}{ Small pelagics } & $\begin{array}{l}\text { for home } \\
\text { consumption } \\
\text { (Kgs) }\end{array}$ \\
\hline $\begin{array}{l}\text { Highest } \\
\text { catch }\end{array}$ & & & & & & & \\
\hline $\begin{array}{l}\text { Average } \\
\text { catch }\end{array}$ & & & & & & & \\
\hline $\begin{array}{l}\text { Lowest } \\
\text { catch }\end{array}$ & & & & & & & \\
\hline & & & & & & & \\
\hline
\end{tabular}

\begin{tabular}{|l|l|l|l|l|l|l|l|}
\hline $\begin{array}{l}\text { Tuna } \\
\text { Prices in } \\
\text { PhP (2013 } \\
\text { and 2014): }\end{array}$ & \multicolumn{2}{|l|}{ Yellowfin } & \multicolumn{2}{l|}{ Skipjack } & \multicolumn{2}{l|}{ Small pelagics } & $\begin{array}{l}\text { for home } \\
\text { consumption } \\
\text { (Kgs) }\end{array}$ \\
\hline $\begin{array}{l}\text { Highest } \\
\text { price }\end{array}$ & & & & & & & \\
\hline $\begin{array}{l}\text { Average } \\
\text { price }\end{array}$ & & & & & & & \\
\hline $\begin{array}{l}\text { Lowest } \\
\text { price }\end{array}$ & & & & & & & \\
\hline & & & & & & & \\
\hline
\end{tabular}




\begin{tabular}{|l|l|}
\hline Who are the buyers of tuna? (mark X) & $\mathrm{O}=$ Casas \\
\hline & $\mathrm{O}=$ Local consumer \\
\hline & $\mathrm{O}=$ Restaurants \\
\hline & $\mathrm{O}=$ others, specify \\
\hline
\end{tabular}

Break-even catch (in $\mathrm{kg}$ ) per fishing trip

Difference in price before and after joining FIP?

Difference in fish volume before and after joining FIP?

\section{H. ALTERNATIVE ACTIVITIES:}

During low season of tuna, what species do you catch?

Where do you fish?

\begin{tabular}{|l|l|}
\hline $\begin{array}{l}\text { What will make you exit tuna } \\
\text { fishery? (Rank from 1-5) }\end{array}$ & \\
\hline Low supply & \\
\hline Stiff competition & \\
\hline Stringent regulation & \\
\hline Age & \\
\hline Others & \\
\hline
\end{tabular}

Alternative activity when you exit tuna fishery? (Mark X)

\begin{tabular}{|l|l|l|l|l|l|}
\hline $\mathrm{O}=$ Farming & $\begin{array}{l}\mathrm{O}=\text { Grocery } \\
\text { store }\end{array}$ & $\begin{array}{l}\mathrm{O}=\text { tricycle } \\
\text { driving }\end{array}$ & $\begin{array}{l}\mathrm{O}=\text { other } \\
\text { business } \\
\text { venture }\end{array}$ & $\begin{array}{l}\mathrm{O}=\text { construction } \\
\text { work }\end{array}$ & O=others, specify \\
\hline
\end{tabular}


Appendix C. Testing the explanatory variables for multi-collinearity using a Variance Inflation Factor (VIF)

\begin{tabular}{lrr}
\hline Variable & VIF & \multicolumn{1}{c}{ 1/VIF } \\
\hline Fishingyears & 1.72 & 0.581286 \\
Educ & 1.09 & 0.914702 \\
Membershiptoasso & 1.45 & 0.68818 \\
Training & 1.68 & 0.596774 \\
Initialinv & 1.35 & 0.73808 \\
Boatown & 1.53 & 0.653497 \\
Boatcap & 1.38 & 0.722977 \\
Financeop & 1.26 & 0.792804 \\
Fishingtrips & 2.42 & 0.413616 \\
Season & 1.53 & 0.655531 \\
Opdistance & 1.29 & 0.774056 \\
Fishingdays & 2.25 & 0.444646 \\
Risksattitude & 1.2 & 0.834178 \\
Age & 1.78 & 0.563052 \\
Fammem & 1.17 & 0.857847 \\
Sourinc & 1.16 & 0.862938 \\
Mean VIF & 1.54 & \\
\hline
\end{tabular}

Appendix D. Testing the explanatory variables for heteroskedasticity

\begin{tabular}{l}
\hline hettest \\
\hline Breusch- Pagan / Cook- Weisberg test for heteroskedasticity \\
Ho: Constant variance \\
Variables: fitted values of stages \\
chi2 $(1)=1.90$ \\
Prob $>$ chi $2=0.1679$ \\
\hline
\end{tabular}




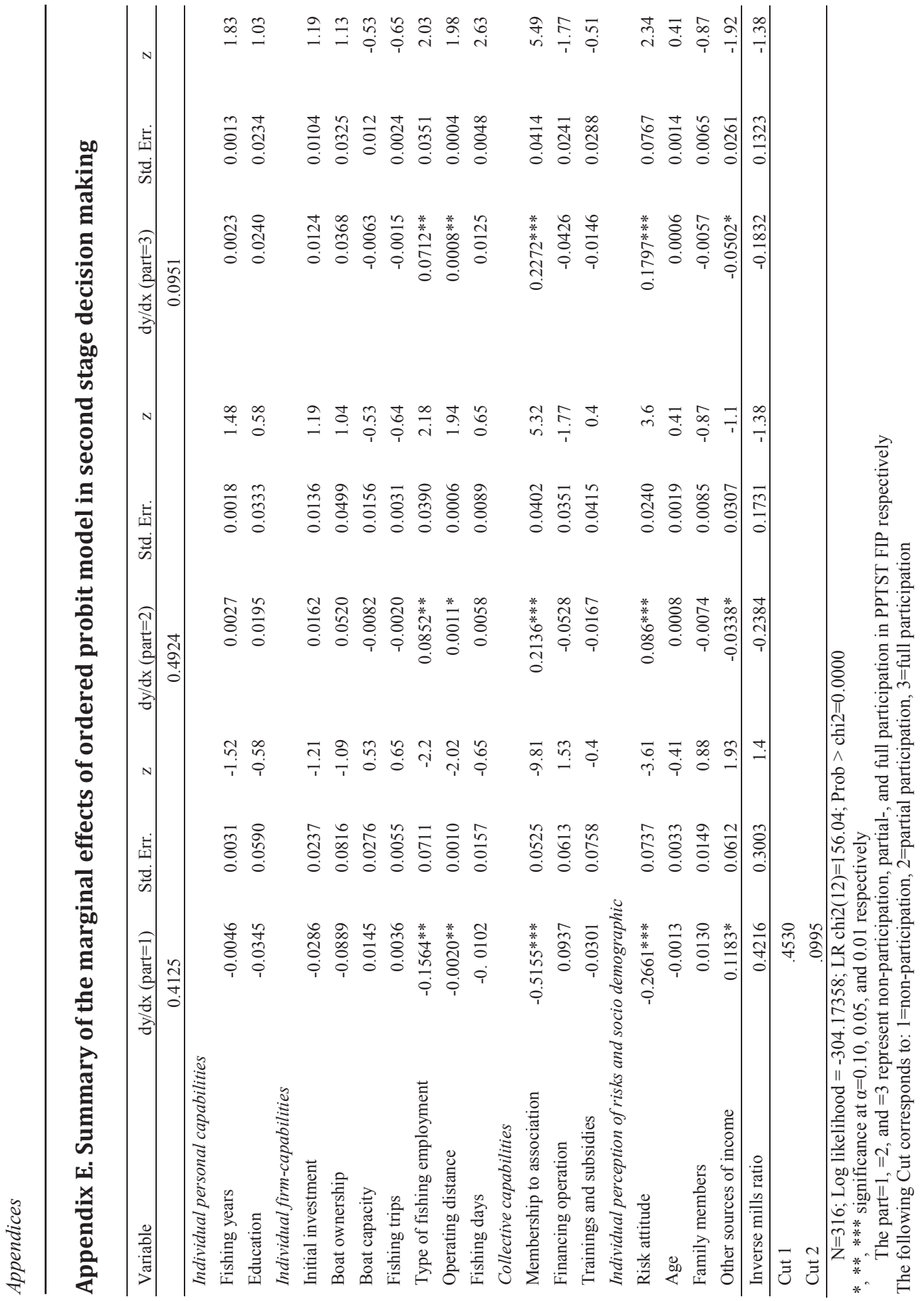


Appendix F. Ordered probit model of fisher data from Sablayan and Mamburao, Occidental Mindoro, with inverse Mills ratio

\begin{tabular}{lccc}
\hline Ordered probit regression & \multicolumn{3}{c}{$\begin{array}{c}\text { Number of obs }= \\
\text { LR chi2(16) }=\end{array}$} \\
\multicolumn{1}{c}{ Log likelihood $=-138.76397$} & $\begin{array}{c}\text { Prob.chi2 }=0.000 \\
\text { Pseudo R2 }=\end{array}$ \\
\hline Stages & Coefficients & Standard error & 0.3088 \\
\hline Fishing years & 0.016 & 0.011 & $\mathrm{Z}$ \\
Education & -0.036 & 0.209 & -0.17 \\
Membership to association & 1.68 & 0.252 & $6.65^{* * *}$ \\
Training & 0.148 & 0.259 & 0.57 \\
Initial investment & 0.036 & 0.072 & 0.5 \\
Boat ownership & 0.485 & 0.246 & $1.97 * *$ \\
Boat capacity & -0.052 & 0.084 & -0.62 \\
Financing operation & -0.296 & 0.200 & -1.48 \\
Fishing trips & -0.037 & 0.024 & -1.55 \\
Fishing employment & 0.255 & 0.236 & 1.08 \\
Operating distance & 0.004 & 0.003 & 1.52 \\
Fishing days & 0.051 & 0.053 & 0.96 \\
Risk attitude & 0.957 & 0.410 & $2.33^{* *}$ \\
Age & -0.003 & 0.010 & -0.28 \\
Family members & -0.007 & 0.065 & -0.11 \\
Other sources of income & -0.422 & 0.204 & $-2.07^{* *}$ \\
Inverse Mills Ratio ${ }^{1}$ & -0.865 & 1.1018 & -0.79 \\
& & & \\
\hline /cut1 & 1.20 & 0.573 & \\
/cut2 & 2.31 & 0.606 & \\
\hline
\end{tabular}

${ }^{1}$ The inverse Mills ratio is insignificant in ordered probit model of fisher data from Sablayan and Mamburao, Occidental Mindoro 
Appendix G. Ordered probit model of fisher data in Occidental Mindoro without inverse Mills ratio

\begin{tabular}{|c|c|c|c|c|}
\hline \multicolumn{2}{|l|}{ Ordered probit regression } & \multirow{4}{*}{$\begin{array}{l}\text { Number of obs } \\
\text { LR chi2(16) } \\
\text { Pseudo R2 } \\
\text { Standard error }\end{array}$} & \multirow{3}{*}{$\begin{array}{l}= \\
= \\
=\end{array}$} & \multirow{4}{*}{$\begin{array}{r}296 \\
166.46 \\
0.2705 \\
Z\end{array}$} \\
\hline & & & & \\
\hline \multicolumn{2}{|c|}{ Log likelihood $=-224.41025$} & & & \\
\hline Stages & Coefficients & & & \\
\hline Fishing years & 0.010 & 0.008 & & 1.3 \\
\hline Education & 0.067 & 0.151 & & 0.45 \\
\hline Membership to association & 1.54 & 0.181 & & $8.54 * * *$ \\
\hline Training & 0.147 & 0.189 & & 0.78 \\
\hline Initial investment & 0.052 & 0.058 & & 0.89 \\
\hline Boat ownership & 0.292 & 0.203 & & 1.44 \\
\hline Boat capacity & -0.047 & 0.070 & & -0.68 \\
\hline Financing operation & -0.241 & 0.158 & & -1.52 \\
\hline Fishing trips & -0.011 & 0.014 & & -1.82 \\
\hline Fishing employment & 0.490 & 0.179 & & $2.73 * * *$ \\
\hline Operating distance & 0.006 & 0.002 & & $2.31 * *$ \\
\hline Fishing days & 0.007 & 0.038 & & 0.17 \\
\hline Risk attitude & 0.597 & 0.221 & & $2.7 * * *$ \\
\hline Age & 0.002 & 0.008 & & 0.28 \\
\hline Family members & -0.054 & 0.035 & & -1.52 \\
\hline Other sources of income & -0.313 & 0.157 & & $-2 * *$ \\
\hline /cut1 & .913 & .446 & & \\
\hline /cut2 & 2.44 & .464 & & \\
\hline
\end{tabular}




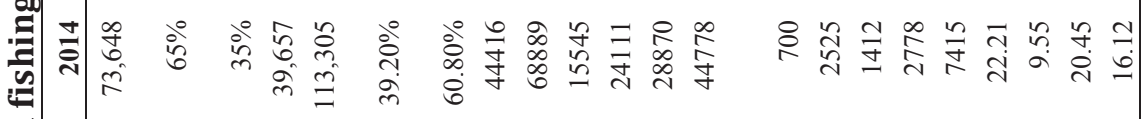

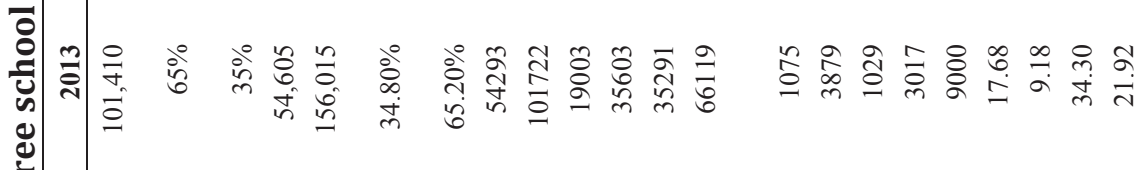

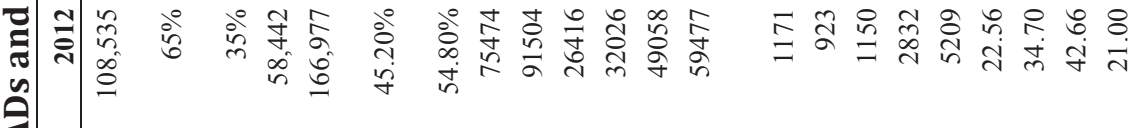
空 .

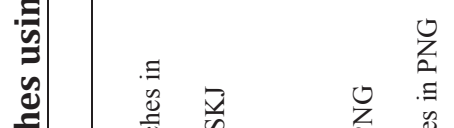

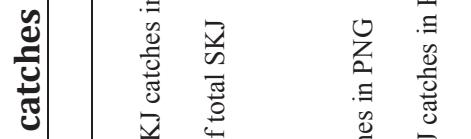

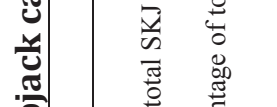

क्षे

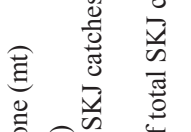

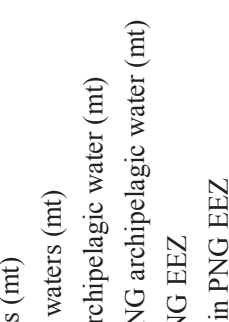

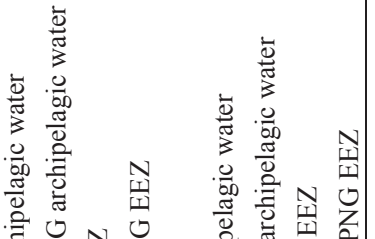

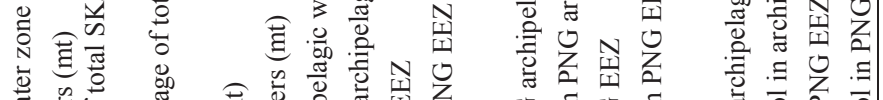

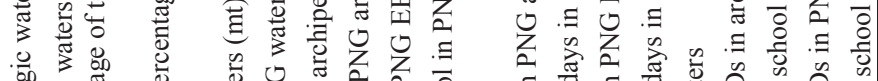

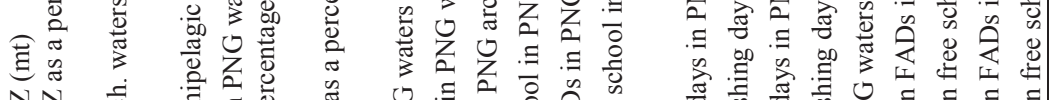

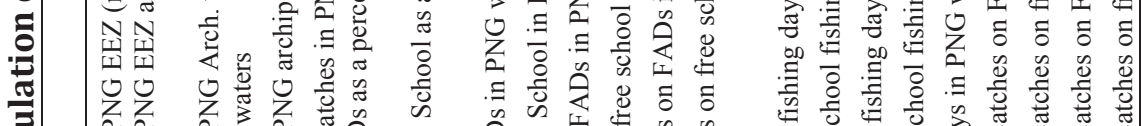

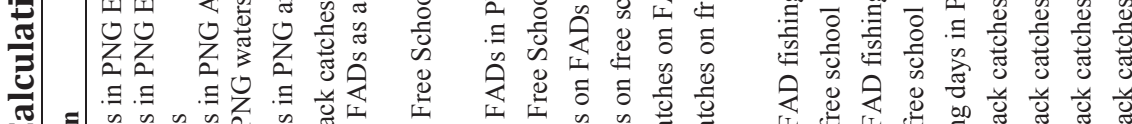
త⿹

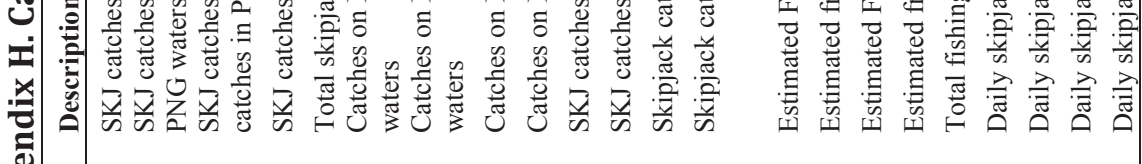
傕| r $m$ ti $0+\infty a \circ=\simeq 9$

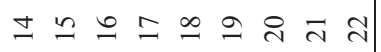


Appendix I. Detailed fishing vessels operation on FADs and on free school (2014)

\section{FAD fishing Free school fishing}

\begin{tabular}{|c|c|c|}
\hline Average fuel consumption (L) & 3000 & 6000 \\
\hline Range of fuel consumption (L) & 1500 to 3500 & 4000 to 10000 \\
\hline Hours of fishing & 6-7 hours & 10-12 hours \\
\hline $\begin{array}{l}\text { Time of fishing (searching, preparation, and } \\
\text { setting) }\end{array}$ & 4:00AM to $10-11: 00 \mathrm{AM}$ & $\begin{array}{l}\text { Between 6:00AM to } \\
6: 00 \mathrm{PM} \text {, depending on } \\
\text { the time of sunset }\end{array}$ \\
\hline $\begin{array}{l}\text { Average number of times to set per fishing } \\
\text { day }\end{array}$ & 1 & $1-2$ \\
\hline Vessel engine speed (in knots) & $8-10$ & $12-14$ \\
\hline
\end{tabular}

Source: Field interviews in Lae PNG, 2014

Appendix J. Variable costs of Vessel Monitoring System valued at 2015

\begin{tabular}{|c|c|c|}
\hline \multirow{4}{*}{$\frac{\text { Items }}{\mathrm{a} .}$} & & Cost (US\$/day) \\
\hline & Electronic tracking & \\
\hline & Staffing costs & 1.65 \\
\hline & $\begin{array}{l}\text { Costs of airtime ((US\$66 per trip x } 15 \text { trips/year)/230 } \\
\text { days }\end{array}$ & 4.30 \\
\hline & Electronic monitoring & \\
\hline & Observer costs for viewing & 65 \\
\hline & Observer travel rate & 35 \\
\hline \multicolumn{3}{|c|}{ c. Electronic reporting } \\
\hline & Staffing costs & 2.10 \\
\hline & e-log & 0.21 \\
\hline & e-obs and observer management & 0.42 \\
\hline & e-Catch Documentation Scheme (CDS) & 0.52 \\
\hline & Trip management and communication & 0.04 \\
\hline Total & variable costs & 109.24 \\
\hline
\end{tabular}

Source: Poseidon Aquatic Resource Management Ltd, 201 


\section{Acknowledgements}




\section{Acknowledgement}

"No man (or woman) is an island".

As this quotation suggests, the accomplishment of this $\mathrm{PhD}$ is made possible through the help of different organisations and individuals I encountered throughout my five years of $\mathrm{PhD}$ journey. It is my pleasure to acknowledge them.

I am grateful to the financial support provided by the BESTTuna (Benefiting from Innovations in Sustainable and Equitable Tuna Management in the Coral Triangle and Western Pacific) project, funded by Interdisciplinary Research and Education Fund (INREF) of Wageningen University to my $\mathrm{PhD}$ project. I am also thankful to the financial supports of University of the PhilippinesVisayas during my stay in the field, Stichting LEB for enabling me to attend conference in Australia, and the partial support of Business Economics (BEC) and Environmental Policy (ENP) Groups to extend my $\mathrm{PhD}$ research stay in Wageningen.

I would like to express my sincerest gratitude to my co-promotor Paul Berentsen and to my promotors Simon Bush and Alfons Oude Lansink for their tremendous supports and guidance during the five years of this $\mathrm{PhD}$ process. They have contributed in their own ways to my development as an individual and as a PhD student. Paul, I deeply cherish the daily supervisions you had given to me. Thanks for your constant reminder on how to write scientifically and properly, rigorous check-ups on my methodologies, useful feedbacks to improve my presentations for $\mathrm{PhD}$ meetings, and even the thoughtful concerns on how I am doing in general. Thank you for your unselfish help and quick response whenever I have questions and for not leaving this $\mathrm{PhD}$ project given that you have a new work. Simon, thank you for giving more colours to my $\mathrm{PhD}$ papers because of your 'out of the box' ideas and of the unselfish time you have given in editing and critically commenting on our papers (and on the other PhD chapters). I must admit that I often find your questions very difficult and challenging but you motivated me to think deeper and to enhance further my capabilities. You have opened lots of opportunities for me by pushing me to move beyond my comfort zone. Alfons, thank you for helping me balance the challenges of academics and family lives. I have learned from you to not only do mathematical modelling and to apply economic methods to research problems, but also to be more efficient and more productive in my research papers. I am also indebted with your kindness because you have shown sympathy and understanding during the difficulties in my pregnancy and have motivated me to finish the $\mathrm{PhD}$ despite the challenges of raising my son.

I would also like to give credits to people who have made the fieldworks possible, more especially the fishers. I am deeply indebted to these fishers who spent their precious time for interviews and provided deeper knowledge for my research. I thank WWF-Philippines PPTST team such as Joan Binondo, Joselito Tiongson, Marietta Calacal, Anthony Castillano, Johnson Peralta, Linda Corazon, and Leah Villanueva for allowing and assisting me to conduct interviews with fishers in Mindoro and Lagonoy and for making my stay fruitful and fun. I also acknowledge the generous support of the executives of Frabelle Fishing Corporation such as Sirs Frannie Tiu Laurel Jr., Augusto Natividad, and James Johnston during my fieldwork in Port Moresby and Lae, Papua New Guinea (PNG). Your generosity enabled me to collect data in a place that is difficult to penetrate by researchers. 
Moreover, thanks to Glenn Mesias for assisting in my interviews with skippers and with executives of canneries in PNG and for showing me around the region.

I also acknowledge our BESTTuna international advisors, Tony Lewis, Bob Deacon, Kate Barclay, and Quentin Hanich for their inputs and comments in this PhD project during the yearly BESTTuna meeting. I enjoyed the interactions and sharing of knowledge in those meetings. Moreover, thanks to fishery experts Tony Lewis and Maurice Brownjohn for the kindness and generosity in giving information and in expanding my tuna networks.

The support of different individuals has also made my fieldwork travels and going back and forth to the Netherlands less stressful and manageable. Thank you Anne Houwers, Corry Rothuizen, and Jeanette Lubbers-Poortvliet for the administrative supports during my stay in Wageningen (BEC/ENP). Anne, apart from the admin support, thank you for the friendship, thoughtfulness, and concern in terms of how I am coping with my $\mathrm{PhD}$ and daily life situations' challenges and dilemmas. Corry, thanks for all the administrative help and for constantly reminding me about my $\mathrm{PhD}$ budget in the project. And Jeanette, thank you for always booking our supervisory meetings and for the fun conversations about babies and children.

The PhD days in WUR have been memorable due to the colleagues whom I have shared with fun times. Thank you to my BESTTuna colleagues Agnes, Megan, Mandy, Steven, Shinta, Edison, and Whidya for the warm company during lunch, dinner, and meetings and for inspiring each other to do well in our research. Special thanks to Steven for helping me conduct interviews with the tuna big guys during our stay in Bangkok Thailand and for quickly responding whenever I have questions. I also thank Agnes for the friendship and for the fun, deep talks about academics and personal lives. I can't help but smile when I think of all the memories we have shared with each other in many countries (Indonesia, Philippines, Belgium, Netherlands and Australia) including the moment that we lost each other in a shopping mall in Brisbane.

I have realised that the $\mathrm{PhD}$ journey also flies very quickly because I enjoyed the pleasant working environment in the BEC group. Ngoc, Tsion and Eliana, thank you for being my good friends since we started the $\mathrm{PhD}$ and for sharing special moments of my life such as my engagement, wedding, and birth of my son. Eva, I appreciate our talks and your words of encouragement, especially at times when I felt that the $\mathrm{PhD}$ process was too hard. Nurul, thanks for your thoughtfulness and for the friendship especially during the last year of my $\mathrm{PhD}$. I enjoyed our going outs in the center together with Lien and Laya and the laughter and fun chats in the office together with Dikky. Miranda, Jaap, Felix, and Xudong, big thanks for all the critical comments and challenging questions in my presentations during $\mathrm{PhD}$ meetings. Sometimes they made me feel nervous. Andreas, Gumi, Farahnaz, Juliano, Beshir, Jamal, Tariku, Hugo, Yann, Mariska, Tadesse, and Esmee thanks for the warm companies during barbeque, outings, dinners, coffee and cake breaks.

I am also thankful for the support of Filipino friends in Wageningen more especially in times that I needed their help. I deeply appreciate the care and support of Rica, Lysette, Lean, and Stella during the time of my pregnancy and delivery. I also thank Robby, Angelo, Ate Malou, and Tita Maria for helping us move to our new house.

I also like to extend my gratitude to Ilonka van Hek for taking care of my son more especially on the finishing stage of this $\mathrm{PhD}$. 
In addition to the circle of friends and colleagues, I am fortunate to have family who always supports and encourages in order for me to accomplish things in life. Thank you Marian, Koos, Lars, Marjolein, Francine, Morris, Gideon, and Rohani for the warm welcome in the family and for helping me to integrate in the Dutch society. This makes me feel that the Netherlands is not a foreign country to me anymore. I also thank my family in the Philippines - Inay (mom), Daddy, ate Frida, kuya Bogie, Popot, and Francis, for the endless moral support and unconditional love despite the long distance away from home. I am greatly indebted to Inay and Daddy for giving me the education I needed to prepare me to do MSc and to go forward to do the $\mathrm{PhD}$ in Wageningen.

Finally, finishing this $\mathrm{PhD}$ was made possible because of the unconditional love, sacrifices, and support of my husband and partner Niels and my son Bastiaan. Niels, I am forever grateful to you for enduring the hardships, for giving love and strengths in times of my difficult moments in finishing this $\mathrm{PhD}$, and for sharing happiness in the accomplishments of both this $\mathrm{PhD}$ journey and the raising of our little son. Bastiaan, you bring bliss in our life and definitely you are the unwritten accomplishment of this $\mathrm{PhD}$ journey! Thank you for showing mama (and papa) that there is more life than merely doing PhD. I dedicate this book to Niels and Bastiaan. 


\title{
About the Author
}

\author{
About the Author \\ Training and Supervision Plan
}




\section{About the author}

Frazen Tolentino Zondervan (maiden name: Frazen Garcia Tolentino), is born in Tanauan City, Batangas Philippines on April 26, 1987. She studied and obtained her bachelor's degree in Agribusiness Management (cum laude) at the University of the Philippine Los Baños (UPLB) (June 2004-November 2007). After bachelor, she worked in the Department of Agribusiness Management and Entrepreneurship (DAME) at UPLB as a science research specialist in a project entitled Impact assessment on sustainable endoparasite control for small ruminants in the Philippines. She also worked in their family owned retail business in Liquified Petroleum Gas (LPG), which has now six branches in the Philippines. In 2010, she pursued a master degree in Wageningen University \& Research, the Netherlands under the Netherlands Fellowship Program (NFP) of the Dutch government. She worked on her MSc thesis on standards setting organisation on sustainability of cotton supply chain. In 2012, she obtained her MSc in Management, Economics, and Consumer studies under the specialization Marketing Management. Her interests and work on topic of sustainability continued when she was accepted for a PhD project under the BESTTuna programme of Interdisciplinary Research and Education Fund (INREF) of Wageningen University \& Research. During her $\mathrm{PhD}$, she received grants from University of the Philippines-Visayas, LEB Foundation of Wageningen University, and partial support from Environmental Policy and Business Economics Groups. 
Frazen Tolentino-Zondervan

Wageningen School of Social Sciences (WASS)

Completed Training and Supervision Plan

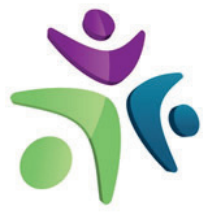

Wageningen School

of Social Sciences

Name of the learning activity

Department/Institute

Year

ECTS*

A) Project related competences

Proposal writing

WUR

2012-2013 6

Organisation of the Agribusiness,

WUR

2012

6

BEC 31306

Environment and Development,

WUR

2013

6

ENP 33306

Advanced Agricultural Business

WUR

2013

6

Economics, BEC 30306

BESTTuna Course

WUR

2013

3

B) General research related competences

Introduction course
'Improving sustainability in tun
fisheries through market-based
incentive mechanisms'
'Evaluating private incentive
mechanisms in Philippine tuna
fisheries'

Research methodology, From topic to proposal

BEC PhD meeting

BESTTuna Annual meeting
WASS

$7^{\text {th }}$ International Institute of

2013

2014

Fisheries Economics and Trade

Conference (IIFET), Brisbane

Australia

$6^{\text {th }}$ International Conference on Agribusiness Economics and Management (ICAEM), Davao City Philippines

WASS

2012

4

WASS

2012-2017 3

WUR-UP-IPB-USP

C) Career related competences/personal development

\begin{tabular}{llll} 
Interviewing professionals & WASS & 2012 & 0.5 \\
Voice matters & WGS & 2013 & 0.3 \\
$\begin{array}{l}\text { Techniques for writing and presenting a } \\
\text { scientific paper }\end{array}$ & WGS & 2013 & 1.2 \\
$\begin{array}{l}\text { Guest Lecture (Environment and } \\
\begin{array}{l}\text { Development) } \\
\hline\end{array}\end{array}$ & ENP-WASS & 2015 & 1 \\
\hline
\end{tabular}

Total 44

*One credit according to ECTS is on average equivalent to 28 hours of study load 
The research described in this thesis was financially supported by the Benefiting from Innovations in Sustainable and Equitable Tuna Management in the Coral Triangle and Western Pacific (BESTTuna) programme at Wageningen University with funds from Wageningen University Interdisciplinary Research and Education Fund. A partial support in the field work is provided by the University of the Philippines-Visayas (UPV).

Cover design by: Flordeliza Tolentino Leones

Printed by: Proefschriftmaken.nl 